\title{
ASSESSING THE IMPACT OF COMPUTER USE ON LANDSCAPE ARCHITECTURE PROFESSIONAL PRACTICE: EFFICIENCY, EFFECTIVENESS, AND DESIGN CREATIVITY
}

\section{LOLLY TAI \\ PROFESSOR, BS, MLA, RLA, ASLA}

$\mathrm{PhD}$ Thesis

HERIOT-WATT UNIVERSITY

DEPARTMENT OF LANDSCAPE ARCHITECTURE

MAY 2001

This copy of the thesis has been supplied on condition that anyone who consults it is understood to recognize that the copyright rests with its author and that no quotation from the thesis and no information derived from it may be published without the prior written consent of the author or the University (as may be appropriate). 
List of Tables and Illustrative Material

Acknowledgments

ABSTRACT

CHAPTER 1 - INTRODUCTION

1.1 General introduction 2

1.2 Objective 4

1.3 Hypothesis and methodology 6

1.4 References 8

CHAPTER 2 - LITERATURE REVIEW 9

2.1 History of computer use by landscape architects 9

2.2 Computer hardware $\quad 12$

2.2.1 Media Storage 13

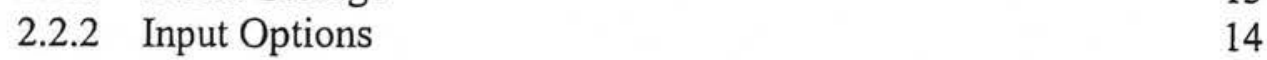

$\begin{array}{ll}2.2 .3 \text { Output Options } & 16\end{array}$

2.2.4 Other available input/output options 18

2.2.5 Electronic communication devices 21

$\begin{array}{ll}2.3 \text { Computer software } & 21\end{array}$

2.3.1 Image editing 35

$\begin{array}{ll}\text { 2.3.2 Visual simulation } & 37\end{array}$

2.3.3 Virtual reality 44

2.3.4 Multi-media $\quad 47$

2.3.5 CAD/CAM 49

2.4 The Internet 51

2.5 Summary 55

2.6 References 62

CHAPTER 3 - COMPUTER SURVEYS 69

3.1 Introduction 69

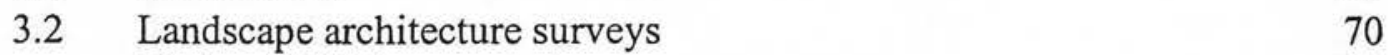

3.2.1 1983 Survey: stats on computer use $\quad 70$

3.2.2 1993 Survey: a status report on computers 71 in landscape architecture

3.2.3 1994 Survey: business of landscape architecture poll $\quad 72$

3.2.4 1996 Survey: the 1996 status report 73

3.2.5 The 1996 status report on computing skills 75 and training in landscape architecture

3.2.6 2000 ASLA membership satisfaction survey 77

$\begin{array}{ll}\text { 3.2.7 Summary of the landscape architecture } & 79\end{array}$ computer surveys

3.3 Architecture surveys 82

3.3.1 The 1987 American Institute of Architects firm survey $\quad 82$

3.3.2 The 1989 American Institute of Architects firm survey 83

3.3.3 The 1991 American Institute of Architects firm survey 85

3.3.4 1994 CAD utilization in the architectural design process: $\quad 86$ implications for computer integration in practice by Journal of Architectural and Planning Research

3.3.5 1994 IT survey of computer use by RIBA Journal (UK) 
3.3.6 1999 Survey by Barbour Index (UK)

3.3.7 Preliminary results from the AIA 2000-2002 firm survey 90 on high tech firms

3.3.8 Preliminary results from the AIA 2000-2002 firm survey 91 on Internet use

3.4 Construction industry surveys

3.4.1 1988 RIBA compares computer survey results (UK) 93

3.4.2 1993 Survey of data communications in the UK 93 construction industry

3.4.3 1998 RIBA information survey of use of computers by UK construction industry specifiers: hardware, operating Systems and delivery media

3.4.4 1999 Survey of CAD and virtual reality within

the house building industry (UK)

3.4.5 Summary of allied professionals computer surveys

3.5 References

CHAPTER 4 - CASE STUDY

4.1 Introduction

4.2 Objective

4.3 The project

4.4 Methodology

4.5 Results

4.6 Discussion

112

4.7 Conclusions

117

4.8 References

CHAPTER 5 - METHODOLOGY

5.1 Introduction

5.2 Design of the pilot survey questionnaire 121

5.3 The final survey 123

$\begin{array}{lll}5.4 & \text { Structure of the questions } & 127\end{array}$

5.5 Format of the Web questionnaire 128

5.6 The sample 128

$\begin{array}{lll}5.7 & \text { Data collection } & 129\end{array}$

$\begin{array}{lll}5.8 & \text { Supplemental interviews } & 133\end{array}$

5.8.1 Supplemental interviews conducted on the use of Web sites 133

5.8.2 Supplemental interviews conducted on 134 the use of 3-D modeling

5.9 Conclusions 135

5.10 References 136

CHAPTER 6 - RESULTS OF THE SURVEY 137

$\begin{array}{lll}6.1 & \text { Introduction } & 137\end{array}$

6.2 Analysis of frequency tables 138

6.3 Results from supplemental interviews 158

6.3.1 Results from supplemental interviews conducted 158 about firms' Web sites

6.3.2 Results from supplemental interviews conducted on 159 the use of 3-D modeling 
CHAPTER 7 - DISCUSSION

7.1 Introduction

7.2 Execution of design tasks

7.3 Design efficiency

7.4 Efficiency in communication 165

$\begin{array}{lll}7.5 & \text { Firm Web site } & 167\end{array}$

$\begin{array}{lll}7.6 & \text { Professionals in the design office } & 169\end{array}$

$\begin{array}{lll}7.7 & \text { Office size } & 171\end{array}$

7.8 Use of CAD in the design process 172

7.9 Role of computers in the design process 176

7.9.1 Working drawings 177

7.9.2 Final presentations and firm qualification presentations $\quad 178$

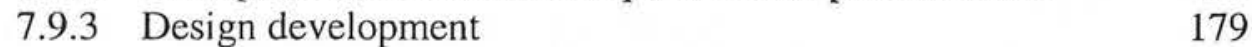

$\begin{array}{ll}\text { 7.9.4 Schematic design } & 180\end{array}$

7.9.5 Conceptual design 181

$\begin{array}{lll}7.10 & \text { References } & 184\end{array}$

CHAPTER 8 - IMPLICATIONS 185

$\begin{array}{lll}8.1 & \text { Introduction } & 185\end{array}$

$\begin{array}{lll}8.2 \text { References } & 199\end{array}$

APPENDIX ONE - MATERIALS USED 200

Pilot survey 201

Comparison of the pilot survey and final survey 205

Modified survey after pilot questionnaire 216

Design format of the final survey 222

Final survey in Web format 223

APPENDIX TWO - MATERIALS USED 232

Frequency distribution of variables 233

Data reduction categories 243

List of cross-tabulations that are statistically significant $\quad 249$

APPENDIX THREE - BIBLIOGRAPHY \& GLOSSARY 259 
Tables:

Table 1 Arcview Software.

Table 2 Most common brands of software used by landscape architects.

Table 3 Computing skills of practicing landscape architects.

Table 4 Percent of respondents regularly having computer problems.

Table 5 Comparison of surveys conducted in 1983, 1993, 1994 and 1996.

Table 6 Hours spent on design process stages by three groups.

Table 7 Data reduction categories (Appendix 2).

Table 8 Data reduction categories (Appendix 2).

Table 9 List of cross-tabulations that are statistically significant (Appendix 2).

Figures:

Figure 1 Early GIS.

Figure 2 Left: (1980) Early wireframe perspective. Right: (1969) Three dimensional symbols in a landscape based on numbers in a raster data set.

Figure 3 The graphics tablet system is a tool which is used to draw, sketch, trace, navigate and erase displayed content directly on the LCD screen as with pen and paper.

Figure 4 Graphics created with the use of graphics tablet.

Figure 5 Left to right-Views of the data target as seen through the Cyrax 3-D laser scanner and the supporting Cyrax software.

Figure 6 Left-Once the data for the model has been gathered, Micro station can generate other views and perform editing. Right-The Scyrax 3-D scanner system.

Figure 7 Left-Hand held 3-D FastSCAN scanning system. Right-3-D digitally modeled image.

Figure 8 MicroScribe digitizing process.

Figure 9 Autodesk software.

Figure 10 Subdivision map created in Land Development program by Autodesk.

Figure 11 Autodesk Civil Design does cut and fill calculations.

Figure 12 LandCADD quantity take-off.Figure 13: Irrigation suppliers and software.

Figure 14 Irrigation plan executed with Irrigation Design by LandCADD.

Figure 15 Three dimensional viewing of a vehicle travelling along the road.

Figure 16 FormZ used in urban design studies. Graduate students' work from Trancik's LA701/CRP555 course: Designing Cities in the Electronic Age created in Form $\mathrm{Z}$ and Photoshop.

Figure 17 List of Data Vendors.

Figure 18 Top left-A DTM using extruded contours drawn as straight-line segments. Top right-A DTM using a regular-grid-“fishnet”. Bottom- A (Triangular Irregular Network) TIN representation-created in FormZ on Macintosh.

Figure 19 GIS of Flathead County Master Plan.

Figure 20 Image editing software.

Figure 21 Left-Animation showing a seed that grows and transforms a barren planet into a virtual Eden. Right-Animation sequence showing leaves moving in the wind.

Figure 22 Resources for computer programs for modeling natural phenomena. 
Figure 23 Left to right-Existing site/base image; wire-frame of Acropolis on base image; 408-565 A.D image; 1870 image; existing site with reconstructed Acropolis.

Figure 24 Simulations picturing recontouring of the site after reclamation.

Figure 25 Computer modeling and simulation of vast landscape.

Figure 26 Panoramic image in QuickTime VR.

Figure 27 Left: Professor Hogan in the VRML lab equipped with Silicon Graphics Inc. (SGI) hardware using UNIX operating system. Right: VRML drawing created by a student, Mark Moehring.

Figure 28 Left-Multi-media CD-ROM helps user to understand design alternatives. Right-A 36-foot wide street is compared with a 18 -foot wide street. The navigation bar at the bottom allows flexible simulation vs. a linear one.

Figure 29 Layers of Rome, a multi media CD-ROM .

Figure 30 Computer manufactured landscape element.

Figure 31 Computer manufactured landscape element.

Figure 32 ASLA Web page.

Figure 33 Speech Software.

Figure 34 Top-Sketches and models of coliseum were created. Bottom-Computer Generated set designs.

Figure 35 The cumulative adoption over time of computers for five uses by landscape architecture firms.

Figure 36 Percentage of firms using computers for various applications, 1986 and1988.

Figure 37 CADD utilization by design philosophy.

Figure 38 CAD Productivity satisfaction by CAD package.

Figure 39 Firms using AutoCAD and other packages by design philosophy.

Figure 40 Average contract value per project and average net billings per employee.

Figure 41 Share of firms with web site quadruples since 1996.

Figure 42 Percentage of respondent organizations using CAD systems; by organization category.

Figure 43 Preference for CAD systems.

Figure $44 \mathrm{CAD}$ products used in development housing British industries.

Figure 45 Area in which VR is seen to have the most benefit.

Figure 46 Center: Conventional and digital drawing; Bottom left to right:

1)Conventional; 2 and 3)Conventional and digital; 4)Digital only.

Figure 47 Comparison of students' time logs.

Figure 48 Critique of design in computer lab with overhead projector.

Figure 49 Top: Computer model. Bottom: Traditional model.

Figure 50 Pilot survey (Appendix 1).

Figure 51 Comparison of pilot and final survey questions (Appendix 1).

Figure 52 Final survey questions (Appendix 1).

Figure 53 Design format of the questionnaire survey (Appendix 1).

Figure 54 Final Web survey (Appendix 1).

Figure 55 Frequencies (Appendix 2).

Figure 56 Type of CAD software used.

Figure $57 \mathrm{CAD}$ plays a large role in the design process.

Figure $58 \mathrm{CAD}$ use in the design process.

Figure 59 Drawing quality.

Figure 60 Effect on creativity.

Figure 61 Artistic quality.

Figure 62 Firms with a Web site. 
Figure 63 Inquiries obtained from Web site.

Figure 64 Use of Internet or e-mail to transfer drawings.

Figure 65 Impact of electronic drawing transfer on the number of meetings attending.

Figure 66 Tasks accomplished with extra time saved.

Figure 67 Firm composition.

Figure 68 Execution of computer tasks.

Figure 69 Skills expected from new hires.

Figure $70 \mathrm{CAD}$ limitations.

Figure 71 Respondents considered these features to be ideal in CAD.

Figure 72 Respondents desired these features to be perfected in CAD.

Figure 73 Totally digital office will replace the traditional office.

Figure 74 Roger Trancik in Martha Van Rensselaer lab, Cornell University.

Figure 75 On-line CAD course description offered by ASLA in partnership with Penn State University.

Figure 76 Hardware required for on-line CAD course offered by ASLA in partnership with Penn State University.

Figure 77 Left-visual speechreader. Right-wired glasses. 


\section{$\underline{\text { ACKNOWLEDGEMENTS }}$}

1. This research project is dedicated in memory of Professor Bill Tucker (Edinburgh College of Art, School of Landscape Architecture) who was a mentor and inspired me throughout my studies.

2. Professor Catharine Ward Thompson, Bill Tucker, Alison Murison, and Peter Aspinall (Edinburgh College of Art, School of Landscape Architecture) for supervising this work. Professor Derek Cassidy (University of Central England) for serving as the external examiner and Professor Seamus Filor (Edinburgh College of Art, School of Landscape Architecture) for serving as the internal examiner.

3. Professor Jim Witte and Cindy Roper (Clemson University, College of Business and Public Affairs) for assistance with the statistical analysis, encouragement and support.

4. My husband, family and friends for encouragement and support.

5. Survey respondents for their time and effort in completing the survey.

6. My landscape architecture students (Clemson University, Planning and Landscape Architecture Department) for participation in the experimental design studio.

7. Clemson University Department of Sociology for allowing me to use the SPSS lab.

8. Marco Alvarez (Clemson University, Department of Information Technology) for assistance with Web design.

9. American Society of Landscape Architects (ASLA), Professor Jim Palmer, and Roger Trancik for providing me with supplemental reference material.

10. Clemson University Gunnin Library for assistance with inter-library loan. 
Landscape architects claim that computers are efficient and effective presentation tools. However, to date, no one has evaluated the impact of computer use on the nature and quality of design in a practice setting. To further explore this issue, a trial was conducted with landscape architecture students in which they worked in conventional, mixed and digital media. Results indicated that although computer use was efficient in some tasks, the nature of the design process did not yield itself effectively yet to complete computerization. In addition, to assess the impact of computer use more broadly on office practice today, a survey was conducted of over 100 Chapter Executive Members of the American Society of Landscape Architects in the United States of America.

Survey results indicated that computer use has permeated all areas of landscape architecture practice, and that it has genuinely improved drawing quality and capability. However, it has not significantly impacted the artistic or creative aspects. Few respondents believed the computer can improve these facets of the profession or that traditional practice methods will be totally replaced by the computer.

The results suggest that academic and professional sectors of landscape architecture must help educate existing professionals to fully grasp the benefits of current and emerging computer technologies and to prepare the future professionals for an increasingly digital practice. 


\section{CHAPTER 1 - INTRODUCTION}

\subsection{General introduction}

Landscape architects design projects by utilizing a design process comprised of research and site analysis, conceptual design, initial costings, design development and presentation of schemes, construction/implementation drawings, preparation of final costings, specifications and bills of quantities, and supervision of construction on site. These steps involve the understanding of the subject of the project, analysis of the site conditions, conceptualization of the design in relation to the project program, development and refinement of the design, and completion of the construction and implementation drawings and documents in order that contractors can bid for and build the project. Until the advent of the use of computers in the landscape architecture profession, drawing and design work were generated by hand. In addition to the design and drawing-based work, landscape architects are also involved in a range of documentation, costings, report writing associated with specific project work and with more general office management.

Landscape architects started using computers in the late 1960 s and continued to embrace their use until the present day period. Literature reviews and previous surveys have documented the use of computers by landscape architects. Anderson's 1983 survey indicated that most landscape architects used word processing and spreadsheet software for record keeping, accounting, correspondence, proposals, mailing lists, etc. (1). Palmer's 1993 survey reported specifications (specs) and computer-aided design (CAD) for drafting were also commonly used, but that computers had not made any significant impact in the area of graphics or design. Few professionals used computer software for conceptual design, interactive 3-D visualization, or geographic information 
systems (GIS). While many landscape architects used CAD, it was mainly for construction drawings as a drafting tool (2). Landscape architects achieved efficiency (or time-savings), for example, with the use of stock symbols and details, and the ease of creating template sheets and making revisions, and attained effectiveness (or improved quality of drafting) with software capabilities that enabled precision, consistency, and technical capabilities (e.g. landscape construction details and symbols, cut and fill calculation, and irrigation calculation).

In 1994, the American Society of Landscape Architects (ASLA) Business of Landscape Architecture poll reported that landscape architects embraced the use of computers and had added a vast array of software and hardware to their firms. It also indicated that the use of computers has become an integral part of practice and has changed the way landscape architects do business (3).

Overall, these previous surveys show that landscape architects have adopted computer use. They reported 1)various types of software used, 2)utilization of CAD as a drafting tool, 3)efficiency and effectiveness of CAD for construction drawings, 4)low use of 3-D visualization, and 5)a desire for training.

In summary, what previous surveys and literature have shown is that efficiency and effectiveness are two good measures of computer use in landscape practice, but the details of this have yet to be fully explored. In addition, the contribution of computers to design creativity has yet to be fully developed. 


\subsection{Objective}

Following a review of previous surveys, several related and relevant questions surfaced. "Are landscape architects now using $\mathrm{CAD}$ as more than just a drafting tool and as a means of enhancing design creativity?" "Have there been any new impacts on efficiency and effectiveness with advanced technologies?" "What does this mean for the future of the profession and for the education of professionals?" As no surveys have been conducted on the use of computers by landscape architects since the mid-1990s, this thesis research addressed these questions through a new survey. Examining the effect of computer use on creativity was considered important, since the notion of creativity significantly impacts the way landscape architects design, including the way landscape architects think about their designs, the time they may spend on design or other tasks (perhaps with time saved through computer use), and the nature and quality of their designs.

This research incorporated the criterion of "creativity" into the study, but recognized that creativity is not easily quantifiable or measurable (as compared to, for example, practice income or number of project hours). It is subjective, an intuitive process, and an inherent characteristic within each individual and varies from one person to another. It is, nonetheless, a fundamental part of the design process and therefore desirable to include in any assessment of the contribution of computers to the profession. The aspect of creativity was therefore "measured" with dichotomous structured questions such as, "Has the use of computers improved your creativity?" "Yes" or "No." The answer to this question, in conjunction with open-ended questions and supplemental interviews ensured a collective of insightful, descriptive data about the attitudes of landscape architects and their assessment of the role of computers in relation to creativity. 
Assessing computer use with regard to efficiency and effectiveness was also important, since these factors significantly impact office procedures in the landscape architecture design practice. These variables were incorporated in the new survey study in order to assess new or detailed information about the impact of computer use on efficiency (time savings) and effectiveness (quality of drawing) which resulted from using new software/hardware, the Internet, and the World Wide Web (WWW).

The primary objective of this research was to investigate selected variables related to the use of computers and, moreover, the impact of computers on the nature and quality of design. It also explored the following more specific, questions arising out of this:

- To what extent does computer use permeate landscape architecture practice and work in the office?

- In which areas has computer use simply enhanced old capabilities or replaced old methods with electronic versions?

- Has computer use contributed genuinely new capabilities, particularly in the quality of landscape design itself, and in what ways?

- What does this mean for future professionals in the discipline?

The research concentrated on the North American context, as this enables comparison of data with earlier surveys of the same context. Within the last two decades, there have been only a few surveys conducted on the use of computers by landscape architects. In the meanwhile, computer technology has advanced very quickly, and so new investigations on this topic are urgently needed. The research conducted in this study has contributed new information about the landscape architecture discipline relevant to both practice and education sectors. Practitioners can benefit from understanding the 
positive and productive impact of computer use in a firm and the importance of supporting the training needs of employees, while educators can benefit from understanding the significance of reassessing the academic curriculum to meet the demands of an increasingly digital profession. The findings in this research indicate that cross-communication between practitioners and educators as well as software designers will foster mutually beneficial relationships in the future.

\subsection{Hypothesis and methodology}

The hypothesis for this research is based on the question, "Has computer use not only influenced the speed, efficiency and presentation methods of landscape architecture office procedures, but also (more recently) the actual quality and content (or nature) of design itself? What implications does this have for the future of the profession?"

The methodology used for this research included:

1. An extensive literature review on the history of computer use, computer hardware and software, the Internet, and the WWW. This groundwork provided in-depth background information on the use of computers by landscape architects.

2. A review of previous surveys conducted about the use of computers by landscape architects and allied fields. This provided insight as to the type of questions asked by others and helped to formulate and structure survey questions in this research study.

3. An exploratory case study which compared the use of computers and traditional methods in the design process in an academic studio environment. Efficiency and effectiveness of the use of alternative drawing/design methods, including hand-only, computer/hand, and computer-only were compared and evaluated. The study also 
evaluated how and when computer use should be taught in the landscape architecture design curriculum.

4. A questionnaire was developed in order to canvass opinions about the use of computers in professional practice of landscape architecture. A pilot survey was conducted and responses from this helped to clarify and generate succinct final survey questions.

5. The full questionnaire survey was then conducted and made accessible via the WWW. The sample was composed of 250 ASLA executive committee members.

6. The data were collected and the results were statistically analyzed. Included were frequency distributions and cross-tabulations.

7. A follow-up survey was carried out using more in-depth interviews to explore the effect of the use of 3-D modeling and a Web site that arose from the main survey.

8. Conclusions of the survey indicate that:

- Computer use improved efficiency and effectiveness in design, but not creativity.

9. Discussions of implications suggest that:

- Practicing professionals need to invest in employees in a formal as opposed to informal manner.

- Schools need to evaluate the way computer use is integrated in the design curriculum.

- Professionals and educators need to communicate better with each other as well as with software design companies so that all are working together towards a common goal. All parties would benefit from the current and future high technology by taking initiatives to prepare for that increasingly digital design working environment. 


\subsection{References}

1 Anderson, P. (1984). "Stats on Computer Use." Landscape Architecture, 64 (5), 101-102.

2 Palmer, J. \& Buhman, E. (1994). "A Status Report on Computers.” Landscape Architecture, 84 (7), 54-55.

3 Donnenmaier, M. (1994). "Reconfiguring the Practice Pie." Landscape Architecture, 84 (7), 51-53. 


\section{CHAPTER 2 - LITERATURE REVIEW}

\subsection{History of computer use by landscape architects}

Landscape architects have a long track record of adopting computers for use in their design practice. Computers were used for Geographic Information Systems (GIS) as early as the 1960 s for data gathering and analysis work, although it was a very cumbersome process at that time.
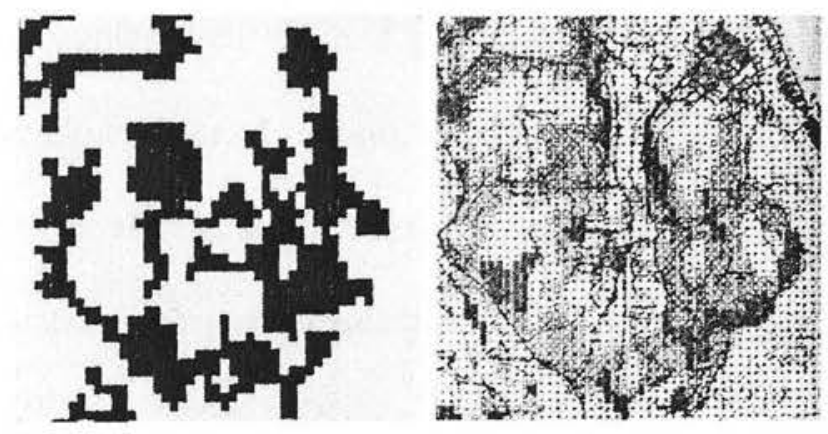

Figure 1: Early GIS (4).

From 1965 through 1974, computer development moved from mainframe computers, to minicomputers, and to microcomputers. The floppy disk, dot-matrix printer, and the ARPANET (precursor of the Internet) were introduced, and NASA initiated a research program that lead to earth-sensing satellites (5).

The thrust of computer use began between 1975-1979 with the development of Microsoft software and Apple computer companies. Computer-based word processing and spreadsheet programs and dot-matrix printing capabilities replaced typewriters and hand-held calculators (6). Landscape architects began to use the computer with these software programs for reports, brief writing, tender documents, 
specification writing, cost estimates, scheduling material quantities, etc.

Between 1980 and 1984, Autodesk released AutoCAD (computer aided design) for 2-D (two-dimensional) drafting, Apple Macintosh was developed, and pioneers in academia began to use computers (7). Although computer aided design (CAD) capability became available, little use of CAD and GIS for drawing purposes was made at that time (8). However, spreadsheets, word processing, and specification sheets were used extensively. Though landscape architects were using computers, surveys and reports indicated they were lagging behind allied professionals in adopting computer use. For example, a 1987 article by Mark Lindhult, a landscape architect and educator reported that $90 \%$ of landscape architects were using Microsoft "Word" as word-processing program at a time when the program had already reached maturity (9).

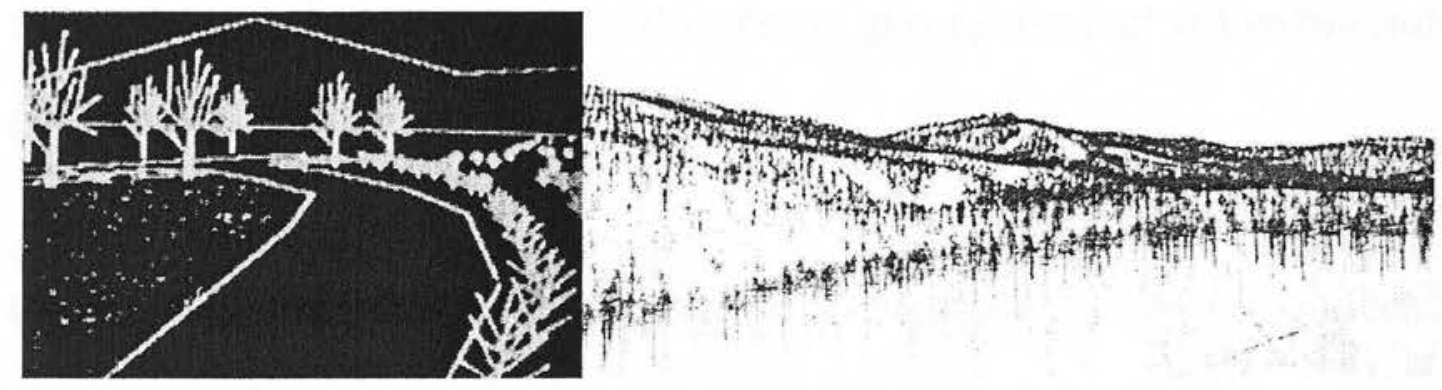

Figure 2: Left-(1980) Early wireframe perspective. Right-(1969) Three dimensional symbols in a landscape based on numbers in a raster data set (10).

From 1985 through 1989, practicing professionals began to adopt 2-D and 3-D computer tools for drawing. Technology such as fishnet meshes and Triangulated Irregular Networks (TINs) made it possible for landscape architects to visualize complex landforms. Additionally, image-processing techniques enabled manipulating photographs for visual-impact assessment (11). 
Also, by the end of the 1980s, incredible advancement in technology produced laptops which were quickly gaining in popularity, the Internet was more easily accessible, new software programs were coming out rapidly, and inkjet printers began replacing pen plotters. During this period, micro-computer-based CAD systems reached a similar level of maturity, along with word processing software, because low cost, yet more powerful, hardware was available (12). These tremendous advancements made owning a computer possible for most professionals.

Surprisingly, landscape architects were slow to enter the stream of professionals using computers, even though costs were going down and capabilities were going up (13). The major reluctance appears to have been limited training opportunities and software selection specifically for landscape architects and, even at that time, fear of obsolescence. Another hurdle was the pride that landscape architects took in their manually produced work and their reluctance to give up this skill and craftsmanship (14).

From 1990 through 1994, the World Wide Web emerged and changed the entire culture of computer use. Communication became more convenient and instantaneous. In addition, it affected the way landscape architects conducted business with regard to product specification selection, marketing services, obtaining business leads, submitting proposals and bids, and recruiting new employees. During this period, the computers became more powerful and faster. Landscape architects began to communicate through local area networks (LANs) as well as the Internet (15).

During this period, $\mathrm{CAD}$ became ubiquitous and the $\mathrm{CAD}$ software jumped from 2-D to 3-D to 4-D (animation over time) capabilities. GIS became widely available and, spatial data for the United States of America was available over the Web. Walk-throughs, fly- 
overs, QuickTime VR for panoramas, and interactive Web sites were now possible and available. Most of the documents, correspondence, working drawings, renderings and brochures done by landscape architects were being produced on computers and printed using digital output devices in landscape architectural practice offices (16). Computers generated spectacular graphics, but the greatest benefit to landscape architects was the ability to explore design alternatives systematically and "answering the "what ifs"' (17). In addition, the $\mathrm{CAD}$ layering capacity allowed different design scenarios to be displayed at will.

The increase in CAD use during the later part of the 1990s appears to be attributed to various factors including affordability, ease of use, necessity and improved hardware and software capabilities. Major advancements continued in the recent period, from 1995 through 1999, with the introduction of Pentium chips and PowerPC processors. These enhancements enabled professionals to execute many more complex tasks such as simulations, animations, walk-throughs, fly-overs, and interactive multi-media presentations. Also, QuickTime VR introduced the use of Virtual Reality that is now a powerful technology used by landscape architects. Currently, the capability to create virtual landscapes is available to everyone (18). Stephen Ervin, a landscape architecture professor at Harvard University, stated that the next revolution in computing will come when users immerse themselves in virtual reality environments, along with developments in speech recognition and computer-generated speech (19).

\subsection{Computer hardware}

Today's modern landscape architect is typically equipped with powerful desktop or laptop computers that have large internal storage capacities; external media storage devices such as Superdisk, Zip, Jazz, CD-ROM, and DVD-ROM as well as CD-writers (CD-R, CD-RW); input devices such as scanners (flatbed and/or slide), digital and 
video cameras, graphics tablets and digitizers; output devices such as printers and/or plotters (inkjet, laser or wax) and LCD (liquid crystal display) projectors; and electronic communication devices such as modems.

A majority of the offices use IBM compatible computers, however some use the Macintosh platform. Computers are now faster, cheaper and easier to use. The Pentium III runs at speeds from $450 \mathrm{MHz}$ (megahertz) through a projected speed of $1130 \mathrm{MHz}$ by the year 2001. Apple's new G4 is also very powerful with a $733 \mathrm{MHz}$ clock speed and hard disk drives of up to 60 GB (20). A closed CPU (Central Processing Unit) system in which the CPU does not have to be opened to add peripherals is expected to come on the market next. This system would allow computer parts, such as DVDROM, HD and CD-ROM to be purchased separately and plugged in externally (21).

Today, many professionals have laptop computers, since they are almost as powerful as desktops and are easily transportable. Many newer computers are even smaller than the typical laptop, making mobile computing truly possible-an important consideration for future personal information systems. In 1999, landscape architect, Jim Sipes stated that the most popular would be the hand-held computer. Hand-held computers offer more functionality than palm size computers but less than notebooks. They are capable of word processing, project management, budgeting, and cost estimating but not $\mathrm{CAD}$, GIS or modeling work (22).

\subsubsection{Media Storage}

Various media storage hardware is available including Zip, Jazz and Firewire drives (which store up to $250 \mathrm{MB}, 2 \mathrm{~GB}$, and $20 \mathrm{~GB}$ of data, respectively), CD-ROMs (which store up to 80 minutes or 700MB of data), and DVD-ROMs (high-density CD-ROM formats which store 8.5 gigabytes or over 2 hours of compressed video). CD-R is one of 
the very important hardware tools for digital information publishing and distribution (23). Today, most landscape architecture professionals rely on this technology to store, archive, and to back up their files. Large storage capacity is essential to storing large files such as for $\mathrm{CAD}$, image, sound, video and multi-media.

\subsubsection{Input Options}

Landscape architects use a variety of computer input devices. Flatbed and slide scanners are common to most offices, since they have become very affordable. For example, landscape architects scan photo and/or slides to use for assembling base maps in which the scanned base images are "placed" or "pasted" into a CAD drawing and developed further from there. Scanners are also used for site documentation in which images are "stitched" together for the purpose of studying a site and in simulation for visualizing and assessing before and after site development scenarios. They offer an easy means of converting paper copies of text and photographs to digital formats that can be easily edited.

Digital and digital video cameras are also widely used. Digital cameras have the capability of capturing digital images, and many take short digital videos. Often, digital cameras can be purchased for under $\$ 1000$. (£696.); digital video cameras are slightly more expensive. The digital images can be easily downloaded directly from camera to computer to provide instant photo or video documentation. These devices are ideal for landscape architects. For example, it is much easier and more efficient to construct a photo inventory with images that are already in a digital format as opposed to having to scan an image from a photograph. Incorporating digital videos in a presentation using a multi-media software program produces sophisticated and engaging presentations due to the added animation and sound features. 
Graphics tablets such as the Intuos graphics tablet developed by Wacom is a digital input device. The graphics tablet system allows more intuitive rendering, freer illustrating, as well as faster image editing. It is capable of helping with drawing smooth curves and for providing gradual transitions with the use of a pressure-sensitive pen (24). Another tremendous benefit is that the system works with photo editing, graphic, and $\mathrm{CAD}$ programs. Various design professionals, especially graphics artists, use graphics tablet systems. No literature has been found concerning landscape architects' utilization of this device, although this product is advertised in CAD vendors' Web site (e.g. DataCAD)(Figure 3). The graphics tablet is an appropriate tool for landscape architects to use since it interacts with photo editing and CAD programs and offers a potentially more intuitive drawing option. Drawings created with the graphics tablet display a natural, fluid and artful quality (Figure 4).

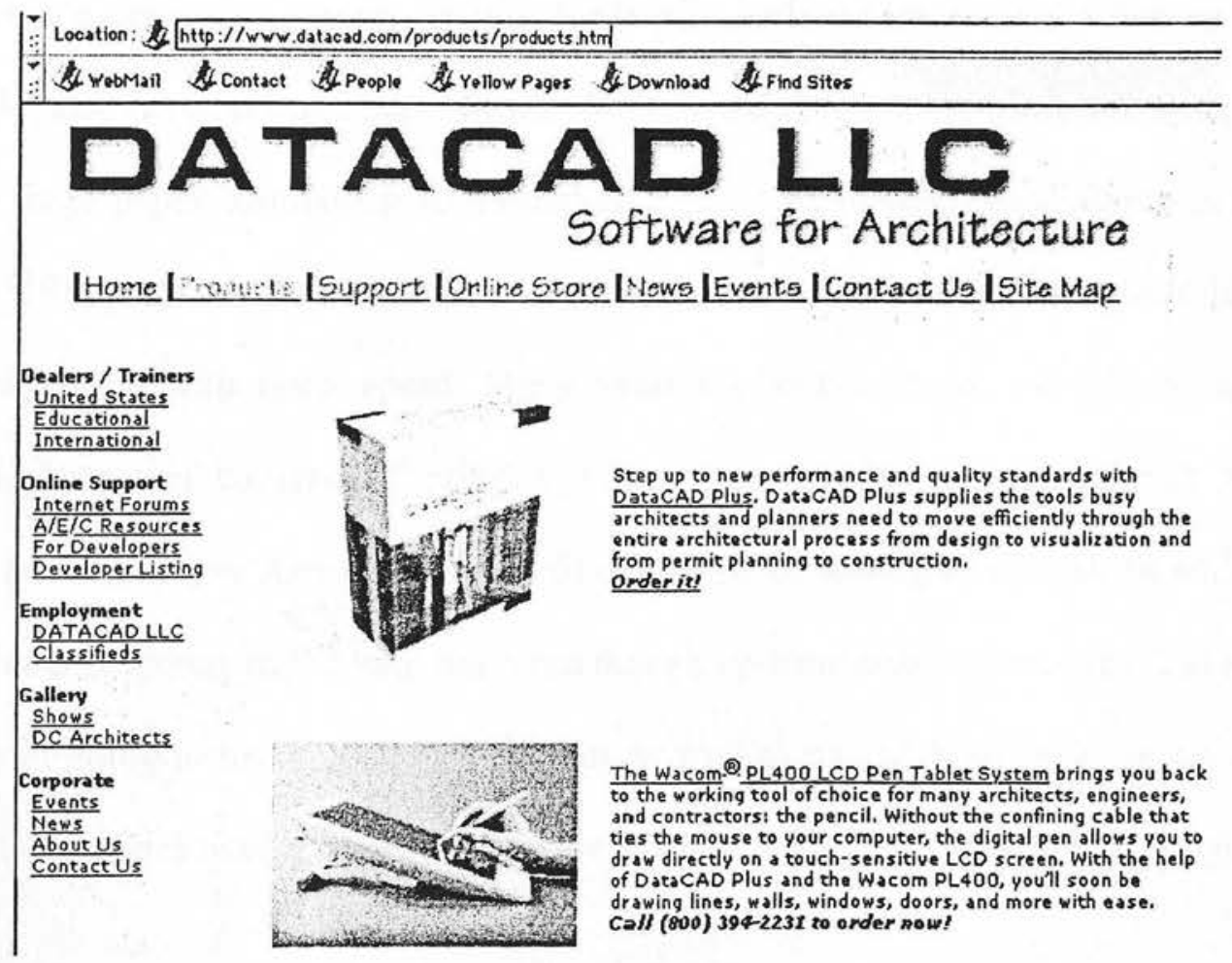

Figure 3: The graphics tablet system is a tool which is used to draw, sketch, trace, navigate and erase displayed content directly on the LCD screen as with pen and paper (25). 

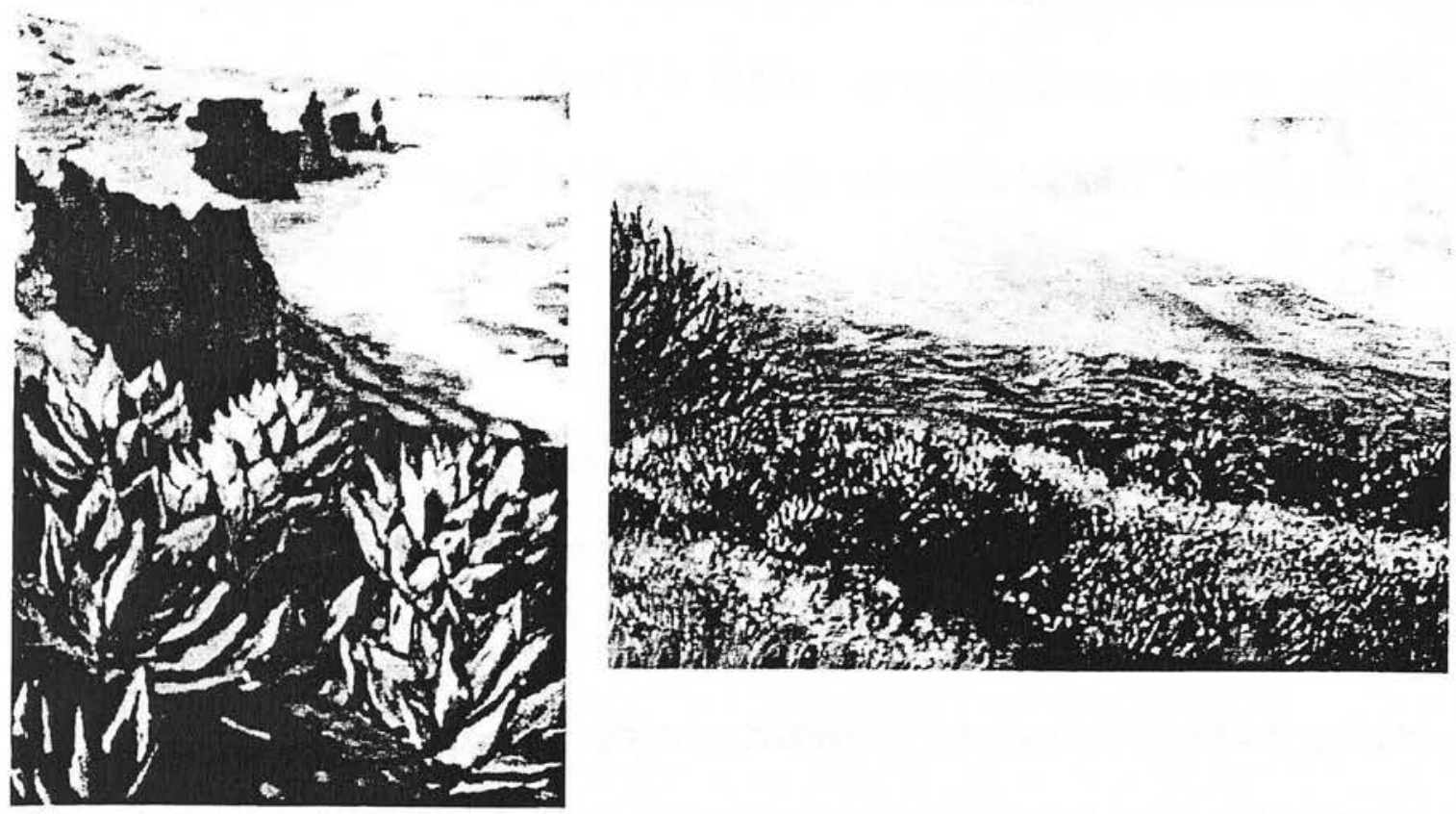

Figure 4: Graphics created with the use of graphics tablet (26).

\section{$\underline{2.2 .3}$ Output Options}

Printers are commonplace in today's landscape architecture design office as new technological developments make them more affordable and more powerful. Some can handle large paper formats up to 48 -inches wide (1.22 meters); have serial, parallel and/or USB ports, or 10/100-Base T Ethernet cards for networking; and have higher print resolution with faster speed. Many landscape architects are using large-format printers/plotters or "oversized" printers/plotters that can print at least 24 -inch width (609.6 millimeters) or Arch-D. The benefit of owning or leasing an over-sized printer is that 1)it saves money in the long run, even though up-front cost may be high, 2)it saves time from going to printing service bureaus as well as paying high costs for printing, and 3)it eliminates having to wait in line for plotting when project deadlines are tight.

Several different types of printers, including thermal, dye-sublimation, thermoautochrome, laser, and ink-jet printers are available. Each differs in print resolution, 
speed, quality of color and text, format size, paper variety accepted, and price. Color ink-jet plotters are the most affordable $(\$ 4,000 .-\$ 10,000).(£ 2784 .-£ 6959$.$) and are$ commonly used by landscape architects. Ink jets reproduce color by squirting ink on paper from tiny nozzles. More expensive printers (up to $\$ 20,000$.)( $£ 13,918$.) use a variety of printing techniques. Thermal printers produce images by applying melted wax from ribbons to a page. Dye-sublimation printers use a technique that blends melted pigments to create continuous colors. Thermo-autochrome printers are similar to dye-sublimation except that they use specialized paper instead of ribbon cartridges. Color laser printers use the same printing process as the monochrome laser printer, however they are still very expensive. Manufacturers of oversized printers include the following companies: Roland Digital Group, Hewlett-Packard, ENCAD, Epson America, Selex, Fuji, Calcom Technology, Xerox, Mutoh and Alpha Merics (27). Regardless of the printer used, professionals find resolution to be one of the important factors in printing.

LCD projectors are now common to most landscape architecture offices for PowerPoint presentations and are particularly effective when used for multi-media presentations as well. For appropriate applications, it is a more than satisfactory alternative tool to use when compared to the traditional hard copy presentation. A digital presentation accomplishes two tasks at one time and saves time and money. It is a way of producing the presentation and also documenting the work digitally that can be archived for potential future use. In the past, traditional presentation drawings typically had to be produced, mounted on boards, documented and archived with slides and photographs. Many professionals today have an LCD projector, as this device has become more portable and lightweight as well as more affordable with prices down from $\$ 5000$. (£3479.) to just $\$ 2500$. (£1740.) in the past 3 years. 


\section{$\underline{2.2 .4}$ Other available input/output options}

There are several additional input and output devices that are available to design professionals but have been cited in literature as being used by allied professionals, with no mention of landscape architects. One of these devices is the advanced 3-D scanner manufactured by Cyrax Technologies. These devices are able to scan areas up to 328 feet x 328 feet (100 meters x 100 meters) in 3-D. These scans can later be "stitched" or overlapped together for a composite image (28).

The utilization of the advanced digital scanning device is especially ideal when traditional methods are not possible due to the dangerous nature of a specific site condition. For example, the scanning device was used in obtaining as-built information for the Detroit Edison industrial plant. In this project, 3-D models of the existing structure were created using 3-D data obtained from the Cyrax scanner and ported to Microstation (Figure 5 and 6)(29). Landscape architects could use this device as well for similar purposes.
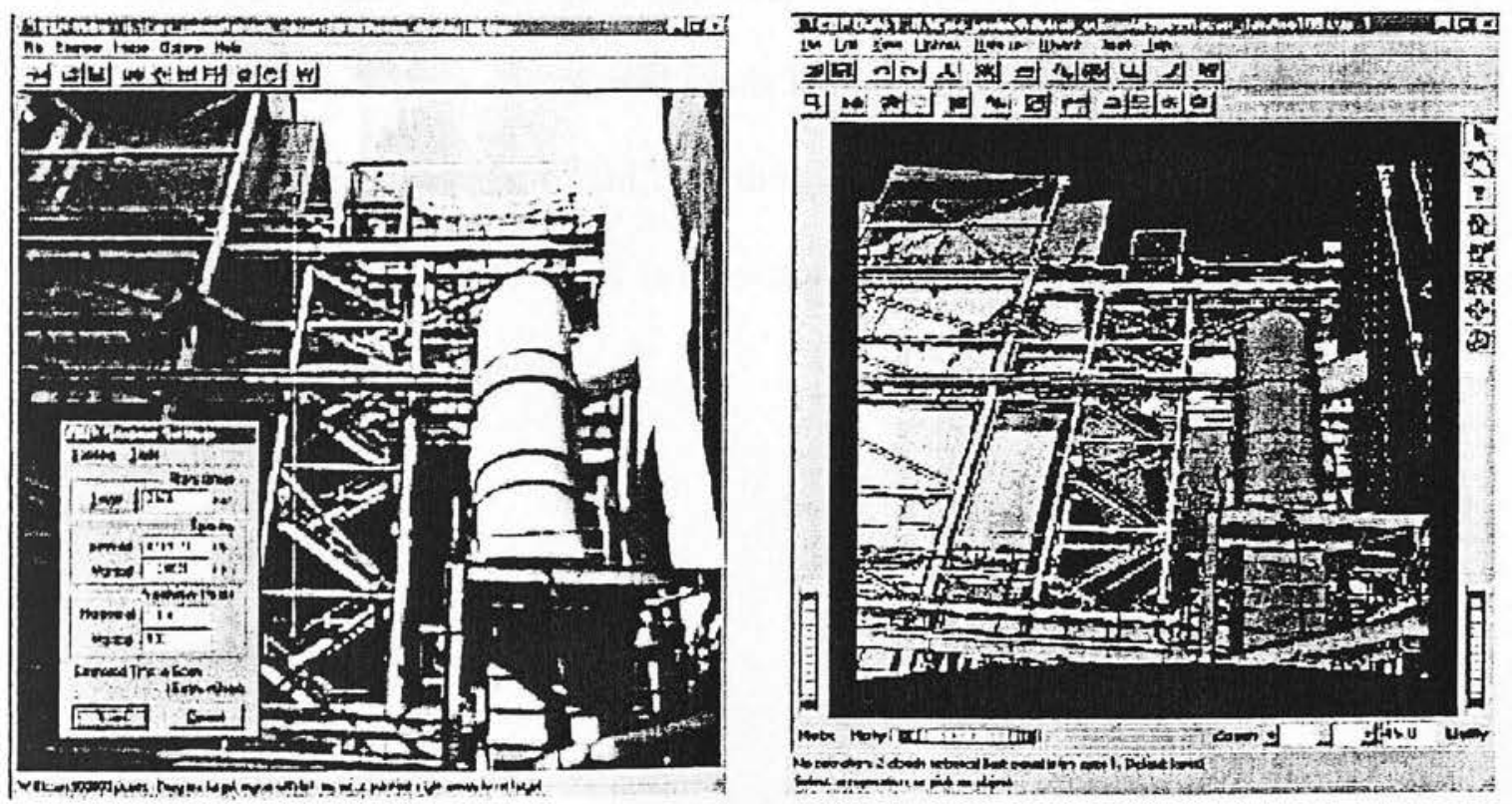

Figure 5: Left to right-views of the data target as seen through the Cyrax 3-D laser

scanner and the supporting Cyrax software (30). 

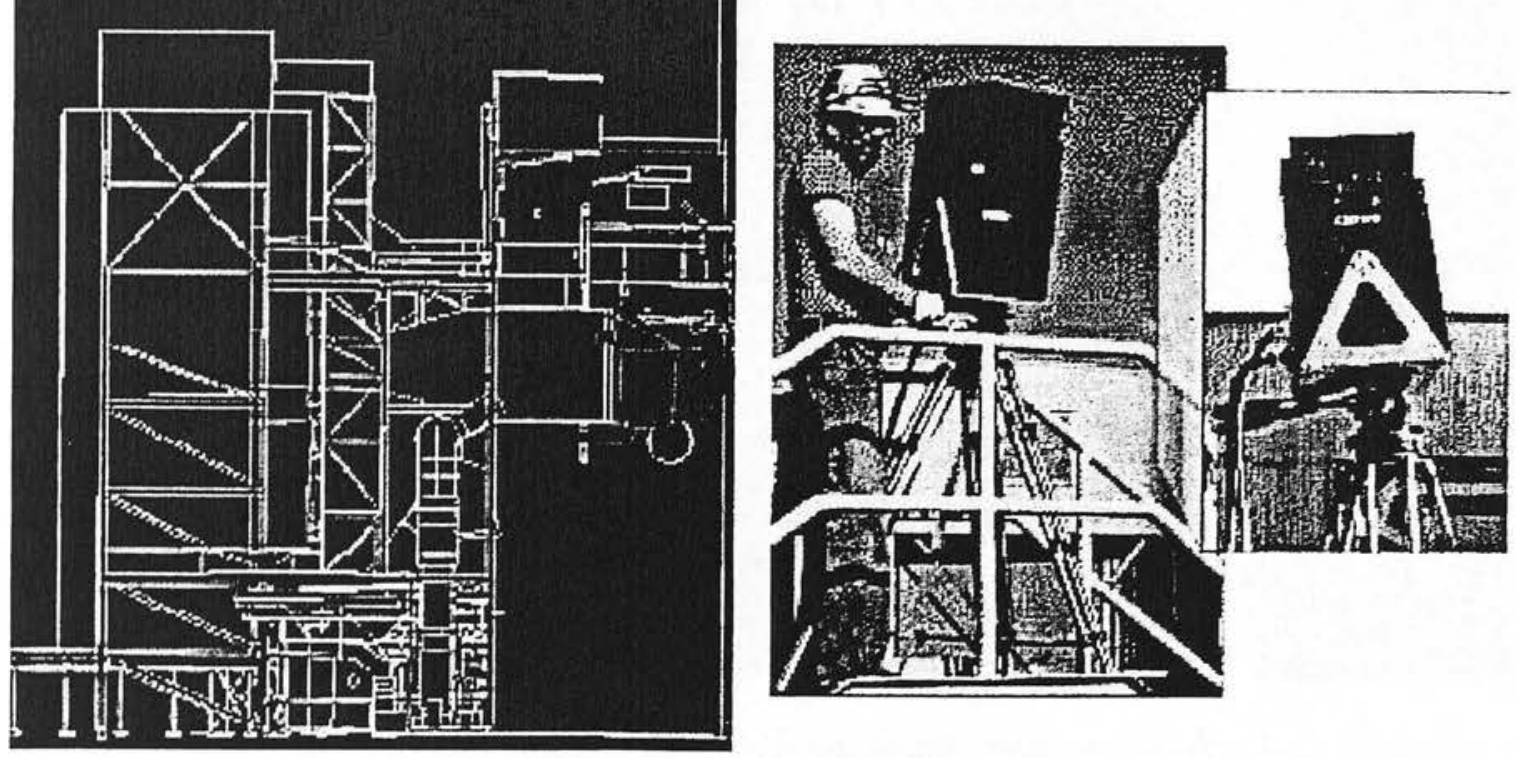

Figure 6: Left-once the data for the model has been gathered, Microstation can generate other views and perform editing. Right-the Scyrax 3-D scanner system (31).

Another 3-D scanning device available is the FastSCAN hand-held laser scanner produced by Polhemus. The FastSCAN system enables a traditional model to be brought into 3-D digital model. The scanning wand sends an adjustable-angle laser band across the surface of the object. The laser movement is picked up by two cameras, which establish the 3-D geometry, and sends the data directly to the computer (Figure 7)(32). No literature has been found regarding landscape architects using this device, but it can be used perhaps to input small-scale 3-D landscape forms or details to be studied and/or rendered digitally. 

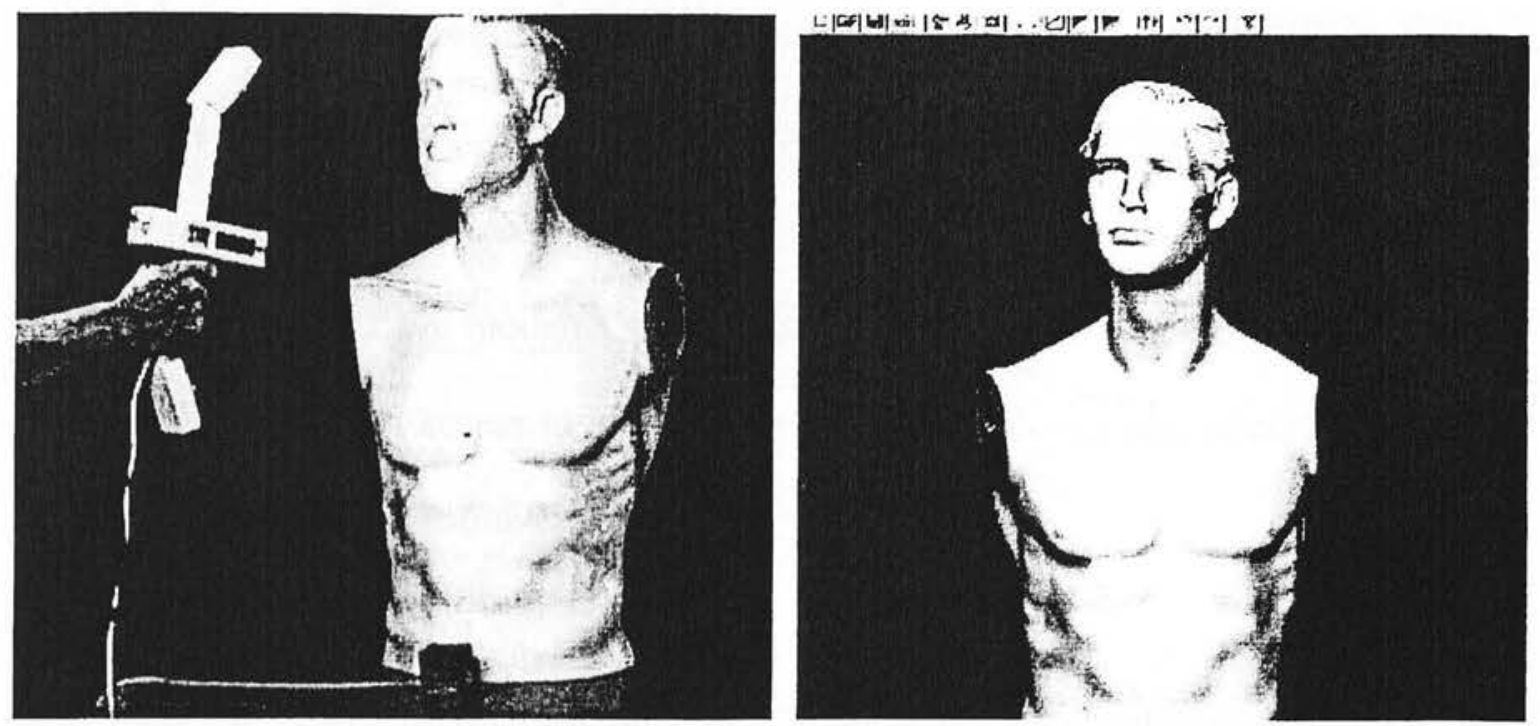

Figure 7: Left-Hand held 3-D FastSCAN scanning system. Right-3-D digitally modeled image (33).

MicroScribe (Figure 8) is a 3-D digitizing process and a tool that enables constructing detailed computer 3-D models by tracing the surface features of real physical objects. Those who use it for working in 3-D include animators, engineers, designers, video game developers, and scientists (34). Although literature was not found with regard to landscape architects using this device, it seems unlikely that there would not be a place for these professionals to utilize it.
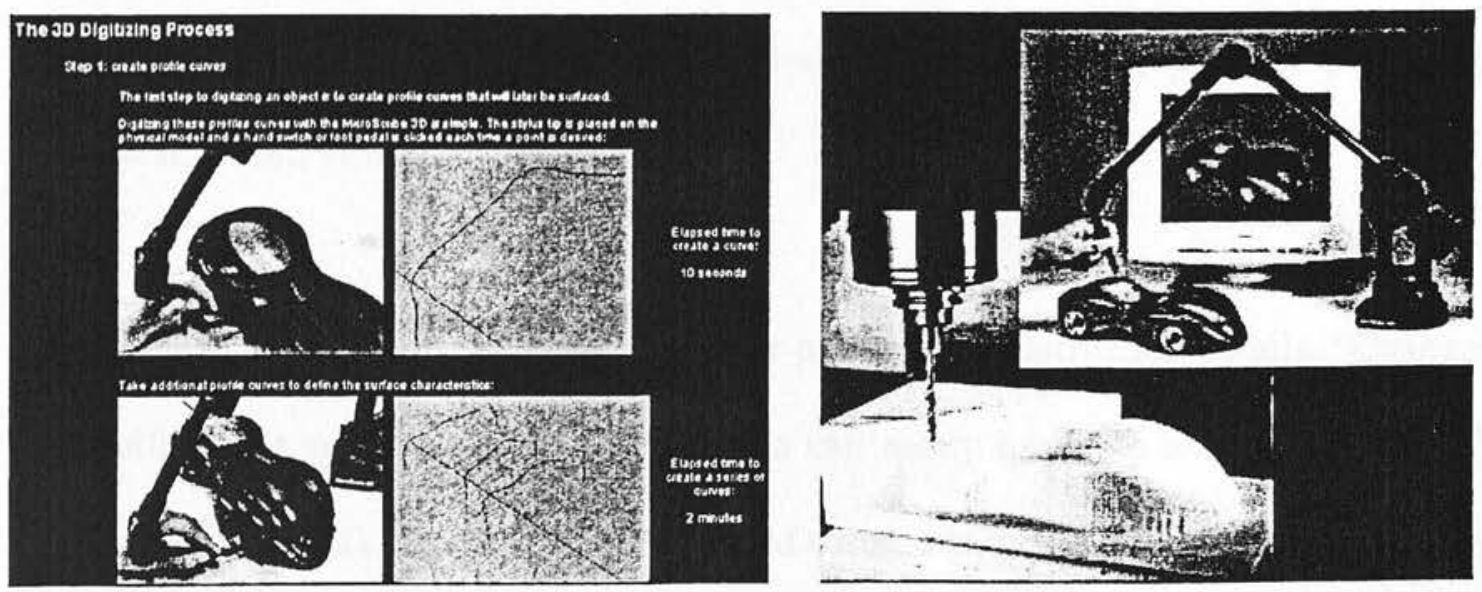

Figure 8: MicroScribe digitizing process (35). 


\subsubsection{Electronic communication devices}

Computers use digital data, and in order to send/receive this data, it must be transmitted through phone lines and cable systems via an analog channel. A high percentage of landscape architects have modems today. It allows them to be connected to the World Wide Web and to gain access to e-mail. The modem is a device that allows computers on a network to share information.

The word "modem" is the technical abbreviation of "modulate/demodulate." The modem in the sending computer modulates the digital data into an analog format, and then the modem in the receiving computer demodulates the signal back into digital data. Modems help to bridge the distance between computing systems using existing transmission mediums (36).

\section{$\underline{2.3}$ Computer software}

Sophisticated software programs have helped landscape architects perform graphic and technical drafting, drawing, and analysis work with innovative efficiency. The software serves different functional needs in an office including data gathering and analysis (GIS); cut and fill calculations; road geometry and structural calculations; plant selection; irrigation design; estimating; 2-D drafting; perspective graphics; 3-D imaging and visualization; virtual reality; etc. (37).

One of the most common uses of $\mathrm{CAD}$ is for producing construction details. "Changes to specifications and construction documents can easily be made without redrawing" (Sipes, 1996, p. 38). Basic features in CAD that contribute to drawing efficiency include a layering system, stock details and symbols and imported text and graphic images (jpeg, pict, bmp, etc.). Today, the features in CAD extend far beyond basic 
capabilities and accomplish more sophisticated tasks in the design office. Some of the CAD programs are described in the following section (38).

AutoCAD: AutoCAD is by far the current industry CAD standard and is used by most landscape architects. When AutoCAD 2-D first came out between 1980-1984 it brought innovation in the way drawings could be executed more efficiently. However, it was a new technology, challenging and intimidating with its menu driven program, expensive and had little or no 'point and click' capabilities (39). In this so-called Stone Age CAD, "Architects murmur that the computers are narrow minded and inflexible while the computers cast the architect as slow and unimaginative" (Bissell, 1990, p. 95).

AutoCAD has evolved through several versions already. AutoCAD R9 was a DOS based program with no 3-D capabilities. Shortly after came AutoCAD R10 with integrated 3-D which greatly improved the versatility of the program. The interface of these programs was still command based, with pull down menus. AutoCAD R11 for DOS was similar to R10 with a few more features. The major breakthrough came with AutoCAD R12, designed for the Windows OS, a graphical user interface (GUI) program with point and click capabilities. This was upgraded with AutoCAD R13 for Windows 95 and some improvements were made such as the way hatch patterns were created and stored in the drawing database. When AutoCAD R14 was introduced, several more improvements were added. For example, hatch patterns were easier to modify, 3-D capabilities were greatly improved, and toolbars were added. AutoDesk recently introduced AutoCAD 2000, which integrates many new features into the endless list of those already in the program, but the new version has greatly improved its ease of use. 
AutoCAD was and is still the industry standard today and carries a high price tag. Most landscape architects use AutoCAD for its compatibility with architects and engineers. Today, AutoCAD 2000i lists for $\$ 3295$. (£2293.) with additional add-ons at about $\$ 400$. (£278.). The " $\mathrm{i}$ " in the name indicates that the latest release also contains Internet functionality and allows the addition of hyperlinks in drawings. It also has a quick send command to allow e-mailing from AutoCAD (40). AutoCAD has followed industry change along with other software, and perhaps has been ahead of others, in the evolution of computing. AutoCAD will most likely stay the leader in design software.

Autodesk produces a large array of software (Figure 9). These programs have capabilities to create complex site designs, technical drawings and calculations, sophisticated renderings (such as with 3-D solid modeling and enhanced lighting), as well as interact with the Internet. Its Land Development program is designed for land and urban planners, surveyors, and civil engineers. It offers a "CAD solution with topographic analysis functionality, real-world coordinate systems, volume totals, roadway geometry all in an environment that promotes collaborative design and analysis" (Design Gallery. Land Development, 2000)(41).

-3D Studio MAX \& Character Studio

-3D Studio VIZ

-Actrix Technical

-AutoCAD

-AutoCAD AEC

-AutoCAD Architectural Desktop

-AutoCAD Data Exchange

-AutoCAD Express Tools

-AutoCAD LT

-AutoCAD Land Development Desktop

-AutoCAD Map

-AutoCAD Mechanical

-AutoSketch

-Autodesk Object Enablers

-Autodesk CAD Overlay

-Autodesk Civil Design

-Autodesk IFC Utility

-Autodesk Inventor

\author{
-Autodesk MapGuide \\ -Autodesk OnSite \\ -Autodesk OnSite View \\ -Autodesk PowerLine \\ -Autodesk Survey \\ -Autodesk Symbols \\ -Autodesk View \\ -Discreet Products \\ -EducationProducts/ACES Subscription \\ -Lightscape \\ -Mechanical Desktop \\ -S8 Architectural and \\ Building Design Software \\ -VISION* \\ -Volo View \\ -Volo View Express \\ -WHIP! Viewer
}

Figure 9: Autodesk software (42). 


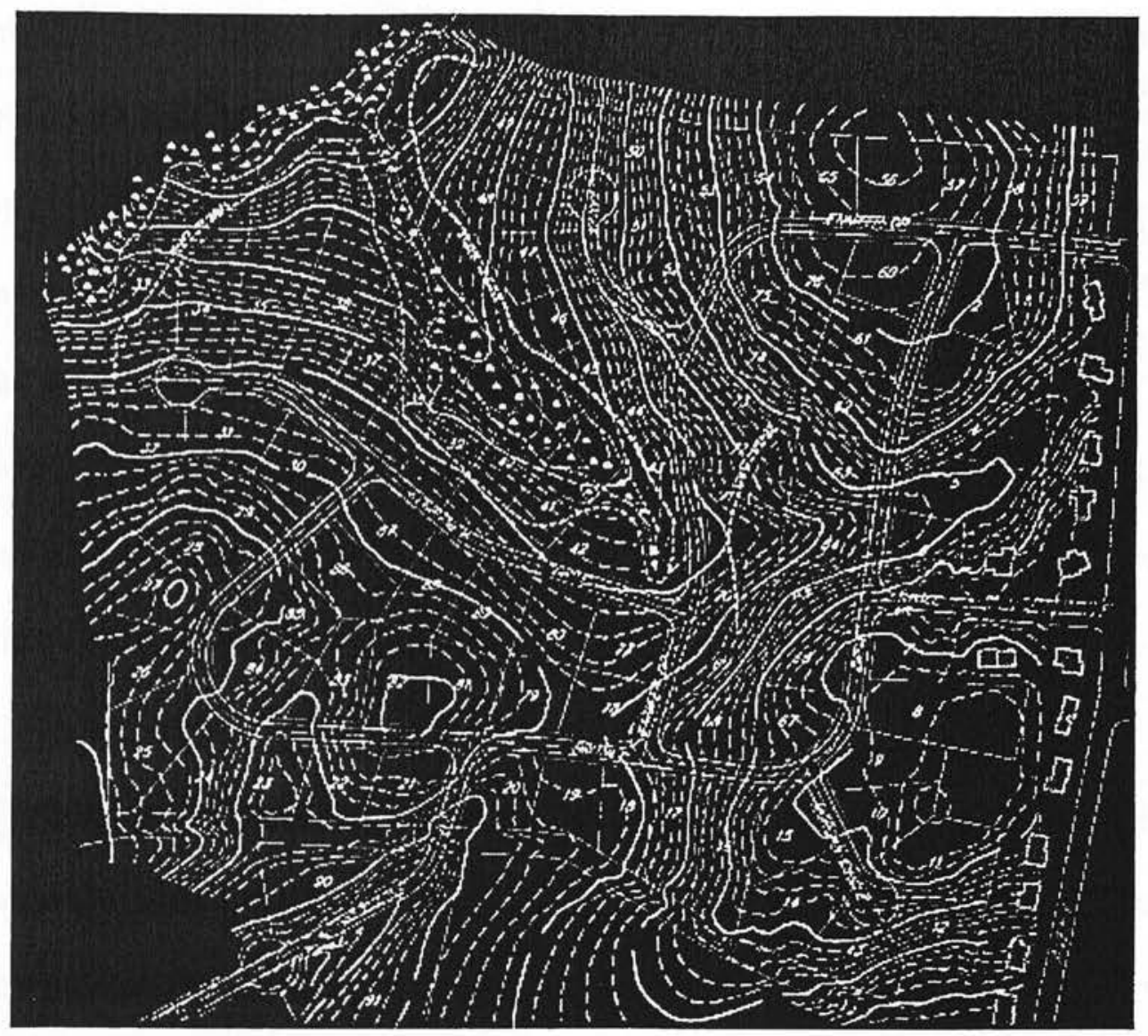

Figure 10: Subdivision map created in Land Development program by Autodesk (43).

Another popular Autodesk program is Civil Design. It delivers "real-time engineering results" and provides functionality for grading including cut and fill calculations with a click of the mouse (Figure 11)(44).
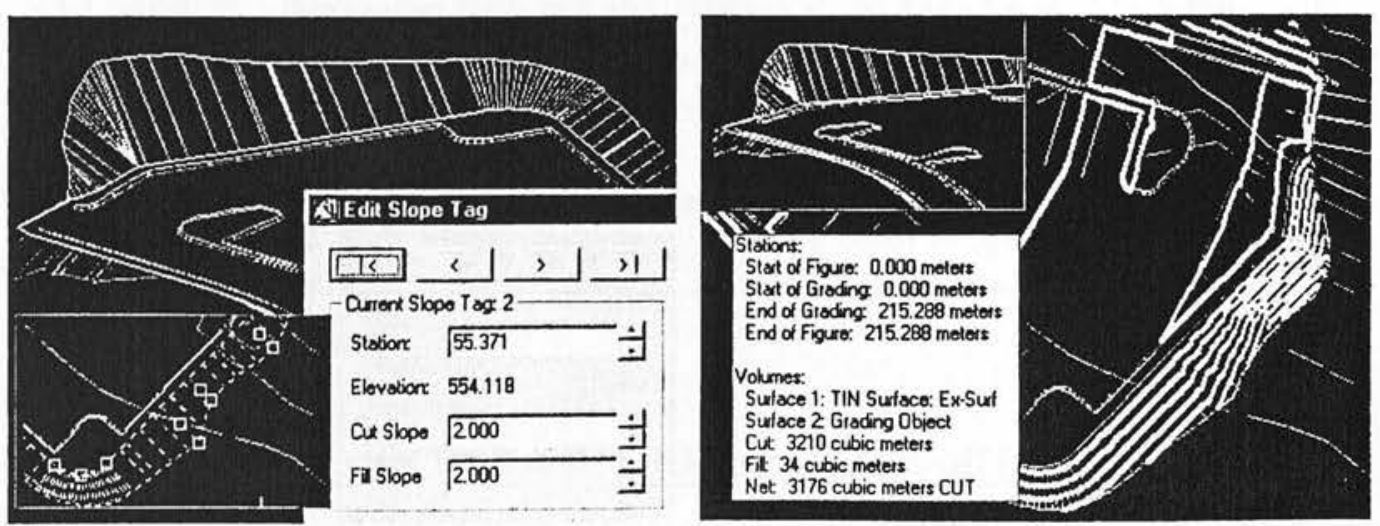

Figure 11: Autodesk Civil Design does cut and fill calculations (45). 
The ability to draw in one program and be able to import it into another is an important feature. Since AutoCAD is such an industry standard, many programs will note "compatible with AutoCAD." The downside is that contamination and data loss is not uncommon. In addition, since AutoCAD 14 and 2000 uses a new file format, earlier versions of AutoCAD (11,12, and 13) cannot open it and neither can any other software. Autodesk's WHIP! displays AutoCAD drawings using the Drawing Web Format (DWF) and is used to view drawings over the Internet which can be downloaded from Autodesk's Web site (46).

LandCADD: LandCADD by Eaglepoint is very popular among landscape architects. It produces a variety of software programs to accomplish individual module solutions. The choices in their software package include Base Plan, Colorfast, Construction Details, Irrigation Design, Picture Perfect, Plant Data Base, Quantity Take-off (Figure 12), Site Analysis, Site Design, Surface Modeling, Virtual Image, Virtual Simulator and Visual Landscaping (47).

\begin{tabular}{|c|c|c|c|c|c|}
\hline \multicolumn{6}{|c|}{ Manage Dalabase. } \\
\hline Item ID & Description & & Uniks & \multicolumn{2}{|l|}{ Urit Cost 1} \\
\hline 15500000 & \multicolumn{2}{|c|}{ 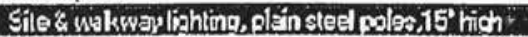 } & Ea & \multicolumn{2}{|l|}{$\mathbf{D}, \mathbf{m}$} \\
\hline 1653000110 & \multirow{3}{*}{\multicolumn{2}{|c|}{$\begin{array}{l}\text { Sile \& wakway lighting, ornementèl poles, } 10^{\prime} \text { righ } \\
\text { Sile \& wakway lighting, ornamental poles, } 15^{\prime} \text { high } \\
\text { Paking lot lighling, vood poles, } 30^{\prime} \text { high }\end{array}$}} & Ea & \multicolumn{2}{|l|}{0.00} \\
\hline $18530 \cot 20$ & & & Ea & 0.00 & \\
\hline 1653000130 & & & Ea & $0 . \infty$ & \\
\hline 1653000140 & \multicolumn{2}{|c|}{ Pakking lot lighling, sleel poles, 20 ' high } & Ea & 0.60 & \\
\hline 1653000150 & \multirow{2}{*}{\multicolumn{2}{|c|}{$\begin{array}{l}\text { Palking lat lighling, sleel poles, 30' high } \\
\text { Private toadwey lighting, wood poles, } 30 \text { high }\end{array}$}} & Ea & $0 . \infty$ & \\
\hline $16530 \mathrm{cot} 60$ & & & $E_{a}$ & 0.00 & \\
\hline 1653000170 & \multicolumn{2}{|c|}{ Private roodway lighting. ste el poles, 20 ligh } & Es & \multicolumn{2}{|l|}{$0 . \infty$} \\
\hline 1653000180 & \multirow{2}{*}{\multicolumn{3}{|c|}{ Private madway lighting, ste el poles, $30^{\prime}$ high }} & \multirow{2}{*}{\multicolumn{2}{|c|}{$0 . \infty$}} \\
\hline $4 \mid$ & & & & & \\
\hline \multirow[t]{2}{*}{ Eller... } & Assemblies... & \multirow{2}{*}{\multicolumn{2}{|c|}{ Numbet of Records found in Fller: }} & 42 & \\
\hline & & & & Close & \\
\hline
\end{tabular}

Figure 12: LandCADD quantity take-off (48). 


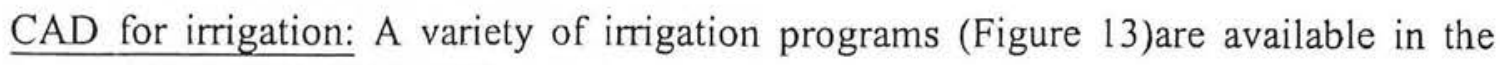
trade today which will do hydraulic calculations and also suggest head placement. Some of the programs are interactive with $\mathrm{CAD}$, and other informative databases. Irrigation Design by LandCADD is an example of a program that will lay out, design, and perform calculations on any size irrigation project using a popular manufacturer's equipment. When a boundary is selected, the program will automatically insert sprinkler heads at all the appropriate places. Once pipes are laid out, they will automatically be sized for each zone. The program also has the ability to automatically locate all the sprinkler heads inside a given area, define zones to include all heads into a particular zone to ensure that there is enough water, and automatically size the lateral and mainlines based on criteria defined by the user (Figure14)(49).

Many landscape architects use the software to design irrigation plans while some will do the plans by traditional means particularly to accommodate specific criteria that are not within the capabilities of the software. Landscape architect, Georgia Harrison said, "My impression of all of the software, though, is that they are only good if they are very flexible. I am picky about providing thorough head to head coverage, and like to consider how each type of plant will potentially block the spray from adjacent plants. I think the programs tend to generalize conditions, and find the mean value, rather than solving specific problems well" (personal communication, December 20, 2000). 
Aqua Engineering, Inc., Forc Collins, Colorado. (970) 229-9668. IDA 4.1 IrrigationDesign-Assist Software: Computer-aidedengineering software package used with AutoCAD.

AEI Software, Canterbury, New Zealand. 64 (3) 325-3723. IRRICAD: A CAD package developed for designing pressurized irrigation or watersupply systems.

Cranfield University, Silsoe College, Silsoe, Bedford, England. 01525 863292. AWSET, HOURLYET, DAILYET, BALANCE, IWR, and IMS: Programs for application of weather daca to water-management problems, including irrigation scheduling.

Eagle Point Software, Dubuque, lowa. (800) 678-6565. Irrigation Designer IANDCADD Tools and Irrigation Designer: Irrigationdesign programs; first is an add-on for AutoCAD, second is a stand-alone.

HR Wallingford Led., Wallingford, Oxon, England. 01491 835381. MIDAS (Modular Irrigation Design Aid Software): AutoCAD add-on for irrigation designers. MOBILE: Software that estimates maximum potential efficiency of irrigation systems.

IFAS Software Support, University of Florida, Gainesville, Florida. (904) 392-7853 MOBILE: Software that estimates maximum porential efficiency of irrigation systems. Water-Management Utilities: A series of more than forty programs for irrigarion-system design and management.

Irrigation Association, Fairfax, Virginia. (703) 573-3551.

Irrigation Training and Research Center (ITRC), California Polyrechnic State University, San Luis Obispo, California. (805) 756-2434. Drip/Micro System Evaluation Software: Tool for irrigation-system improvement, verification of performance, and drip- or micro-irrigation systems. IRRIGMAN: A comprehensive simulation model for water-management analysis and planning in large irrigation and drainage networks. Irrigation Eualsation Software: A suite of seven programs for estimating irrigation efficiency and discribution uniformity. Landscape Water Management Software: Software and training class for landscape irrigation auditing and budgeting.
Nelson Irrigation Corporation, Walla Walla, Washington. (509) 525-7660 FASTQUOTE: A package intended primarily for calcularing residential irrigation systems. IRRICAD: A program for designing the hydraulics of an irrigacion system, working our the materials required, and plotting a plan.

Rain Bird Sales, Inc., Azusa, California. (818) 963-931 1. XERI-CALC: Used to determine the low-volume irrigation requirements of watersensitive flowers and vegecation

Salco Products, Inc., Houston, Texas. Texas Agricultural Extension Service, Texas A\&M University, College Scation, Texas. (409) 845-9689. Salco Drip-Irrigation Software: Several modules laid out in the order in which drip systems are designed and installed.

Texas Agricultural Extension Service, Texas A\&M University, College Station, Texas. (409) 845-9689. Calculating Irrigation Capacity Unknowns: Calculates parameters concerning irrigarion capacity. MacPET: Software designed to calculate potential evapotranspiration.

TKO Software, Houston, Texas. (800) 3483243. IRRICALC-PRO and IRRICALC-EZ: Software for determining the most efficient irrigation watering schedule. RAINCAD SUITE and RAINCAD 5.0: Programs for irrigation and landscape design.

Utah State University, Biological and Irrigation Engineering, Logan, Utah. (801) 7502785. CATCH 3D 4.60: Simulates uniform water applicarion of rectangular and triangular sprinkler patterns. IRRIGMAN: Software for watermanagement analysis and planning in large irrigation and drainage networks. MULTILAP: Selects sprinkler spacing for uniform water application. SIRMOD: Simulation program for surface-irrigation systems.

Figure 13: Irrigation suppliers and software (50). 


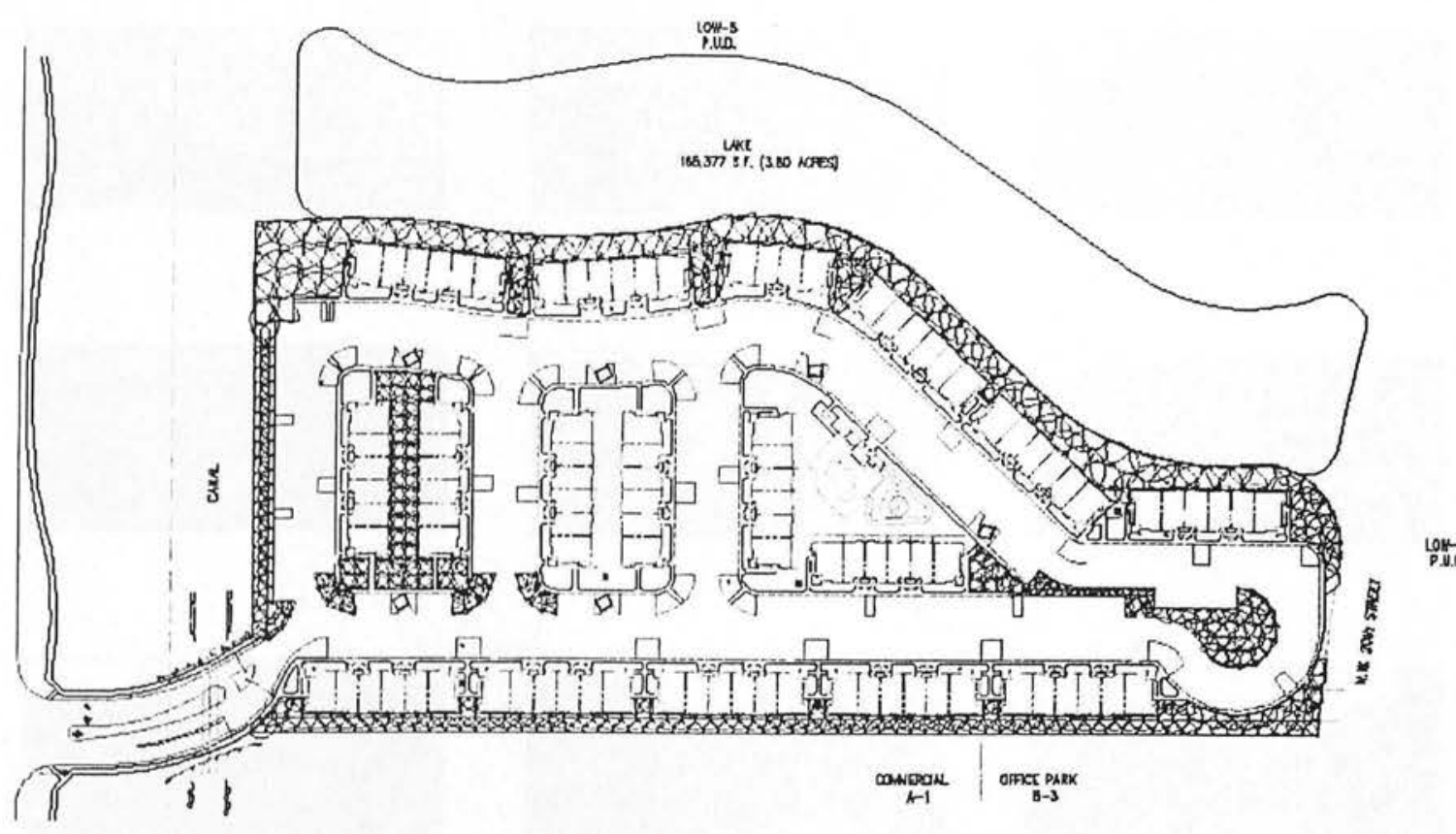

Figure 14: Irrigation plan executed with Irrigation Design by LandCADD (51).

$\underline{\mathrm{CAD}}$ for road design and visualization: MacRoad "is an interactive graphical application for geometric design of roads and highways. It provides for import of terrain data in a variety of formats, formation of triangulated ground models, interactive design of roadways, and export of drawings for data for road construction" (MacRoad, retrieved September 15, 2000)(52). After the road has been designed, drive through simulation along the road can be created. Professionals utilize 3-D viewing from vehicle traveling along the road to judge appropriate sight distance on curves and crests. Figure 8 shows a sequence of the drive from screen shots taken from QuickTime VR. 

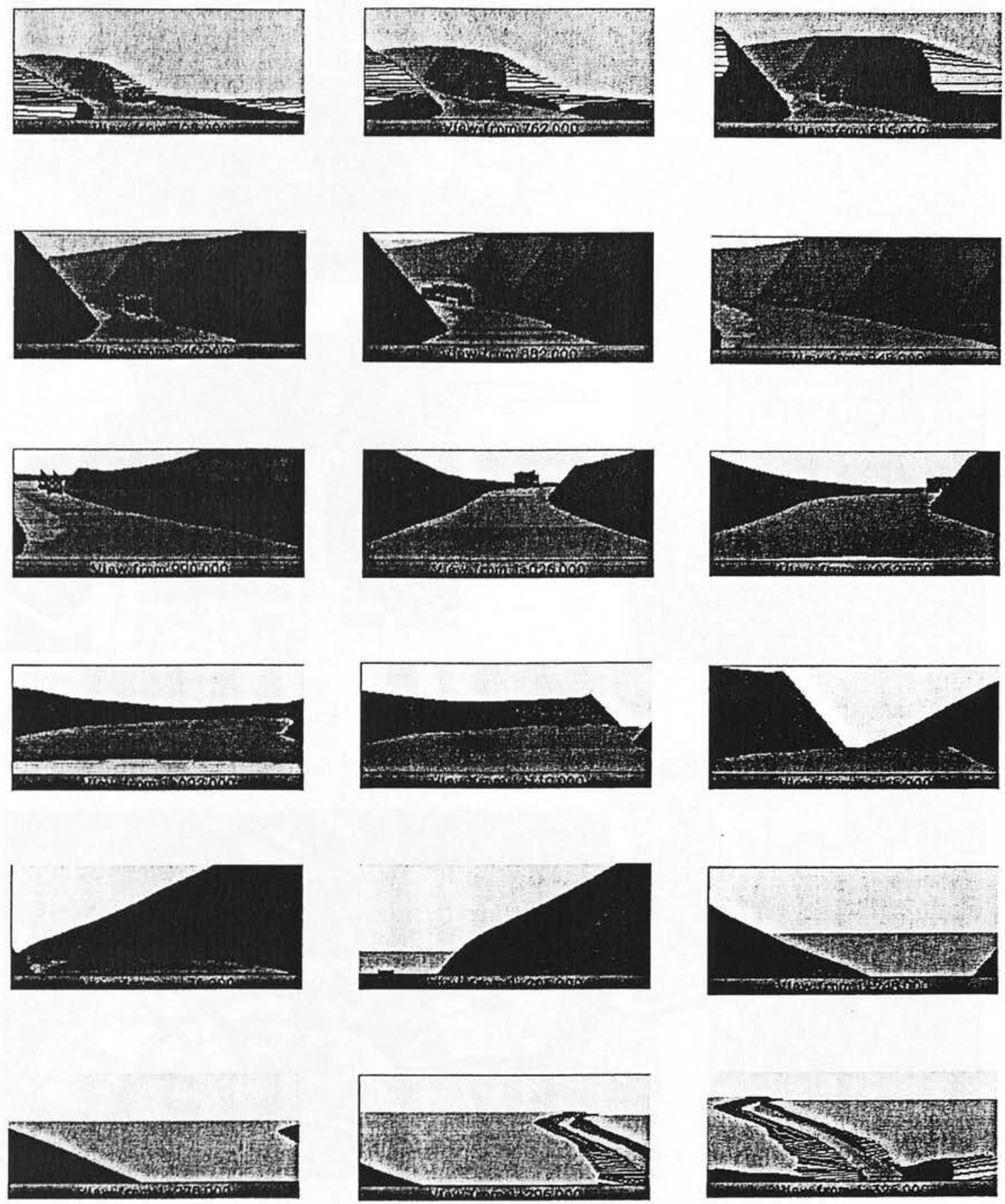

Figure 15: Three-dimensional viewing of a vehicle travelling along the road (53).

CAD for 3-D solid modeling: FormZ by Autodessys, Vectorworks by Nemetschek, 3-D Studio Viz by Autodesk are just three examples of popular and powerful 3-D modeling programs, which are capable of performing digital terrain models. These programs combine solid and surface modeling and are used by landscape architecture, urban design and architecture professionals (54 and 55). 


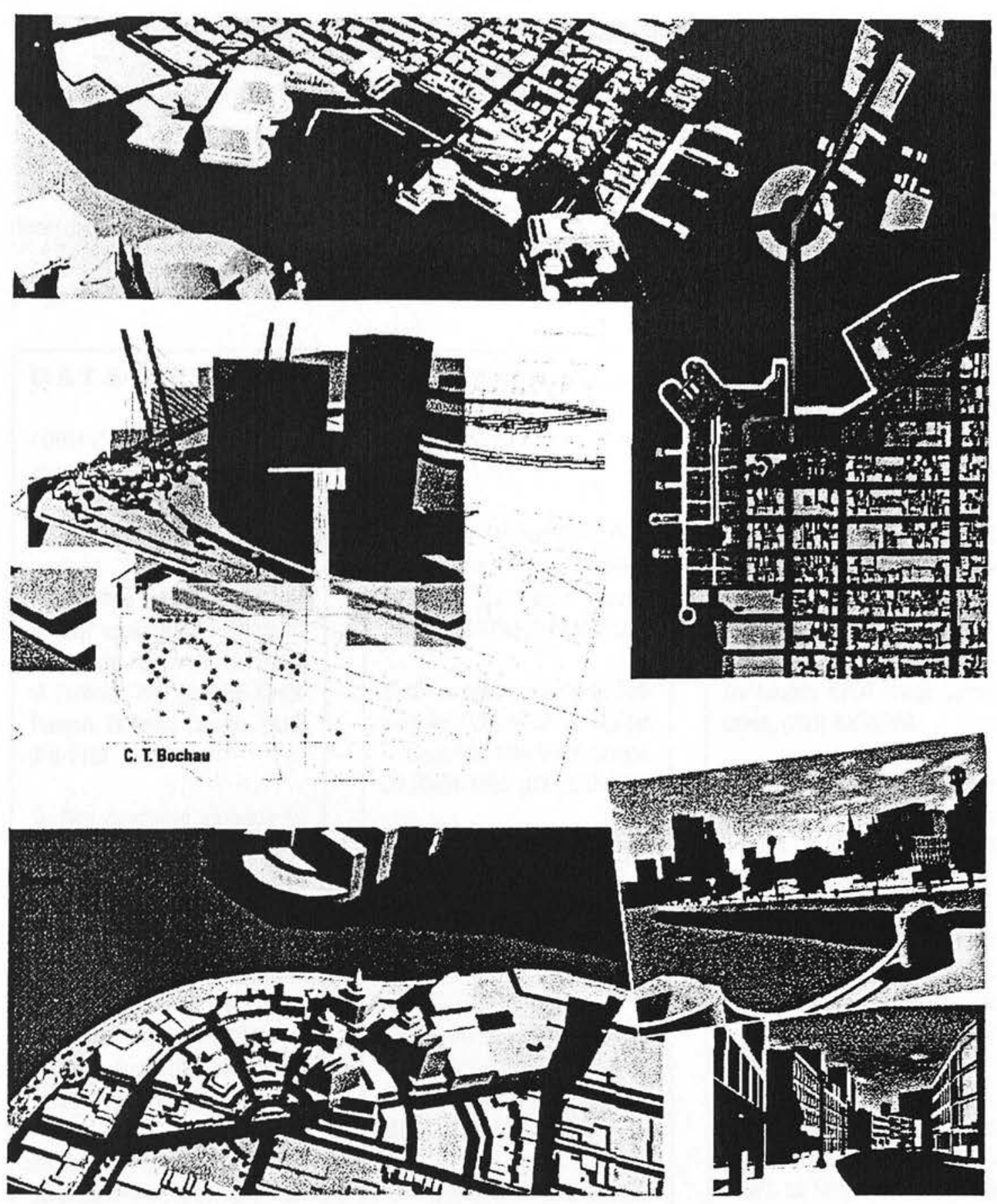

Figure 16: FormZ used in urban design studies. Graduate students' work from Trancik's

LA701/CRP555 course: Designing Cities in the Electronic Age created in Form $\mathrm{Z}$ and

Photoshop (56).

With the development of software capable of displaying curved surfaces, landscape architects are able to incorporate a digital method of representing terrain through digital terrain modeling (DTM). In the past, DTM was difficult for landscape architects to use 
when designing landform because of the magnitude of data required to encode the complex and variety of surface shapes and textures that contours can assume. There are a number of software programs available for DTM, although no commercial software is designed solely for DTMs and none is specialized for landscape architecture design (Figure 17).

\section{DATA VENDORS \\ FORM-Z 2-D. 3-0 Terrain Mod- eling for tfe Macintosh. AutoDesSys. Iric. 2011 Riverside Drive. Colum- bus, OH 43221. (614) 488.9777 \\ POL YIRIMS Mudeling Soltware for SGI workstations, Center for Landscape Research. University of Toronto, 230 College Street. Toronto. Ontario. Canada. (416) 978.7197}

Surface Modeling software for AutoCAD and MicroStation. Engineering Data Syslems. 4131 WestMark Drive, Dubuque, IA 52002. (800) $369-6344$

ERDAS Imagine for Sun Workstations. ERDAS. Inc.. 2801 Bulord Highway. Suite 300 . Allanta, GA 30329. (404) 248-9400

Arc/Into, TIN for DOS. Windows. Sun, ESRI, Inc.. 380 New York Street, Redlands. CA 92373. (714) 793-2853
ContoursPro for the Macintosh. Graphsoft. 8370 Courl Avenue. Suite 202. Ellicor City, M0 21043. (410) 290.5114

GWN-DIM for AutoCAD, GWN Systerris. Inc.. 11133124 Street, Suite 200. Edmanton, Alberta, Canada I5M0J2. (403) 452.0090

Sunter contouring and display sof?ware for DOS/Windows. Golden Sothwarc. 809 14th Slreet. Golden, CO 80401-1866. (800) 972-1021

LANOCADD QUADRANGLE for AUIOCAD. LANDCADD Interna. tional. 7388 South Revere Parkway, Suite 901\& 902. Englewood. CO 80112

CivilMaster for 00S/Windows. PacSoft Inc.., 82.5 Fillh Ave. Suite 100. P. O. Box 3419. Kirkland. WA 98033. (206) 827-0551

TerraModel (TerraCADD) for DOS/ Windows, Plus III Soltware. Inc.. One Duniwoody Park. Suile 250. Atlanta. GA 30338. (800) 235-4972
Quick Surf for AutoCAD, Schreiber Instruments, Inc., (800) 252-1024

AEC Soltware modules for Auto$C A D$, includes GenCADD-DTM SoltDesk, Inc., 7 Liberty Hill Road. Henniker, NH 03242. (603) 4283199

Digital Terrain Model Data, Satellite Images. SPOT Image Corporalion, (703) 620-2200

MetaSile for the SGI his. Stephen Daedalus, Inc.. 1150 S.E. Maynard Road. Suite 100. Cary. NC 27511, (919) $467-7072$

MacG/S software for the Macintosh, Universily of Oregon, Department of Landscape Architecture. Eugene. OR 97403. (503) 3463634

Digitat Terrain Modet Data, Topographic Maps. USGS. (800) USAMAPS lor Earth Science Information Center

Figure 17: List of Data Vendors (57).

The use of DTM is growing in the area of analysis, planning and design on projects of various scope and scale. There are 3 ways to represent curved lines digitally: 1)approximation by a series of straight-line segments: this method produces 3-D drawing by extruding contours lines. This process takes more memory with each line 
segment drawn; 2)purely mathematical construction: shapes of ellipses, parabolas and hyperbolas can be expressed mathematically. This takes less memory since equations are more compactly stored; 3)spline curves and surface patches: a compromise between the other two approaches. This process locates control points and the lines and surfaces between the points are mathematically described. It requires advanced mathematics (58).

Two-dimensional grading plans produced with the use of CAD and spline curves is the simplest form of computer landform design, but offers few advantages from hand drawing. Steve Erwin, a professor at Harvard University said that DTM is a powerful tool, but still has a long way to go before it can have the artistic quality of a sketch produced by an experienced landscape architect (59).
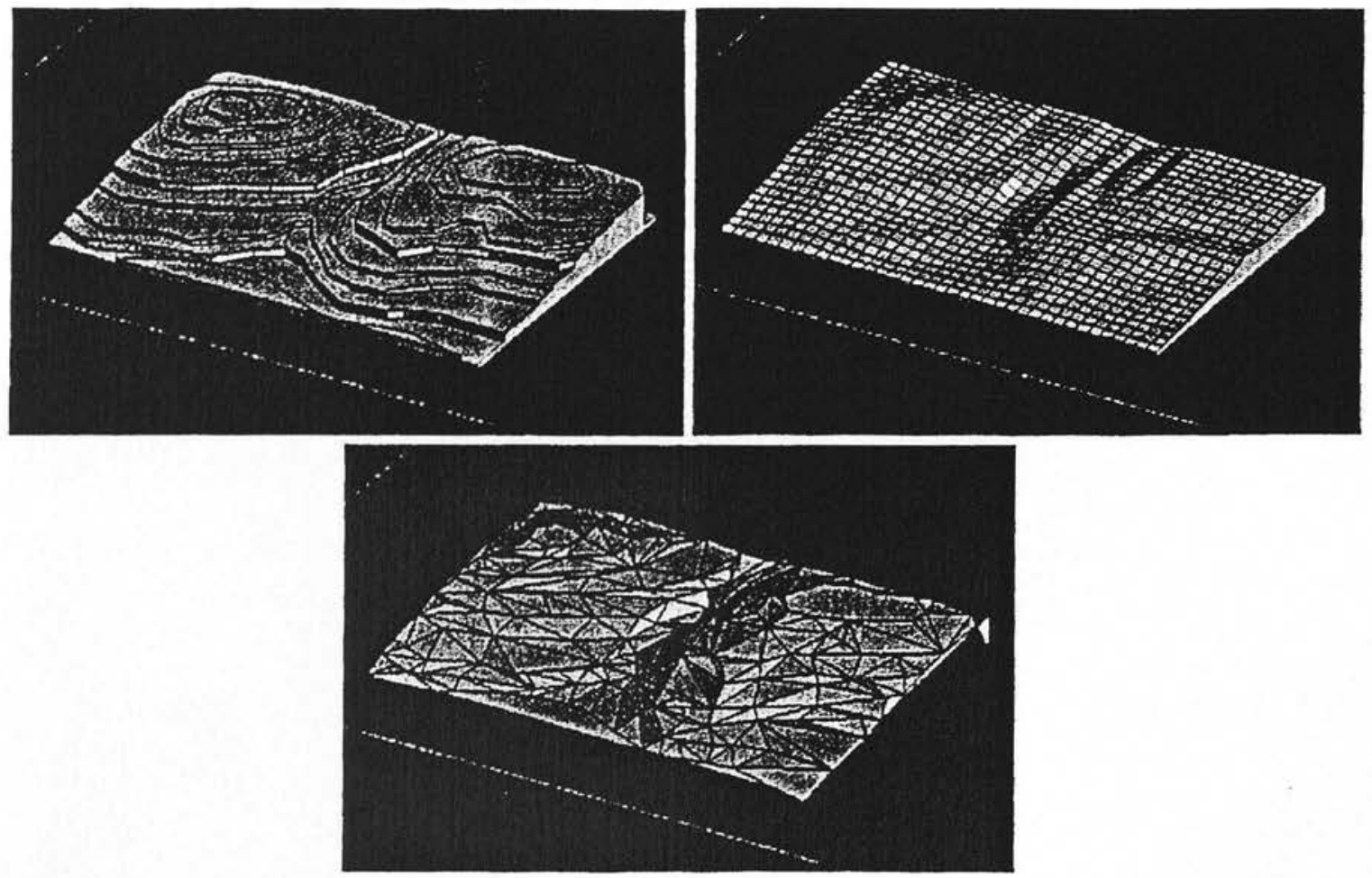

Figure 18: Top left-A DTM using extruded contours drawn as straight-line segments. Top right-A DTM using a regular-grid-"fishnet." Bottom-A (Triangular Irregular Network) TIN representation-created in FormZ on Macintosh (60). 
CAD for data and analysis (GIS): The modern version of GIS (Geographic Information Systems) is a vast improvement from the cumbersome McHargian overlay system, which involved working with maps of varying scales and sources. This technology has radically improved since 1994-97.

GIS makes it possible for landscape architects to do work within a matter of minutes as opposed to days or weeks by hand. It is suitable for large scale projects involving plans that require overlay and analysis in relation to one another; clear and concise maps; speed of analysis; and production of alternative designs with efficiency (61).

When GIS first came out on the market, it was cost prohibitive because of its infancy and novelty and few landscape architects were using it. In 1997, GIS reportedly became more affordable and easier to use. Today GIS systems start under \$2000. (£1392.) with sophisticated workstation-based systems at $\$ 40000$. (£27836.). Landscape architects still find this to be expensive. Therefore there is still a low percentage of GIS use (62). Table 1 shows various Arcview software, and corresponding functions and prices (63). 


\section{AVAILABLE SOFTWARE}

\begin{tabular}{|c|c|c|c|c|}
\hline IIU NL MBI.R & DH:SCRIIIOS & $\begin{array}{l}\text { ISkJ'I vit } \\
\text { I'uke }\end{array}$ & $\begin{array}{l}\text { ASLA Me MaER } \\
\text { THERE }\end{array}$ & $\begin{array}{l}\text { Shrots: } s \\
\text { Hiven:s. }\end{array}$ \\
\hline $11(0) !$ & Arcliew (.IS for Windows / $(\mathrm{U}) \mathrm{R}(\mathrm{N}) \mathrm{M}$ & $\$ 1.195$ & $\$ 717.00$ & $\$ 10$ \\
\hline AVot) & An liew C,Is Version 3.0 for Maninesh il D - ROM & $\$ 1.195$ & 5717.00 & sio \\
\hline 11003 & Areview (ils for DEC Digital (NIX iCL ROANII & $\$ 2.195$ & $\$ 1317.00$ & sio \\
\hline 10001 & 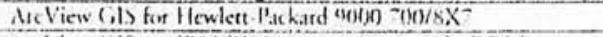 & $\$ 2.195$ & $\$ 1317.10$ & 510 \\
\hline AV005 & 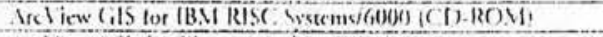 & $\$ 2.195$ & $\$ 1317.00$ & $\$ 10$ \\
\hline AVuot & Aret iew (.IS for Stlicon Ciraphics (CI) R(I)M & $\$ 2.195$ & $\$ 1317.00$ & $\$ 10$ \\
\hline AVno & Arc View CiIS for Sun Solaris (CI) ROMI & $\$ 2.195$ & 51317.00 & 510 \\
\hline NAIMI & AreView Nerwork Analest for Winduws & $51 .+45$ & 5897.50 & 810 \\
\hline NAOOS & Arc View Network Aitulyst for (IEC Digital L NIX & $\$ 2.495$ & $\$ 1.497 .00$ & N/A \\
\hline NAOOS & 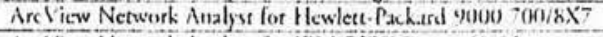 & $\$ 2.495$ & 51.497 .00 & N/A \\
\hline NAOOS & Arcliew Nerwork Analyst for IBM RISC Systcin/Goo() & $\$ 2.495$ & $\$ 1,497.00$ & N/A \\
\hline $\mathrm{N} \wedge 006$ & ArcView Netwonk Analys for Silicon Ciraphics & $\$ 2,495$ & $\$ 1,497.00$ & $N / A$ \\
\hline VAOOS & Arc View Netroik Analyst for Sun + Solais & $\$ 2.495$ & $\$ 1497.00$ & N/A \\
\hline $5(1001$ & ArcVien Spatial Analyst for Windows (CD ROM) & $\$ 2,495$ & $\$ 1497.00$ & $\$ 10$ \\
\hline 5,0003 & Arclicw Spatial Analyst for DEC Digital UNIX & $\$ 2,995$ & $\$ 1797.010$ & NIA \\
\hline 5100.4 & Inclicen Spatial, Inalust lor Hewlete-Paikund $900-00 / 8 \times 7$ & $\$ 2,993$ & $\$ 1797.00$ & N/A \\
\hline 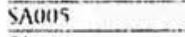 & Arcview Spatial Anslyst for IBMI RISC Sysecm/6006 & 52.995 & $\$ 1797.00$ & NIA \\
\hline SAUU, & AreView Spatial Mualyu for Silicon Cirsphis & $52 . \% 95$ & $\$ 1797.00$ & N/A \\
\hline 51008 & Arcview Spatial Andyst for Sun- i Solaris & 32.995 & $\$ 1797.00$ & N/A \\
\hline 35001 & dicliew 3D) Analyot fir Wrindous (CD-ROMI) & $\$ 2,195$ & $\$ 1497.00$ & 810 \\
\hline $3[0003$ & ArcVien 31 Anslys lor DEC: Digical UNIX & 52,995 & $\$ 1797.00$ & $\mathrm{~N} / \mathrm{A}$ \\
\hline $3[\mathrm{~B} \div 4$ & 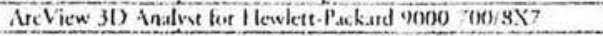 & $\$ 2.995$ & $\$ 1797.00$ & N/A \\
\hline 310005 & Arcliew 3I) Analsst for IBNI RISC St stent/6006) & $\$ 2,995$ & $\$ 1797.00$ & N/A \\
\hline $300\left(K_{1}\right.$ & Arc View i[) Analyst for Silicun (itaphics & $\$ 2,995$ & $\$ 1797.00$ & NIA \\
\hline 3)(408 & Arcliew ID Analus for Sun + S Solutis & $\$ 2.995$ & $\$ 1797.00$ & NIA \\
\hline
\end{tabular}

Table 1: Arcview software (64).

An example of the use of GIS can be seen in the case of the Flathead County Project

(Figure 19), in which GIS software assisted in predicting impacts of future growth. It delineated areas appropriate for planning new development with the least amount of environmental impact. It also enabled projection of population growth under different scenarios to forecast needs for public services such as schools, parks and police protection (65). Mullen, landscape architect for this project expressed his conviction about GIS when he said, "...we must, instead, be more comprehensive in what, where and how we build. GIS gives us the power to do this" (Juhl, 1994, p. 46). 


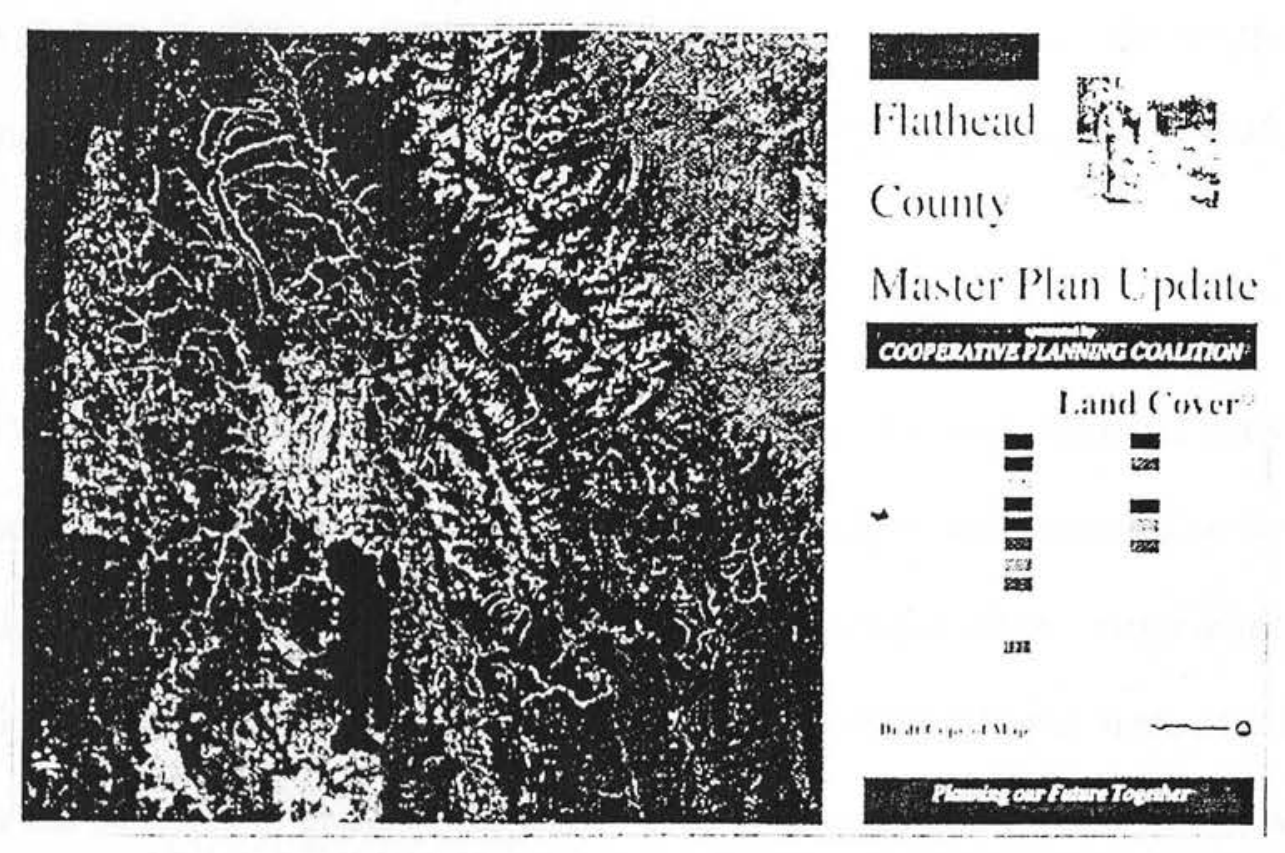

Figure 19: GIS of Flathead County Master Plan (66).

\subsubsection{Image editing}

Since 1985, practicing landscape professionals have had image-processing techniques available to them for manipulating photographs. It was one of the means for creating effective before and after development design scenarios that assisted in visual impact assessment of a proposed design on existing site conditions (67). Image editing is very important in creating effective drawings. Landscape architects can create efficient precise vector drawings in $\mathrm{CAD}$ then take them into image editing programs and produce artful presentation drawings. CAD programs are not equipped to produce highly complex, interesting and exciting drawings. However, the easy compatibility with image editing software allows simple vector drawings to spring to life. New digital rendering software also presents an option to the traditional means.

Paint and image processing programs give color and texture to CAD drawings, but are not typically part of a $\mathrm{CAD}$ package. For example, Adobe Photoshop is affordable, popular and unmatched in terms of its image editing features. Its abundance of features 
allow a multitude of imaging effects to be made with very little effort. Other affordable options for painting include Print House Magic, Live Pix, Paint Shop Pro, Windows Draw 6, and Color It.

More versatile programs, such as Fractal Design Painter, features traditional artist tools to render a $\mathrm{CAD}$ drawing. One of the tools called, "image hose" seems to be designed especially for landscape architects in mind. Similar images of the same subject are stored in special files called, "nozzles." For example, twenty different trees of different colors can be stored in a nozzle and can be used to spray an entire forest within minutes A list of image editing software is shown in Figure 20.

\section{SOFTWARE}

Color It 3.2 ( $\$ 149.95)$, MicroFroncier,

Des Moines, Iowa; ( 515$)$ 270-8109;

(ururv.microfrontier.com).

Expression (\$449), Fractal Design, Scotts Valley, California, (408) 430-4000; fax (408) 4389670; (wrun.fractal.com).

HotShors $(\$ 100)$, PictureWorks Technology, Danville, California; (800) 303-5400; (unuru.pictureworks.com).

Imagineer Technical 2.0 (\$495), Intergraph Corporation, Huntsville, Alabama; (800) 2929761 or (205) 730-5499;

(unvuintergraph.com/imagine).

Kai's Photo Shop (\$50), MetaCreations Corporation, Carpinteria, California; (888) 4566382; (ununumetacreations.com).

LivePix 1.1 (\$50), The LivePix Company, San Francisco; (800) 724-7900; (wruv.livepix.com). MGI PhotoSuite 8.5 (\$50), MGI Software, Richmond Hill, Ontario; (888) 644-7638; (wrerumgisoff.com).
Paint Shop Pro 4.0 (\$69), JASC, Eden Prairie, Minnesora 55344; (800) 622-2793 or (612) 930-9800; fax (612) 930-9172; (unurujass.com). PhotoDeluxe 2.0 $(\$ 0)$, Adobe Systems, San Jose, California; (800) 843-7263; (ururuadobecom).

PhotoFinish 4 ( $\$ 50)$, The Learning Company, Cambridge, Massachusetts; (800) 227-5609; (wrurv.learmingro.com).

Photolmpact 3.0 (\$99.95), Ulead Systems, Torrance, California; (800) 858-5323; (urunutead.com).

PhotoStudio ( $\$ 90)$, ArcSoft Incorporated, Fremont, California; (800) 762-8657; (urenuarcsoff.com).

Picture It! 2.0 (\$55), Microsoft, Redmond, Washington; (800) 621-7930; (unvw.microsoff.com).

PlotPack ( $\$ 250)$, Robert McNeel Associates, Seartle, Washington; (206) 545-7000.

Print House Magic 3.0 ( $\$ 40)$, Corel Corporation, Ottawa, Ontario; (800) 772-6735; (wneru.corel.com).

Vdraft 1.5 (\$495), SoftSource, Bellingham, Washington; (800) 877-1875, (360) 6760999; (wrwv.vdraft.com).

Windows Draw 6 $\$ 50)$, Designer 7, Micrografx, Richardson, Texas; (800) 676-3110; (unurumicrografx.com).

Figure 20: Image editing software (68). 
Fractal's Expression is another rendering program. It combines natural-media tools with vector-based accuracy and functionality. Because it is in vector format, it can be edited and scaled easily without loss of quality. These programs can create presentation quality photorealistic images (69).

\subsubsection{Visual simulation}

3-D simulation: Modeling natural phenomenon with computer generated images allows landscape architects to simulate landscape conditions such as drought or entire ecosystems. To create modeling of natural phenomenon, the essence of the developmental process that leads to a form must be captured. This is accomplished by allowing the computer to create the details in response to instruction about the object. Such techniques are called "procedural" because the computer produces the detailed geometry of the object by following programmed procedures. Detail is generated algorithmically to describe the object. For example, this process can be used to tell the story of a seed that grows and transforms a barren planet into a virtual Eden (Figure 21). Systems such as fractals, L-systems, graftals, cellular automata and particle are used to model natural phenomena. Standard dxfs (data exchange file) can be imported directly into procedural modeling programs and be manipulated like in any other CAD program. 

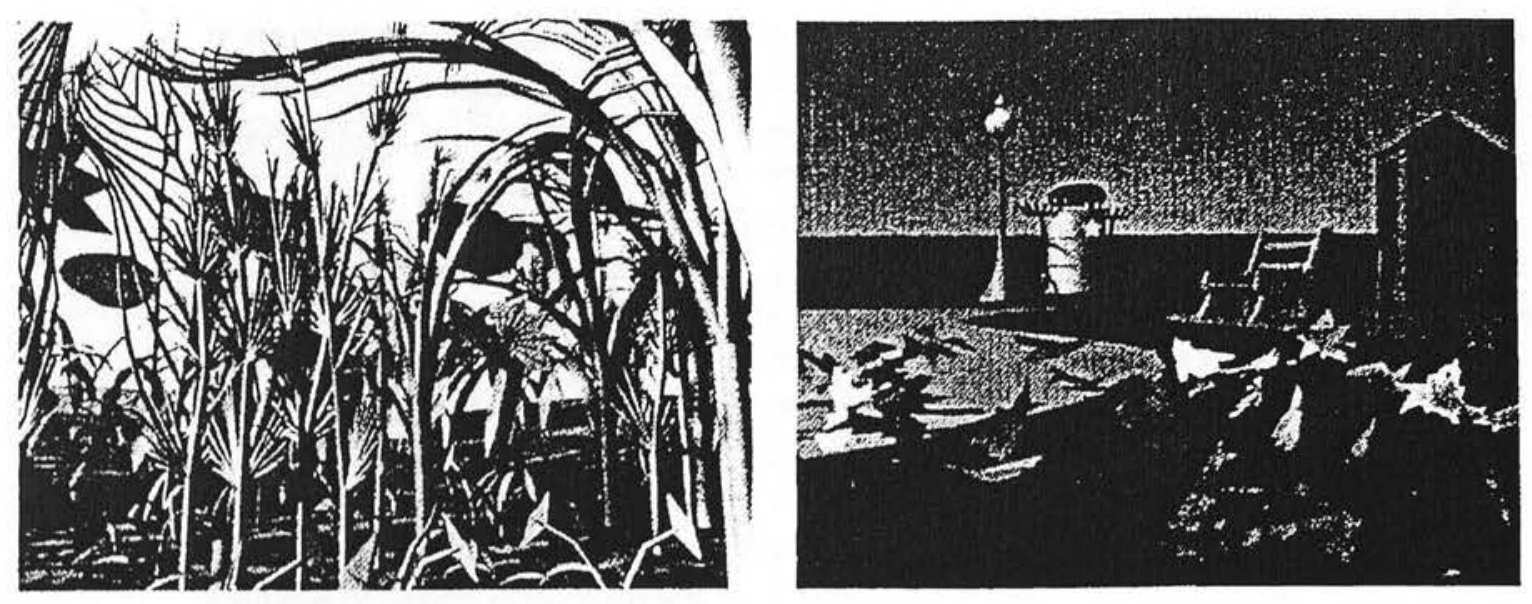

Figure 21: Left-Animation showing a seed that grows and transforms a barren planet into a virtual Eden. Right-Animation sequence showing leaves moving in the wind (70).

Landscape architect, Jim Sipes, ASLA, with Jones and Jones, Architects and Landscape Architects commented, "The strength of procedural modeling lies in its ability to transform a small set of simple constraints into a complete description of complex objects.” He continues, “...despite procedural modeling's potential, we must keep in mind that, like any other program, it requires a creative mind to put it to good use" (Sipes, 1994, p. 32)(71). 


\section{COMPUTER PROGRAMS FOK \\ MODELING NATURAL \\ PHENOMENA}

These progmams are arailahle through national computer vullets specializing in graphics softuare. Information in parentheses is the softwure developer. who should be cited when ordering.

\section{VISTAPRO (VIRTUAL REALITY LABS) $\$ 70$}

Allows the user to generate and animate 3-D fractial landscupes. IBM, Amiga and Macintosh versions.

Cellutar Automat lab (Rudy RuckER, AUTOULsk, INC.) \$55 Used to explore the patterns of nature, simulate physical and biological processes and generate dynamic full-color graphics. Therra Simulator (Dr. Thomas S.
$\mathrm{R} \Lambda \mathrm{Y}) \$ 65$ Creates a virtual world in which self-replicating computer models evolve by niatural selection.

Pickuveh Samíler Softwark. (BotirRAKI, INC.) \$25 Fractal software for generating a wide variety of unique image types, included biumorphs, random plants and spiral plants.

Dynamical Software (Dynamicat. SYSTF.MS) \$575 A professional package for studying nonlinear dynamics and chaos.

Cha0s The Software (James Gleick ANI RUINY RUICKER, AUTODESK, INC.) $\$ 50$ Includes six modules that explore chans patterns; one module includes fractal generation of clouds, mountains, planets and other landscupes.

Fracted-A Fractal Scenf. RfindiTION SYSTEM (TARDis SYSTEMS INC.)

Designs 3-D fractal models of trees, flowers, ferns, mountains, gaiaxies and abstract shapes. Models can be exported to 3-D CAD programs.

L-SYSTEM (PAUL BoURKE) \$45 Generates complex plant material by using $\mathrm{L}$ systems. MacIntush.

IMAGINE NURSEIRY (SCHRIEBER INSTRUMENTS) \$149 Creates 3-D models of trces with highly detailed branching structure and leaf geometry. For use in 3-D Studio or AutoCAD.

AMAP (CIRAD MUDELING) $\$ 100,000$ Frovides butanically turrect models of plant material; can be used to accurately prediet plant behavior based upon userdefined environmental conditions. AMAP Version 2 North American packages range from $\$ 25,000$ to 60,000 . IPAS PACRAGES (YOST GRUUP, INC.)

Figure 22: Resources for computer programs for modeling natural phenomena (72).

Visual simulation of reconstructed historic site: Computer-aided visual simulation is a powerful tool when it comes to reconstructing a historic site. It demonstrates the potential role landscape architects can play in landscape restoration. 
Landscape architect, Meneloas Triantagillou, with the firm of Viewshed and graphic designer, Eric Triantagillou reconstructed the Temple of Zeus near the Acropolis and visually simulated it to different historic periods, 404 B.C. to 565 B.C. and 1870 . These respective periods were chosen due to the archeological remains and base maps available from archives.
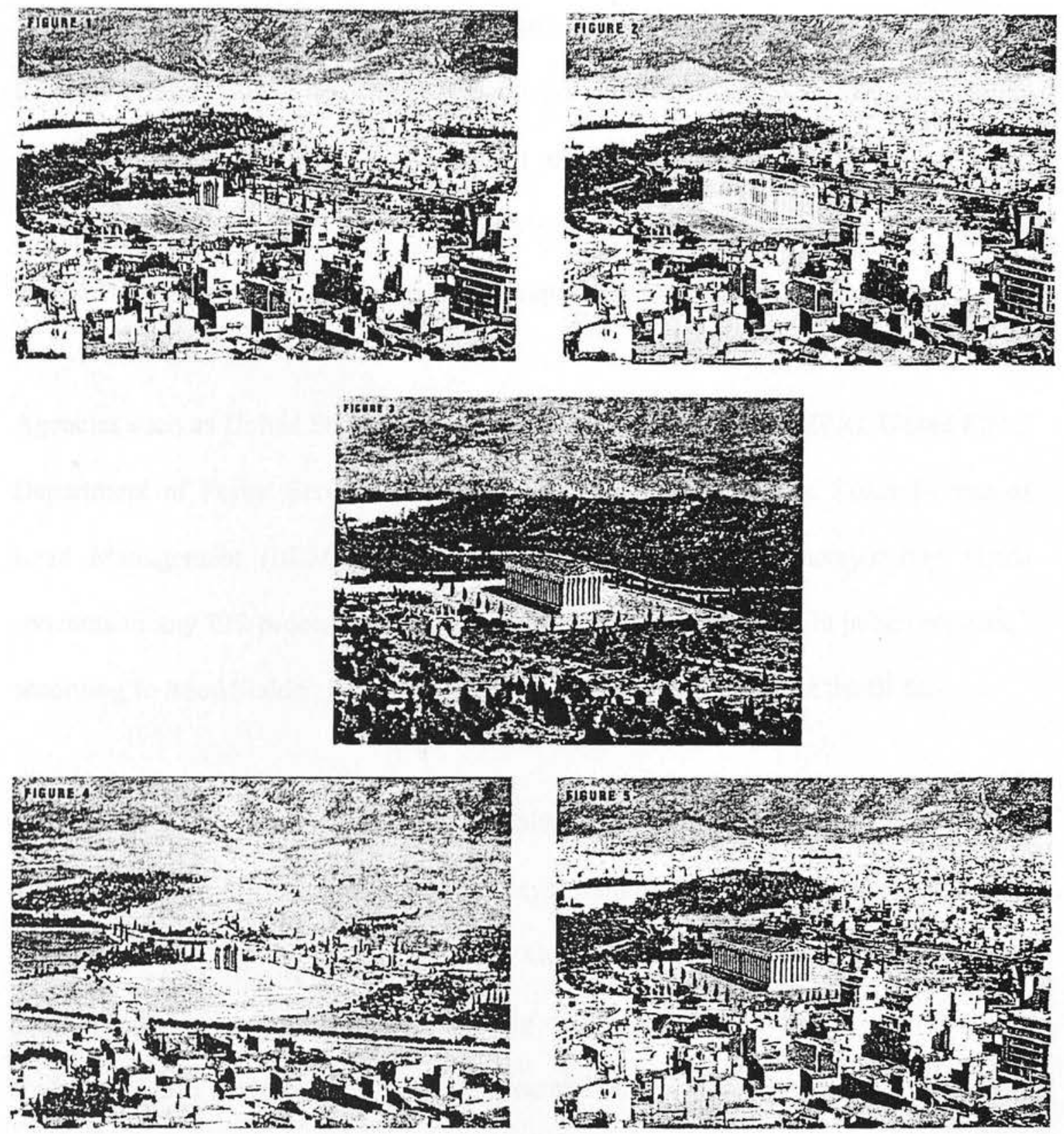

Figure 23: Left to right-Existing site/base image; wire-frame of Acropolis on base

image; 408-565 A.D image; 1870 image; existing site with reconstructed Acropolis 
Photos of the site were the initial input. It was scanned and used as the base image. A wire-frame 3-D model of the temple was assembled with AutoCAD. The wire-frame image was then rendered with paint software using the temple as a source of the color. Landscape elements were scanned and added to the image. The final image was rendered and edited in Adobe Photoshop and Stratavision 3-D (74).

Visual simulation of proposed land reclamation: Computer-aided visual simulation is a highly effective tool in showing changes made in the landscape. It can show policy makers and other stakeholders the results of major landscape changes on highways, ski slopes, and mining operations etc. Today, visual simulation is often required on public lands in the West as part of environmental impact statements (EIS).

Agencies such as United States Environmental Protection Agency (EPA), United States Department of Forest Service (USDA Forest Service), and United States Bureau of Land Management (BLM) have their own requirements for incorporating visual concerns in any EIS process, particularly "on sites that are elevated in public concern," according to Reed Stalder, landscape architect with the Utah office of the BLM.

Ellsworth and Associates, Lansdcape Architects (EALA) in Utah is a firm that has created many simulations, including highways, ski areas, oil rigs and surface mines. In a project involving the Barrick Mercur Gold Mine in west-central Utah, EALA prepared simulations picturing recontouring of the site after reclamation. To do this, EALA designed landforms resembling the natural landforms of the area and graded the site for revegetation and erosion control. 
According to Ellsworth, "A problem with such imaging is that a simulation based on far-less-than-accurate data can be as photorealistic as this one" (Thompson, 1998, p. 34)(Figure 24)(75). "The difficulty is in 'grounding truthing'--the issue of locating points in three-dimensional space with a two-dimensional image", says Jim Palmer, a professor of landscape architecture at the State University of New York at Syracuse (Thompson, 1998, p. 36). He continues, "The software is not to blame-part of the problem is that detailed topographic data is not always available for wild lands." In order to gain confidence in a simulation, certain questions must be asked, such as "How did you build the image?" and "What steps did you go through to arrive at it?" (Thompson, 1998, p. 36).
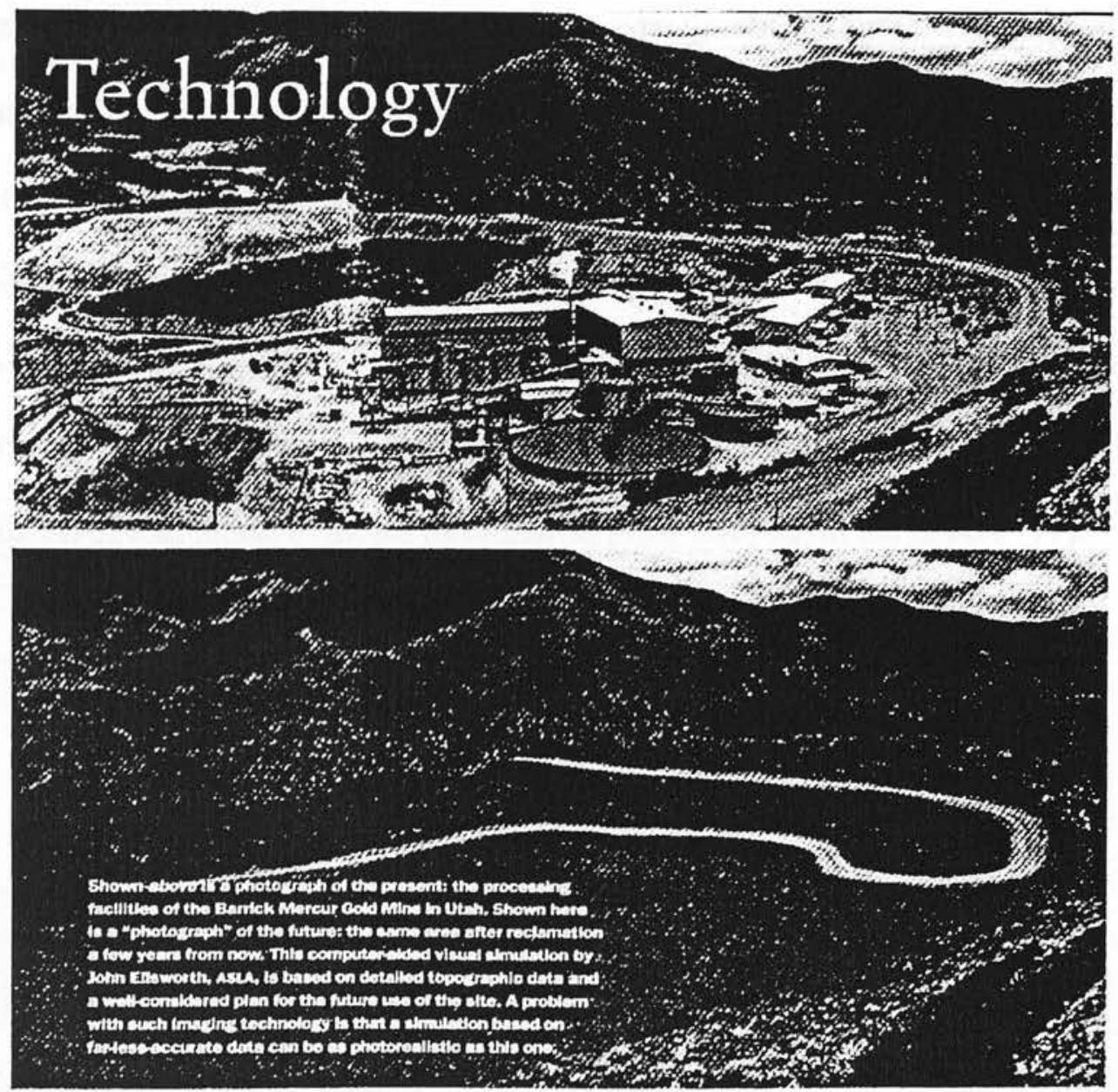

Figure 24: Simulations picturing recontouring of the site after reclamation (76). 


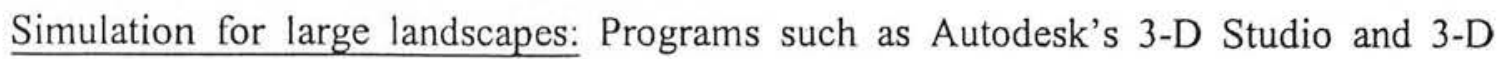
Studio Max; Microsoft's Softimage 3-D, Autodessy's FormZ; Strat, Inc.'s StrataVision; and New Tek's Light Wave are suited for modeling objects, but not large spaces. However, landscape architects have the ability to simulate visual complexities of the vast and real landscapes with a new generation of computer programs. The tools in these programs create effective landscape elements at the "extra-human" scale.

New scenery animator programs include AnimaTek's World Builder from AnimaTek, Vista Pro from Virtual Reality Labs, Scenery Animator from Natural Graphics, and Bryce 2 from Metatools. They are developed to interact with databases of geological information. These programs involve defining landforms, plants, water and sky. A program like World Builder allows for the specification of trees to be distributed differently in the landscape drawing depending on the landform. For example, deciduous trees can be distributed more densely in valleys and evergreen trees more densely on hills or in areas with increasing elevations. These programs also include a selection of sunny to stormy sky options (Figure 25). With some of the programs such as Vista Pro and Scenery Animator, the flight path can be drawn for a camera to create the illusion of animation as in, for example, as grass swaying in the breeze (77). 


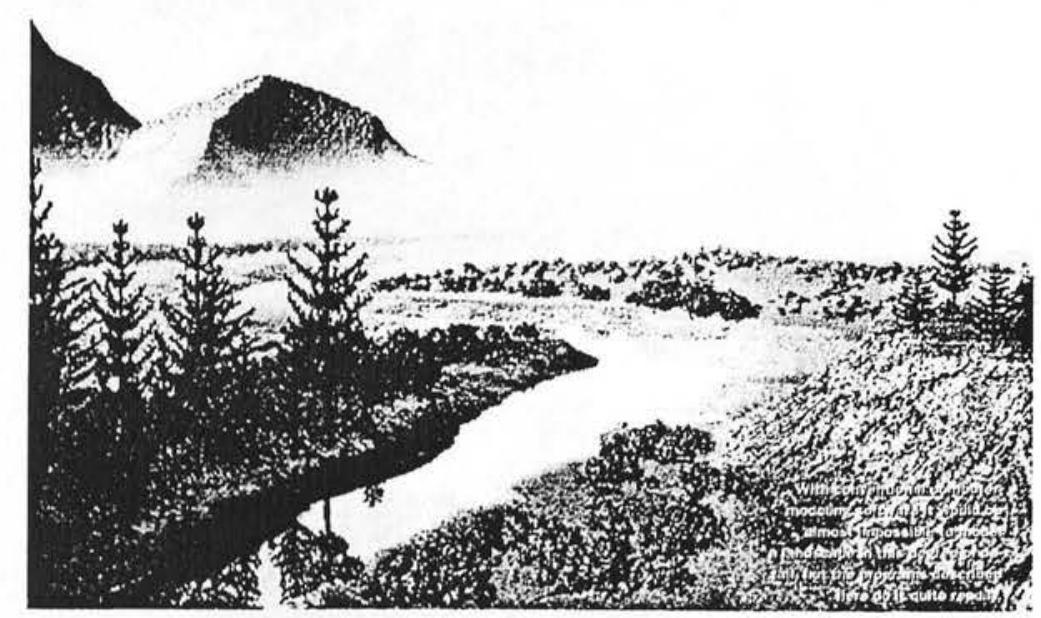

Figure 25: Computer modeling and simulation of vast landscape (78).

\section{$\underline{2.3 .3}$ Virtual reality software programs}

QuickTime VR: QuickTime VR (QTVR) is an extension of the QuickTime technology developed by Apple Computer Inc. It is a photorealistic cross-platform virtual reality technology that makes it possible to look and study environments almost as if you were really there. All major applications that play QuickTime movies can also play QuickTime VR movies. They are comprised of a collection of object and panoramic nodes (79). Almost all-interactive CDs require the QuickTime Extension in order to function. It allows standard animations, movies, and sound files to run (80). At the juncture of commercial photography and new media technology, QuickTime VR transforms photographic images from 2-D into a more immersive experience of 3-D imagery with interactive components. The viewer is able to explore virtual worlds using a computer and mouse, as opposed to cumbersome goggles, headsets or glove (81). 


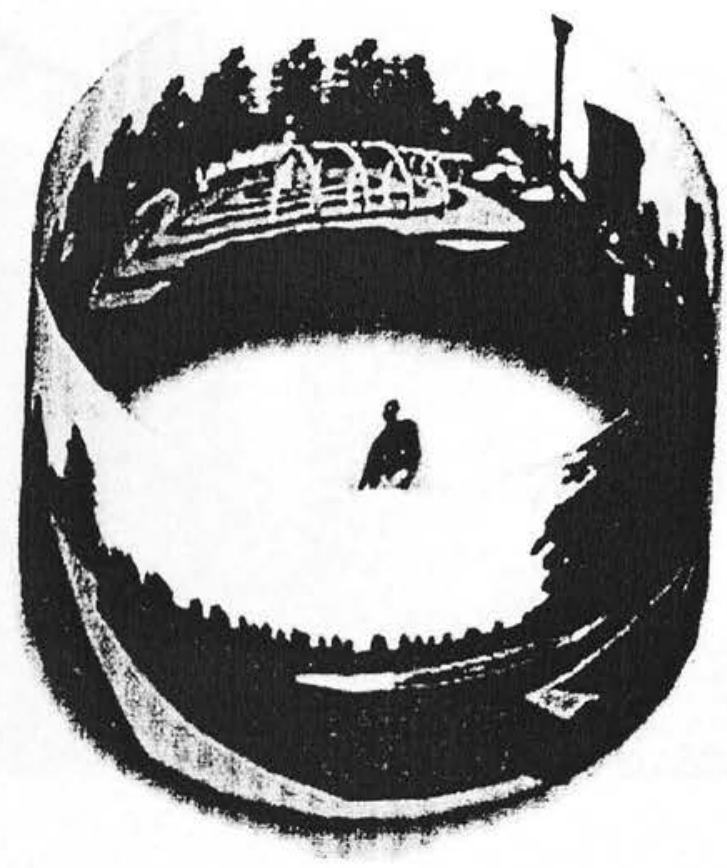

Figure 26: Panoramic image in QuickTime VR (82).

QTVR "stitches" photos with (50\% overlap) together to formulate the panorama (Figure 26). Many landscape architects use this imaging technology, not only to study a project but also to present their designs. This is an effective way of illustrating the design in its context since it is able to immerse the viewer in the middle of a panorama view. An example of the use of QTVR can be seen in the 1996 case study of Atlanta's Chattahooche River Project. Teams of landscape architects very effectively used several different ways of conveying spatial information in this project (83).

Virtual Reality Modeling Language (VRML): Designed environments can be viewed with full visual immersion with the use of VRML (virtual reality modeling language), which runs on SGI's (Silicon Graphics Inc.) UNIX operating system. This technology requires, a visualization tool (such as hypershow or stereoshow) along with stereo glasses. 


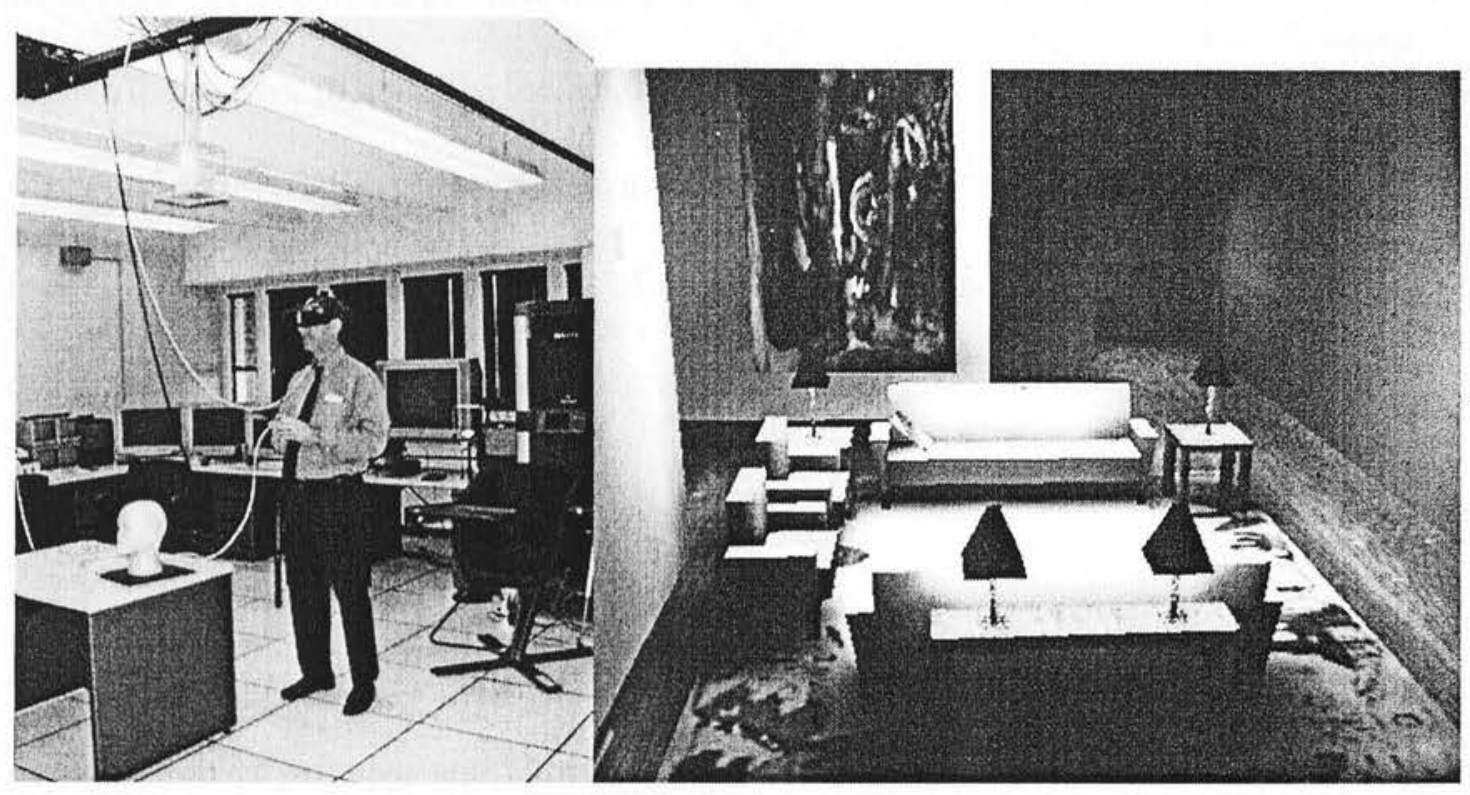

Figure 27: Left-Professor Hogan in the VRML lab equipped with Silicon Graphics Inc. (SGI) hardware using UNIX operating system. Right-VRML drawing created by a student, Mark Moehring (Photos from Hogan, 2000).

The viewer moves through the space and uses a mouse to move forward or backward in the virtual environment, but the viewer has bodily control when he or she turns his or her head to look at a particular view within the virtual environment. Clemson University Professor Robert Hogan who teaches VRML remarks, "When my students put on the stereo glasses and enter the virtual environment, it is interesting to watch their physical/psychological responses. I see them stop when they get to the top of the steps or when they get near a wall" (personal communication, October 26, 2000). The main difference between VRML when compared to 3-D modeling is that in 3-D modeling drawings, one looks at a computer screen and moves around with the mouse. Another difference between them occurs in the way the lighting is manipulated for the environment. In VRML, ambient and incident light must be carefully designed and remains as designed. Thus, as the viewer moves through the environment, the lighting changes automatically with the change in viewer position. In contrast, lighting is 
adjusted to each particular view in 3-D modeling. The benefit of virtual reality is that it allows the viewer to actually feel as if he or she is physically in the space. Many aspects of virtual reality still need work. For example, landscape elements are cumbersome to model because "they eat up" a lot of memory. The model has to be "tight" enough in order to run real time (24 frames/second) and detailed enough to appear real (84).

\section{$\underline{\text { 2.3.4 }}$ Multi-media}

Multi-media in computing represents the integration of sound and video. It is a combination of software and hardware capable of using a wide variety of media such as film, video, and music as well as text and numbers (85). It is a very effective means of communication and many landscape architects have utilized this technology for presentations.
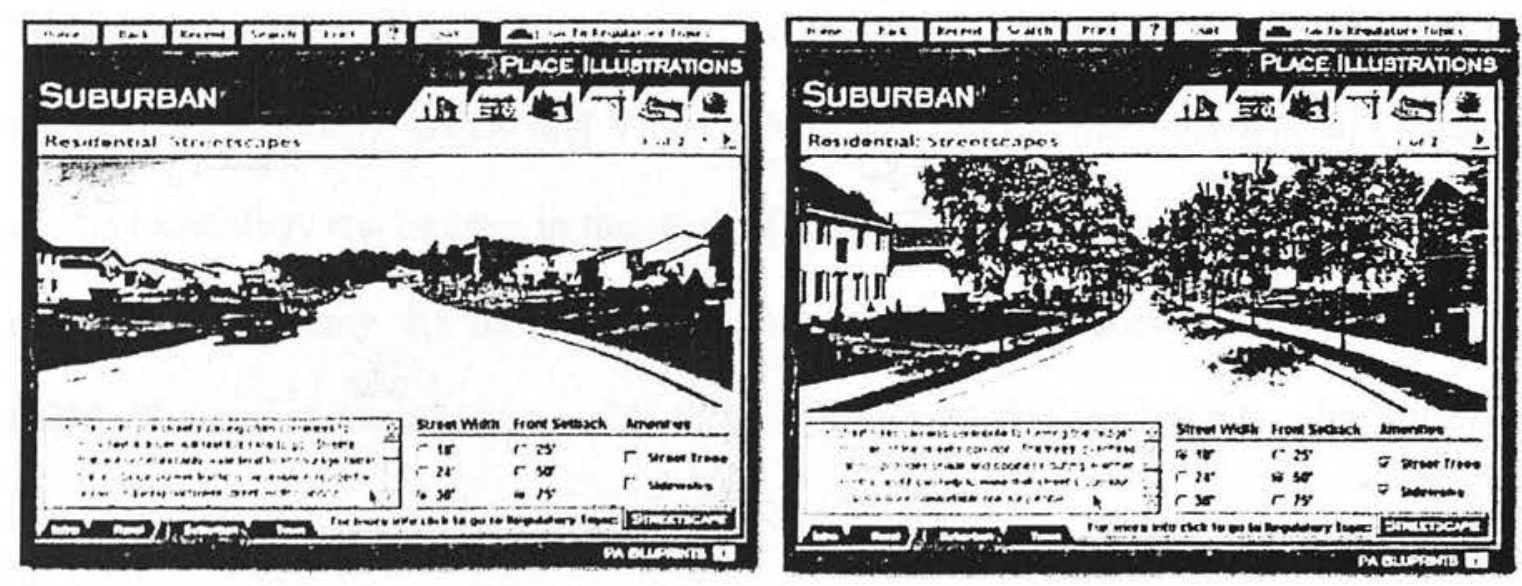

Figure 28: Left-Multi-media CD-ROM helps user to understand design alternatives.

Right-A 36-foot wide street is compared with a 18-foot wide street. The navigation bar

at the bottom allows flexible simulation vs. a linear one (86).

In a project by Penn State University, an interactive multimedia CD-ROM was developed, called PA BLUPRINTS (Best Land Use Principles \& Results, INTeractively 
Shown) to help shape better planning policies and regulations through visualization of their impact on the community resources. Many exemplary approaches are shown together with illustrations and examples from Pennsylvania. Included also are commentaries from each group of audiences so that perspectives can be gained for each other. Since this was developed with interactive multi-media, it engaged the user by allowing him or her, the ability to change a scene when variables (road widths; with or without sidewalks, street trees, buried utilities or signs) are manipulated. The content of the project is in six areas including agriculture, community character, natural systems, sign control, streetscapes, and trees/woods. Each simulation was created in Adobe Photoshop and the ability for the user to control the simulation was created in Macromedia Authorware. Thus, BLUPRINT is more flexible than a linear simulation (87).

Today, options for presentations go far beyond the slide presentation by utilizing interactive CD-ROMs, DVDs and Video CD players. An excellent example of the use of this technology can be seen in the work of Roger Trancik, an urban design professor at Cornell University. He has developed an interactive educational multi-media CDROM, "Layers of Rome" (Figure 29) that explores how this ancient city rebuilt itself layer upon layer into a modern metropolis (88).

The design of Rome is experienced while moving through images of the city. These images were generated from 3-D computer models and combined with color photographs, video and narratives. "Virtual-space renderings and animation take you back 2000 years to Rome's Campus Martius and provide unique visualization tools for studying the design of cities from within" (Trancik, 1998)(89). 


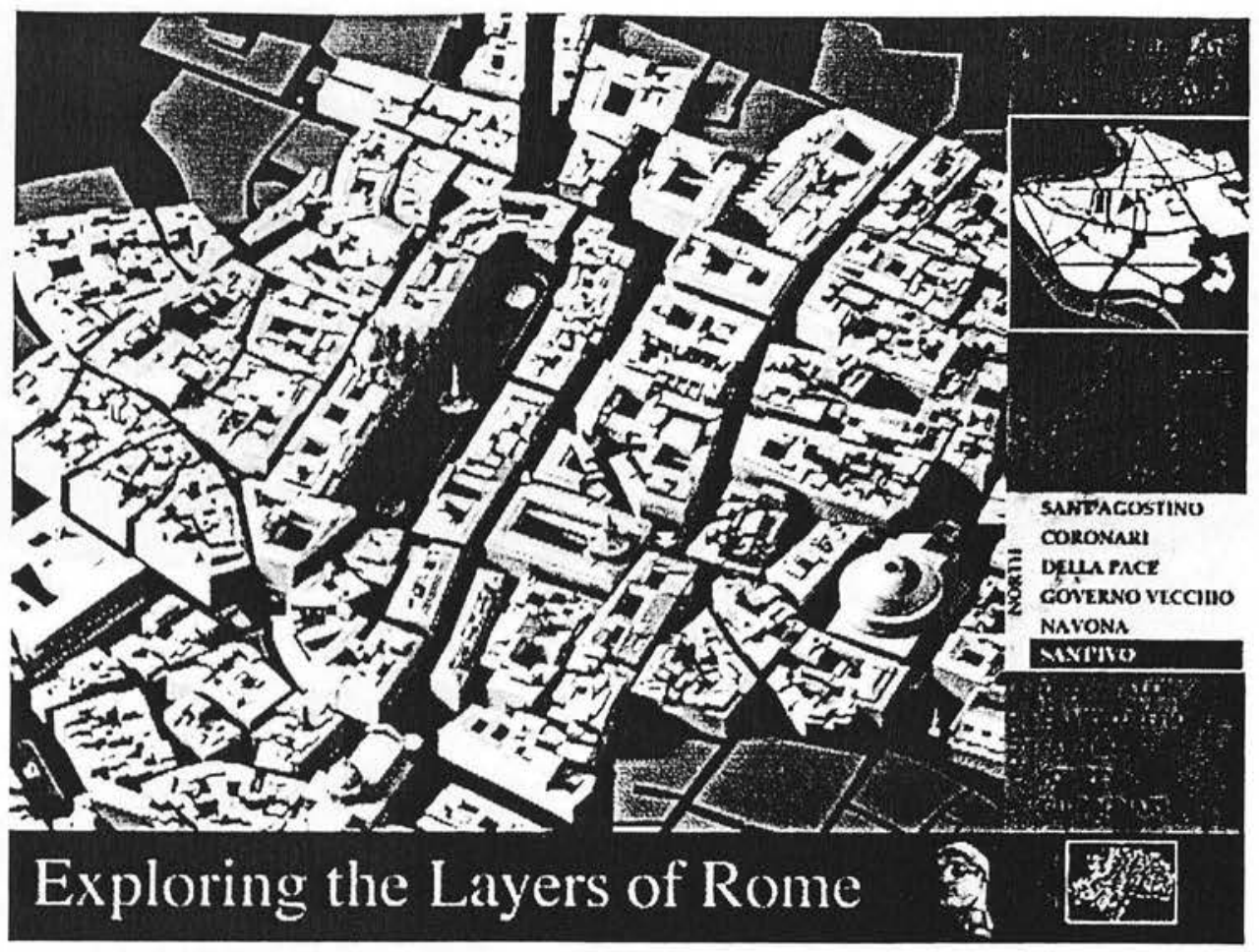

Figure 29: Layers of Rome, a multi-media CD-ROM (90).

\section{$\underline{2.3 .5} \mathrm{CAD} / \mathrm{CAM}$}

Computer Aided Design/Computer Aided Manufacture makes it possible to draw and manufacture complex landscape elements such as drawing silhouettes of a wall and then fabricating it at full scale. An example of this is the William Smith Clark Memorial Garden at University of Massachusetts (Figure 30). These virtual landscapes can be projected onto large screens. In the William Smith Clark project, foreground, midground and background of a photo were digitized onto individual layers. It was time and cost efficient to have used the computer as a design tool for construction drawings and technical specifications due the fact that calculating and drawing radii and angles were not necessary. There was a $25 \%$ time savings when the design was submitted to the manufacturer on disk rather than having the technicians enter the data. Finally, a computer-controlled flame cutter cut the steel walls precisely from the data digitized from the photos (91). 


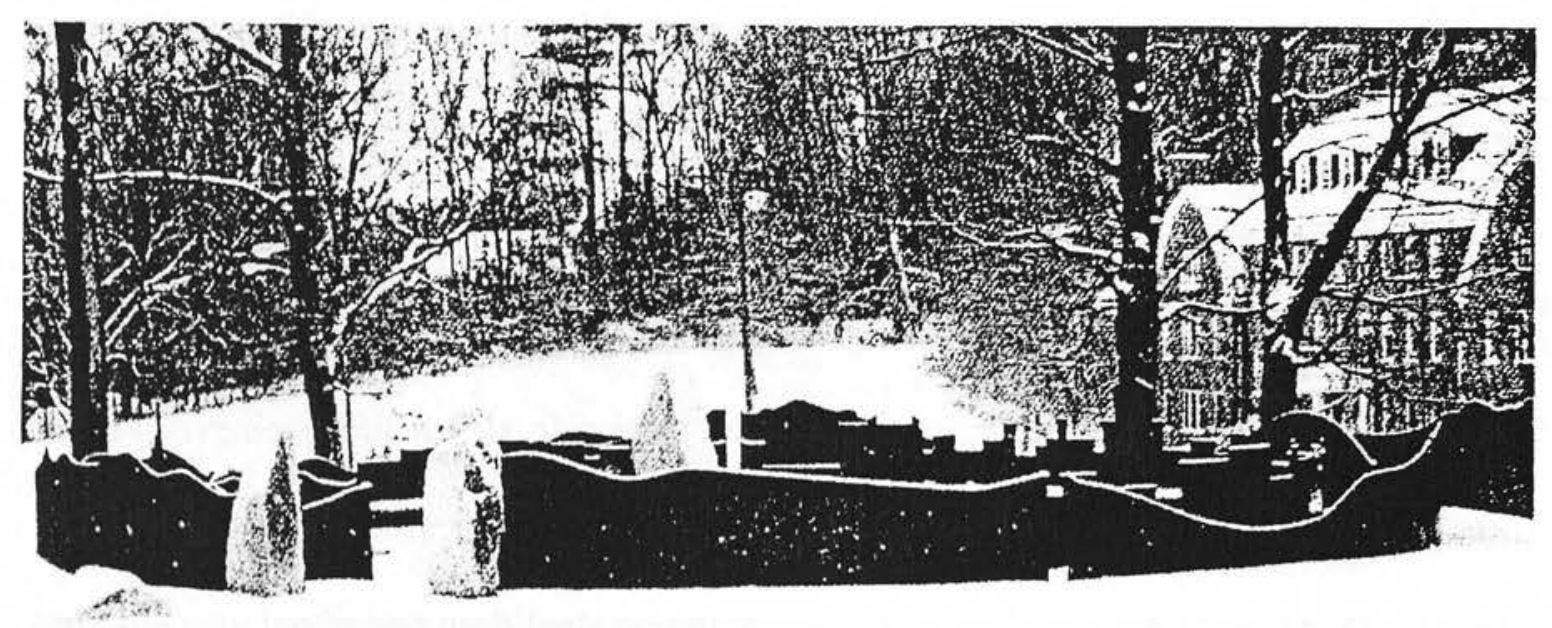

Figure 30: Computer manufactured landscape element (92).

In another project, 3-D AutoCAD model was used to create the concept for the United States Armed Forces Memorial Garden. The CAD program was capable of accurately dimensioning the parabolic planes and surfaces of a basin (Figure 31). Constant evaluation of the design was possible due to the computer modeling. The robotic saw of the $\mathrm{CAD} / \mathrm{CAM}$ allowed the granite to be cut with precision.

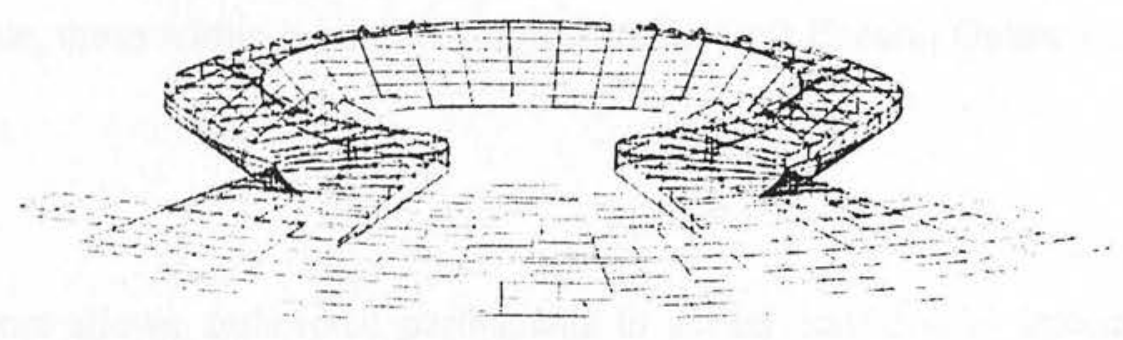

Figure 31: Computer manufactured landscape element (93).

In both instances, the use of computer data insured the accuracy of the design intentions, which were critical in the case of these two pieces of artwork (94). 
When the World Wide Web emerged during the early 90's, it changed the entire culture of the developed world. During this period, the computer became more powerful and faster (95) and it changed the way we do business. Not only did communication become more convenient, but it was also instantaneous. In addition, the World Wide Web has expanded exponentially as a source of information. This technology has affected not only the way landscape architects communicate, but also in the way they select product specification, market services, find business leads, submit proposals and bids, and recruit new employees.

Use of a Web site, Intranet and Extranet: Many design firms have some sort of presence on the World Wide Web today and are utilizing interactive communication with the technology of the extranet. This technology is "an extension of the organization's intranet. Extranet gives authorized outsiders, for example customers, suppliers, or business partners, controlled access to parts of the intranet" (Microsoft Encarta Online Encyclopedia, 2000)(96). The intranet is "a network of computers, especially one using World Wide Web conventions, that can be accessed only by an authorized set of users, for example, those within a single company" (Microsoft Encarta Online Encyclopedia, 2000)(97).

The extranet allows authorized participants to access confidential information on a particular web site for project collaboration. Sharing and retrieving documents, on-line conferencing, drag and drop file sharing, and message board posting are some of the features. This is an instantaneous way of communicating, which is particularly helpful if the project team members are in geographically different locations or time zones. 
The so-called academic "virtual studios" are an example of the extranet at work. Students can have productive exchanges in critiques through video teleconferencing and other Web-based interactions. For example, a virtual studio was conducted at Harvard University via the Web site (http://www.gsd.harvard.edu/ worlitz). Web pages are one of the ways to mass data, but tracking it and making it easy to retrieve is critical if designers are going to use it efficiently. This area of collaborative design was the focus for Stanford professor and engineer Renate Fruchter. She developed software and design methods that allow effective team collaboration. For example, she "established a change-notification system that alerts each team member to any design changes by others that might have some consequences on the member's work" (Novitski, 1997, p. 140)(98). She has her engineering students work with architecture students at University of California at Berkeley with shared and private workspaces. Links are created to the workspaces and passwords allow members of the team to view information.

Another illustration of network-based technology is the Web-based discussion forum. This is similar to a bulletin board, news group, or list serve and can collect opinions from the intended audience. LARCH-L, a landscape architecture electronic forum, is an example of this web based communication process.

Web sites with this type of communications capability require expertise beyond marketing on the web. Products and services are available through various companies such as HotOffice (www.hotoffice.com/home.asp), Instinctive Technologies' eRoom (www.instinctive.com/), BlueLine/OnlLine (www.bluelineon-line.com), MPInteractive Corp's e-Builder (www.e-builder.net), and Framework Technologies' Active Project (www.frametech.com/)(99). 
It is apparent that the American Society of Landscape Architects (ASLA) is utilizing the Web (www.asla.org) for delivery of information about the profession to their members in the most expedient and efficient manner. In 2000, it had the following items on-line (Figure 26): ASLA CADdetails; Landscape Architecture Registration Examination: A Guide for Professional Development; LAND; JobLink; Membership Handbook; Surveys; Landscape Architecture Technical Information Series (LATIS); ASLA Sample Contract Documents; ASLA Bylaws, Constitution, Code and Guidelines for Professional Conduct, ASLA In Practice Directory; and Landscape Architecture Links (100) . As reported by the ASLA in their 1998 Membership Satisfaction Survey, $92 \%$ of its members have access to the Internet and $80 \%$ have visited their site on-line. These results suggest that landscape architects are moving away from printed media and adopting digital media (101). 


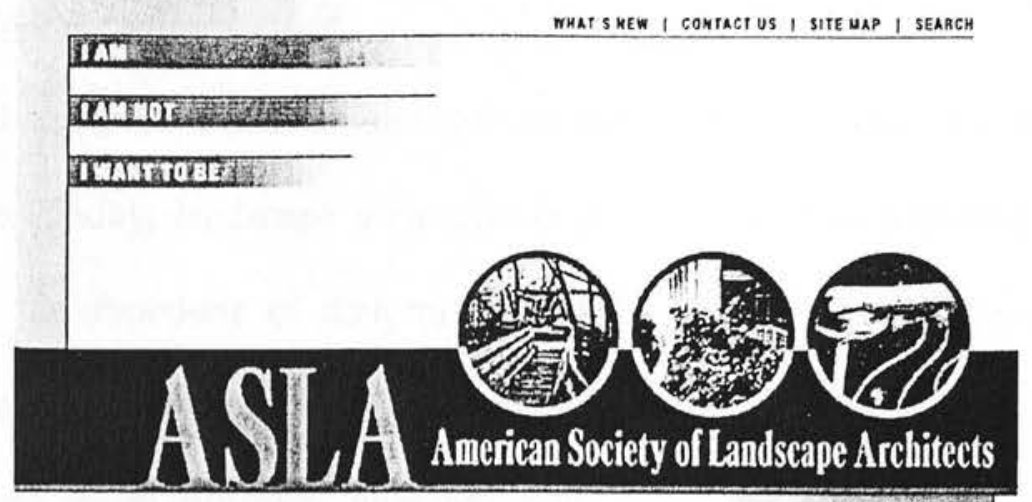

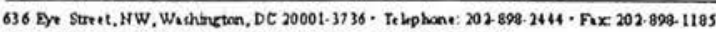

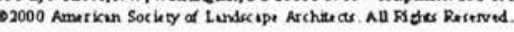

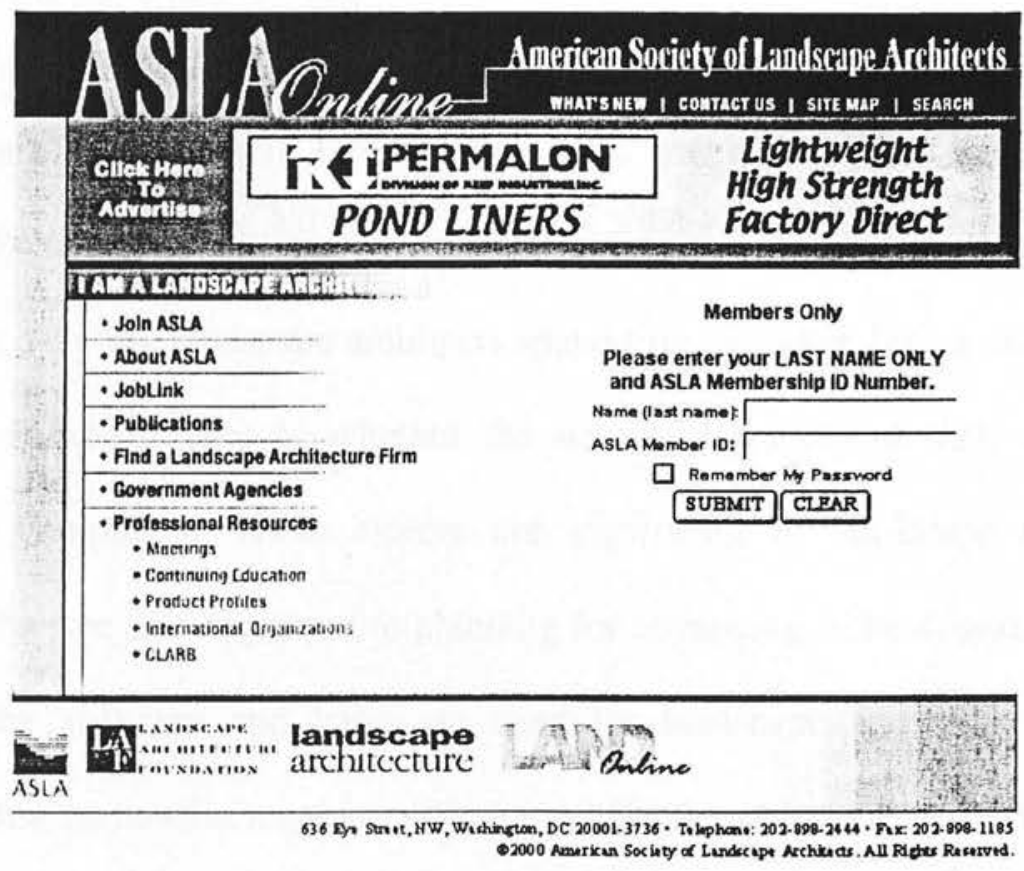

Figure 32: ASLA Web page (102). 


\section{$\underline{2.5}$ Summary}

Incredible advancements in computer technology have led to powerful new hardware and software. Today, landscape architects have many options available to them for carrying out the functions of their practice. This technology has given landscape architects the capability to visualize, study, revise and enhance their design work in vastly different ways. However, although many advanced software and hardware are available, landscape architects appear to be mostly using the technology for construction drawings.

Interestingly, there was no reference, in relation to the impact of software and hardware on the nature of design itself. Furthermore, there was no information on whether the software and hardware available had impacted the way landscape architects think about their designs, whether landscape architects spend time on other design tasks (with time saved from computer use) or whether the nature or quality of their designs were affected by computers. These effects are significant to landscape architects, to producing effective drawings, and to planning for advancing technologies in the future. Therefore, the software and hardware used by landscape architects were further explored in this thesis with regard to efficiency, effectiveness, and creativity in design.

\section{Efficiency and effectiveness:}

The capabilities in hardware and software appear to have afforded efficiency and effectiveness. Computers are more powerful, with affordable input devices and high quality digital output devices, and can generate excellent output with great speed. Computers loaded with large hard disk drives and large amounts of random access memory (RAM) are capable of handling sophisticated programs. Digital and video cameras produce high-resolution images that can be directly downloaded to the 
computer. Over-sized printers produce high quality printing without ever leaving the office. Software programs deliver features with enormous capabilities that also streamline various tasks such as road design, irrigation design, land analysis (GIS), estimating, etc. Multi-media capabilities enable effective interactive presentation with the use of animation, graphics, photographs, video, and sound. VRML and stereo glasses allow immersion into 3-D modeled spaces in a virtual environment. There are also many effective input devices available today such as 3-D scanners and digitizers. With all of the powerful tools available today, it seems landscape architects may be moving towards an increasingly digital practice and potentially approaching closer to the totally digital office. The research in this thesis examined this potential.

\section{Place in the market:}

There are well over 140 licensed CAD programs on the market, but only one-third are designed for landscape architects (103). These do not include the large number of specialized freeware and open source software programs available. This suggests that software companies are producing products for the larger market that does not include landscape architects. Why is this so? How will this impact the practice of landscape architecture in the future? These are inquiries which are examined in this research.

\section{Keeping up with technology:}

With the vast and rapid advancements in computer technology, landscape architects will need to constantly monitor new developments in order to stay abreast of their profession. A few examples of new technological developments include speech synthesis, WebTV, portable printers (without the need of a computer) and electronic ink technology. Speech synthesis technology or "Text-to-Speech" programs convert written input to spoken output by automatically generating synthetic speech. In programs such 
as OmniBabel, produced by Vocal Systems, speech-to-speech software listens in one language, then translates and speaks in a foreign language (Figure 33)(104). WebTV enables Internet access without the use of a computer. The Internet-accessible WebTV box connects to the TV. Turning on the TV connects directly to the Internet and allows one to send email, surf the Internet, and interact with new forms of entertainment-all from the TV. "The new WebTV Plus's picture-in-picture capability allows one to watch TV while a slow page loads, or surf the Web during a commercial and TV shows can be browsed on-line" ("What is Webtv?" 2000)(105).

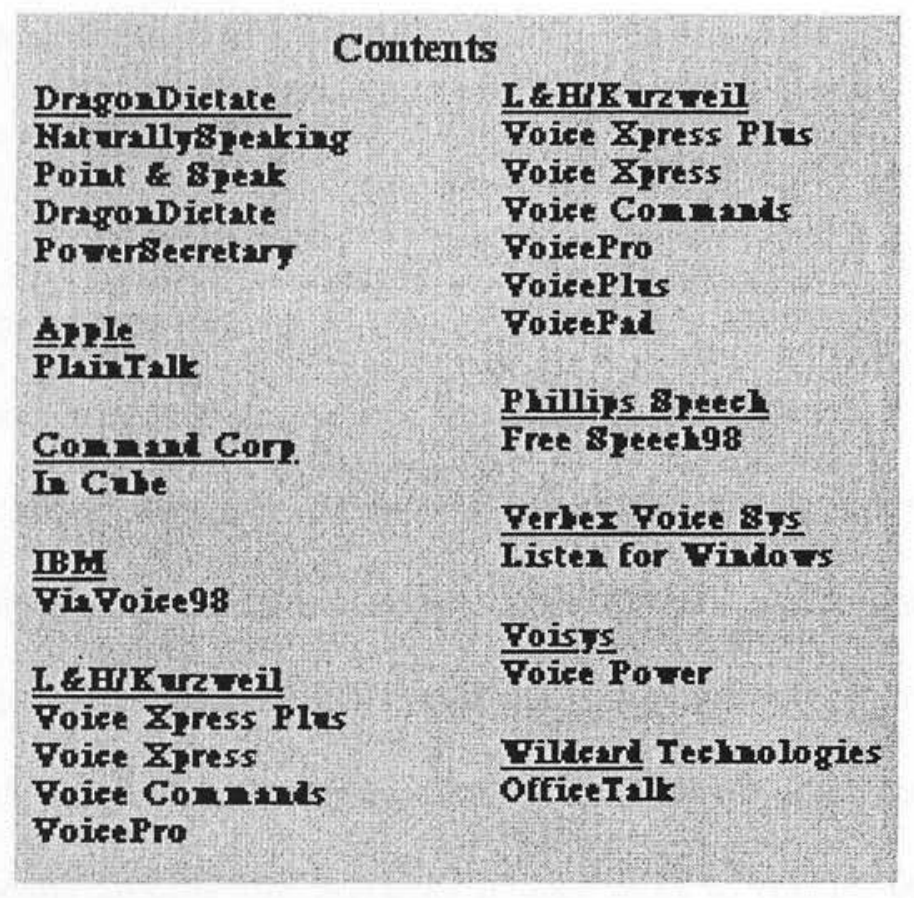

Figure 33: Speech Software (106).

In addition, an industry organization, VoiceXML Forum (Extensible Markup Language), founded by AT\&T, IBM, Lucent and Motorola is developing and promoting VoiceXML, a new computer language designed to make Internet content and information accessible via voice and phone (107).

New technology in printers includes portable printers without the need of a computer. They use removable cards that hold image files. The Roland Digital Modela modeling 
system prints in 3 dimensions by taking shapes of a 3-D modeled drawing and turning them into foam, plastic, wax or wood models (108).

Printers are also currently being developed which incorporate electronic ink technology. MIT's media lab has been researching electronic ink that can be attached to almost any surface using electronic fields. These inks contain polymers that remain in place even when the field is turned off. You can keep the final output as long as you want, or simply reset it and "print" something else (109). For landscape architects, this would be a tremendous break-through as it would help save time and money in printing multiple check sets of drawings.

\section{Outfitting the design practice:}

Landscape architects recognize the importance of CAD integration and realize they must carefully choose tools that are appropriate for their practice. Outfitting an office can be an expensive proposition and requires a commitment and investment. In order to obtain a return on the investment it is beneficial to make the appropriate decisions for the office from the beginning. Understanding the options offered by new technologies is crucial to landscape architecture practices if they wish to remain competitive in the digital age.

Madis Pihlak, ASLA, educator and director of continuing education on the digital office at Pennsylvania State University believes managing computer resources is a key component for success. He remarked, "It is easy, as anyone who owns a business knows, to waste a lot of money with computers and software. So you really must have a strategy, maintain your resources, and manage them wisely. The firms that manage 
information technology most successfully are moving forward and investing in it..." (Welsch, 2000, p. 9)(110).

Jim Sipes, ASLA, practitioner and former educator concurred with Madis Pihlak and added, "With all the new technology coming down the pike, how do you determine what will become an essential part of your business or what is just a passing fad? Probably the best advice is to look at the long term, pay for quality, and focus on what you really need" (Sipes, 1999, p. 98)(111). Sipes remarked, "The computer revolution may be over, but the evolution of digital technology has just begun" (Sipes, 1999, p. 98).

Weld Coxe, AIA and David Meister, a former Harvard Business Professor suggested their ideas in recent article, "Planning a computer technology strategy for design professionals." They theorized that design firms are oriented in one of three market positions. These include "1)strong delivery/procedural work, or firm that is best at solving routine problems by providing quick and simple solutions; 2)strong service/"gray hair" work, or those who can solve broad, complex problems and offer comprehensive advice; or 3)strong ideas/brain work, or those who excel at solving unique problems through innovative thinking" (Laiserin, 1998, p. 148)(112). They believe determining a firm's orientation helps in determining choice of computer technology. For example, they suggested the procedural firm is a late adopter of technology in contrast to the gray hair/brain firm who is more cutting edge in technology. The procedural firm, in contrast to the brain firm, would be unlikely use either $\mathrm{CAD}$ in earlier phases of the design process or 3-D modeling in later design phases. Therefore, procedural firms would probably only need CAD software for production of working drawings. 
Allied fields such as engineers and architects are ahead of landscape architects when it comes to the use of computers (113). One of the leaders in computer technology is the entertainment industry. They are able to produce movies with elaborate set designs. For example, in the recent movie, "The Gladiator", state-of-the-art computer graphics imaging (CGI) was utilized to create a virtual environment. CGI was employed to finish the circumference of all the tiers of the Coliseum replete with statuary, produce the velarium or retractable canvas roof, and populate the Coliseum arena with a virtual "sell-out" crowd of 33,000 computer-generated spectators alongside 2,000 extras. The CGI elements were so seamlessly blended with the real sets and people, that the filmmakers could do sweeping 360-degree panoramic shots and overhead views in which actual and visual effects elements are indistinguishable (114). The extraordinary outcome of this virtual creation was simply put by director of the movie, Ridley Scott, "We can do anything today, it just depends how much money and time you have" ("Gladiator Creating the Roman World," 2000). This comment suggests that a virtual environment can likely be created by landscape architects with similar abundant resources. 

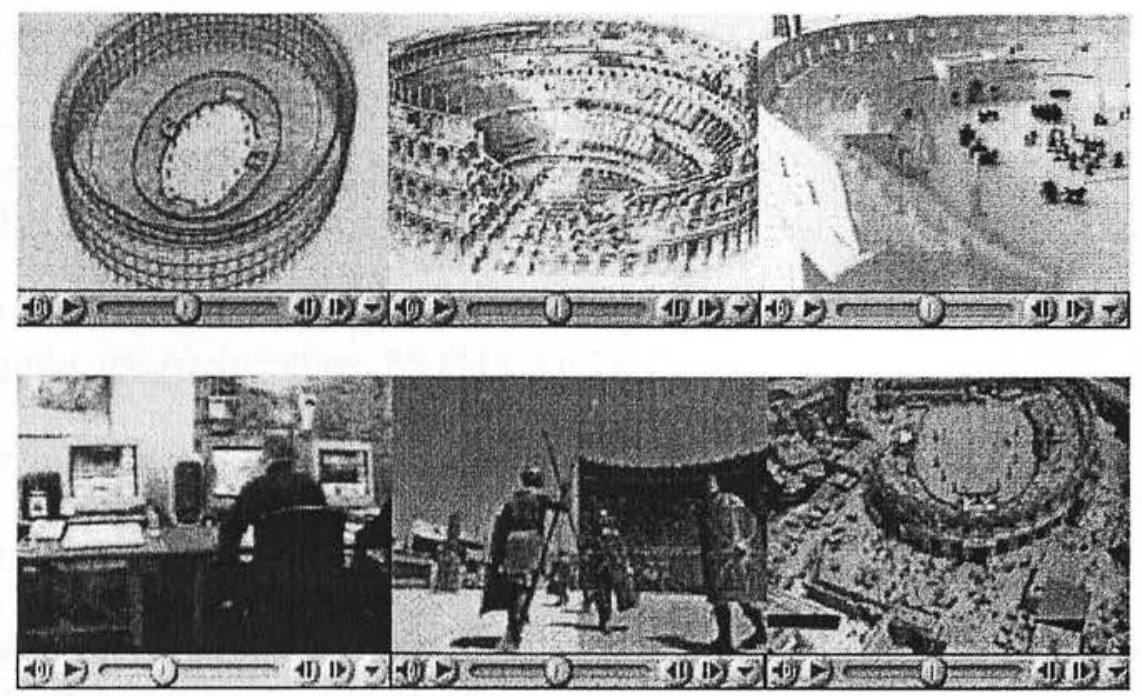

Figure 34: Top-Sketches and models of Coliseum were created.

\section{Bottom-Computer generated set designs (115).}

Stephen Ervin, ASLA, educator, commented that representation, visualization and evaluation of landscapes is widespread and virtual landscapes are created by everyone (116).

Opinions from experts in the field suggested various considerations for outfitting software and hardware for the design office. However, no one has explored the issue of personnel in the office and how their needs will need to be "outfitted." This issue is explored in this thesis.

Today, computers are affordable, more efficient and effective. It is likely that landscape architects have been impacted by computer technology in the way they are doing their design work and have been affected in terms of precision and quality. However, the question still remains as to how computers have impacted the nature or creative aspects of design itself. This would seem to be an important aspect that should be explored as landscape architects continue to use the computer technology in the future. 
4 Steinitz, C., Parker, P., \& Jordan L. (1976). "Hand-Drawn Overlays: Their History and Prospective Uses.” Landscape Architecture, 66 (5), 444-455.

5 Ervin, S. (1999). "Thirty Years of Computing in Landscape Architecture." Landscape Architecture, 89 (11), 54-55.

6 Ervin, S. ibid.

7 Ervin, S. (1999) op. cit.

8 Anderson, P. (1984). "Stats on Computer Use." Landscape Architecture, 64 (5), 101-102.

9 Lindhult, M. (1988). “The Road Beyond CAD." Landscape Architecture, 78 (4), 40-45.

10 Ervin, S. (1999) op. cit.

11 Ervin, S. (1999) op. cit.

12 Ervin, S. (1999) op. cit.

13 Sharky, B. (1988). “Confessions of a Computer Convert.” Landscape Architecture, 78 (4), 72-75.

14 Lindhult, M. (1988). "The Road Beyond CAD." Landscape Architecture, 78 (4), 40-45.

15 Ervin, S. (1999) op. cit.

16 Ervin, S. (1999) op. cit.

17 Ervin, S. (1998). “Answering the What Ifs.” Landscape Architecture, 88 (10), 64-73.

18 Ervin, S. (1999). "Three Computer Revolutions in Landscape Architecture." Landscape Architecture, 88 (10), 56.

19 Ervin, S. ibid.

20 "Apple Home Page," Apple. Retrieved September 15, 2000 from the World Wide Web:

21 Sipes, J. (1999). "Issues for the Digital Office." Landscape Architecture, 88 (12), 70-73, 98.

22 Sipes, J. ibid.

23 Sipes, J. (1999) op. cit. 
24 “About Wacom." Wacom. Retrieved September 15, 2000 from the World Wide Web:

"DataCAD LLC Software for architects." Retrieved March 1, 2001 from the World Wide Web:

"About Wacom." Wacom. Retrieved September 15, 2000 from the World Wide Web:

27 Sipes, J. (1998). "Picture Perfect.” Landscape Architecture, 88 (9), 38-43.

28 "Carving as-built plans with a Laser Cannon." MicroStation Manager. Retrieved September 15, 2000 from the World Wide Web:

http://www.msmonline.com/extra/jan00/plant1.htm

29 "Carving as-built plans with a Laser Cannon." ibid.

30 "Carving as-built plans with a Laser Cannon." op. cit.

31 "Carving as-built plans with a Laser Cannon." op. cit.

32 "FastSCAN The fast easy way to digitally scan." Polhemus. Retrieved September 15, 2000 from the World Wide Web:

http://www.polhemus.com/fastscan.htm

33 "FastSCAN The fast easy way to digitally scan." ibid.

34 "3D Digitizing Demonstration and Frequently Asked Questions." Retrieved September 15, 2000 from the World Wide Web:

MicroScribe-3d, <http://www.microscribe.com/3d-digitizing/index.html

35 “3D Digitizing Demonstration and Frequently Asked Questions.” ibid.

36 Encarta World English Dictionary [North American Edition] \& (P). (2001). Microsoft Corporation.

37 Sipes, J. and Moore, R. (1998). "CAD for the Masses." Landscape Architecture, 88 (7), 34-39.

38 Sipes, J. (1996). “Digital Details.” Landscape Architecture, 86 (9), 38-43.

39 Bissell, D. (1990). "The Uneasy Marriage of CAD and Architecture." Cadence Magazine, (6), 95-98.

40 "AutoDesk Online Store." Retrieved September 15, 2000 from the World Wide Web:

41 “Design Gallery. Land Development.” (2000). Retrieved September 15, 2000 from the World Wide Web: 
42 "AutoDesk Online Store." Retrieved September 15, 2000 from the World Wide Web:

43 “Design Gallery. Land Development." (2000). Retrieved September 15, 2000 from the World Wide Web:

44 “AutoDesk Civil Design.” Retrieved September 15, 2000 from the World Wide Web:

45 “AutoDesk Civil Design.” ibid.

46 “AutoDesk Product Center - Whip Viewer.” Retrieved September 15, 2000 from the World Wide Web:

47 Eaglepoint. Retrieved September 15, 2000 from the World Wide Web:

48 "Quantity Takeoff." Eaglepoint. Retrieved September 15, 2000 from the World Wide Web:

49 "LandCADD Irrigation Design." Retrieved December 15, 2000 from the World Wide Web: http://eaglepoint.com/LANDCADD/modules/idesign.htm

50 Sipes, J. (1997). “Virtual Irrigation.” Landscape Architecture, 87 (40), $42-46$.

51 "LandCADD Irrigation Design." Retrieved December 15, 2000 from the World Wide Web: http://eaglepoint.com/LANDCADD/modules/idesign.htm

52 "MacRoad - 3D viewing and drive through simulation module..." MacRoad, Retrieved September 15, 2000 from the World Wide Web:

53 "MacRoad - 3D viewing and drive through simulation module..." ibid.

54 "Gallery: Design type: Urban." Retrieved September 15, 2000 from the World Wide Web:

55 "Products." Nemetschek. Retrieved September 15, 2000 from the World Wide Web:

56 Ervin, S. (1994). "Digital Terrain Modeling.” Landscape Architecture, 84 (1), 31-35.

57 Ervin, S. ibid.

58 Ervin, S. (1994) op. cit.

59 Ervin, S. (1994) op. cit.. 
60 Ervin, S. (1994) op. cit..

61 Sipes, J. (1997). “Mapping for the Masses.” Landscape Architecture, 87 (10), 82- 94.

62 Ervin, S. (1999). op. cit.

63 "ESRI Donates Software to ASLA." (2000). Retrieved November 8, 2001 from the World Wide Web: http://www.asla.org/members/ESRIonln.pdf

64 "ESRI Donates Software to ASLA." ibid.

65 Juhl, G. (1994). “Using Intelligent Maps.” Landscape Architecture, 84 (6), 4649.

66 Juhl, G. ibid.

67 Ervin, S. (1999) op. cit.

68 Sipes, J. (1998). “Digital Dazzle.” Landscape Architecture, 88 (3), 44-49.

69 Sipes, J. ibid.

70 Sipes, J. (1994). "Simulating Natural Phenomena." Landscape Architecture, 84 (5), 30-32.

71 Sipes, J. ibid.

72 Sipes, J. (1994) op. cit.

73 Triantafillou, M. \& E. (1993). "Historic Landscape Reconstruction: An Application of Visual Simulation.” Landscape Architecture, 83 (6), 82-83.

74 Triantafillou, M. \& E. ibid.

75 Thompson, W. (1998). "Mining for Digital Reality.” Landscape Architecture, 88 (1), 32-37.

76 Thompson, W. ibid.

77 Sipes, J. (1996). “Creating Digital Worlds.” Landscape Architecture, 86 (11), 48-53.

78 Sipes, J. ibid.

79 "QuickTime VR Authoring." Apple.Com. Retrieved September 5, 2000 from the World Wide Web: http://www.apple.com/quicktime/qtvr/

80 Broback, S. \& Williams, R. (1997). Beyond the Little Mac Book. Peachpit Press, Berkeley, CA, 65. 
81 Bertol, D. \& Foell, D. (1997). Designing Digital Space: An Architect's Guide to Virtual Reality. John Wiley and Sons, Inc., New York.

82 Lindhult, M. \& Thompson, W. (1998). "Rescuing a River.” Landscape Architecture, 88 (2), 38-43.

83 Lindhult, M. \& Thompson, W. ibid.

84 Bertol, D. \& Foell, D. (1997). Designing Digital Space: An Architect's Guide to Virtual Reality. John Wiley and Sons, Inc., New York.

85 "Multimedia." Microsoft Encarta Online Encyclopedia. (2001). Retrieved January5, 2001 from the World Wide Web: http://encarta.msn.com

86 Foster, K. \& Johnson, T. (2000). “Understanding Alternatives.” Landscape Architecture, 90 (3), 38-43.

87 Foster, K. \& Johnson, T. ibid.

88 "Cities from Within: A Screening and Discussion of the CD-ROM." Layers of Rome, Kansas State University News. Retrieved September 15, 2000 from the World Wide Web:

http://aalto.arch.ksu.edu/newsevents/calendar/events/trancik.htm

89 Trancik, R. (1998). "Exploring the Layers of Rome." Retrieved September 15, 2000 from the World Wide Web: http://www.cd-rome.com/about/

90 "Cities from Within: A Screening and Discussion of the CD-ROM." Layers of Rome, Kansas State University News. Retrieved September 15, 2000 from the World Wide Web:

http://aalto.arch.ksu.edu/newsevents/calendar/events/trancik.htm

91 Lindhult, M. (1994). "Computer Aided Manufacturing of Custom Landscape Elements.” Landscape Architecture, 84 (3), 30.

92 Lindhult, M. ibid.

93 Lindhult, M. (1994) op cit.

94 Lindhult, M. (1994) op cit.

95 Ervin, S. (1999). "Three Computer Revolutions in Landscape Architecture." Landscape Architecture, 88 (10), 56.

96 "Internet." Microsoft Encarta Online Encyclopedia. (2000). Retrieved September 15, 2000 from the World Wide Web: http://encarta.msn.com

97 “Internet." Microsoft Encarta Online Encyclopedia. ibid.

98 Novitski, B. (1997). "The Architecture of Cyberspace." Architectural Record, Nov. 97, 139-142. 
99 Ervin, S. (1999). "The Internet Advantage." Landscape Architecture, 89 (6), 36 42.

100 "Site Map." (2000). ASLA Online. Retrieved September 15, 2000 from the World Wide Web:

101 Murray, L. (2000). “Survey Shows Increased Member Satisfaction.” Land, 42 (7), 14-15.

102 "Welcome to ASLA." (2001). Retrieved September 15, 2000 from the World Wide Web: http://www.asla.org/

103 Pihlak, M. \& Barrett, T. (2000, October 29). "Design Computing for the Real World." ASLA Conference, St. Louis, Missouri.

104 Hunt, A. (1997). "Frequently Asked Questions. Comp Speech.” Retrieved December 15, 2000 from the World Wide Web:

105 "What is Webtv?" Retrieved September 15, 2000 from the World Wide Web:

106 Rehor, K. (2000). "Features - Article \#1, VoiceXML Review." Retrieved March 7, 2000 from the World Wide Web:

http://www.voicexmlreview.org/features/Jan2001_what_is_voicexml.html

107 Rehor, K. (2000). "Features - Article \#1, VoiceXML Review.” ibid.

108 Sipes, J. (1999). “Issues for the Digital Office." Landscape Architecture, 88 (12), 70-73, 98.

109 (1998). "MIT team Develops New Way To Create Microscopic Patterns on Surfaces, MIT News." Retrieved September 15, 2000 from the World Wide Web:

110 Welsh, B. (2000). “ASLA Seminar to Offer New Perspectives on Digital Computing." Land, 42 (3), 9.

111 Sipes, J. (1999). "Issues for the Digital Office." Landscape Architecture, 88 (12), 70-73, 98.

112 Laiserin, J. (1998, September). "Planning a Computer Technology Strategy for Design Professionals.” Architectural Record, 147-149.

113 Anderson, P. (1984). "Stats on Computer Use." Landscape Architecture, 64 (5), 101-102.

114 "Gladiator Roars Past \$200M Internationally, Headlines." Retrieved July 27, 2000 from the World Wide Web:

115 "Gladiator Creating the Roman World." Retrieved September 15, 2000 from the World Wide Web:

http://www.apple.com/trailers/dreamworks/gladiator/creating.html 
116 Ervin, S. (1999). "Three Computer Revolutions in Landscape Architecture." Landscape Architecture, 88 (10), 56. 


\section{CHAPTER 3 - COMPUTER SURVEYS}

\subsection{Introduction}

In the early 1980s, computer technology was just coming to the forefront in the professional practice of landscape architecture. Julius Fabos, a professor of Landscape Architecture at the University of Massachusetts predicted in 1983 that the "paperless office" was not far away (117). Today, although paper is still much in evidence in landscape architecture offices, computers are definitely dominant in the business and seem to be here to stay. To obtain and track information regarding the status of computer use in landscape architecture practice, several computer surveys have been conducted since the 1980 s. The review of some of these previous surveys helped to explore issues pertinent to the research in this thesis and provided indicators to factors that may have been significant with regard to CAD utilization.

Several surveys were conducted by landscape architects. One of the earliest surveys, "Stats on Computer Use" was conducted in the spring of 1983 by Paul Anderson, a professor of Landscape Architecture and Agronomy at Iowa State University. Anderson was recognized with a 1984 ASLA Honor Award for this important survey research work. Ten years later, in the summer of 1993, another survey, "A Status Report on Computers in Landscape Architecture" was conducted by James Palmer, director of the landscape imaging and analysis laboratory and BLA program director at the State University of New York, College of Environmental Science and Forestry, together with Eric Buhman, an instructor at the Institute for City and Regional Planning, University at Karlsruhe, Germany. In the spring of 1994 the, "Business of Landscape Architecture Poll" was conducted by Molly Donnenmaier for Landscape Architecture. Most recently, 
surveys include Palmer's “The 1996 Status Report on Computers in Landscape Architecture," and ASLA's “2000 Membership Satisfaction Survey.”

Surveys have also been conducted by allied professionals. Some of these surveys were reviewed in this research to obtain insight on factors significant with regard to the use of CAD.

\subsection{Landscape architecture computer surveys}

\subsubsection{Survey: stats on computer use}

The primary objective of Anderson's survey, "Stats on Computer Use" was to determine what should be the role of computer technology in landscape architecture, architecture and urban and regional planning. The purpose was to obtain data on applications used by professionals within these disciplines and to obtain answers to questions such as, "What is expected from computer technology?" and "What is expected from potential employees?"

The professionals surveyed included members of American Society of Landscape Architects, American Institute of Architects or the American Institute of Certified Planners. Results from the survey indicated that, of the three professions, landscape architects utilized computers $5-15 \%$ less than allied professionals. Of over half of the landscape architects who worked in organizations that used computer technology, Anderson found over $40 \%$ of the organizations using spreadsheets, $35 \%$ using word processing, 30\% using spec sheets, and under $10 \%$ using CAD and GIS. "Most of the organization's employees have no computing skills, although there is almost an even chance that the professional uses computer technology" (Anderson, 1984, p. 101). The study also indicated that the use of computers was more common in larger 
organizations in planning, landscape architecture and architecture. Larger firms used more applications than smaller firms, but there was little difference in use rates from those in private, academic, or public practice. Few landscape architects said computers affected the number of professionals in their organizations. Almost $50 \%$ said that computers increased efficiency.

The question Anderson asked was, "Will landscape architects still be in third place five years from now?" (Anderson, 1984, p. 102). He projected that more changes were going to come in the future with computer software-software not yet developed,hardware, and affordability of computers (118).

\subsubsection{Survey: a status report on computers in landscape architecture}

Ten years after Anderson's survey, in the summer of 1993, Palmer and Buhman conducted their survey, "A Status Report on Computers in Landscape Architecture" with the objective of updating Anderson's findings.

Questionnaires were sent to American Society of Landscape Architects (ASLA) member firm practitioners. Of those surveyed, only $7 \%$ indicated they did not use a computer. Of those using computers in their practices, more than $86 \%$ used word processing, $65 \%$ used spreadsheets for calculations, $41 \%$ used computerized specs, $57 \%$ used CAD for drafting, and a mere $6 \%$ used GIS (Figure 35). A high correlation could be seen between the number of employees and the number of computers in an office (e.g. 30 employees to 11.5 computers). The break down of the use of CAD was as follows: $67.2 \%$-AutoCAD, 18.0\%-LandCADD, 6.6\%-Intergraph Microstation, 3.2\%Blueprint, ClarisCAD, DesignCAD, GDS, GenericCAD and Vango. 
Those who used GIS favored the following software: ArcCAD, ArcInfo, AutoCAD, CIS, ERDAS, GDS, Geo/SQL, Landmark, Map.Graffix and Spans. Preferred software for specifications included: Microsoft Word and Word Perfect, in combination with AIA Master Spec, CSI Spectext, PlantSpec, SiteSpec and Sweets. Many firms were using AutoCAD, but primarily for construction drawings (119).

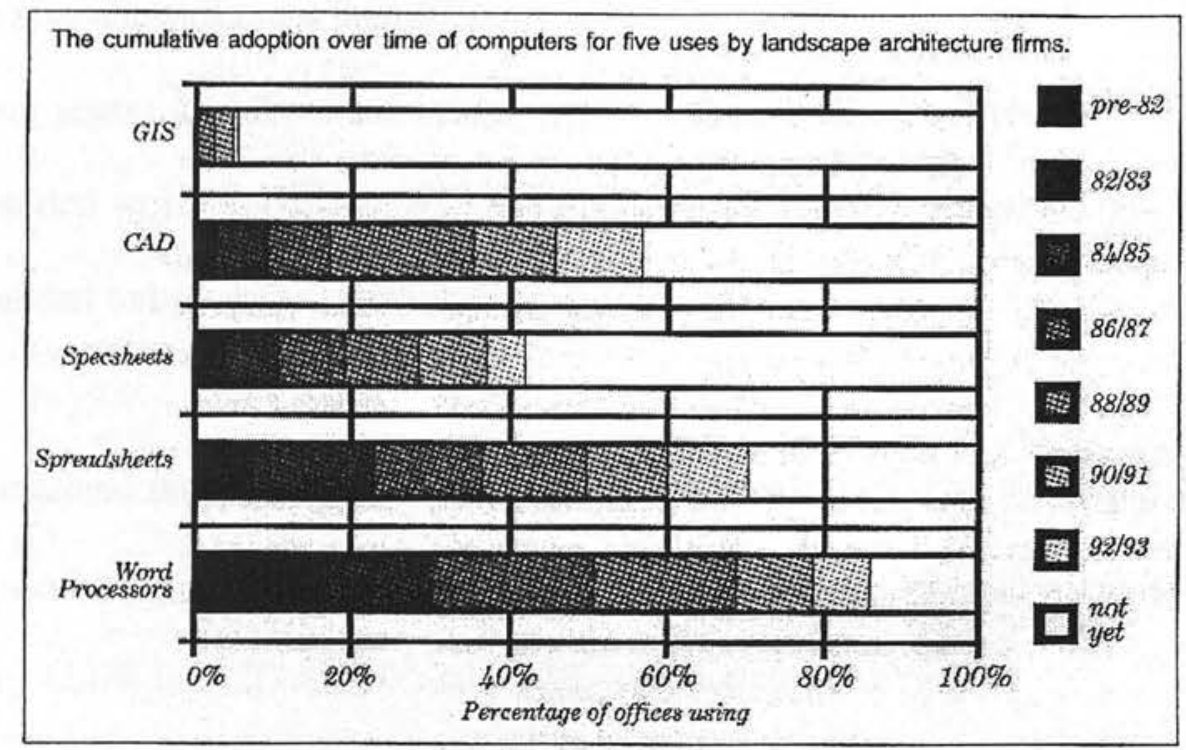

Figure 35: The cumulative adoption over time of computers

for five uses by landscape architecture firms (Palmer, 1993).

\subsubsection{Survey: business of landscape architecture poll}

In March of 1994, another survey was conducted to track the then current economy and technological utilization. The survey was sent to ASLA member firms. The 1994 Business of Landscape Architecture Poll asked twenty questions and of the twenty, five were about computers.

The survey showed $2 / 3$ of the landscape architects who responded were negatively affected by the depressed economy of the late 1980s and early 1990s. However, even in 
the times of economic uncertainty, respondents continued the addition of new technologies. Rick Ciardella, a survey respondent and landscape architect with SWA said, "Quite frankly, computers have saved us, especially in terms of our marketing and proposal development." Conversely, other respondents stressed that it was more important to gear business strategy toward success rather than computer wizardry.

Results also showed more than $67 \%$, or $2 / 3$ of the respondents, had added CAD in the past four years; $22.5 \%$ added image processing; $58.9 \%$ added accounting software; $75.7 \%$ added word processing; $62.1 \%$ added spreadsheets; $46.3 \%$ added data bases and $27.5 \%$ added online networking in the past four years.

$14.1 \%$ claimed they used both Mac and IBM computers; $67.2 \%$ used only IBM; and $18.7 \%$ used Mac. For design purposes, $78.5 \%$ used IBM and $21 \%$ used the Mac. In addition, $42.6 \%$ had CD-ROMs and 66.3\% had modems (120).

\subsubsection{Survey: the 1996 status report}

In July 1996, Jim Palmer conducted the 1996 Status Report. The primary objective of this survey was to 1)determine the status of computers in landscape architecture since his 1993 Survey and 2)to find out what firms expected from prospective employees, how professionals were acquiring computer skills, and what they needed in terms of training. The survey was sent to ASLA practitioners and asked questions regarding the type of services offered; computers (desktop or laptop)used; application adoption; ratio between computers and employees; and software brands used most (121). 
In this survey, $7 \%$ of the respondents did not use computers-a number that was unchanged from the 1993 Survey. 80\% used desktop computers, $12 \%$ used desktops and laptops, and $1 \%$ used just laptops (122).

Most common brands of software used by landscape architects.

\begin{tabular}{lrrr}
\hline & \multicolumn{3}{c}{ Brand (Percent total) } \\
\cline { 2 - 4 } Computer software: & \multicolumn{1}{c}{ First } & \multicolumn{1}{c}{ Second } & Third \\
\hline Word processing & Word Perfect (45) & MS Word (40) & \\
Spread sheets & MS Excel (45) & Lotus 123 (27) & Quatro Pro (12) \\
Data base & dBase (29) & MS Access (26) & MS Works (11) \\
Specification & Master Spec (48) & write own (38) & \\
Project scheduling/manage & MS Project (30) & MacProject (14) & Primavera (14) \\
CAD & AutoCAD (76) & Microstation (10) & \\
Land engineering & LandCADD (67) & Softdesk (10) & \\
2-D graphics & Corel Draw (43) & Illustrator (11) & Virtus (22) \\
3-D graphics & AutoCAD (22) & Autodesk 3D (22) & \\
Image editing/simulation & Photoshop (79) & & ArcView (16) \\
GIS & ArcInfo (47) & MapInfo (16) & Lantastic (10) \\
Local network & Windows (46) & Novel (31) &
\end{tabular}

Table 2: $\underline{\text { Most common brands of software used }}$

by landscape architects (Palmer, 1996).

With regard to software applications in 1996, over $90 \%$ of landscape architecture offices used word processing and electronic spreadsheets, $67 \%$ used CAD and $40 \%$ used local networks and nearly $50 \%$ were connected to the Internet. Table 2 shows the most common brands of software used by landscape architects (123). Less-used applications lay in the following areas: less than $33 \%$ used land engineering software, only $15 \%$ used GIS software, which had grown slowly since 1980 s. Other less used software includes data base management, writing standard specifications, and project management. Overall, landscape architecture offices had 1.17 professionals per computer. 


\subsubsection{Status report on computing skills and training in landscape architecture}

Respondents were asked about their knowledge with thirteen types of software. Table 3 shows landscape architects were not very proficient in any of the programs. Half of the landscape architects considered themselves to be at an intermediate level and a quarter at a proficient level with word processing; almost $50 \%$ considered themselves to be at a proficient or intermediate level with $\mathrm{CAD}$; and $38 \%$ considered themselves to be at an intermediate level with spreadsheets. These percentages are then followed by skill levels with Internet and networking software, land engineering, 2-D graphics, data base, project scheduling, image editing, and GIS. $90 \%$ of the respondents had no experience with 3-D graphics.

\begin{tabular}{|c|c|c|c|c|c|c|c|}
\hline \multirow{2}{*}{\multicolumn{2}{|c|}{ Computin: rotivare: }} & \multicolumn{5}{|c|}{ Percentare } & \multirow[b]{2}{*}{ Mean } \\
\hline & & Name & Bepimer & Intermediate & Proficient & & \\
\hline Word processing & & 10.1 & $\cdot 14.1$ & 53.5 & .22 .2 & & 2.88 \\
\hline Spread sheets & & 29.3 & 28.3 & 38.4 & 4.0 & & 2.17 \\
\hline Data base & & 66.7 & 23.2 & 9.1 & 1.0 & - & 1.44 \\
\hline Specification & 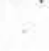 & 75.5 & 12.2 & 10.2 & 2.0 & & 1.39 \\
\hline Project scheduling/manage & . & 72.7 & 11.1 & 16.2 & 0.0 & & 1.43 \\
\hline CAD & & 34.7 & 17.3 & 30.6 & 17.3 & & 2.31 \\
\hline Land engineering & & 64.6 & 19.2 & 10.1 & 6.1 & & 1.58 \\
\hline 2-D graphics & & 67.7 & 17.2 & 13.1 & 2.0 & & 1.49 \\
\hline 3-D graphics & & 91.9 & 8.1 & 0.0 & 0.0 & & 1.08 \\
\hline Image eciting/simulation & & 74.7 & 18.2 & 6.1 & 1.0 & & 1.33 \\
\hline GIS & - & 80.8 & 11.1 & 7.1 & 1.0 & : & 1.28 \\
\hline Local network & & 61.6 & 19.2 & 17.2 & 2.0 & & 1.60 \\
\hline Insemet & & 54.5 & 18.2 & 22.2 & 5.1 & 5 & 1.78 \\
\hline
\end{tabular}

Table 3: Computing skills of practicing landscape architects (Palmer, 1996). 
With regard to the level of computing skills expected from a recent landcape architecture student when applying for a job; in general, students were not expected to be proficient in any of the areas, but over half of the respondents expected beginning or intermediate skills in office programs and CAD. Exposure to land engineering was desired by $66 \%$, visual simulation by $78 \%$ and GIS by $85 \%$ of the respondents. Practitioners expect new hires to be more skilled than themselves in land engineering, visual simulation, and GIS, but did not expect them to be more skilled with office programs and CAD.

Two thirds of the respondents learned computing skills by teaching themselves and one third learned from co-workers. Workshops seemed to be an important way to learn complicated programs such as GIS, CAD, and image editing. A majority of the respondents had problems finding time to learn new software and $35 \%$ had problems obtaining good training (Table 4). $43 \%$ found translation of data between programs to be a problem (124). 


\begin{tabular}{lc}
\hline Problem & Percent \\
\hline Finding time to learn new software & 84.9 \\
Translate data between programs & 43.0 \\
Obtaining good training & 34.9 \\
Poor support from software firms & 29.1 \\
Poor support from hardware firms & 27.9 \\
Difficulty integrating computer into practice & 26.7 \\
Requests to help others with their computer & 24.4 \\
Conflicts or incompatibilities & 24.4 \\
Transferring data between computers & 20.9 \\
Confusing or non-existing documentation & 19.8 \\
Disorganized approach to filing (can't find things) & 18.6 \\
Poor advice about what to buy & 16.3 \\
Network or server not working & 16.3 \\
Virus infection or other corruptions & 11.6 \\
Loss of files without recent backup & 8.1 \\
\hline
\end{tabular}

Note: $\mathrm{n}=86$.

Table 4: Percent of respondents regularly having computer problems

(Palmer, 1996).

\subsubsection{ASLA membership satisfaction survey}

The primary goal of this 2000 survey was for ASLA to track the areas in which members placed value when it comes to belonging to the Society. Although this was a membership satisfaction survey, many questions were related to the computer and the Internet. Results of the survey as reported in the September 2000 LAND is as follows:

- $92 \%$ have access to the Internet.

- $80 \%$ have visited ASLA OnLine.

- Most visited area within ASLA OnLine is JobLink.

- 21-31 year olds mostly visit JobLink.

- 40-49 year olds mostly visit LATIS.

- $\quad 50+$ year olds mostly visit Product Profiles and Directory. 
- $56 \%$ prefer the Member Handbook on ASLA OnLine as opposed to hard copy.

- Of $65 \%$ who are aware of ASLA CADetails:

- $60 \%$ have used or plan to use it on projects.

- $\quad 75 \%$ found the details useful.

- $\quad 89 \%$ would find ASLA member-developed details of non-product related items useful.

- $69 \%$ would submit a detail, if given the opportunity.

The survey data indicated landscape architects have definitely accepted information technology and were moving away from the printed media. When comparing the 1994 and 2000 ASLA Membership Satisfaction Survey, both surveys indicated the key area of "increased member perception of importance was the Internet, for reasons that need no explanation" (Murray, 2000, p 15)(125). 


\subsubsection{Summary of the landscape architecture computer surveys}

The survey comparison chart in Table 5 shows that the landscape architecture profession has embraced computer technology. The surveys provided valuable information on the use of computers by landscape architects as well as specific computer applications used. Several findings were derived from the surveys: 1)there had been increased computer use by landscape architects, 2)a lack of computer use in conceptual design, 3)a need for computer training, and 4)an escalation in electronic delivery and communication.

\begin{tabular}{|c|c|c|c|c|}
\hline Survey: & Anderson & Palmer & $\begin{array}{c}\text { Donnen- } \\
\text { maier }\end{array}$ & Palmer \\
\hline & 1983 & 1993 & 1994 & 1996 \\
\hline \# of people surveyed & 400 & 291 & 2000 & 288 \\
\hline$\#$ and $\%$ of respondents & $\begin{array}{c}252 \\
(63 \%) \\
\end{array}$ & $\begin{array}{c}291 \\
(41 \%) \\
\end{array}$ & $560(28 \%)$ & $101(36 \%)$ \\
\hline \multicolumn{5}{|l|}{ Firms that use or have: } \\
\hline Computers & $54 \%$ & $93 \%$ & -- & $93 \%$ \\
\hline Spreadsheets & $40 \%$ & $67 \%$ & $62 \%$ & $80 \%$ \\
\hline Word processing & $35 \%$ & $86 \%$ & $76 \%$ & $93 \%$ \\
\hline Spec sheets & $30 \%$ & $41 \%$ & --- & $23 \%$ \\
\hline Project management & --- & --- & --- & $27 \%$ \\
\hline CAD/GIS & $\begin{array}{c}10 \% \text { CAD } \\
\& \text { GIS }\end{array}$ & $\begin{array}{c}57 \% \\
\text { CAD } \\
6 \% \text { GIS }\end{array}$ & $\begin{array}{c}67 \% \\
\text { added } \\
\text { CAD in } \\
\text { last } \\
\text { last } 4 \text { yrs. }\end{array}$ & $64 \% \mathrm{CAD}$ \\
\hline Land engineering software & --- & --- & --- & $30 \%$ \\
\hline Image process & --- & --- & $23 \%$ & --- \\
\hline Accounting & --- & --- & $59 \%$ & --- \\
\hline Added data bases & -- & $-\ldots$ & $46 \%$ & $35 \%$ \\
\hline On-line networking & --- & --- & $28 \%$ & $40 \%$ \\
\hline Have CD-ROM & -- & --- & $43 \%$ & --- \\
\hline $\begin{array}{c}\text { Have modem or } \\
\text { connection to internet }\end{array}$ & -- & -- & $66 \%$ & $50 \%$ \\
\hline
\end{tabular}

Table 5: Comparison of surveys conducted in 1983, 1993, 1994 and 1996. 
Anderson's 1983 Survey revealed that landscape architects were using computers to accomplish various tasks. It showed low utilization of CAD and GIS (126). Palmer's 1993 and 1996 Survey showed widespread use of CAD for drafting, low GIS use, and relatively low usage of computer software for conceptual design or interactive 3-D visualization. Although this is an interesting finding, no information was found on how computers had impacted all the phases of the design process. Thus this thesis inquired about the role of CAD use in each phase of design including schematic, conceptual, design development and working drawings. The research also examined the impact that computer use had on the creative aspects, and the way professionals actually think about and create their designs.

Respondents in the surveys indicated that computers were efficient. Although, this was one of the findings from the surveys, they did not reveal how efficiency was gained and if there was any impact on other design tasks with the time saved. It seems with time saved, there would be more possibilities to create better designs as it would potentially give landscape architects more time to think about design; revise, perfect, and produce design alternatives; and/or visualize the project in 3-D. For this reason, the thesis research explored further into the relationship of time savings/other design tasks.

The surveys also expressed a need for graphics, user-friendly software, expanded random access memory (RAM), and additional peripherals (127). Respondents indicated that high learning curve was a primary drawback for learning as well as keeping up with new and upgraded software. Thus, this thesis asked, "Is it likely that landscape architects will remain hindered if the software does not become more userfriendly in the future?" "Where" are landscape architects today? "Where are they heading" in the future? 
The surveys indicated training was important. Anderson's 1983 survey indicated handson skills would be needed and future professionals should learn a programming language (128). Palmer's 1993 and 1996 surveys indicated most professionals trained themselves about computers because of the problem of finding time, as well as good training. Landscape architects recognized the need for training in the areas of GIS, 3-D imaging and visualization (129). Has this attitude changed since the mid-1990s? Current trends and attitudes of landscape architects were examined in this research and a progress report revealed new and relevant updated information.

Palmer's 1993 and 1996 Survey reported that although there had been rapid growth in the use of local networks and the Internet during this time period, landscape architects still relied on the print media for information about computing and its use in landscape architecture practice. Palmer noted that LArch-L and LandNET were just coming out in the electronic media (130). The ASLA 1994 Survey reported that landscape architects had continued to add new technologies, even in times of economic stress. In addition to the use of word processing, spreadsheets, databases, image processing, accounting software, and CAD, they had also added CD-ROMs, and modems for on-line networking. Donnemaier of ASLA remarked that it was clear landscape architects were changing the way they were doing business (131). The 1998 ASLA Membership Satisfaction Survey indicated that a vast number of professionals had access to the Internet and had visited ASLA OnLine. More than half of them preferred the Member Handbook on ASLA OnLine as opposed to hard copies. ASLA commented that the survey data indicated landscape architects had accepted information technology and were moving away from the printed media (132). Are landscape architects getting closer to Julius Fabos' concept of the "paperless office?" The attitudes remained 
disclosed until this research inquired whether the digital office was going to replace the traditional office.

Many questions were answered in the previous surveys. Thus, the objective of this thesis was to research and find results to previous and current questions that would be relevant to the current and future practicing professional landscape architects.

\section{$\underline{3.3}$ Allied professionals computer surveys}

\subsubsection{The 1987 American Institute of Architects (AIA) firm survey}

The 1987 AIA Firm Survey asked their members questions pertaining to gross and operating revenues, the architectural services by project and by client type, professional liability insurance and claims, employment and compensation, computers and CAD and expectations for the future.

The survey reported, "The practice of architecture is becoming increasingly automated. A third of all firms reported having at least one personal computer in house; another third reported having two or more. The computers are used principally for word processing, specifications, and financial management. $20 \%$ of firms reported having two-dimensional, computer-assisted design capability, and $11 \%$, reported threedimensional CAD capability" (AIA, 1987, p. iv)(133). 
The following findings were revealed in the area of computer use:

- Number of computers: Architects reported that $1 / 3$ of their firms had at least one computer and $1 / 3$ had two or more computers

- Use of 2-D and 3-D CAD: $11-20 \%$ were using 2-D or 3-D CAD software.

- Proficiency with CAD: $20 \%$ of firms had architects proficient with CAD and $25 \%$ of firms had other staff proficient with CAD.

- Amount of work done on CAD: $25 \%$ of construction drawings were being done with $\mathrm{CAD}$ by those who reported it and $75 \%$ produced up to half of their construction drawings on CAD.

- Software used: Word processing was the most used software.

- Use by size of firm: Larger firms used computers more than smaller firms, due to cost factors. The percentage of firms who used Microsoft Word increased with the size of the firm.

- Expenditure by size of firm: $70 \%$ of all firms had computer-related expenditures in 1986, with increased spending as firm size increased. In 1986, expenditures by firm size were as follows: small-\$2500. (£1740.), medium-\$4800. (£3340.), medium to large-\$7600. (£5289.), medium to large-\$17300. (£12039.), large-\$35200. (£24495.)(134).

\subsubsection{The 1989 American Institute of Architects (AIA) firm survey}

The 1989 AIA Firm Survey asked their members questions pertaining to revenues, projects, clients, professional liability insurance and claims, employment and compensation, computers and $\mathrm{CAD}$, marketing and expectations for the future.

Results of this survey indicated that, "As in the rest of the business and industry, computers are being used more and more in the architectural design firms. Two-thirds 
of firms now have at least one personal computer, and those still without computers tend to be the very smallest firms. A third of all firms use CAD to generate $15 \%$ of the construction drawings produced by firms last year" (AIA Survey, 1989, p. 73)(135).

The following findings were revealed in the area of computer use:

- Use of CAD: Use of CAD jumped from $23 \%$ in 1986 to $35 \%$ in $1988.45 \%$ of firms used AutoCAD, $10 \%$ used DataCAD, $4 \%$ used Arris, Cadvance and Versacad.

- Benefits of CAD:Use of CAD was believed to increase productivity and improve quality control and standards. Using CAD for marketing outweighed firms' belief that it improved design work. There were more non-architects who were proficient with $\mathrm{CAD}$ in firms with 5 or more employees. Firms used $\mathrm{CAD}$ as drafting tool, as opposed to a design tool.

- Software used: $73 \%$ of the firms used word processing and $35 \%$ used CAD (Figure 36). 


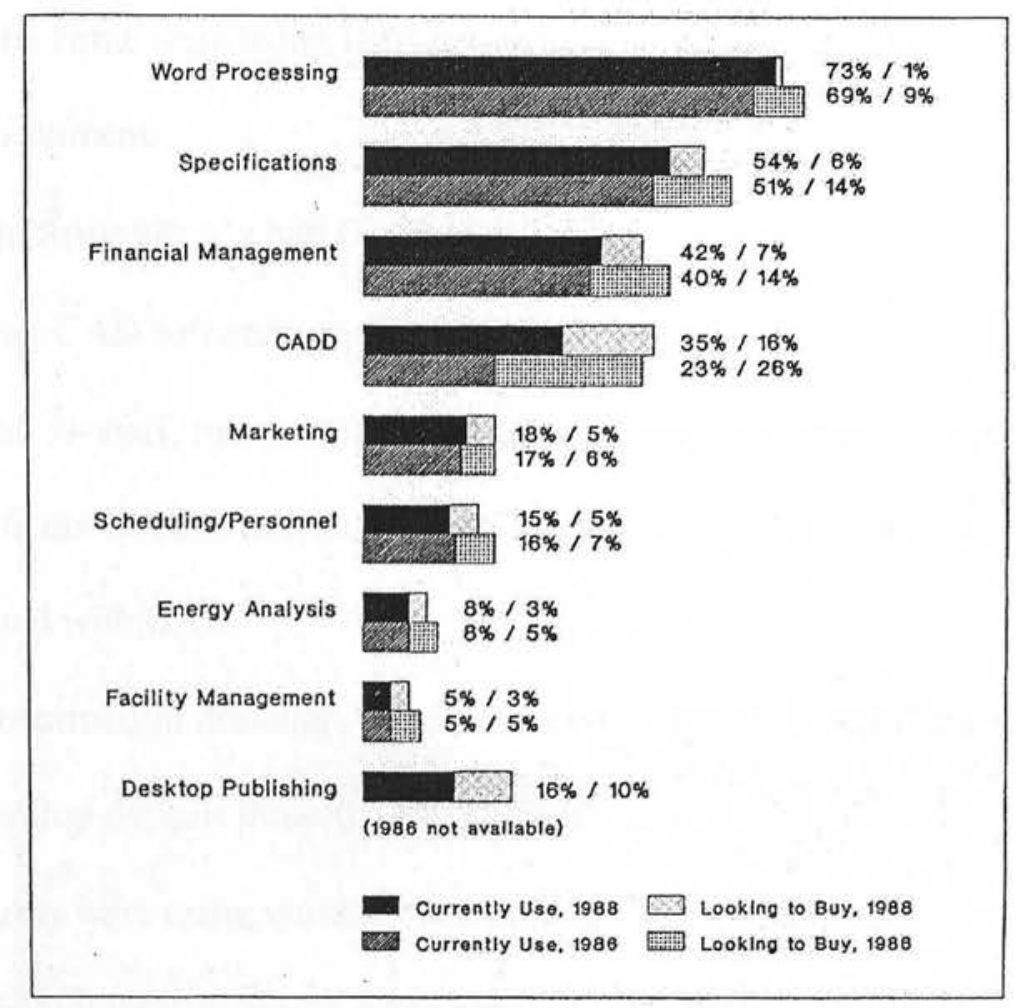

Figure 36: Percentage of firms using computers

for various applications, 1986 and 1988 (AIA, 1989).

- Amount of work done on CAD: Work produced on CAD doubled from 8\% in 1986 to $16 \%$ in 1988 . Smaller firms produced more construction drawings on $\mathrm{CAD}$, but larger firms did the bulk of CAD-generated work (136).

\subsubsection{The 1991 American Institute of Architects (AIA) firm survey report}

The 1991 AIA Firm Survey updated findings from the 1987 and 1989 Survey. The survey asked questions pertaining to the architectural service industry and addressed revenues, projects, work force, compensation, professional liability, marketing, expectations and computers. The following findings were revealed in the area of computer use:

- $80 \%$ of all firms used computers. 
- Most of the firms were using IBM or compatible personal computers working in the DOS environment.

- Most large firms already had CAD capability.

- The leading CAD software application was AutoCAD.

- In firms of 5+ staff, more non-architects were proficient than architects with use of CAD. In firms of $10+$ staff, there were twice as many non-architects than architects who worked with CAD.

- $50 \%$ of construction drawings were produced on CAD. Small firms used CAD as a tool to develop designs more than large firms.

- $97 \%$ of firms were using word processing.

- Average computer investment was approximately $\$ 8600$. ( $£ 5985$.) for small firms to $\$ 251,000$. (£174670.) for large firms (137).

\subsubsection{CAD utilization in the architectural design process; implications for}

computer integration in practice by Journal of Architectural and Planning Research

The purpose of this survey was to establish an indicator to define a firm's approach to design. AIA members were surveyed. Of those surveyed, $61(47.3 \%)$ of the firms were using $\mathrm{CAD}$. AutoCAD was the dominant $\mathrm{CAD}$ package used by $42.7 \%$ of the respondents. Of the CAD users, $98.2 \%$ were using 2 -D features, $40.7 \%$ were using 3-D features and $20.4 \%$ were using solid modeling features.

The unique aspect of this survey was the analysis of CAD-using firms with regard to design philosophy. Firms were grouped into categories that reflected their approach to design. Firms were asked to rank their design philosophy on a scale of 1.0 ("Design/Theory") to 5.0 ("Pragmatic/Service"). "The validity of the design philosophy categories was supported by examining the use of CAD in design phases (Schematic 
Design and Design Development) versus documentation phases (Construction Documents) of a project by each group" (Journal of Architectural and Planning Research, 1994, p. 139)(138). Figure 37 shows design firms in 1983 using 2-D and 3-D $\mathrm{CAD}$ more in the early stages of the design process than the other groups. Conversely, Pragmatic firms used 2-D CAD more for documentation than the other groups and 3-D CAD was not used at all in documentation.

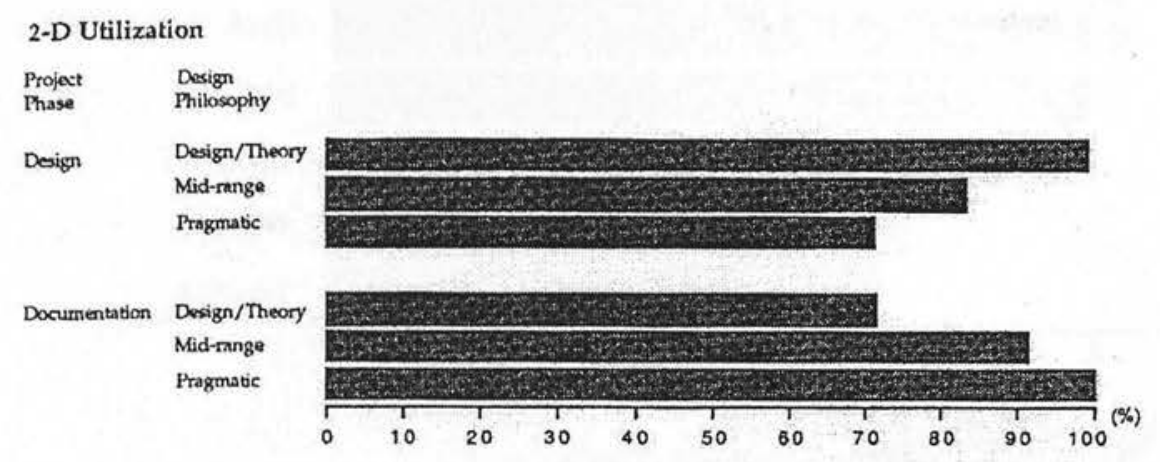

3-D Utilization

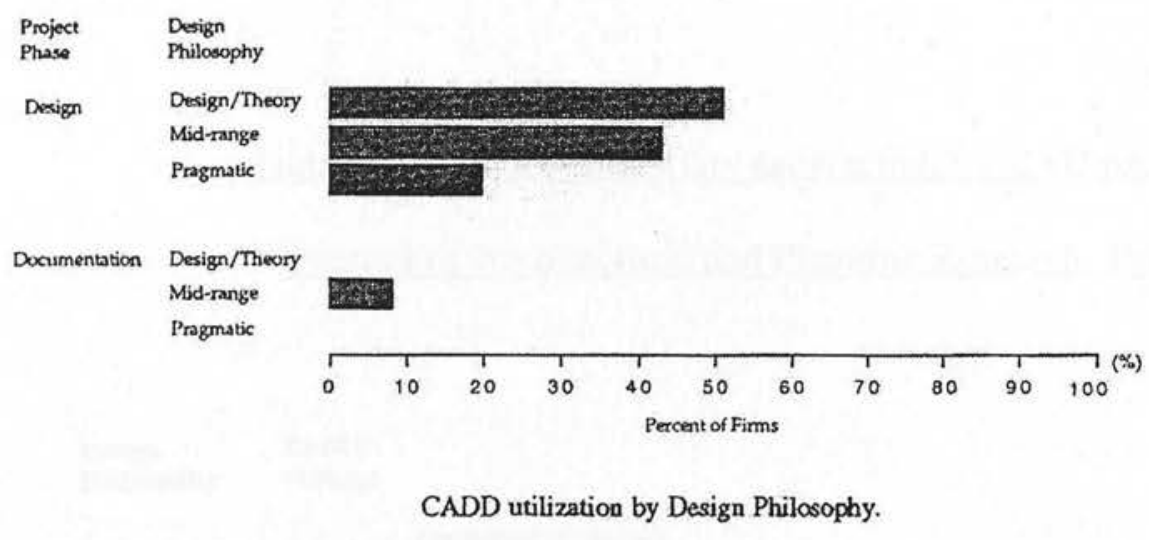

Figure 37: CADD utilization by design philosophy

(Journal of Architectural and Planning Research, 1994).

Satisfaction-productivity of CAD packages was recorded from a scale of 1.0 ("Very Satisfied") to 5.0 ("Not Satisfied"). Even though AutoCAD was the most widely used CAD package, it had the lowest rating for satisfaction with a mean of 3.1. This indicated that AutoCAD was a document-oriented package. The CAD-productivity 
satisfaction varied very slightly between the three groups. Most satisfied was the pragmatic group, followed by the mid-range group, and lastly, the design/theory group. Middle-range and pragmatic firms used AutoCAD most.

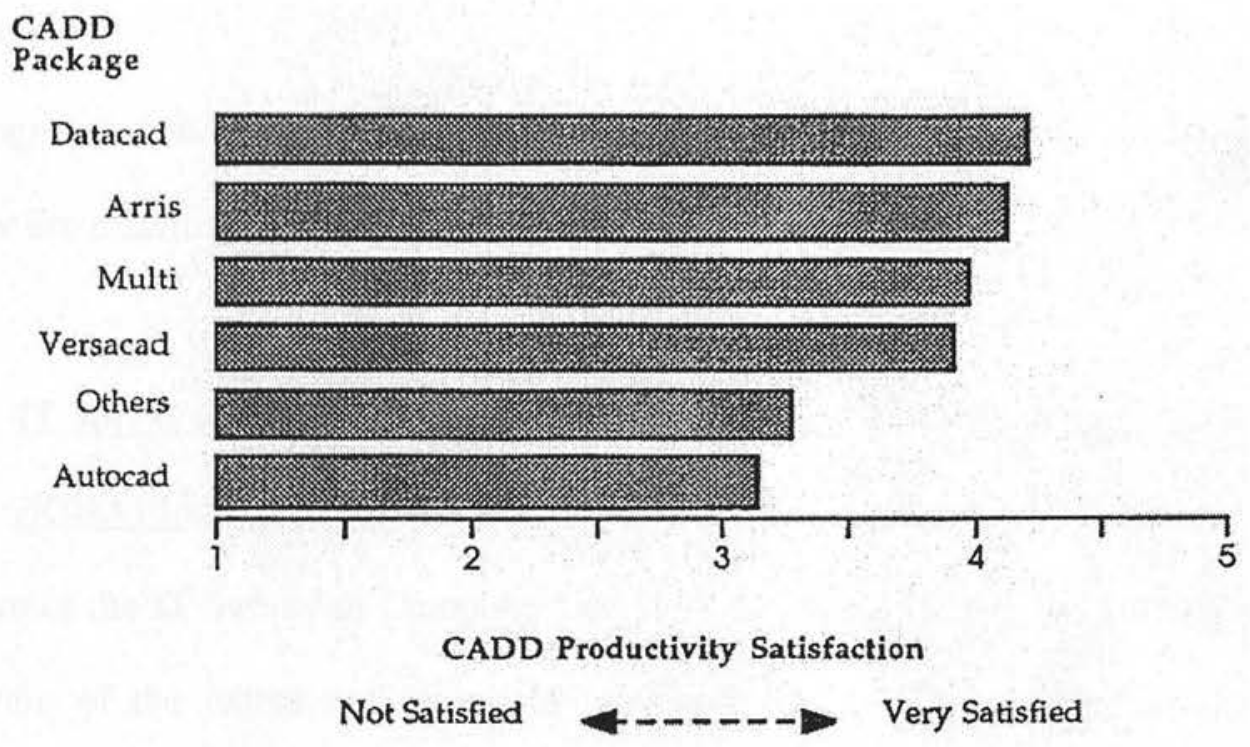

Figure 38: CAD Productivity satisfaction by CAD package

(Journal of Architectural and Planning Research, 1994).

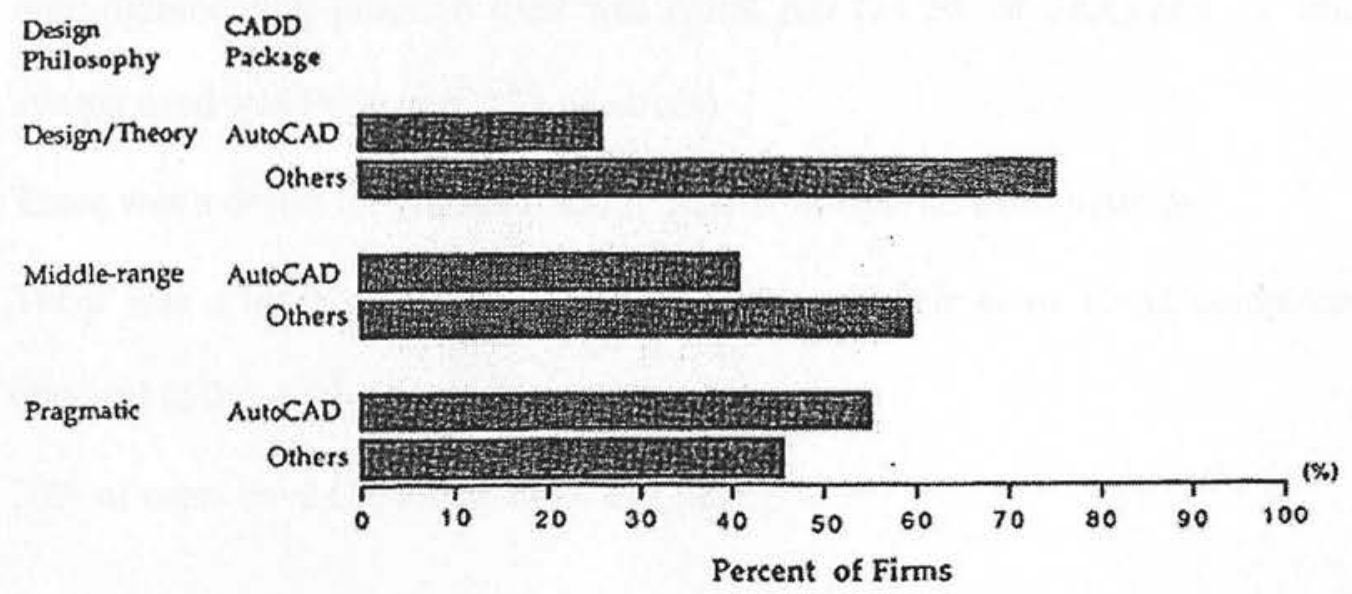

Figure 39: Firms using AutoCAD and other packages by design philosophy

(Journal of Architectural and Planning Research, 1994). 
The results pointed to three conclusions regarding computing in the architectural design process:

- The benefits of using CAD appeared to be recognized by architectural firms.

- Some CAD packages seemed to better support the design aspects while other packages appeared to better support the documentation aspects of architectural firms.

- It appeared that CAD manufacturers needed to make refinements in design tools that are essential to the needs of the profession (139).

\subsubsection{IT Survey of Computer Use 1994 by Royal Institute of British Architects} (RIBA) Journal (UK)

The aim of the IT Survey of Computer Use 1994 by RIBA Journal was "to establish an indication of the extent and nature of computer use." Architects or practices were surveyed.

Although no conclusions were drawn, the survey revealed the following factors:

- Architects or practices had embraced computer technology. The leading drafting/modeling program used was AutoCAD (24.2\% of total) and the leading system used was PC-based (233 practices).

- There was a desire for guidance about transfer of data between systems.

- There was a large chasm between those who are who know about computers as opposed to those who don't.

- $20 \%$ of users have CD-ROM capacity (140). 


\subsubsection{Survey by Barbour Index (UK)}

The purpose of the survey released by Barbour Index was to determine "The Sourcing and Exchange of Information Across the Building Project Team" (Martin, 1999, p 5). Construction projects were reviewed, professionals were canvassed and survey responses were analyzed. The survey showed architects were ahead of quantity surveyors in their use of information technology (IT) to source information. Almost half of the architects surveyed had direct access from their desktops. Responses indicated that a third of the architects, M\&E engineers, and contractors were spending $20 \%$ of project time just on sourcing information.

The report claims that "A threefold increase in Internet use is predicted over the next two years, set against a corresponding decline in paper delivery of some 50\%." "While $71 \%$ of building and design professionals currently still prefer information on paper, that figure is expected to drop by $20 \%$ by 2001 . Over the same period, the proportion of those choosing to get material on-line via the Internet is expected to rise from $20 \%$ to 60\%" (Martin, 1999, p. 5)(141).

This increase in electronic communication has brought about corresponding legal and ethical issues. Copyright concerns have surfaced with regard to architects sending drawings via e-mail. In a recent RIBANet electronic conference system, solutions to this problem include "locking" drawings for read only format which eliminates downloading possibilities.

\subsubsection{Preliminary results from the AIA 2000-2002 firm survey on high tech firms}

The report on high tech firms was part of the AIA 2000-2002 Firm Survey that presented updated information from the AIA 1997 Survey. The questionnaire was 
mailed to AIA member-owned firms (142). The survey indicated that investment in technology definitely has positive results. High tech firms have high productivity in terms of higher project fees and more projects (Figure 40). So, what constitutes high tech firms? "High tech firms include those whose responses to the AIA Firm Survey 2000-2002 place them in the top 75 percentile of firms as measured by the criteria established to gauge technological sophistication. High-tech firms reported high-speed Internet access (DSL or faster service), use of the Internet to specify and purchase products, and utilization of software applications indicative of a high level of technology (3-D design and presentation, rendering, and in-house or third-party detail libraries)" (Jacknain, 2000). Results of the survey revealed higher billings outweigh costs for technology (143).

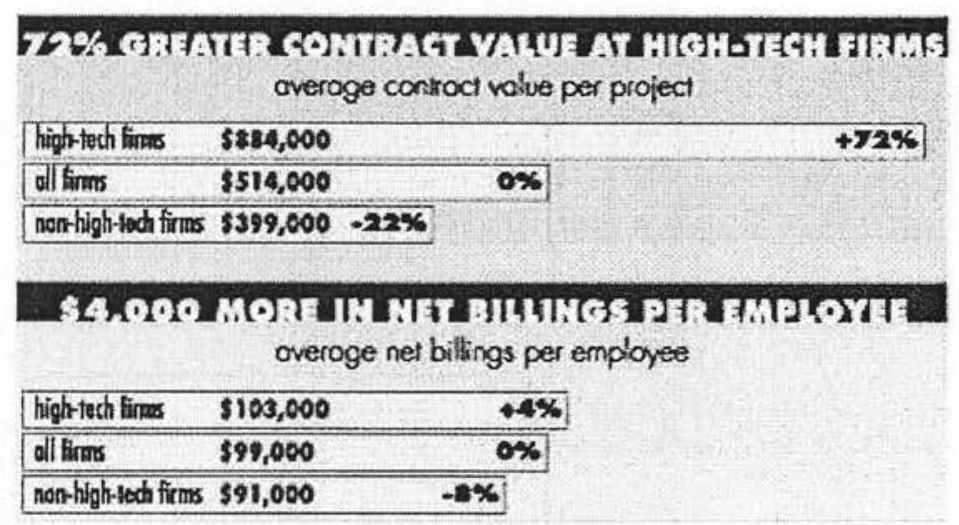

Figure 40: Average contract value per project and average net billings per employee (AIA, 2000)

\subsubsection{Preliminary results from the AIA 2000-2002 firm survey on Internet use}

The report on Internet use by firms was also part of the AIA 2000-2002 Firm Survey. AIA member-owned firms were surveyed (144). The report showed an escalation of Internet use by firms (Figure 41). Architects were researching product specifications; 
federal, state and local regulations; potential consultants or vendors, potential clients and competition; as well as business leads on-line. They were also selecting products, marketing firm services, recruiting new employees and submitting bids and proposals on-line. Many firms justified the need for a Web site as a means to obtain work, and to recruit new employees. In 1999, 36\% of the firms reported having web sites. This figure represents $13 \%$ of small firms, $53 \%$ of the medium (10-19) and $94 \%$ of the large (50 or more) firms. Many were planning to have a Web site in 2000-up 21\% since 1996.

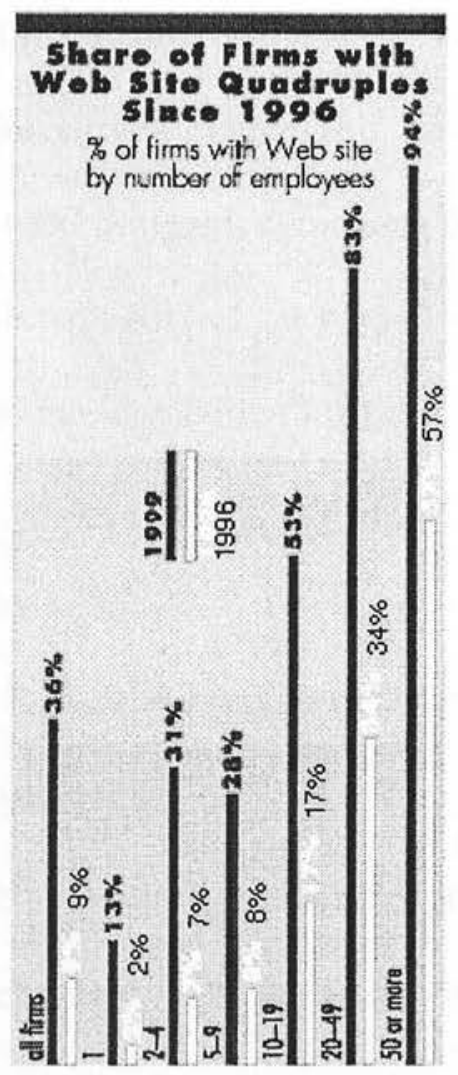

Figure 41: Share of firms with web site quadruples since 1996 (AIA, 2000).

Electronic transfer of drawings has increased to $83 \%$ in 1999. Many firms have Webbased design software or extranets. Over $1 / 3$ of the architects collaborate with engineers and clients this way and over $1 / 4$ of the architects collaborate with contractors using this method. "Project extranets constitute the biggest new leap of where technology is 
affecting the profession" states Frederick C. Gleason, AIA, chair of the BSA New Technology Committee (Dalal, 2000)(145).

\subsection{Construction industry surveys}

\subsubsection{RIBA Compares Computer Survey Results (UK)}

Rob Howard of the UK Construction Industry Computing Association (CICA) compared four computer surveys conducted in 1987 in order to examine the differences depending on the purpose of the surveys and to clarify contradictory findings. Interestingly, regardless of the survey source and statistical differences, AutoCAD remained the most frequently used program, surpassing Robocad, Rucaps and GDS. In addition, microcomputer and the category of "any type" of computer were used most as compared to the mainframe and minicomputer (146).

The surveys were carried out by:

- RIBA Computer Software Survey. All private architects' practices.

- Computer Aided Design Systems.

- The Building Centre Readership Survey. Individual architects, etc.

- Building Information Technology, CICA, Peat Marwich McLintock. Top 800 consultants and contractors (147).

\subsubsection{Survey of data communications in the UK Construction Industry}

This was a survey carried out in 1993 to ascertain the position of technology within the UK's construction industry. The survey encompassed architects, consultants, contractors, materials manufacturers, distributors and quantity surveyors. It showed that electronic mail and data exchange was still restricted in this industry and was used primarily to support finance and accounting processes as opposed to construction 
processes. The survey also provided information concerning problems faced by construction professionals.

Questions were asked in the category of innovation in house design and IT use in house building. Related questions pertained to:

- Hardware and software: The majority of respondents used PC with DOS operating system. There was widespread use of minicomputers and UNIX operating system. PC/DOS was perceived as very efficient on well-defined tasks. Organizations understood the need to develop infrastructure to support changes through the use of larger computers such as minicomputers.

- Data communication within firms and local area networks: There was use of internal (local area networks or LANs) and external data communications. The survey showed very few respondents were connected with LANs and although almost half of them had LAN infrastructure, they were not using it.

- Distribution of computers: Computers were predominantly located at the head office to "support central administration tasks and off-site construction management processes, such as estimating" and almost half were at district offices. There was low use of computers on construction sites as computers were viewed to be expensive. They were not considered suitable outside of the office unless they were going to be used on high profile and long-term projects. However, it was anticipated that PC notebooks and cheap communication facilities would change this condition.

- Types of data transferred: The majority of data transferred involved financial functions of monitoring and controlling work as opposed to facilitating work.

- Data communication between firms: A majority of respondents did not use any form of external communication to link to other firms. Internal communication was well established. 
- Electronic mail: Only $6 \%$ were connected internally and $3 \%$ externally. Five problems cited included problems of utilization (e.g. incomplete connections), technical problems (e.g. loads on existing facilities, problems with poorly installed systems), user-related issues (e.g. users themselves, unwillingness of dispensing paper), cost and practical problems (e.g. terminal at desk difficult in small office).

- Electronic data interchange (EDI): Few firms had EDI. EDI was mostly used for ordering and accounting purposes which were external to the construction industry. Problems with EDI included: needs for integration of EDI facilities with existing software systems, critical mass necessary to achieve cost effectiveness. EDI was primarily used by building materials manufacturers and suppliers.

The survey was conducted to provide software developers with information on how communications was being used by the UK construction industry. The communication infrastructure in 1993 was still small and applications were generic, not specific to the construction industry. Much work remained to be done for software developers to provide extensive infrastructure for exchanging construction data (148).

\subsubsection{RIBA information survey of use of computers by UK construction} industry specifiers: hardware, operating systems and delivery media

The purpose of this market survey was to investigate the use of computers by organizations who were in the construction specifying industry. The survey results were to help "1)construction specifiers: to assist their selection of suitable computer hardware based upon peer group, 2)suppliers of information to the construction industry: to assist in the selection of the best form that electronic delivery should take." 
A questionnaire was sent to construction industry specifying organizations in 1997.

Data results were obtained in the area of:

- User preferences for PC and Apple Macintosh: "Of those organizations using computers, only 1 in 20 does not have access to a PC. Specification tools taking advantage of the high proportion of construction industry specifying organizations with computers must therefore be designed for compatibility with PCs."

- Hard disk storage and memory size: "Increasing RAM to levels suitable for running current multi-media applications is, if necessary, usually relatively simple."

- Use of PC processor types: "Multi-media information packages for the specifier require at least a 486 processor to run effectively-most organizations have this facility."

- Use of PC operating systems: "Applications for PC systems should allow for use via Windows 95 and Windows 3.1/3.11 operating systems to maximize the number of end users."

- Availability of CD-ROM drives: "Computer using specifying organizations are very likely to have CD-ROM drives."

- Use of the screen resolutions for PC: " $88 \%$ of PC using organizations can use the higher screen resolutions necessary to run multi-media applications successfully."

- Availability of modems; actual and potential access to the Internet: "The proportion of specifying organizations linking to Internet is already substantial and will grow."

- Access to CAD: “CAD use varies widely between categories of organizations" (RIBA Information Services, 1998, p. 43)(149). 
Percentage of respondent organisations using CAD systems; by organisation category; total sample 5,960

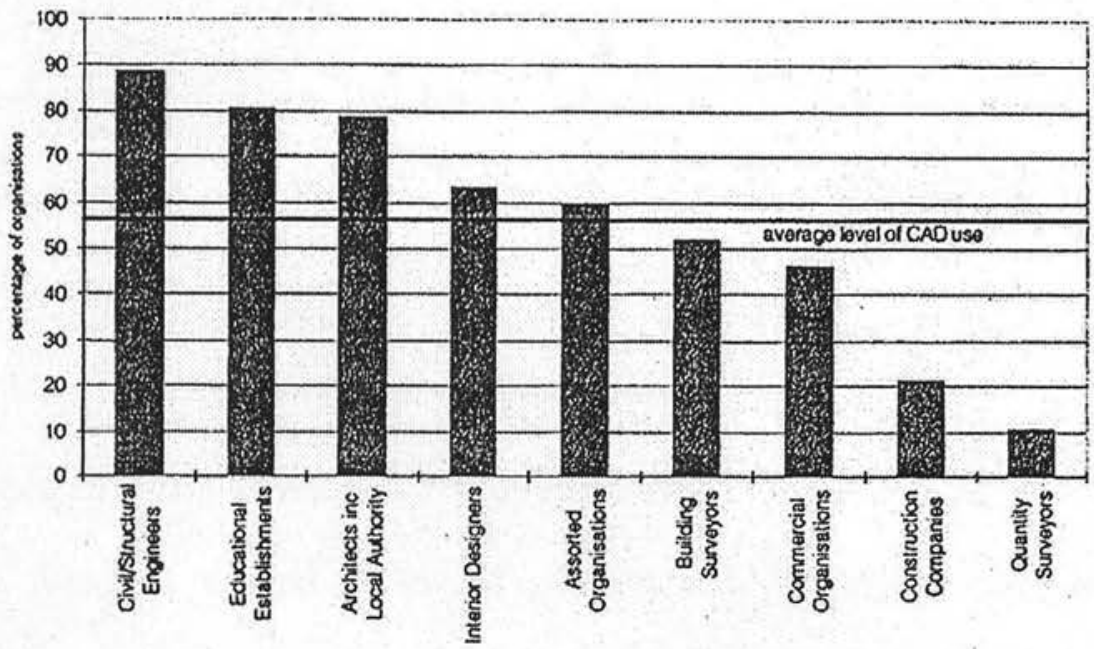

Preference for CAD systems; total sample 3,472 CAD using specifying organisations

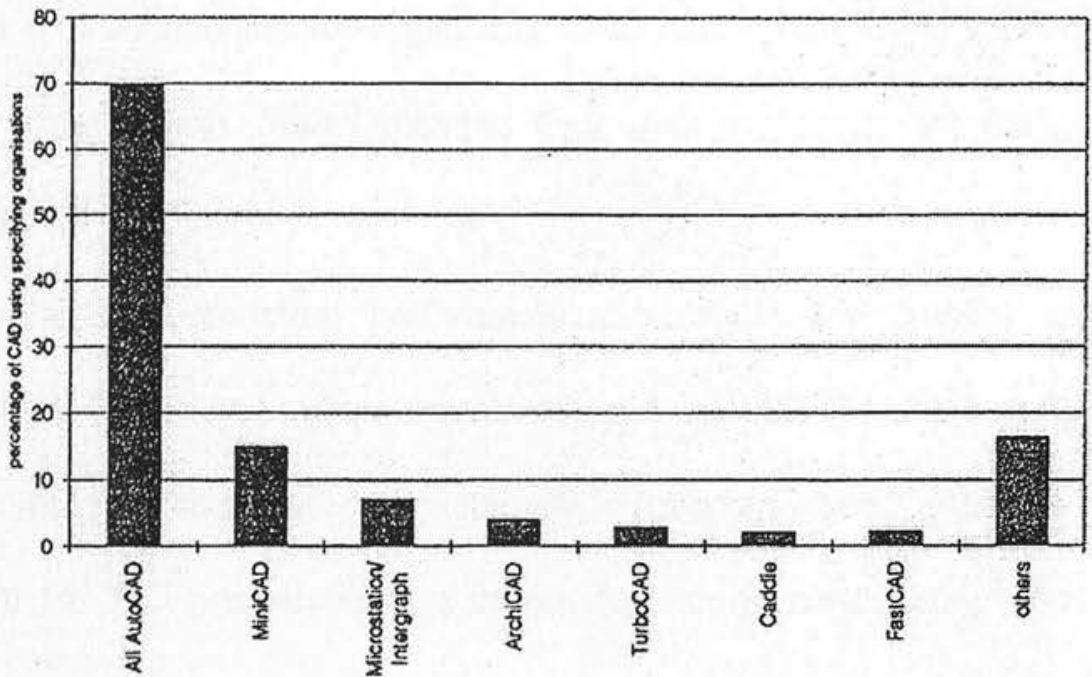

Figure 42: Percentage of respondent organizations

$\underline{\text { using } \mathrm{CAD} \text { systems by organization category }}$

Figure 43: Preference for CAD systems (RIBA Information Survey, 1998).

\subsubsection{Survey of CAD and virtual reality within the house building industry (UK)}

This survey reported on the use of virtual reality in the British Housing Industry. "The extent and nature of use of 3-D modeling and visualization and general computing 
strategies are considered, as well as attitudes towards IT and IT use to support design processes." (Whyte, 199, p. 971)(150).

Surveys were sent to the top 100 British House Building firms with 42 responses. Questions were asked on innovation in house design and IT use in house building. Related questions pertained to:

- Basic CAD product used: Most firms used AutoCAD (Figure 44).

- Importance of CAD training and support considered by building developers and vendors: Vendors wanted to identify, recommend solutions, demonstrate their product and provide scheduled training. Developers wanted to get training so that they can effectively and efficiently use the software.

- Need for a CAD standard for organizing CAD data: Some firms implemented their own layering system. Some invented their own protocols, but found this to be imposing and restrictive.

- Benefits of 3-D modeling and visualization tools for internal and external presentations: Time and manpower constrained use of 3-D modeling. It was useful in-house for working out design details. However, detail was not viewed as important for 3-D presentation for external planning consultation and marketing. The effect of virtual reality (Figure 45). Most companies found this to be effective especially to communicate to non-designers (151). 


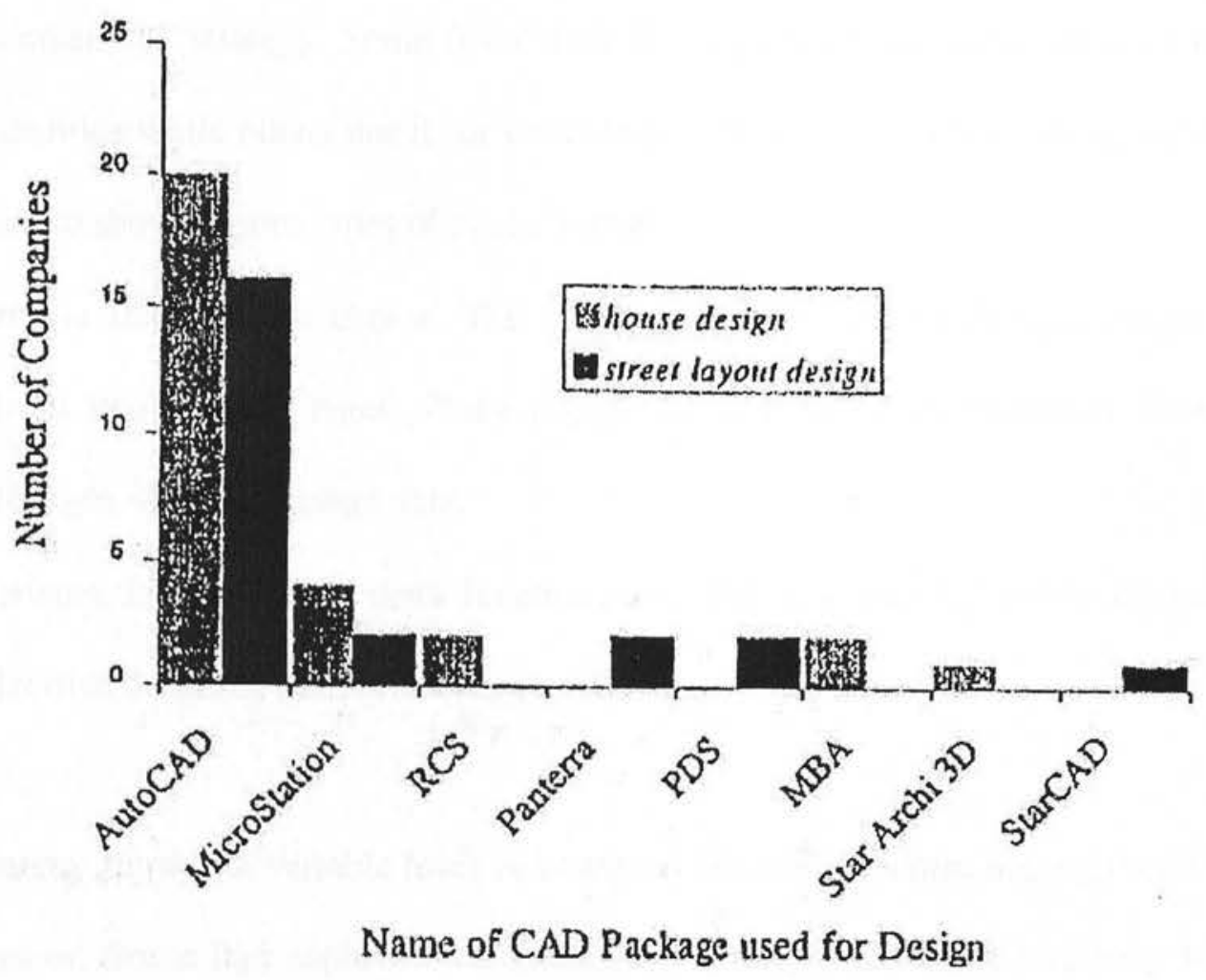

Figure 44: CAD products used in development housing British industries

(Whyte, 1999).

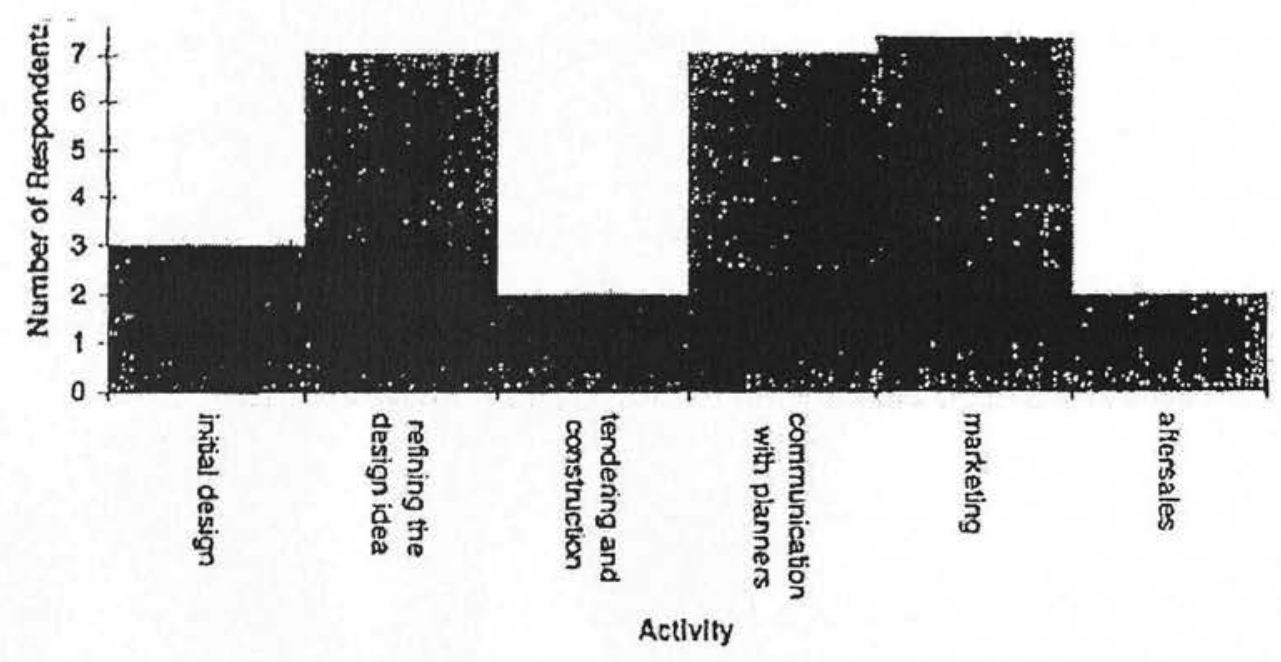

Figure 45: Area in which VR is seen to have the most benefit

(Whyte, 1999). 
- Company IT strategy: Some firms used IT for network and automation of bills of quantities while others use it for marketing sales purposes. For example, QVR was used to show various types of model houses.

- Criteria for software choice. The top three reasons for choosing software were 1)well known trade name, 2)one integrated solution for all functions, 3)separate packages which exchange data.

- Network facilities: The main function of a Web site was for public relations, to advertise the name of the firm as opposed to generate sales .

The survey showed a variable level of computer use and expertise among the different companies. Some had sophisticated technology strategy and some had very little or none (152).

"CAD and VR are an important component in this drive for innovation offering scope for improved quality and customer satisfaction through prototyping and feedback from sales and marketing team and customers" (Whyte, 1999, p. 977). 


\subsubsection{Summary of allied professionals computer surveys}

The comparison among the architecture and building industry surveys clearly shows both industries in the United States (US) and United Kingdom (UK) have adopted computer technology, with architecture moving ahead faster than the building industry. The surveys provided noteworthy information on the use of computers as well as specific applications utilized. The results from these surveys provided a valuable source of comparison to landscape architecture surveys and prompted questions which were explored further in this thesis research.

Computer use increased in architecture in both the US and UK, with AutoCAD as the leading CAD program. Other findings revealed: 1)most firms had CAD capability, 2) $\mathrm{CAD}$ was used as drafting rather than design tool, 3)CAD improved productivity and quality, 4)expenditures were made for computers in both small and large firms, 5)there were more non-architect staff members with increased firm size, 6)high tech firms were more profitable, 7)most were connected to the Internet and many have a Web site, but were not using it for marketing purposes. It is interesting to note finding numbers 4 through 7. Answers to these areas of interest had previously also been explored by landscape architects as they were related to the design tasks within an office.

The survey by the Journal of Architectural and Planning Research (JAPR) revealed that design firms used computers more during the earlier stages of the design process whereas, pragmatic or production oriented firms used the computers later in the design process and rarely used 3-D modeling. Results from landscape architecture surveys only indicated low usage of computers by respondents during conceptual design with no further details. The closer examination about computer use by the JAPR certainly 
provided more insightful results and their work served as a guide to the work in this research.

The UK surveys indicated that architects had a desire for guidance with transfer of data between systems in 1994. In 1999 most of them were connected to the Internet. The survey reported that architects spent a lot of time sourcing information and the survey projected that there would be a drop in paper delivery and an increase in electronic delivery. ASLA's 1998 survey results also seem to point in the same direction in that over half of the respondents indicated they preferred the ASLA Member Handbook online. This type of finding poses the question of whether landscape architects are ready for the 'paperless office.'

In terms of the building construction industry in the UK, there had also been an increase in the use of computers. Most professionals used AutoCAD. The result of the 1993 survey on data communication indicated: 1)e-mail and data exchange was primarily for finance and accounting as well as for monitoring and controlling work as opposed to facilitating work, 2)many (42\%) had a LAN, but only $8 \%$ used it, 3)many electronic problems were cited such as technical, user and practical problems, 4)few firms had electronic data interchange (EDI) and that the low use was attributed to expense and critical mass needed for cost effectiveness. The 1998 construction industry specifier survey reported that: 1)most professionals had modems, 2)hardware such as RAM needed to be increased, processors and operating systems should be upgraded, and CDROMs and higher screen resolutions should be added for multi-media purposes. The results from the UK building industry survey brought up a wealth of questions regarding the use of e-mail and the Internet. Similar questions could be asked of landscape architecture professionals, since minimal information is available. Landscape 
architecture surveys only indicated that a majority of their respondents were electronically connected. Since this impacts design and office procedures it is a new and relevant aspect of this thesis research and was investigated further.

The 1999 CAD and virtual reality within the building industry survey findings showed: 1)3-D modeling was used in-house for working out details and QTVR was used for marketing model homes, 2)IT was used primarily for billing and marketing, 3)a CAD standard was desired, 4)a Web site was primarily for marketing and not for generating sales, 5)software selections were based on trade name, program with one integrated solution for all functions, and separate package for data exchange, and 6)training was considered important by building developers and vendors. Items 4 through 6 are particularly of interest when they are compared to results of previous landscape architecture surveys. Many respondents from the landscape architecture surveys indicated that: they had a Web site, but did not indicate how the Web site was being used and AutoCAD was the standard CAD program, but did not inquire about the basis for software selection. Thus, both these were explored further in this research. Additionally, several of the surveys indicated that respondents desired training. The building survey, in particular indicated that the building developers and vendors were interested in providing training. This finding is unique and raised the question of how landscape architects were progressing with regard to training.

In contrast to the landscape architecture surveys, allied surveys probed into greater detail regarding how computers were changing the way professionals were doing business. Although, the survey conducted by JAPR was the only one that directly related to the effect of computers on design itself, nevertheless, the allied surveys provided a valuable source of information that were not provided by the landscape 
architecture surveys. The allied surveys thus greatly influenced the formulation of questions for this research project. 
117 Fabos, J. (1983). "Paperless Landscape Architecture: Future Prospects?" Landscape Journal, 2 (1), 13-18.

118 Anderson, P. (1984). "Stats on Computer Use." Landscape Architecture, 64 (5), 101-102.

119 Palmer, J. \& Buhman, E. (1994). “A Status Report on Computers." Landscape Architecture, 84 (7), 54-55.

120 Donnenmaier, M. (1994). "Reconfiguring the Practice Pie." Landscape Architecture, 84 (7), 51-53.

121 Palmer, J. (1998). "The 1996 Status Report on Computers in Landscape Architecture." Computing, 11 (1), 2-5.

122 Palmer, J. ibid.

123 Palmer, J. (1998) op. cit.

124 Palmer, J. (1998) op. cit.

125 Murray, L. (2000). "Survey Shows Increased Member Satisfaction.” Land, 42 (7), 14-15.

126 Anderson, P. (1984). "Stats on Computer Use." Landscape Architecture, 64 (5), 101-102.

127 Palmer, J. (1998) op. cit.

128 Anderson, P. (1984). "Stats on Computer Use." Landscape Architecture, 64 (5), 101-102.

129 Palmer, J. (1998) op. cit.

130 Palmer, J. (1998) op. cit.

131 Donnemaier, M. (1994).

132 Murray, M. (1994).

133 The 1987 AIA Firm Survey Report. (1987). The American Institute of Architects Press, Washington, DC, i-iv, 48-49.

134 The 1987 AIA Firm Survey Report. ibid.

135 The 1989 AIA Firm Survey Report. (1989). The American Institute of Architects Press, Washington, DC, 1-2, 73-76.

136 The 1989 AIA Firm Survey Report. ibid. 
137 The 1991 AIA Firm Survey Report. (1991). The American Institute of Architects Press, Washington, DC, 1-2, 71-74.

138 "CADD Utilization in the Architectural Design Process: Implications for Computer Integration in Practice." (1994). Journal of Architectural and Planning Research, 11 (2) Summer, 137-148.

139 "CADD Utilization in the Architectural Design Process: Implications for Computer Integration in Practice." ibid.

140 Howes, J. "IT Survey of Computer Use." (1995). RIBA Journal, 102 (1), 62.

141 Martin, I. (1999. June 11). “Architects Take Pole Position in IT Use.” Building Design, no. 1399, 5.

142 AIA Firm Survey 2000-2002. (2000). The American Institute of Architects Press, Washington, DC, 86-87.

143 Jacknain, G. (2000). "High Tech Firms Report High Productivity." Retrieved December 10, 2000 from the World Wide Web:

http://www.e-architect.com/news/aiarchitect/oct00/tech.asp

144 Jacknain, G. ibid.

145 Dalal, P. (2000). "Internet Use at Firms Accelerates." Retrieved December 10, 2000 from the World Wide Web

http://www.e-architect.com/news/aiarchitect/oct00/tech.asp

146 Howard, R. (1988), April). “Computer Survey Results Compared.” RIBA Practice. 4.

147 Howard, R. ibid.

148 "A Survey of Data Communications in the UK Construction Industry." (1994. September). Construction Management \& Economics, 12 (5), 457-465.

149 "Use of Computers By Construction Industry Specifiers: Hardware, operating system and delivery media." (1998). RIBA Information Services, 43.

150 Whyte, J. (1999). "Survey of CAD and Virtual Reality Within the House." Engineering, construction and architectural Management, 371-379.

151 Whyte, J. ibid.

152 Whyte, J. ibid. 


\section{CHAPTER 4 - A CASE STUDY}

\section{1 $\underline{\text { Introduction }}$}

There has been a revealing change in the approach to the design and drawing process for landscape architecture education as well as practice. While practitioners have been increasingly using digital technology, new pedagogical methods that integrate computers are being developed and used in academia. Most schools today offer some form of CAD course even though the U.S. Landscape Architecture Accreditation Board only recommends and does not require CAD integration in the curriculum. Some schools offer CAD as an elective course, others offer it as a required stand-alone course, while still others offer it as an integrated part of the design studio. Examples of CAD integration in the design studio can be seen in Roger Trancik's urban design studio at Cornell University and Timothy Johnson's design studio at Penn State University. Trancik believes that "It is important to integrate educational content with skill development in any software." In addition, each student must work at a personal computer. Johnson feels that the integration of $\mathrm{CAD}$ in the studio provides "a medium which offers the opportunity for learning and creativity..." The segmented approach of $\mathrm{CAD}$ apart from studio gives the impression that $\mathrm{CAD}$ is specialized, complex, and a difficult graphic tool. At Clemson University, CAD is offered as an elective course. $\mathrm{CAD}$ in the current curriculum produces a wide disparity of CAD knowledge among the students. For example, a fourth year landscape architecture class may have students with very little to very experienced levels of expertise. This imbalance provides the faculty with a difficult class to teach and widely varying approaches to computer use by students. This will impact their later use of computers as employees in office practice. It is thus important to explore how the educational process may influence computer use in office design practice. 
With regard to the extent of digital technology used in the design process, it appears that it varies due to several factors, including efficiency, know-how, hardware, software, trained personnel, and associated costs. In addition, it seems that some aspects of the design process are more conducive to being created with digital technology than others. Nonetheless, its use in the execution of the entire design still appears to be rare.

\subsection{Objective}

A case study was conducted to focus on an alternative studio teaching experience at Clemson University. It investigated the use and integration of digital technology during various phases of the landscape design process and reported on the findings of an empirical study. The aim was to explore the way digital technology can be used by students with varying levels of experience, and how different degrees use can influence efficiency and effectiveness at different stages in the design process.

In this study, 32 third and fourth year students participated in an experimental landscape architecture vertical design studio, which involved a service learning project conducted by two professors. Participants, in three groups, worked concurrently on the same project, however in conventional (non-digital), mixed, and digital media. The progress of each group was monitored and recorded during the course of the studio. The study compared and evaluated the three methodologies, in terms of production time, drawing quality, and participant attitudes. A model was developed based upon the specifics within these findings to suggest an efficient and effective approach to integrate technology in the design and drawing process. 


\subsection{The project}

The project involved the design of the South Carolina American Society of Landscape Architects' (ASLA) Centennial Park: a horticultural therapy garden. The program for the project required provision for raised beds at different heights, so people can garden from a wheelchair or be seated if they have trouble standing for an extended period of time; smooth and barrier free paths so a person using a wheelchair, walker or cane can have easy access; a water feature so that a person with hearing challenges can feel the coolness of the water and for the visually challenged to hear the sound of it; and fragrant plants and plants with special textures to allow people with visual impairments to also experience the beauty of nature.

The overall design process took five weeks from the initial charrette to the final design drawings and models. Throughout the project, students worked on research, developed site analyses, and conceptual design alternatives, models, and various detailed sketches. Drawings produced include illustrative renderings, grading and planting plans, site cross-sections and construction details.

\subsection{Methodology}

The students designed their projects concurrently in three groups. Each group of students used different techniques in their design and drawing methods which ranged from 1)designing and drawing by hand only; 2)designing and drawing by computer only; and 3)designing and drawing by a combination of hand and computer (Figure 46). Each group was comprised of students with and without computer skills. The students were interviewed about their attitudes at the beginning and at the end of the project. 


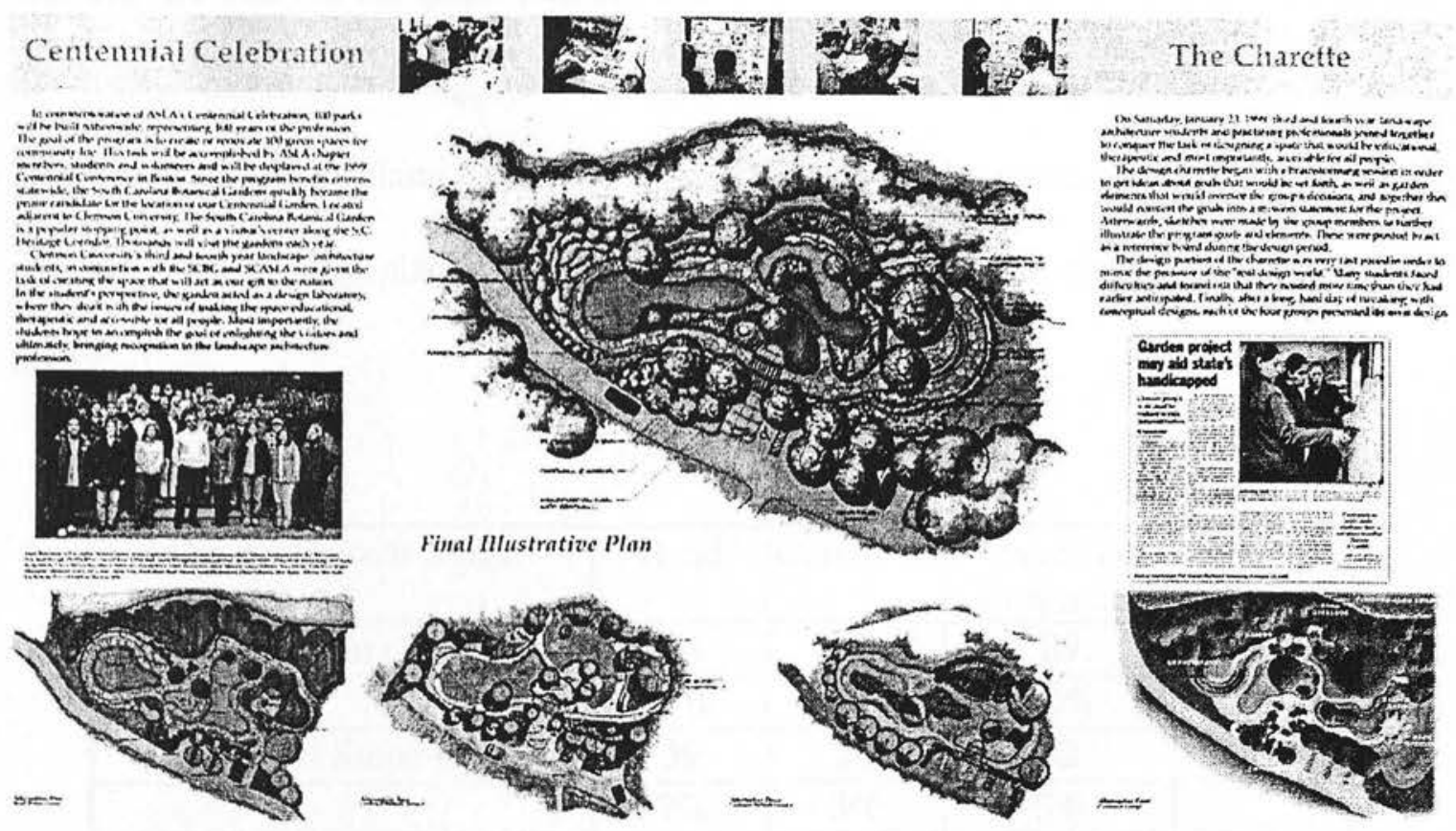

Figure 46: Center-Conventional and digital drawing; Bottom left to right-

1)Conventional; 2 and 3)Conventional and digital; 4)Digital only (Tai, 2000).

The students' time logs for each phase of the design process were collected, processed and assessed. The final products were also reviewed. This approach enabled the instructors to compare and evaluate the efficiency and effectiveness of each of the methods. They were also able to compare the effectiveness of the various presentation and communication methods with the audience. For example, "computer" generated 3D models vs. hand crafted, scaled models and hand drawings mounted on boards vs. computer drawing projections were compared in terms of their effectiveness.

\subsection{Results}

A time comparison of the three methods:

The instructors collected and processed the data from all students who were asked to record their activities for each phase of the project in a time log. Based on the students' time logs, the most efficient team was the combination of hand and computer group 
(Table 6). Overall, this group spent a total of 452 hours, which is 129 and 233 hours less than the hand or computer teams, respectively. This is due to the fact that this group had a choice in determining the tasks that would be done more efficiently by hand vs. those by computer. Taking second place was the hand only group, with an overall total of 581 hours. In third place was the computer only group, with an overall total of 685 hours.

\begin{tabular}{|c|c|c|c|c|}
\hline Design Process Stage & Hand & Computer & $\begin{array}{c}\text { Hand and } \\
\text { Computer }\end{array}$ & Totals \\
\hline Research & $\mathbf{9 6}$ & $\mathbf{1 5 9}$ & $\mathbf{8 9}$ & $\mathbf{3 4 4}$ \\
\hline & $17 \%$ & $23 \%$ & $20 \%$ & \\
\hline Base and Slope Map & $\mathbf{3 9}$ & $\mathbf{3 1}$ & $\mathbf{2 2}$ & $\mathbf{9 2}$ \\
\hline & $\mathbf{7 \%}$ & $5 \%$ & $5 \%$ & \\
\hline Vegetation Analysis & $\mathbf{4 1}$ & $\mathbf{3 2}$ & $\mathbf{1 5}$ & $\mathbf{8 8}$ \\
\hline & $\mathbf{7 \%}$ & $5 \%$ & $3 \%$ & \\
\hline Photo Inventory & $\mathbf{8}$ & $\mathbf{3 6}$ & $\mathbf{7}$ & $\mathbf{5 1}$ \\
\hline & $1 \%$ & $5 \%$ & $2 \%$ & \\
\hline $\begin{array}{c}\text { Model Making - Existing } \\
\text { Site }\end{array}$ & $\mathbf{3 2}$ & $\mathbf{2 8}$ & $\mathbf{3 3}$ & $\mathbf{9 3}$ \\
\hline & $6 \%$ & $4 \%$ & $\mathbf{7 \%}$ & \\
\hline Conceptual Design & $\mathbf{2 8 9}$ & $\mathbf{3 3 4}$ & $\mathbf{2 3 5}$ & $\mathbf{8 5 8}$ \\
\hline & $50 \%$ & $49 \%$ & $52 \%$ & \\
\hline Grading & $\mathbf{2 3}$ & $\mathbf{2 5}$ & $\mathbf{2 2}$ & $\mathbf{7 0}$ \\
\hline & $4 \%$ & $4 \%$ & $5 \%$ & \\
\hline $\begin{array}{c}\text { Model Making - Final } \\
\text { Design }\end{array}$ & $\mathbf{5 3}$ & $\mathbf{4 0}$ & $\mathbf{2 9}$ & $\mathbf{1 2 2}$ \\
\hline & $9 \%$ & $6 \%$ & $6 \%$ & \\
\hline Total & $\mathbf{5 8 1}$ & $\mathbf{6 8 5}$ & $\mathbf{4 5 2}$ & $\mathbf{1 7 1 8}$ \\
\hline & $\mathbf{1 0 0 \%}$ & $\mathbf{1 0 0 \%}$ & $\mathbf{1 0 0 \%}$ & \\
\hline & & & \\
\hline
\end{tabular}

Table 6: Hours spent on design process stages by three groups (Tai, 2000). 


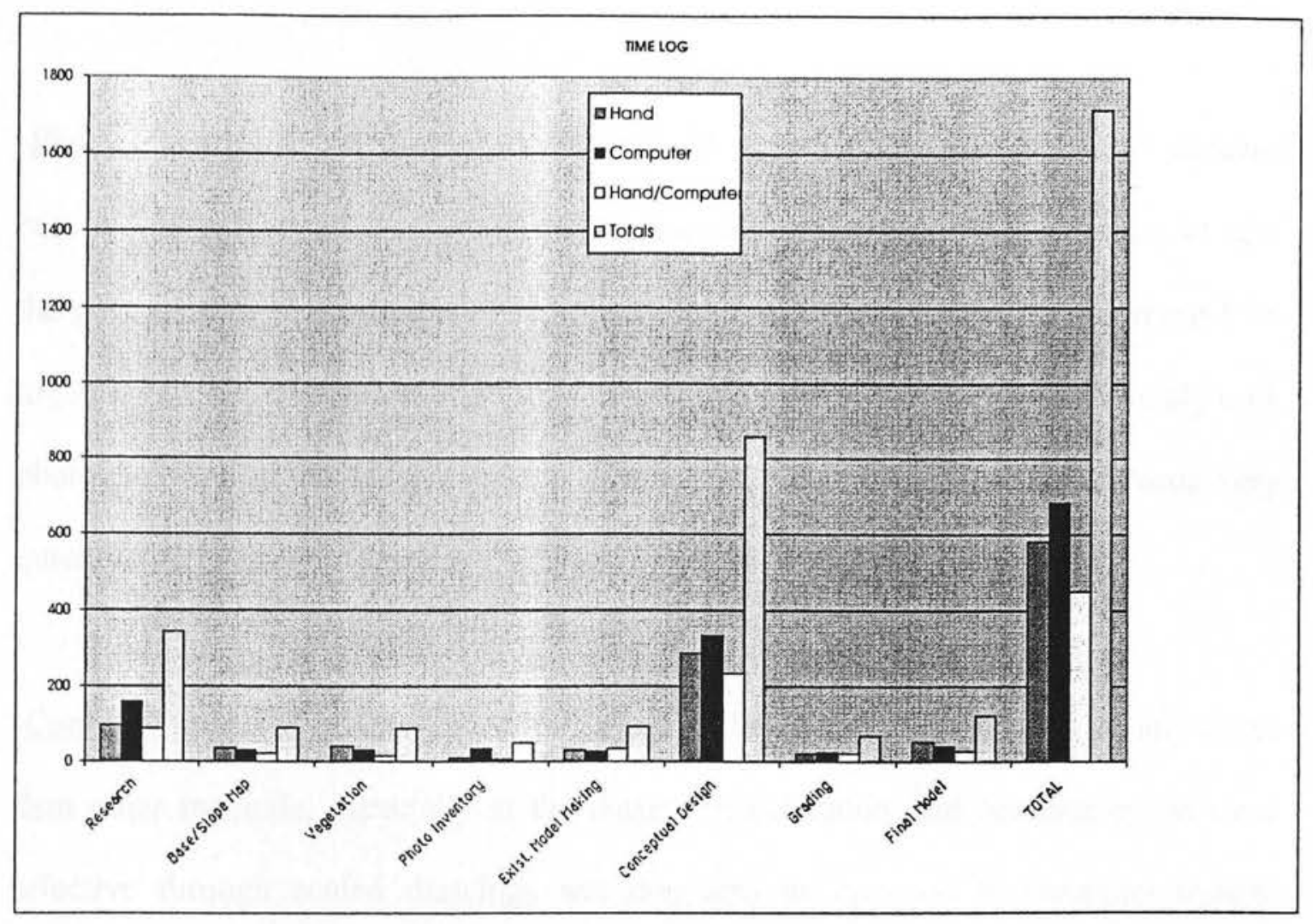

Figure 47: Comparison of students' time logs (Tai, 2000).

\section{6 $\quad$ Discussion}

$\underline{\text { An overall comparative analysis }}$

The largest hours of discrepancy in time efficiency can be seen in the research, photographic inventory, and conceptual design phases. Students in the computer groups took longer for these tasks due to the following circumstances.

-Research: While other groups had access to the resources through the library, the computer group experienced difficulties in narrowing the area of the vast resources on the Internet. They spent more time trying to locate information and to organize their findings on the computer. Time was spent on scanning images vs. photocopying and rendering. In addition to many distractions in searching on the Internet and other digital 
media, they also had technical problems such as frequent computer crashes, difficulties with file transfers, and lack of availability of computers.

-Photo Inventory: Photographic documentation also cost more time for the students required to perform all their work on the computer. After using digital cameras to take the photographs, these students had to edit each file, organize, and put the image files together in a digital presentation format or print/plot the files. Other groups simply took photographs, had the films processed, and used prints to make image boards very quickly.

-Concept Design: Conceptualizing the project by hand on paper was significantly faster than other methods, especially at the outset. Visualization and communication were effective through scaled drawings and diagrams as opposed to computer images displayed on monitors. The computer group had difficulties in grasping the concept of scale. They gradually developed this ability by relating to familiar references such as roads and parking stall dimensions. Still, the total time they spent on computer generated conceptual design took more than the other two groups. This may be explained by the difficulty of feeling the spatial "scale" on the computer screen.

-The Attitudes: Interviews conducted with students from the three groups revealed different attitudes towards the methods used. At the beginning of the project, the students were willing to be placed in any of the groups. They were basically eager to learn about design and did not have any preconceived notions as to the benefits or drawbacks of the alternative methods regardless of whether it was traditional or digital. They were at the third and fourth year level and realized that everything they learned would be new information. At the end of the project, the hand/computer group was most satisfied due to the freedom of choice. The hand only group was disgruntled with 
simple tasks that became wearisome and laborious. The computer group was both satisfied and frustrated at the same time.

Computer-only Group: A student from the computer only group summarized her experience and commented, "Expressing our ideas in the drawings to the level of detail that we imagined in our minds was hard. This whole process was new for us, designing from beginning to end on the computer, and our coordination with the mouse was not fully developed. On a lighter note, it was nice not to have to redraw the base map $\mathrm{x}$ times for each kind of drawing, and we were able to come up with more impressive looking research boards and such because of the Internet images and colors and so forth. We also have something different to put into our portfolios" (Tai, 2000). Also from the computer-only group, another student said, "The experimental studio was a great idea. I was in the computer-only group, and it forced me to learn more about computer graphics. I have been interested in 3-D modeling for a while and this gave me the time to actually practice it. Although I had several problems with the computers, it was a great experience" (Tai, 2000).

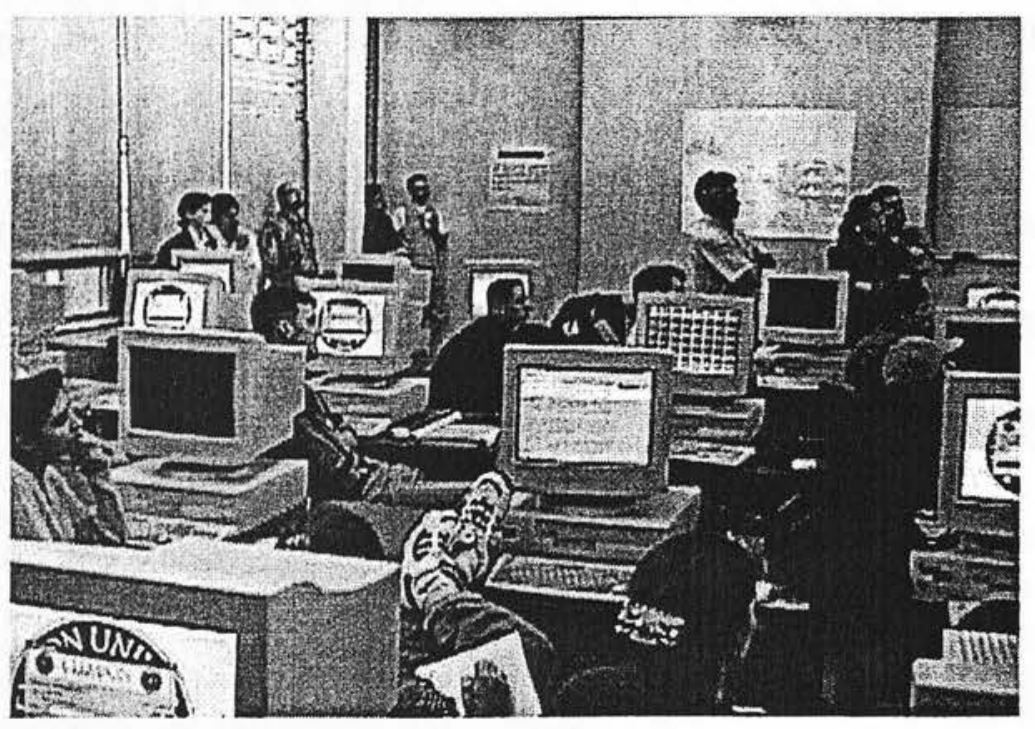

Figure 48: Critique of design in computer lab with overhead projector (Tai, 2000). 
Hand/computer Group: A student from this group made the following comments: "I really enjoyed the experimental studio. I was in the hand/computer group so I could use the best of both worlds. Some things were easier with the computer but by being able to work by hand, I could avoid the technical problems that the computer had. The project was a great experience and I hope to do more studio work this way" (Tai, 2000).

Hand-only Group: "I liked working in the hand-only group. This project forced me to learn how to hand letter. Before this project, my hand lettering was horrible. I also learned a lot from the 4th year students in our group" (Tai, 2000).

For those who used computers, the location of the computers in the lab rather than the studio presented a logistical challenge. These students were not soaking in the studio environment and sometimes missed out on spontaneous feedback and had to make more of a conscientious effort to get to critiques. The group that could choose between the methods to be used was the most time-efficient. Student satisfaction with the overall design process was also the highest for this group. In terms of the effectiveness of the products that were developed, the research board, the "walk-through", and the aerial "fly-by" of the computer model of the computer-only group received compliments during the presentation. However, the hand constructed models were easy to review and since they were physically still on display after the presentation, more people had a chance to walk around them and see them again, as opposed to computer generated models which were reviewed only during the presentation.

The final design:

The final design for the project as a whole, which incorporated elements from all three groups' schemes, was completed by the whole class with the use of both hand and computer methods. The final illustrative master plan could be created quickly by hand 
and take on an attractive quality, non-rigid in appearance. Color markers were used since they can easily be blended for a watercolor effect. The technical drawings, such as research presentation boards, elevations, sections and details, grading and planting plans were completed by computer. Many of these drawings were already created early in the design process and could easily be revised. Base templates were truly time saving. All drawings were scanned and digitized. With the use of computers, these images were incorporated into a fifty-page brochure and a poster presentation board. A model was created by computer and also by hand (Figure 49). The computer model generated many specific perspective views as well as the bird's eye view. The hand constructed model was used for its physical 3-D properties for a more effective display (153).

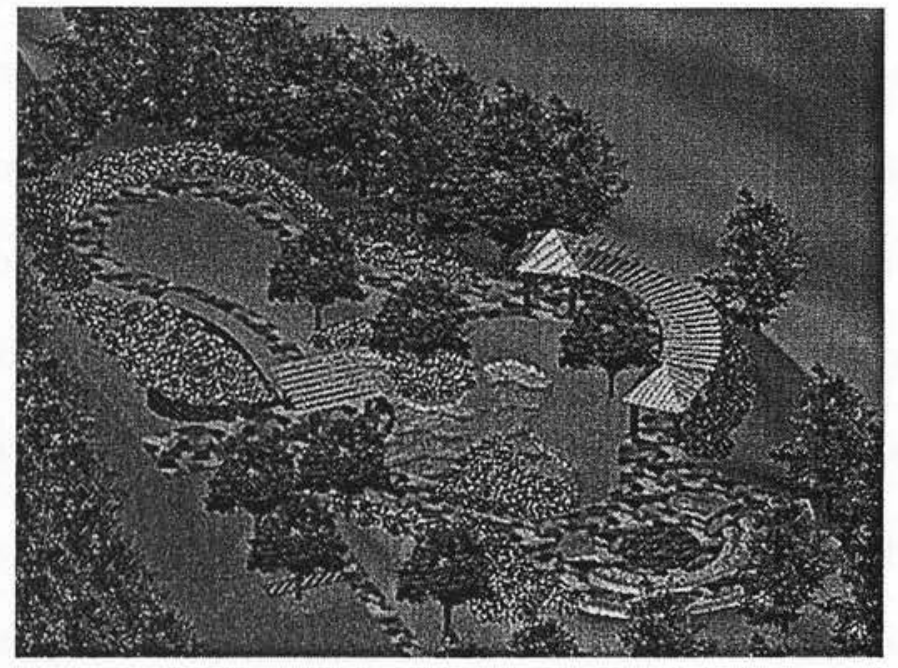

Figure 49: Computer model. Next page: Traditional model (Tai, 2000). 


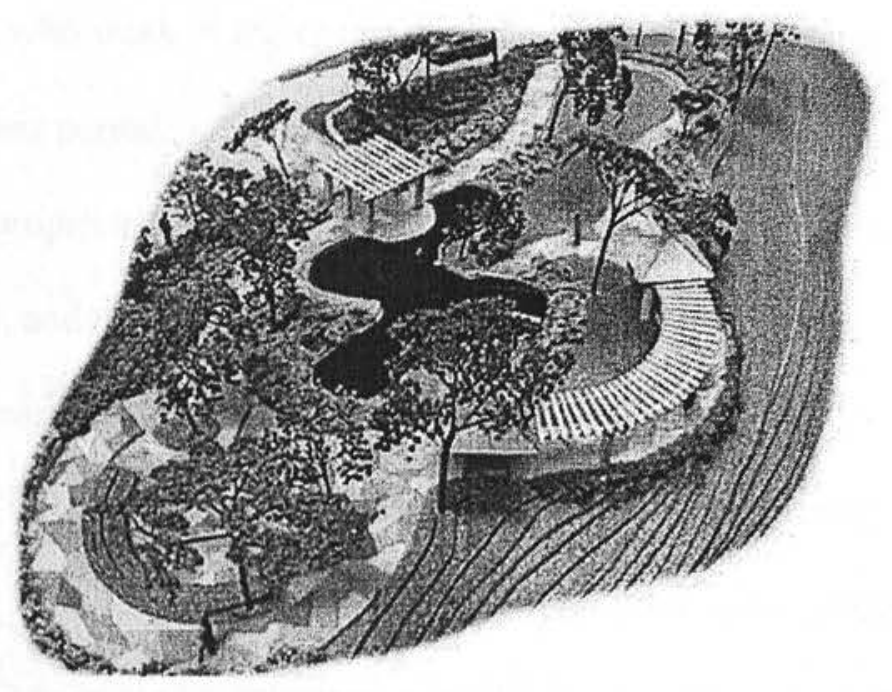

Figure 49: Traditional model. Previous page: Computer model. (Tai, 2000).

\section{$\underline{4.7}$ Conclusions}

Lessons learned by students:

The experimental portion of the project indicated that even though utilization of computers in some tasks was efficient, the nature of the design process does not readily yield itself to complete computerization yet, with the current technology available to students. This was reflected in the total hours spent on the project, as well as student satisfaction. Students learned which way the most efficient and effective method for accomplishing each step of the design process. For this reason, the final design for the project as a whole was completed with the use of both hand and computer methods. Lessons learned by educators. They realized it was important to:

1. Integrate $\mathrm{CAD}$ into the curriculum and structure $\mathrm{CAD}$ into the design studio. Teaching would be more effective if students in the class begin with the same or similar level of knowledge.

2. Know when and how to teach computers to students. $\mathrm{CAD}$ and $\mathrm{CAD}$ workstations should be integrated in the studio so that students can develop CAD skills along with the design project and "soak in" the studio environment. 
Students who work in the computer lab miss out on discussions held during the studio class period.

3. Have appropriate funding for hardware, software, facilities, computer personnel, upgrades, and maintenance.

4. Stay abreast of the emerging technologies and continue to educate and keep students interested in high-technology and sophisticated capabilities. For example, the faculty presented this exploratory case study at a conference utilizing Macromedia Director, a multi-media software program. Students as well as faculty were impressed with the capabilities of the software in making effective presentations and were interested in learning more about the subject of the presentation as well as about the software program.

5. Have administrators who understand and support computer technology. Administrators who believe $\mathrm{CAD}$ is not significant to the design discipline or that it should be taught strictly in the tech schools would not be supportive of any of the above noted points. This would obviously present a serious problem for development of computer use in design.

\section{8 $\quad \underline{\text { References }}$}

153 Tai, L. \& Yilmaz, U. (2000. August 4). "Between the Pen and the Mouse." CELA Conference Presentation, Guelph, Canada. 


\section{$\underline{5.1}$ Introduction}

Initially, a literature review was conducted to identify related research on the use of computers in landscape architecture practice and to provide a background for the current research project. Journal articles, professional periodicals, books, Web sites, interviews with researchers, CDs, and videos were used in the study. After a review of previous surveys on computer use in landscape architecture, a dearth of information was found regarding the impact of computer use as it is related to the design process and quality (and nature) of design. Therefore, the research in this study set out to explore this aspect of the practice of landscape architecture and its importance to the future implications of the profession.

\section{Benefits and limitations of the survey method}

Following the review of literature and of previous research work, a survey was determined to be the most appropriate research method for this study. Previous studies conducted on computer use in landscape architecture and allied fields have also used the survey method. It is very flexible, can be used to gather information for large or small numbers of people, is inexpensive, and can be designed for anonymity or to enable additional questioning at a later time. In addition, a survey presents questions in a consistent format and style, is impersonal and avoids problems that may develop in an interaction between an interviewer and a respondent (interviewer bias). Respondents can answer questions at their own pace as compared to an interview in which they must answer spontaneously (154 and 155). 
Although the survey method has advantages, there are also disadvantages. It is not easy to design a really good questionnaire and even well designed ones do not always manage to produce a high rate of response. This method is only effective for people who are comfortable expressing themselves. It requires more effort and is less likely to be completed, produces a wide range of answers which are often very difficult to categorize and thus to analyze, does little to ensure that all possible answers have not been overlooked. Questionnaires, however, are particularly effective when used to survey a small group of people who are used to expressing themselves in writing and those who are interested in the subject of the survey and who may have similar opinions on the matter (156).

Another disadvantage of this method is that it often lacks qualitative depth. Closedended questions, such as multiple choice are easy to complete and analyze; reduce the possibility of ambiguous answers and are often found as major components of surveys. However, these type of answers do not provide information about "different shades of opinion" (Moore, 1987, p. 17). To accommodate this problem, open-ended questions are used. However, these questions produce a wide range of answers that are often difficult to categorize and analyze. It is best to combine closed and open questions in a survey and end it with an open question to obtain the respondent's overall opinions (157).

Given the problems of the survey method, it is nevertheless very flexible and is widely used. An important aspect to remember is to keep the survey short and simple. "The basic rules to bear in mind: Get the beginning right, make it personal but unpatronizing, use simple words, keep the sentences short, keep sentence construction simple, use basic punctuation, use a large enough type size, avoid block capitals, and make it look 
attractive... avoid introducing bias into the questions" (Moore, 1987, p. 22-23). One good way to encourage response is to offer respondents the results of the survey when it is completed (158).

\subsection{Design of the pilot survey questionnaire}

A pilot questionnaire was designed with a combination of 33 closed and open questions. (Appendix 1, Figure 50: Pilot survey). Included were a broad range of general questions to more detailed questions. The pilot survey established the likely range of answers to questions about the effect of computer use in the landscape architecture design practice. It was organized into 3 categories of questions including 1)level of computer use, 2)effect of computers in the design process, and 3)effect of computers in related aspects of design.

\section{Testing, revising, and formatting of the questionnaire}

- Testing the questionnaire: During the fall of 1999 , the survey was tested through one-on-one interviews with 30 practicing landscape architects from small and large firms. Answers, questions and comments from the interviews helped in the formulation of the final survey. The pilot test assisted in determining clarity of questions, ease of response, and optimum length of questionnaire. Unclear or redundant questions were eliminated, existing questions were reformatted to be as concise as possible, and relevant new questions were added. See Appendix 1, Figure: 51 Comparison of pilot survey and final survey and Appendix 1, Figure 52: Final modified survey after pilot questionnaire

- Deletion and revision of questions: Some questions were redundant and eliminated. An example of this is can be found in the question, "Do you find compatibility a major problem when exchanging files with other offices?" This question was 
deleted, but restated in section II, question 4 as, "What do you experience when exchanging files with other offices?" 1)compatibility problems, 2)miscommunication due to lack of personal contact, 3)no problems, or 4)other. Since this was considered an important question, it was also asked in an open-ended manner in section $\mathrm{V}$, question 6 , "Name one instance in which the use of computers hurt instead of help?"

- Reformatting of questions: The pilot study revealed that it was difficult to obtain answers to questions that did not allow for expanded answers. Thus, many openended questions were incorporated. As these questions take longer to fill in, a low response rate for them was anticipated. An example of this can be seen in the question, "Has the computer changed the way you do work? Where do you spend time saved?" 1)finish one project before going on to another project, 2)spend more time writing memos, etc., 3)spend a lot of time searching on the internet, 4)spend a lot of time learning new programs. This question was restated and revised in Section I, question 7, "Has the way you think about design been affected by the computer? If so, explain."

- Addition of new questions: Interviews revealed circumstances in certain areas of the design practice, which were not originally considered, but were beneficial to the research. For example, several firms mentioned they had hired a number of junior employees with CAD skills. Therefore, the following question which was generated from the pilot questionnaire, "Has your firm increased, decreased or grown in size?" led to the discussion in the final survey about office employee structure and the status of junior employees. This resulted in the formulation of the question in section I, question 19, "Do you feel with expertise and skills in CAD you can 
1)easily advance in the firm, 2)be categorized as the $C A D$ person and must seek a position elsewhere in order to advance, or 3)does not apply to you." Some employees mentioned even though they had $\mathrm{CAD}$ expertise when they first obtained employment, they didn't necessarily want to be cast as a permanent " $\mathrm{CAD}$ operator." They believed that they were categorized as only being capable of working with $\mathrm{CAD}$ and they felt they could not advance from that position unless they moved to another firm.

\subsection{The final survey:}

- Formulating the questions on computer use: The survey in this research utilized some of the same categories of questions that were used in previous surveys noted in the literature review. Many of the previous survey questions covered 1)CAD use (if firms were using CAD), 2)firm size information (if firms were small, medium or large), 3)type of CAD package used (if firms were using 2-D, 3-D, etc.), 4)CAD applications (if firms were using AutoCAD, or other programs). In this survey, questions similar to these were utilized to provide the necessary introductory or background information. These questions include:

- "Do you use computers to draft or enhance your design work?"

- "How long has your office been using computers for these purposes?"

- "What size firm are you working with?"

- Formulating the questions on the effect of computers in design: The questions in this category were formulated to explore selected variables related to the use of computers and explore their impact on design in the following associated areas: 
1. Design process-landscape architects' use of computers, the way they think about design, and the impact of computers on the creativity and innovation of their design work.

2. Efficiency in the design process-the reasons for the efficiency, if it is attributed to computer use, and the effect of efficiency on the way landscape architects do design with the time saved.

The following questions addressed this goal:

- "Does the computer play a large role in your design process?"

- "Has the way you think about design been affected by the computer?"

- "Compared to traditional hand drawings, how is the quality of drawings now?"

- "Has designing on the computer affected your creativity?"

- "Do you feel that overall you save time by using computers in your design process?"

- "What do you do with the extra time saved?"

- "When you design details and symbols, do you draw them as needed or select from libraries and/or revise them as needed?"

- "Do you feel digital drawings are more or less accurate than traditional drawings?"

- "With the ease of making changes on CAD drawings, do you find yourself spending excessive time perfecting your drawings?"

- "When using the computer, how is your artistic quality affected?"

- "With the use of computers, are your drawings looking the same or are they very different each time?"

- "Do you use walk-throughs or 3-D imaging for presentations?"

- "How are projects archived at your firm?"

- "Are you digitizing your slide library?"

- "What type of software do you use for design?" 
- "List the most used software in your office for drawing."

- "What was the main reason you choose the software you are presently using?"

- "Have you switched software since computer design has been in use at your firm?"

- "Are you using 3-D modeling software?"

- "What are you creating on the computer which you feel is very innovative?"

- "What features would you consider would be ideal for landscape architects?"

- "What would be one feature you would want to perfect in regard to the computer?"

- "Would you say that the computer has improved your design work?"

- "Name one instance in which the use of computers hurt instead of help."

- "Have you been involved in a 'virtual' computer project?"

- "Do you do presentations with the use of the computer?"

- Formulating the questions on effect of computers in related aspects of design:

These questions were formulated to address secondary issues that may impact the way landscape architects design and/or practice. These include:

1. Communication in the design process-the way designs are communicated and the impact on the design practice.

2. Professionals in the design practice-the make up or number and mix of design professionals within the firm, requirement for new hires, and the size of the design office.

The following questions addressed this goal:

- "Has the integration of computers affected the make up of your firm?" 
- "Has the integration of computers affected the physical office size?"

- "How does your office execute computer design tasks?"

- "Do you feel with expertise and skills in CAD you can easily advance in the firm?"

- "Do you feel pressured to keep up with the computer graphics skills in order to stay competitive?"

- "Is the use of CAD required by your clients?"

- "When hiring a recent landscape architecture graduate what skills are you expecting from them?"

- "Do you use the Internet or e-mail?"

- "How has electronic communication affected the frequency of meetings with clients and consultants?"

- "Has the communication by e-mail or Internet with your clients, engineers, architects affected the integrity of your designs?"

- "What do you experience when exchanging files with other offices?"

- "Do you have a Web site?"

- "Have you received any inquiry about your firm from your web page?"

- "Have you gotten any new work from the web page?"

- "Does your web page have access to specific areas for your clients?"

- "How will the results of this survey affect your firm in relation to computer use?"

- "Do you feel you can you compete today without the use of computers?"

- "Do you feel the totally digital office will ultimately replace the traditional office?"

- "Do you annually budget for computer use?"

- "Do you think the use of computers in the landscape architecture office has helped promote the profession?" 


\subsection{Structure of the questions}

Care was taken in constructing the final survey for content, wording, format and placement. Considerations involved with the design of the questions were related to deciding on the question content, scope and purpose; determining the response format that will be used for collecting information from the respondent; and formulating the wording of the question to get at the point of interest.

The types of structured questions in the survey included fifteen (15) dichotomous questions (Yes/No response); fifteen (15) general closed-ended questions (multiple choice with "other"); seven (7) open-ended questions; five (5) multiple response items; eight (8) filter or contingency questions (respondent is asked one question in order to determine if respondent can answer the next question), and (2) questions that use a Likert scale. This is a popular and easy to use scale that asks the respondent to indicate the degree to which they agree or disagree with a statement. The number of choices provided is guided by the research question and may include a neutral position (usually an "odd" number of responses with the center being neutral). Other questions may have an "even" number of possible responses, forcing the respondent to answer one way or another with no neutral choice (159).

Considerations were made in the design of the questions so that each variable was to be exhaustive (have all possible options to answer question or "other" category when necessary). Only 15 questions in the survey were dichotomous, while most were classified under the other types of structured questions. The survey questions were carefully designed to obtain descriptive responses that would give greater insight to the way landscape architects were using computers. The potential difficulty of analyzing the data was recognized. 


\subsection{Format of the Web questionnaire}

The questionnaire survey was designed with the use of the Web authoring software, Macromedia Dreamweaver. The features in the software allowed for integration of questions with radio buttons, select boxes, check boxes, and text fields. See Appendix 1, Figure 53: Design format of the questionnaire survey and Appendix 1, Figure 54: Final Web survey.

In total, the final survey was made up of 50 questions. The objective of the final version of the survey was consistent with the pilot survey as the question also targeted responses regarding the impact of computer use on design.

\subsection{The Sample}

The full population sample for this survey consisted of 250 executive members of the American Society of Landscape Architects which is comprised of national and state officers. The ASLA is the primary professional organization of landscape architects in the United States with a membership of nearly 10,000 in 1999 . These executive officers were considered representative of their membership in that they are practicing landscape architects with diverse backgrounds, at various levels in their careers, from small and large firms and with various levels of computer skills. Statistical analysis indicated that respondents to this survey were not significantly different in terms of gender or regional location from those who failed to respond $\left(\chi^{2}=.972, \chi^{2}=.322\right.$, respectively). In addition, because all chapter members are eligible for service on the executive committee (with three exceptions, honorary, affiliate and student associate members), the sample should fairly and adequately represent professional landscape architects and their firms (Witte, personal communication, March 15, 2000). 


\subsection{Data Collection}

An e-mail explaining the nature and location of the survey and requesting their participation was sent to all ASLA Executive Members. They were able to access and complete the survey on the World Wide Web at http://people.clemson.edu/ tlolly. Data was automatically collected via the Web site and stored electronically.

Since e-mail is one of the primary modes of communication today, it was considered an acceptable means of communicating the request (160). This study was intended for firms who used computers. Since the aim was primarily targeted towards the impact of computer use on design and it would not have been effective to survey those who were not regularly using computers (161).

The main survey responses were received by e-mail within a few weeks of the request. Response rate (both the number and speed) was very good. Data were first collected and entered, and then later analyzed by using a statistical software program called Statistical Program in Social Sciences (SPSS). Frequency distributions of the raw data were generated and each variable was carefully analyzed. Some of the string variable data were recategorized or "collapsed and reduced into smaller number of categories in order to better present and understand the data" (Nachmias, 2000, p. 60). Some of the data were collapsed for cross-tabulation purposes. In collapsing the data, care was taken to maintain the validity of the original intent (Appendix 2, Table 7 and 8: Data reduction categories). In the event data could not be appropriately recategorized, they were grouped with the "missing" category. 
- Data for some questions were recoded to reduce the categories while maintaining the original intent of the questions. Example questions which were recoded are described below:

- Computer design tasks executed in an office was reduced from "out-sourced," "in-house CAD specialist," "in-house graphic artist," "task delegated to design team" to "out-sourced" or "in-house." This question pertained to the execution of work inside or outside of the firm. Therefore, recoding the question did not impact the original intent of the question.

- The type of software used by respondents for design was reduced from "2-D CAD," "3-D CAD," "rendering," “animation," "imaging," "graphic" to "basic"(2-D CAD and others), "intermediate"-(3-D CAD and others), "advanced"(animation and others). This question pertained to the types of software used by design professionals in order to determine their levels of expertise and was categorized into the three separate dimensions. As the dimension increases, the level of complexity also increases.

- Data for string variables were coded based on content analysis. The open-ended questions resulted in long answers, which were very helpful descriptive data for the later part of this research. However, coding the data was essential to review and analyze the data. Examples of coded data are as follows:

- The most used software in the firm was coded to include "AutoCAD only," "AutoCAD and others," "Microstation," "Microstation and others." This 
question was designed to verify if AutoCAD was the industry standard as was indicated in the literature review. As the content of the data was analyzed, Microstation was revealed as another leading industry standard and was therefore added as one of the data categories.

- Innovative work created on the computer was coded to "3-D models," "composite images," "proposed design with existing conditions," and "multimedia presentations."

- Features considered ideal for landscape architects were coded to "3-D modeling and walk-throughs," "speed, ease of power and use," "cut-fill capabilities," "slope analysis," "estimating and lighting," and "a program that does everything."

- Features to perfect were coded to include "speed, ease, and power," "technical drawings," "compatibility," "3-D modeling," "less rigid graphics," "more intuitive," "more/better symbols," "precision," "calculations," and "other."

- Instances in which computers hurt instead of help were coded to include "time consumption/high learning curve," "equipment failure," "poor design based on computer drafting limitation," "mistakes due to operator error," "software incompatibility," "drawings look finished when not," and "other."

- Data were recoded for cross-tabulation purposes. Examples of recoded data used in significant cross-tabulations are as follows: 
- Length of time of computer use was reduced from "1 year," "2-3 years," "5-10 years," and " $10+$ years" to " $1-10$ years," and " $10+$ years." The data were reduced in order to present the data in clear 10-year periods. Since literature review indicated landscape architects only started to use computers during the mid 1980s the data reduction would achieve responses for the first $\leq 10$ year period (1980-1990) and the $>10$ year period (1990-2000). This would give a good indication of the percentage of respondents who have been using computers for the more recent period in comparison to those who have used the computer for quite a long period of time.

- The type of firm that respondents work in was reduced from "small $(1-\leq 10)$, , "medium (>10 - $\leq 20)$," and large (>20) to "small $(1-\leq 10)$," and "large (>10)." The data reduction were made based on fact that in the landscape architecture industry, a firm with $\leq 10$ employees is typically considered a small firm and a firm with $>10$ employees is typically considered a medium to large firm.

- The use of computers to accomplish various tasks in the design process (including qualification presentations, conceptual design, design development, schematic design, working drawings, and final presentations) was reduced from a ranking of "1," " 2, , " 3, , " 4, , " 5, , "6" to " $1-3$ " for low use and "4-6" for high use. This question deliberately used a 6-item scale in order to require respondents to be on one side or another and avoid the tendency for them to choose a middle position.

- The skills expected from a new hire in the area of computer drafting, traditional presentation, traditional drafting, and computer presentation were reduced from 
a ranking of " 1, , " 2, ," "3," " 4, ," " 5 " to " $1-2$ " for small role, " 3 " for neutral role and "4-5" for large role.

The cross-tabulations that were generated compared the relation between 1)firm size and other variables, as well as, 2)two selected variables that may have had a relationship with regard to the effect on design, computer use, design process, and other associated aspects. The list of cross-tabulations that are statistically significant is shown in Appendix 2, Table 9.

\subsection{Supplemental interviews conducted}

\subsubsection{Supplemental interviews conducted on the use of Web sites}

Since the study in this research was technologically oriented, incorporating the use of the World Wide Web was an important component to the overall study. The literature review about allied fields indicated that firms who had a Web site did not use it for marketing or for obtaining work. There was no information covering this for the landscape architecture field (162). Thus, several questions were incorporated about the Web in this survey.

Since the questionnaire was considerably long, supplemental interviews were conducted by e-mail in the spring of 2000 to further canvass how landscape architects were using their Web site and to determine whether the Internet had replaced traditional means of marketing. They were asked two questions: 1)"Have you had any responses to your Web site?" and 2)“Have you received any work from your Web site?"

60 firms who actually had a Web site were asked these two questions and 12 responded (a 20\% response rate). These firms were found through a search on the Internet by using 
'key words', such as "landscape architecture" and "landscape architecture projects." The responses were collected, analyzed, and supplemented to the Web survey responses.

\subsubsection{Supplemental interviews conducted on the use of 3-D modeling}

Again, because of the length of the survey questionnaire, supplemental telephone interviews were conducted to ascertain additional opinions regarding the advantages and disadvantages of 3-D computer modeling. This was done to gain further insight as to how landscape architects were utilizing 3-D capabilities and the impact on design creativity. 35 firms were canvassed in the spring of 2000 and 25 professionals of varying positions and experience responded (a $71 \%$ response rate). Those who were interviewed were first asked whether or not they were knowledgeable in this area and if not, they directed the interview to another professional in the firm who was knowledgeable. The questions asked are outlined below and the responses were collected, assessed and supplemented to the Web survey responses.

1) Does 3-D modeling play an important role in your design process and presentations?

2) Has the way you think about design been affected by 3-D modeling?

3) Has designing with 3-D modeling enhanced your designs?

4) Does the use of 3-D modeling help you to save time in the design process?

5) When using 3-D modeling, do you feel a sense of artistic quality is lost?

6) Do you feel pressured to keep up with computer technology in 3-D modeling to stay competitive?

7) Is the use of 3-D modeling required by clients? 
8) Has a client ever not understood what he is looking at when shown an animation or walk-through of a design?

9) Have you gotten a job or won over a client due to 3-D modeling and presentations?

10) What programs do you use for 3-D modeling and presentations?

\section{$\underline{5.9}$ Conclusions}

Conclusions of this study were derived from a comprehensive assessment of the results of the statistical analysis, descriptive data from interviews and the literature review. 
154 Moore, Nick. (1987). How to do Research. Dotesios Printers Ltd, Bradford-onAvon, Wiltshire.

155 Lang, G and Heisss, G. (1984). A Practical Guide to Research Methods. University Press of America, Inc. Lanham, MD, 120.

156 Moore, Nick. (1987). How to do Research. Dotesios Printers Ltd, Bradford-onAvon, Wiltshire.

157 Moore, N. ibid.

158 Moore, N. (1987) op. cit.

159 True, J.A. (1989). Finding Out: Conducting and Evaluating Social Research. 2nd ed. Wadsworth Publishing, Belmont, CA, 317.

160 Lang, G and Heisss, G. (1984). A Practical Guide to Research Methods, University Press of America, Inc. Lanham, MD, 120.

161 Dommeyer, C \& Moriarity, E. (1999. Winter). "Comparing Two Forms of an Email Survey: Embedded vs. Attached." International Journal of Market Research, 42, 39.

162 Jacknain, G. (2000). "High Tech Firms Report High Productivity." Retrieved December 10, 2000 from the World Wide Web:

http://www.e-architect.com/news/aiarchitect/oct00/tech.asp 


\section{$\underline{6.1}$ Introduction}

In the first stage of the analysis, a frequency distribution was generated for each of the variables using the raw data (Appendix 2, Figure 55: Frequencies). Following this, cross-tabulations, the analysis of the relationship between two variables that have been organized in a bivariate table, was utilized. The cross-tabulations were set up to determine the relation between 1)firm size and various other variables, as well as, 2)two variables that may have a relationship when it comes to design, computer use, design process, and other related aspects. (Appendix 2, Table 9: List of crosstabulations that are statistically significant). Chi-square $\left(\chi^{2}\right)$ tests were utilized to test for significant relationships between variables organized in a bivariate table (163). The alpha value of 0.10 was used as a measure of a statistical significance.

In consultation with Dr. James Witte, a reputed statistician, an alpha value of 0.10 was used as a measure of a statistical significance (instead of $\mathrm{p}<.05$ and $\mathrm{p}<.01$ ). He said, "There are two routes to increasing power: One thing you can usually do is collect more information-use a larger sample size. Of course you have to weigh the gain in power against the time and expense of having more participants or gathering more data. The second thing you can do is increase your risk of making a Type I error-increase the chance that you will find a relationship when it's not there. In practical terms, you can do that statistically by raising the alpha level. For instance, instead of using a .05 significance level, you might use 0.10 as your cut off point." (Witte, personal communication, March 15, 2000). Statistical power refers to the probability of observing an effect that is real. There is necessarily a tension between the two: decreasing the probability of a Type I error, and thereby reducing the probability of 
regarding sampling differences as real effects, necessarily reduces the power of your analysis and increases the probability of a Type II error.

Phi $(\varphi)$, a variation of Pearson product moment correlation coefficient (Pearson's r), was used to determine the measure of association of $2 \times 2$ tables, while Goodman and Kruskal's Gamma was used for tables greater than $2 \times 2$. Gamma is "a symmetrical measure of association suitable for use with ordinal variables or with dichotomous nominal variables and provides an indication of the strength and direction of association between the variables. A symmetrical measure of association is a measure whose value will be the same when either variable is considered the independent variable or the dependent variable. Lambda is an asymmetrical measure of association, and is suitable for use with nominal variables. It provides an indication of the strength of an association between the independent and dependent variables." (76).

For this study, measures of association were considered to be weak if they were greater than zero but less than 0.4 . Moderate associations comprised those $\geq 0.4$ and $\leq 0.7$. Any measure $\geq 0.7$ was considered a strong association (Witte, personal communication, March 15, 2000).

\section{2 $\quad$ Analysis of frequency tables}

The effect on Design Process

Survey respondents were from firms of varying sizes. $42.7 \%$ worked in small firms (1$\leq 10$ employees), $17.7 \%$ in medium firms ( $>10-\leq 20$ employees), and $39.6 \%$ in large firms ( $>20$ employees) firms ( $n=96$ ). Collapsed data indicated $42.7 \%$ were from small firms (1- $\leq 10$ employees) and $57.3 \%$ were from medium and large firms $(>10$ employees). $5 \%$ of the respondents indicated they used computers for 1 year, $13.9 \%$ for 
$2-3$ years, $52.5 \%$ for $5-10$ years, and $28.7 \%$ for $10+$ years $(n=101)$. Collapsed data indicated $71.3 \%$ used the computer for $1-10$ years and $28.7 \%$ used it for $10+$ years.

When asked, "What type of software do you use for design?" There were a variety of responses. Collapsed data indicated $46.7 \%$ of them were using basic software (2-D and others), $40 \%$ were using intermediate software (3-D and others), and only $13.3 \%$ were using advanced software (animation and others)(n=75)(Appendix 2, Table 8: Data reduction).

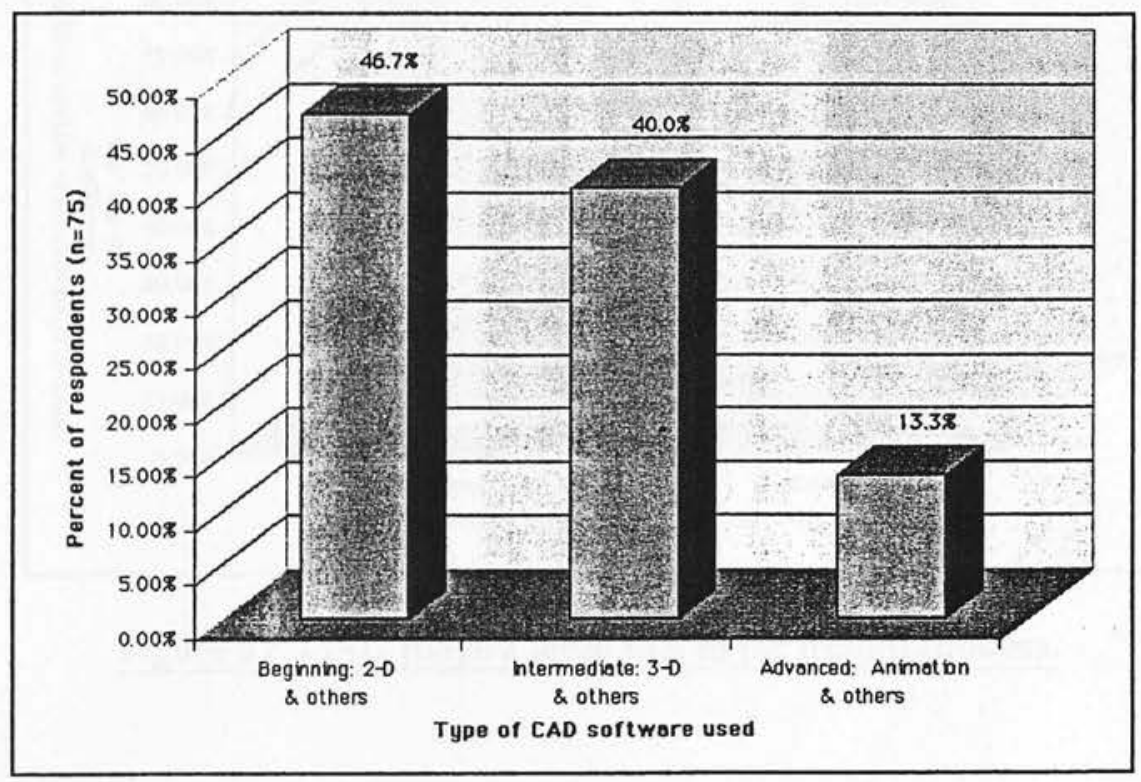

Figure 56: Type of CAD software used.

$32.6 \%$ were using AutoCAD only, $55.8 \%$ were using AutoCAD and other types of software, $9.5 \%$ were using Microstation only, and $2.1 \%$ were using Microstation and other types of software $(n=95) .63 .6 \%$ found 3-D capabilities to be an important feature to have in a software package while $36.4 \%$ did not $(n=77)$. Most of the respondents (68.4\%) stayed with the same software while $31.4 \%$ switched software $(n=98) .75 .2 \%$ felt pressured to keep up with computers while $24.8 \%$ ( $n=101)$ did not. Thus, it is not surprising to have found $78 \%$ of the respondents annually budgeting for computers 
while $22 \%$ did not $(n=100)$. A majority of them $(88 \%)$ had clients who required the use of $\mathrm{CAD}$ while $12 \% \operatorname{did}$ not $(\mathrm{n}=100)$.

$80.4 \%$ of the respondents believed computers played a large role in their design process, while $19.6 \%$ did not $(n=102)$. Figure 57 shows that $C A D$ plays a large role in the design process in large and small firms.

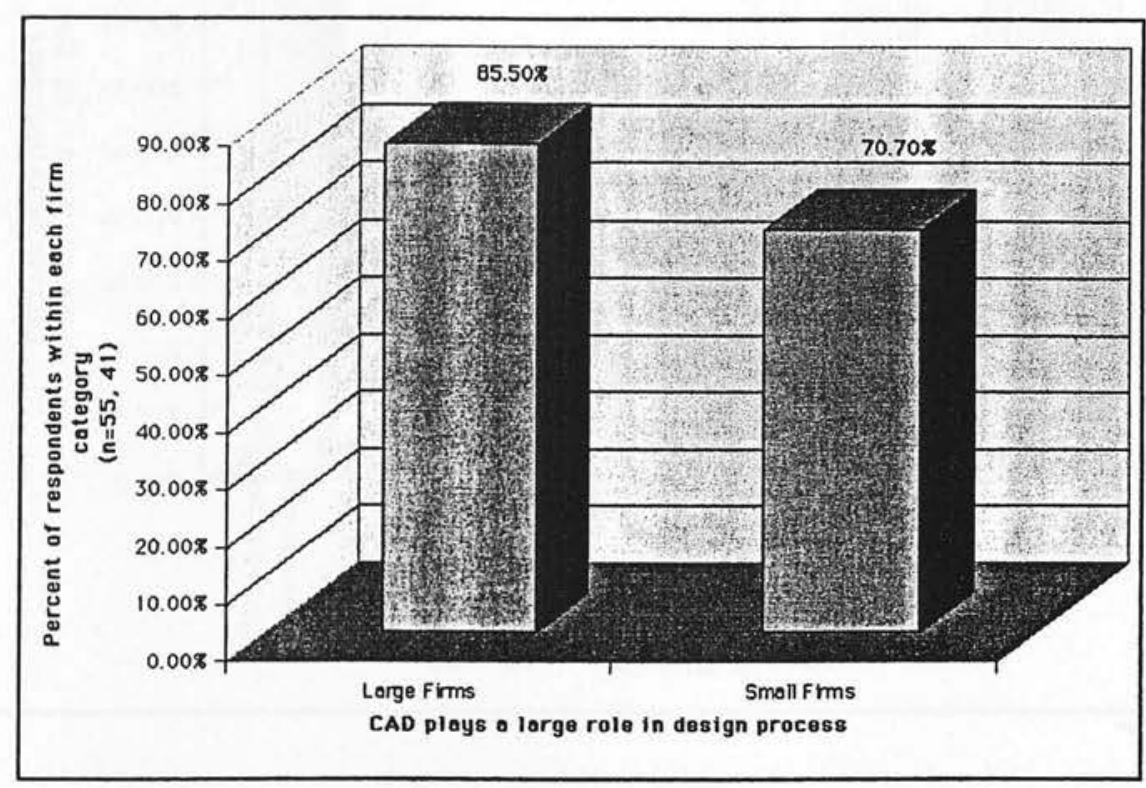

Figure 57: CAD plays a large role in the design process.

Survey respondents ranked the level of computer use from $1=$ small role to $6=$ large role. Collapsed data showed that the largest impact was in the area of working drawings in which $89.5 \%$ of the respondents thought computers played a large role, and $10.5 \%$ thought it played a small role $(\mathrm{n}=95)$ (Appendix 2, Table 7: Data reduction). This was followed by final presentations in which $79.8 \%$ of the respondents thought computers played a large role, and $20.2 \%$ thought it played a small role $(n=89)$. For firm qualification presentations, $79.5 \%$ of the respondents thought computers played a large role, and $20.5 \%$ thought they played a small role $(n=83)$. For design development, $52.7 \%$ of the respondents thought computers played a large role, and $47.2 \%$ thought 
they played a small role $(n=93)$. For schematic design, $41.8 \%$ of the respondents thought computers played a large role, and $58.2 \%$ thought they played a small role $(\mathrm{n}=91)$. For conceptual design, $18.1 \%$ of the respondents thought computers played a large role, and $81.9 \%$ thought it played a small role $(\mathrm{n}=94)$.

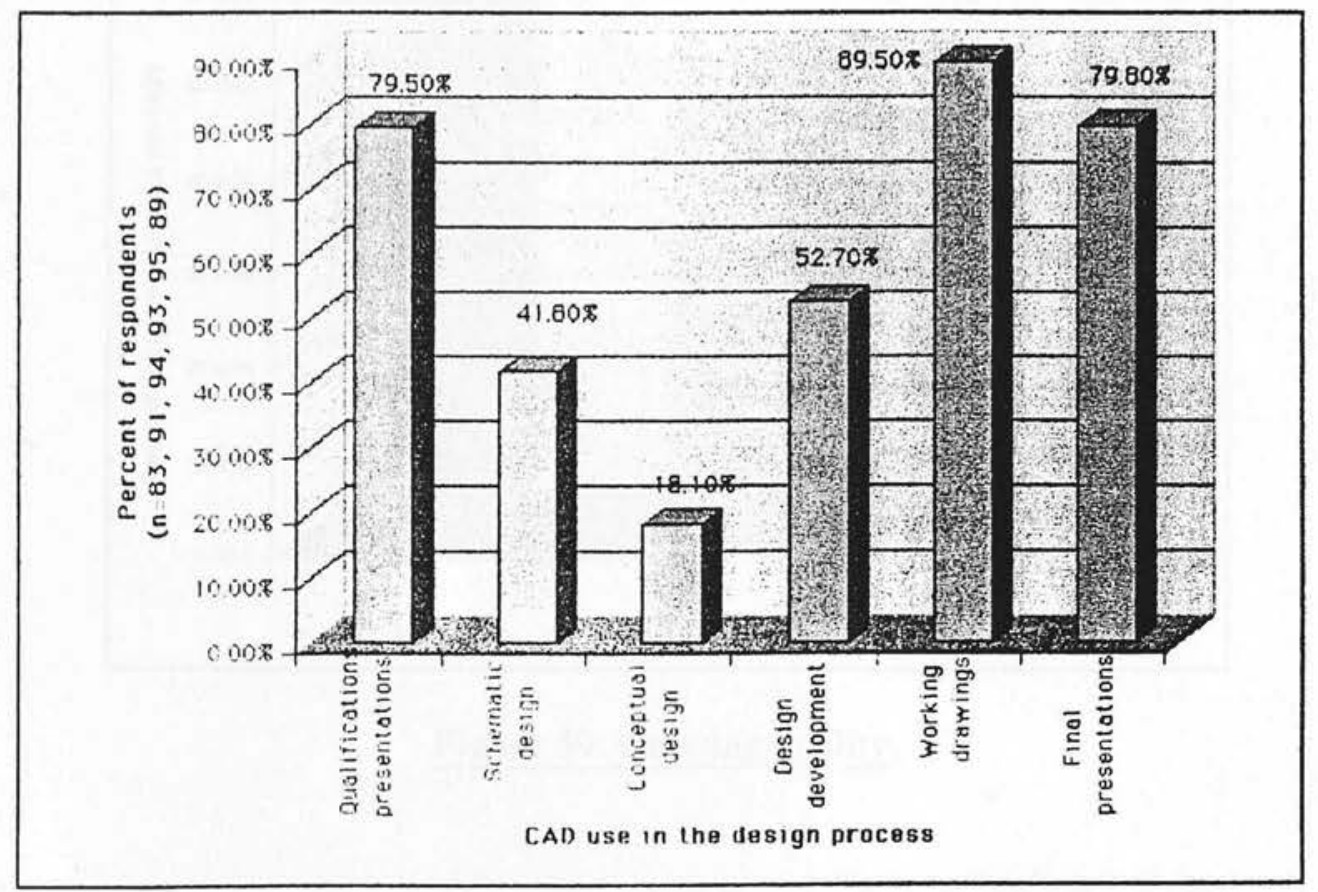

Figure 58: $\mathrm{CAD}$ use in the design process.

$72.4 \%$ percent of the respondents said that computers improved their design work and $27.6 \%$ said they didn't ( $\mathrm{n}=98$ ). When asked, "What are you creating on the computer which you feel is very innovative?" $19.6 \%$ responded with $3-\mathrm{D}$ models, $11.8 \%$ with composite images, $7.8 \%$ proposed design with existing conditions, $5.9 \%$ with multimedia presentations, and $54.9 \%$ with other $(n=51)$. 
Benefits of Computer Use

$59.2 \%$ of the respondents claimed that compared to traditional drawings, their drawings were better now, $13.3 \%$ said they were worse, and $27.6 \%$ said they remained the same $(n=102)$.

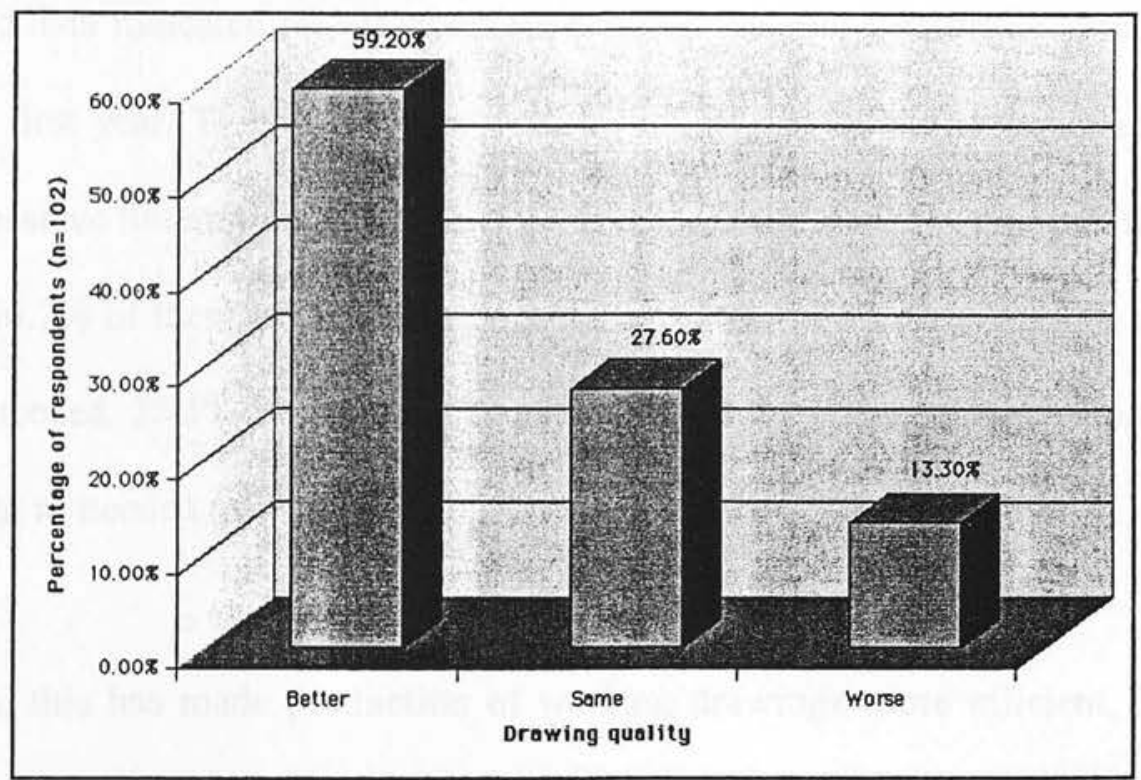

Figure 59: Drawing quality.

$25.5 \%$ said they helped creativity, $29.4 \%$ said computers hindered their creativity, and $45.1 \%$ said they did not affect their creativity $(\mathrm{n}=102)$.

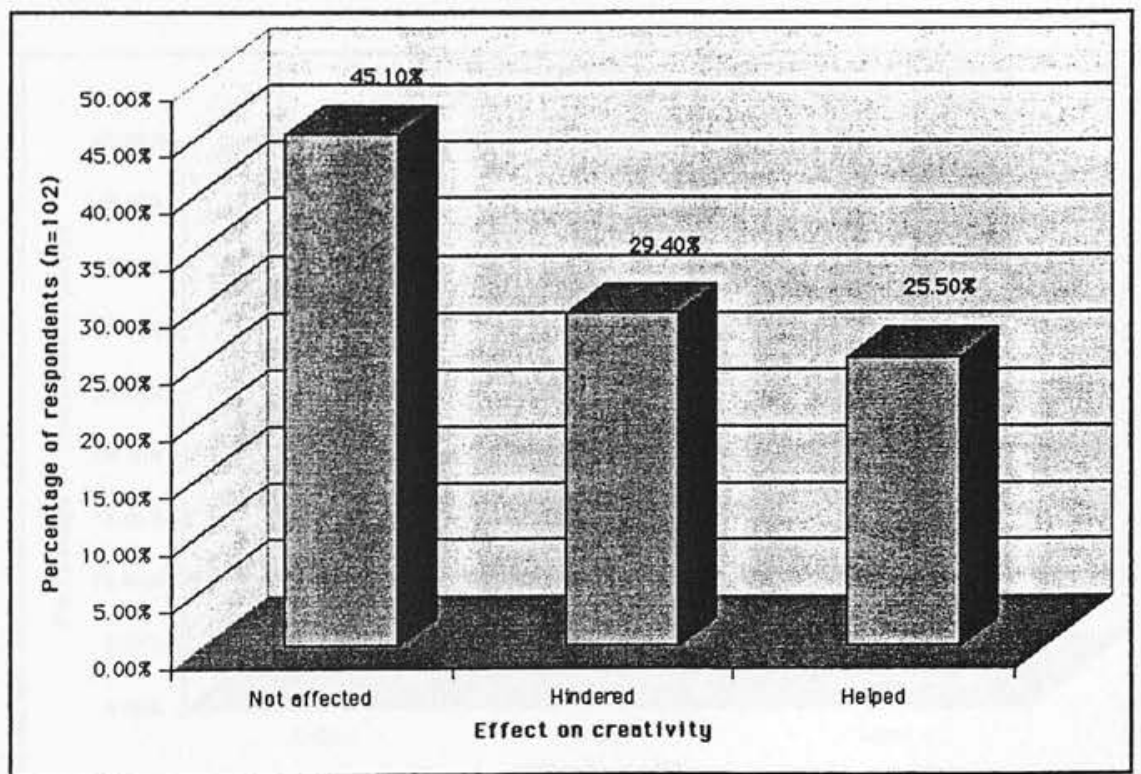

Figure 60: Effect on creativity. 
$70.4 \%$ reported that computers saved time while $29.6 \%$ responded they did not $(n=98)$. In fact, $56.3 \%$ indicated that they saved time during the first year of computer use, $25 \%$ in the second year of computer use, and $18.8 \%$ in the third year of computer use $(n=64)$. Collapsed data indicated $56.3 \%$ saved time during the first year and $43.8 \%$ saved time after the first year. This is the case even though $49.5 \%$ of the respondents said they spent excessive time trying to perfect their drawings, while $50.5 \%$ said just the opposite $(\mathrm{n}=99) .56 .7 \%$ of them selected details and symbols form existing libraries and revised them as needed, $35.1 \%$ used details and symbols from a library they created, and $8.2 \%$ drew them as needed $(\mathrm{n}=97)$.

Although, this has made production of working drawings more efficient, $39.8 \%$ said their artistic quality was poorer, $18.3 \%$ said it was better and $41.9 \%$ said there was no change in their artistic quality $(\mathrm{n}=93)$. In addition, $86.2 \%$ thought their drawings were consistently looking the same, and $13.8 \%$ said their drawings were very different each time $(n=87)$.

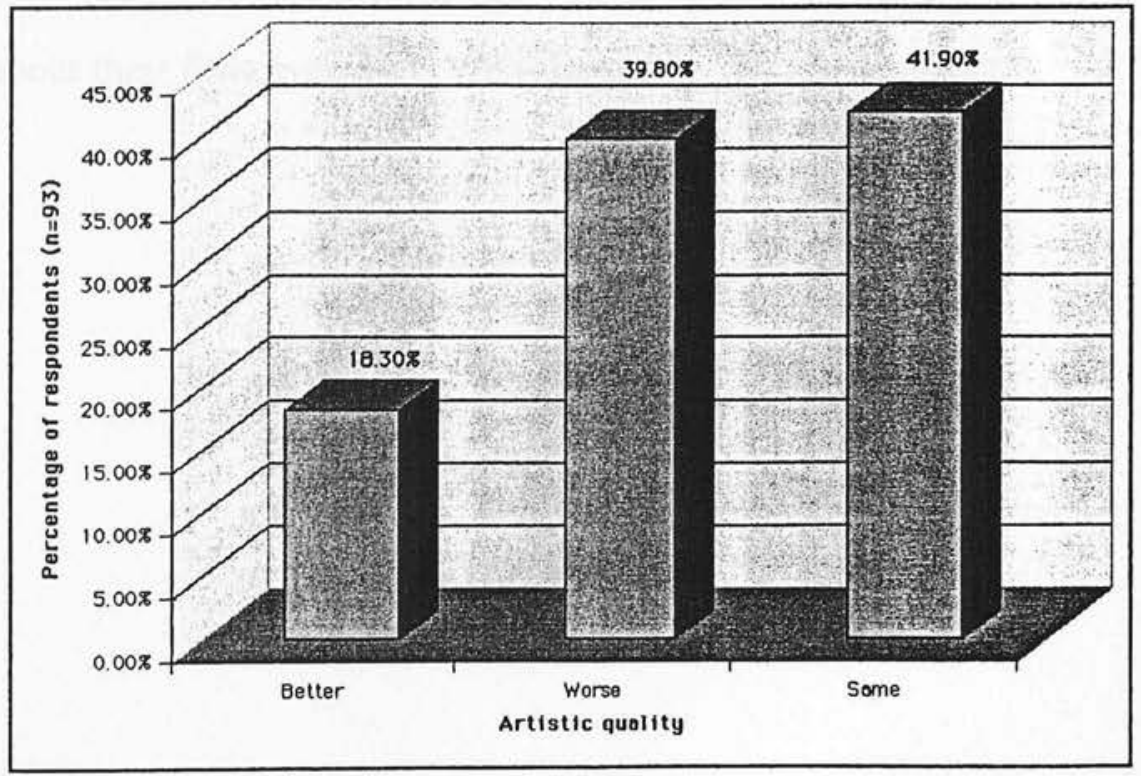

Figure 61: Artistic quality. 
Landscape architects are also saving time through electronic communications. $70.8 \%$ of the respondents indicated they had a Web site, while $29.2 \%$ indicated they did not $(\mathrm{n}=96)$.

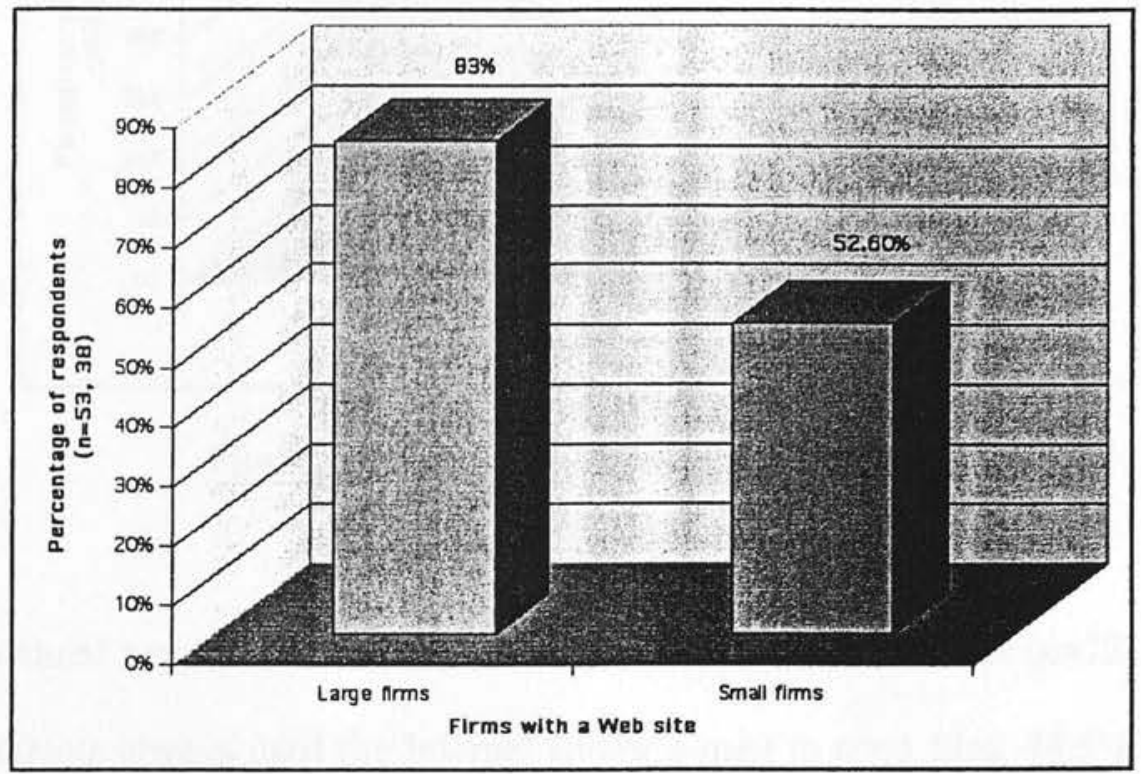

Figure 62: Firms with a Web site.

$65.7 \%$ said their Web site was designed in-house, while $34.3 \%$ said they were designed by an outside design professional $(\mathrm{n}=67) .65 .8 \%$ said that they have areas in their Web site for client access, while $34.2 \%$ said they did not ( $\mathrm{n}=73$ ). In addition, $72.2 \%$ received inquiries about their firm from their Web site and $27.8 \%$ did not $(n=72)$. 


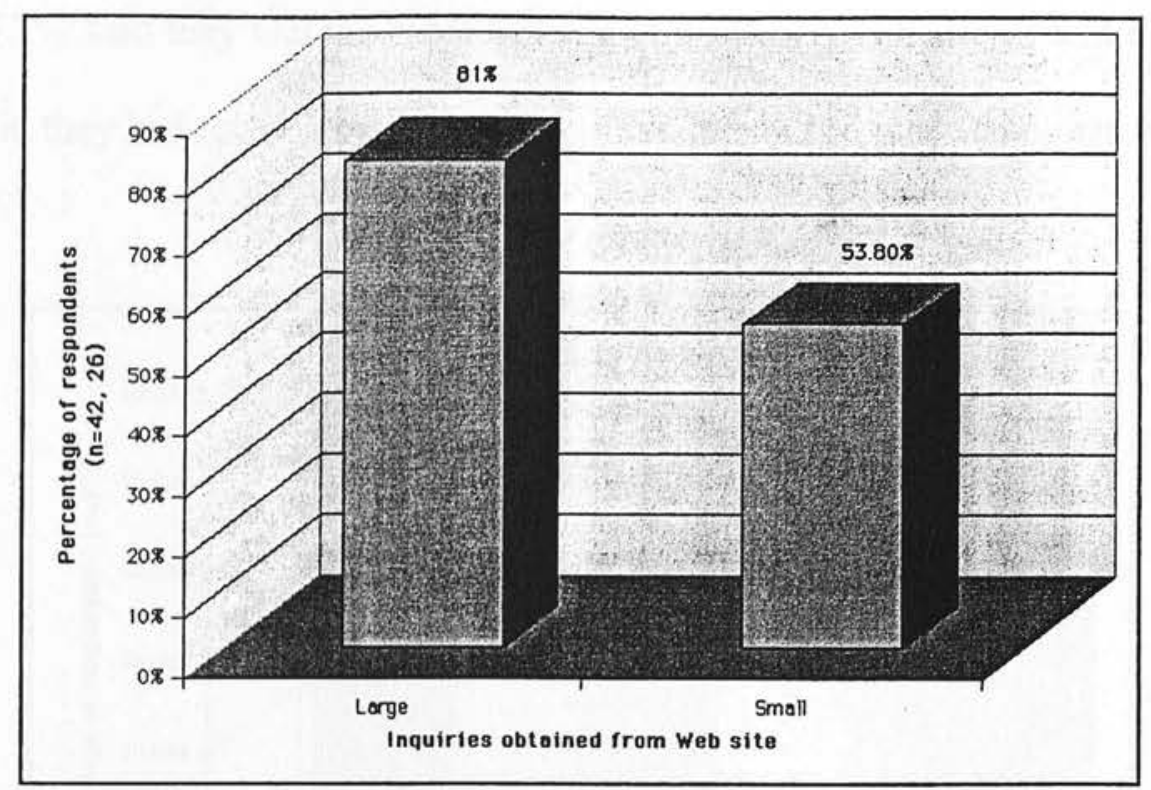

Figure 63: Inquiries obtained from Web site.

$38.9 \%$ obtained new work from their Web site while $61.7 \%$ did not $(n=72) .16 .8 \%$ of the respondents always used the Internet and/or e-mail to send files, $48.5 \%$ often used them to send files, and $34.7 \%$ seldom use them to send files $(n=101)$.

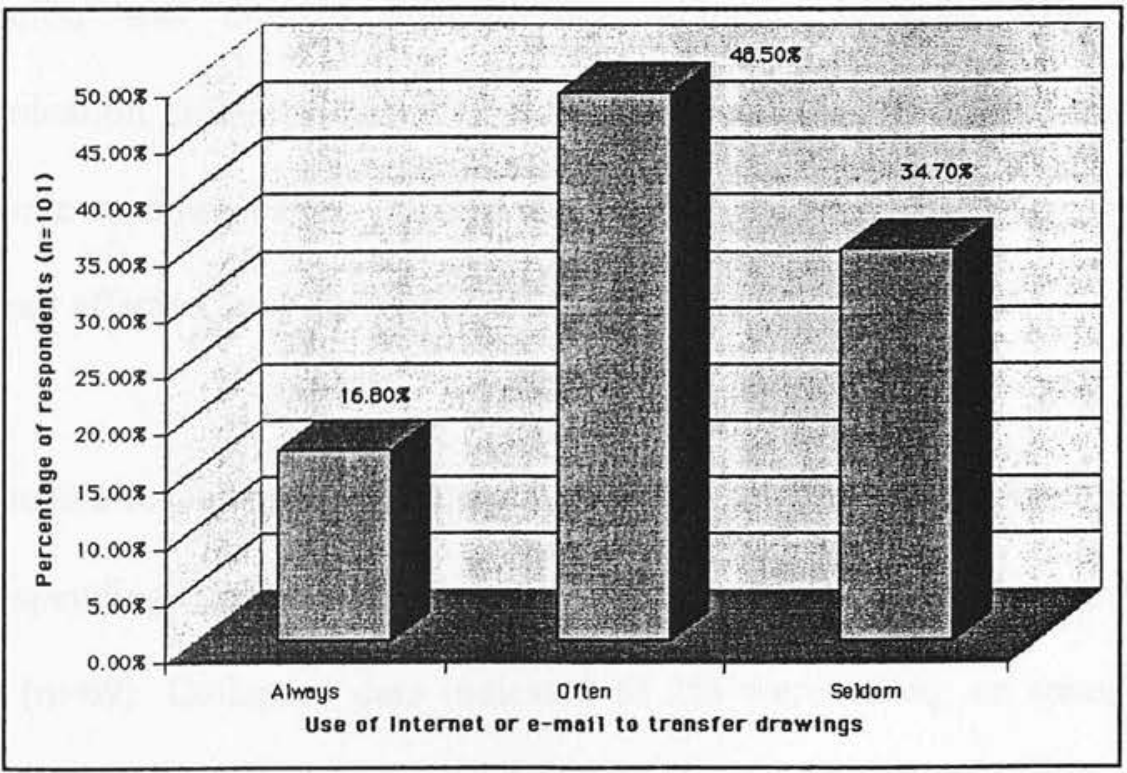

Figure 64: Use of Internet or e-mail to transfer drawings. 
While $55.7 \%$ said they had the same number of meetings with clients and consultants, $42.3 \%$ said they had fewer meetings, and $2.1 \%$ said they had more meetings ( $n=97$ ).

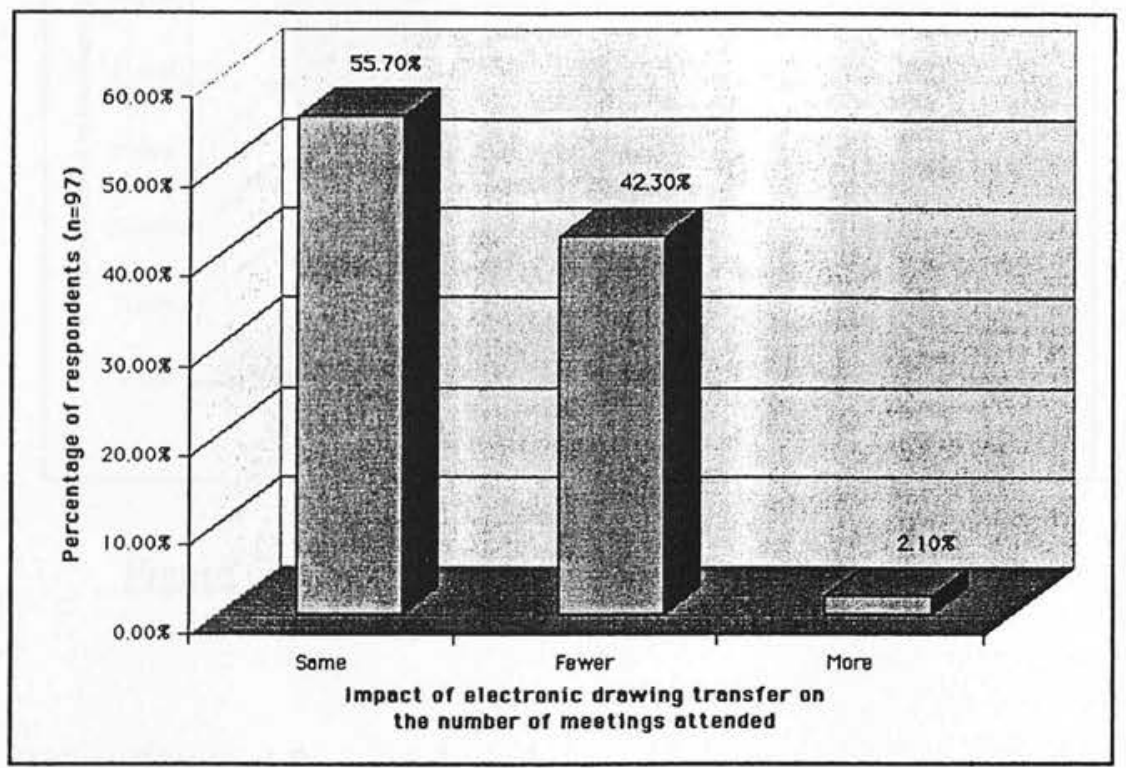

Figure 65: Impact of electronic drawing transfer on the number of meetings attending.

According to $44 \%$ of the respondents, the major draw-back from electronic communication was due to compatibility problems between files, $10 \%$ had miscommunication problems, but $46 \%$ had no problems ( $\mathrm{n}=100)$. Additionally, $51.5 \%$ said electronic communication affected the integrity of their drawings, while $48.5 \%$ said it had not affected their drawings ( $\mathrm{n}=97)$.

$60.9 \%$ of the landscape architects were using the time saved to do more work, $37.7 \%$ of them were spending time doing other design tasks, and only $1.4 \%$ were spending time for leisure $(n=69)$. Collapsed data indicated $61.2 \%$ were taking on more work and $38.8 \%$ were spending more time doing other design tasks. 


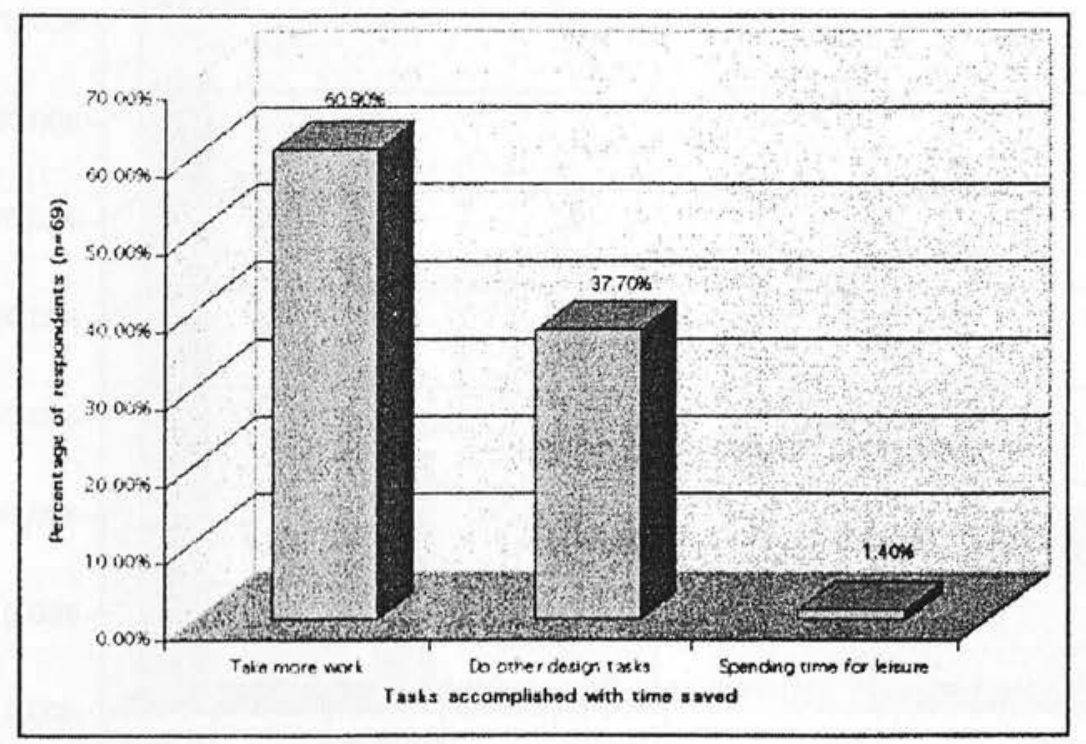

Figure 66: Tasks accomplished with extra time saved.

\section{Impact on Office Size and Personnel}

$62.6 \%$ of the firms remained the same size, $24.2 \%$ are larger with more employees, and only $6.1 \%$ are larger with fewer employees, $5.1 \%$ are smaller with more employees, and $2.0 \%$ are smaller with fewer employees $(n=99)$ as a result of computer integration. $43.6 \%$ of the respondents reported there were no changes in the make up of firm with computer use, $42.6 \%$ reported more junior landscape architects with CAD knowledge, $11.9 \%$ reported more computer technicians, and $2.0 \%$ reported fewer senior landscape architects $(n=101)$. 


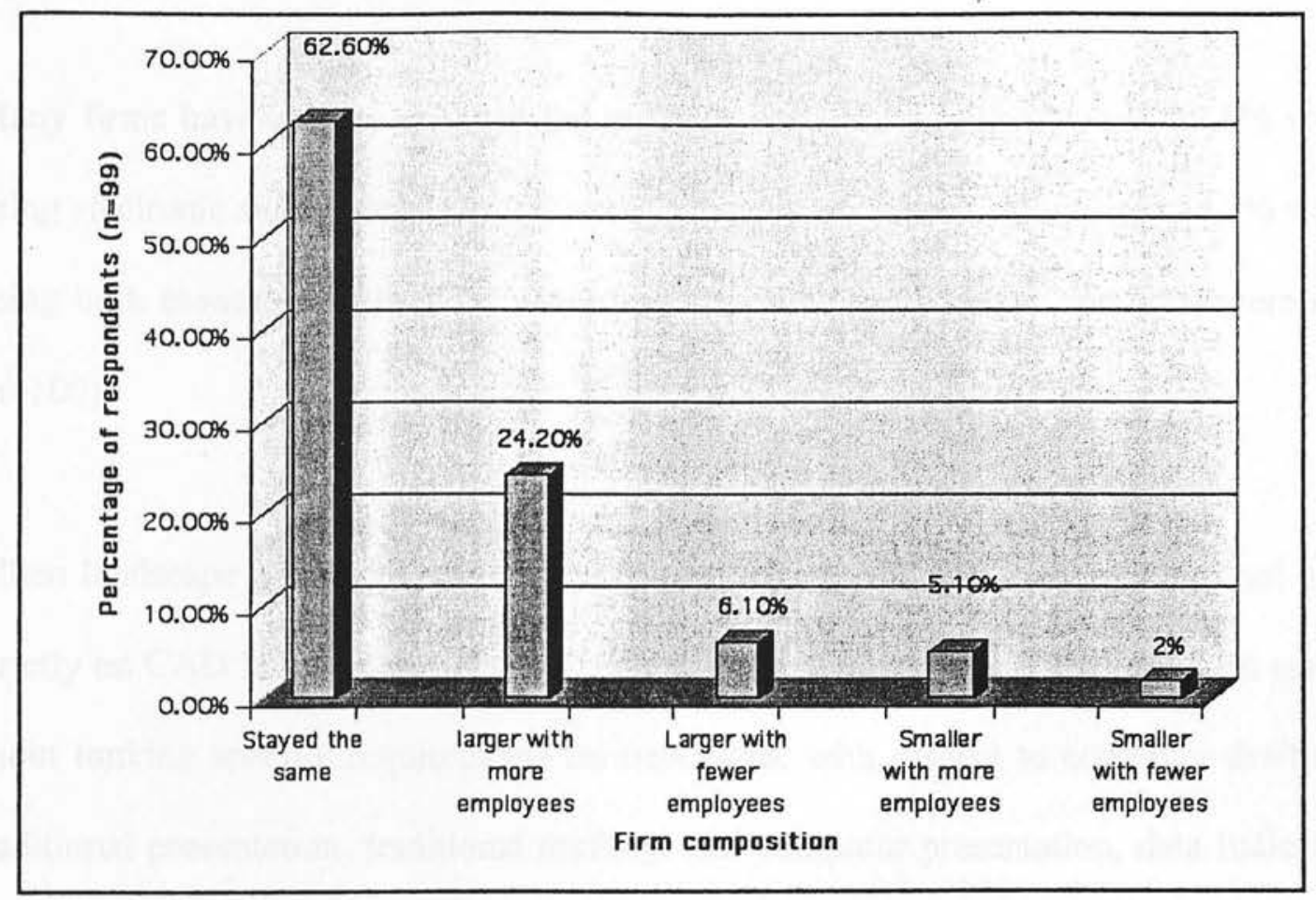

Figure 67: Firm composition.

$59.2 \%$ of the respondents indicated computer tasks were delegated to design team members within the office, $32.7 \%$ were delegated to in-house $\mathrm{CAD}$ specialist or operators, $2.0 \%$ were delegated to in-house graphic artist and only $6.1 \%$ were outsourced $(n=98)$. Collapsed data indicated $93.9 \%$ of the work were executed in-house while $6.1 \%$ were out-sourced.

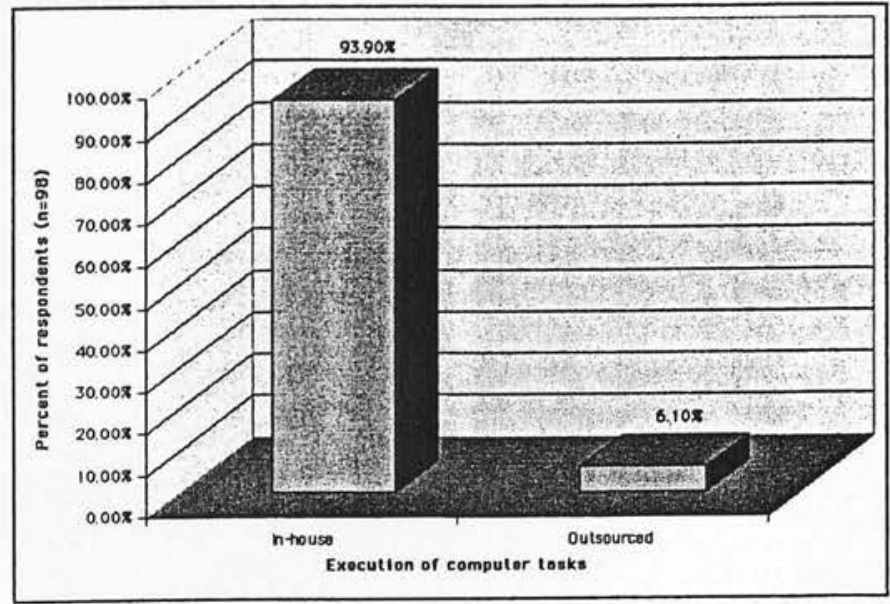

Figure 68: Execution of computer tasks. 
Many firms have already changed the methods for archiving their work. $19.8 \%$ were using electronic storage media, $5.9 \%$ were still using traditional means, and $74.3 \%$ were using both means $(n=101) .43 \%$ were digitizing their slide library and $57 \%$ were not $(n=100)$.

When landscape architects sought new employees, $92.5 \%$ indicated they did not hire strictly on CAD knowledge and only $7.5 \%$ said they did (n=93). However, when asked about ranking specific requirements for new hires, with respect to computer drafting, traditional presentation, traditional drafting, and computer presentation, data indicated the importance of $\mathrm{CAD}$ proficiency. Survey respondents ranked the various expectations (Appendix 2, Table 7: Data reduction). For computer drafting, $52.9 \%$ of the respondents thought it was an important hiring criterion, $23 \%$ felt neutral about it, and $14.9 \%$ thought it was of low importance $(n=87)$. Regarding traditional presentation skills, $33.7 \%$ felt it was important, $32.6 \%$ felt neutral, and $33.7 \%$ thought it was of low importance $(n=86)$. For traditional drafting skills, $38.1 \%$ felt it was important, $26.2 \%$ felt neutral, and $35.7 \%$ thought it was of low importance $(n=84)$. For computer presentation skills $47.1 \%$ felt it was important, $19.6 \%$ felt neutral, and $17.6 \%$ thought it was of low importance $(n=86)$. 


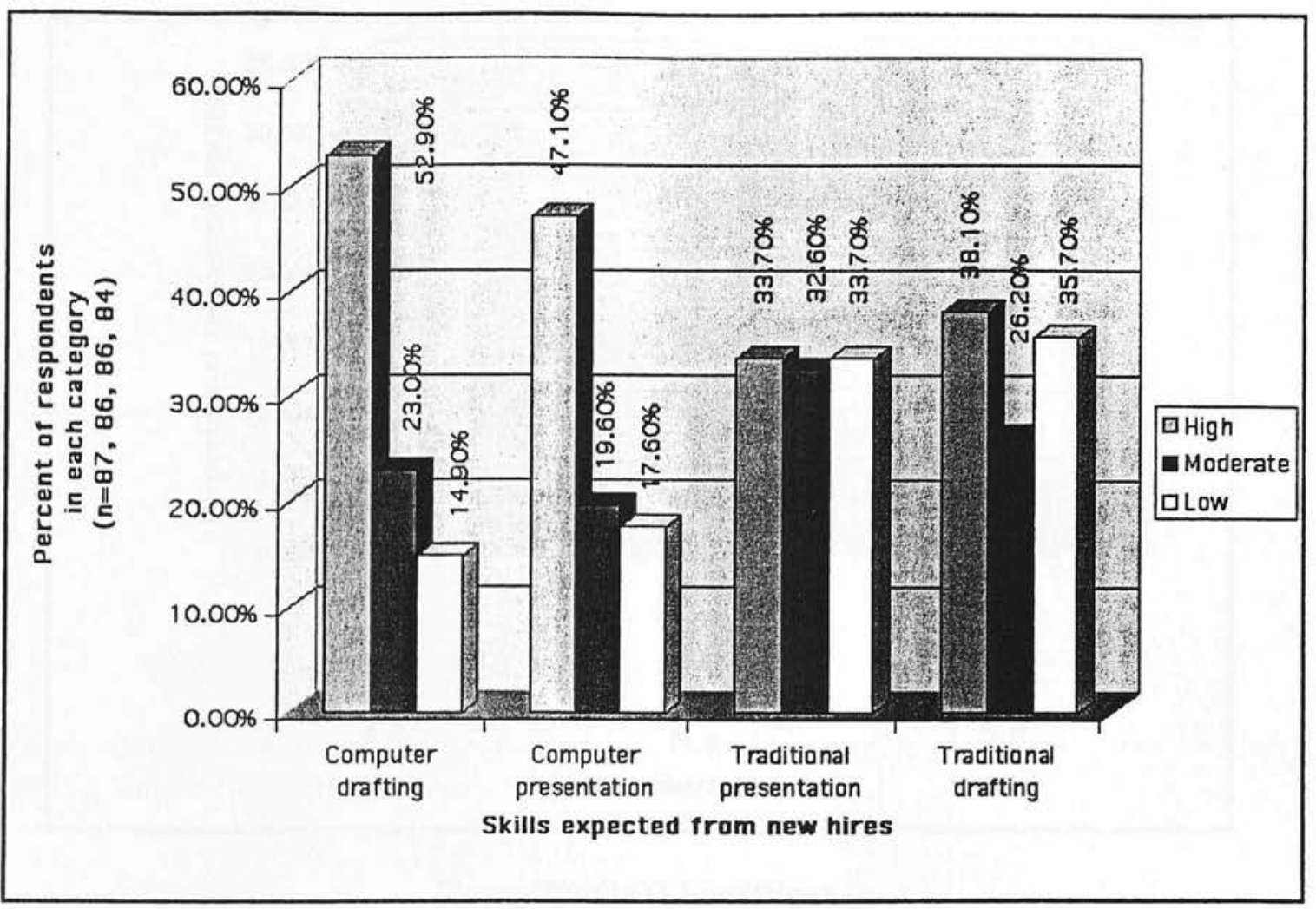

Figure 69: Skills expected from new hires.

\section{Future Outlook}

$86 \%$ of the firms believed they couldn't compete without the use of computers and only $14 \%$ felt just the opposite $(n=100) .58 .2 \%$ of the respondents had not done a virtual project-one done completely on the computer, whereas $41.8 \%(n=98)$ had completed a project of this type.

The following percentage of landscape architects reported computer-related problems: (30.7\%) time consumption/high learning curve, $(22.7 \%)$ equipment failure, $(12.0 \%)$ poor design based on computer drafting limitation, (9.3\%) mistakes due to operator error, $(6.7 \%)$ software incompatibility when exchanging files, $(4.0 \%)$ drawings that look finished when not, and (14.7\%) other $(n=75)$. 


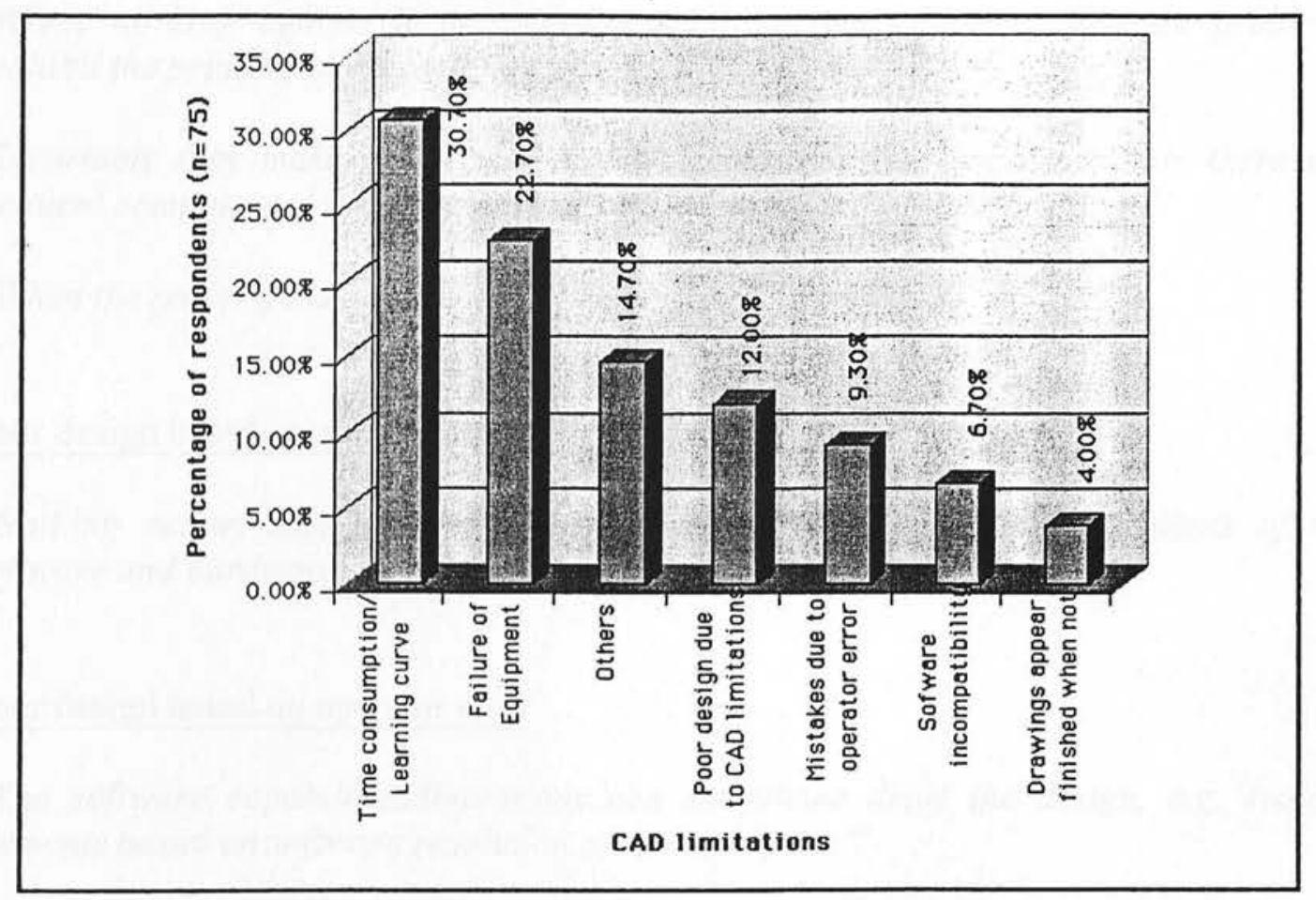

Figure 70: CAD limitations.

Included below are selected comments made by respondents regarding problems with computer use:

\section{Time consumption/high learning curve}

"Ninety-five percent of the time, the computer has hurt us. This comes from the fact that our firm has to take so much time to teach new employees."

"Spend too much time trying to get it just right when quicker traditional methods are available."

"Sometimes the limitations of these programs or the operator's ability to use a program to achieve a design objective can limit the design."

\section{$\underline{\text { Equipment failure }}$}

"Eight hours of design without backup and the computer froze with no alternative but to $c+a+d$ out of the system and lose data."

"When you loose a file--it's gone babe!"

"Failure or trouble with electronic equipment during a presentation!" 
"When working against a presentation deadline and computer network problems prohibit the printing of presentation graphics."

"Invariably they make projects more time consuming. At the last minute there are frequent computer related problems associated with plotting and printing."

"When the power goes off."

$\underline{\text { Poor design based on computer drafting limitations }}$

"Nothing major. Just the less creative designs result from the limitations of the software and hardware available."

Poor design based on operator error

"The software capabilities/limitations can sometimes drive the design, e.g. scaling elements based on software resolution or canned specs."

Software incompatibility when exchanging files

"Getting data from other firms. It rarely translates well."

Drawings that look finished when they are not

"Clients thinking a computer generated drawing was set in stone and not realizing flexibility."

"Tendency to proceed into design development prior to completion of schematic design since on the computer this is counter productive."

When asked, "What features would you consider would be ideal for landscape architects?" Respondents revealed the following ideal conditions: (24.1\%) 3-D modeling/walk-throughs, (19.0\%) speed/ease of power/use, (15.5\%) cut and fill capabilities/slope analysis/ estimating/lighting, (12.1\%) program that does everything, $(10.3 \%)$ more and better symbols, and $(19.0 \%)$ other $(n=58)$. 


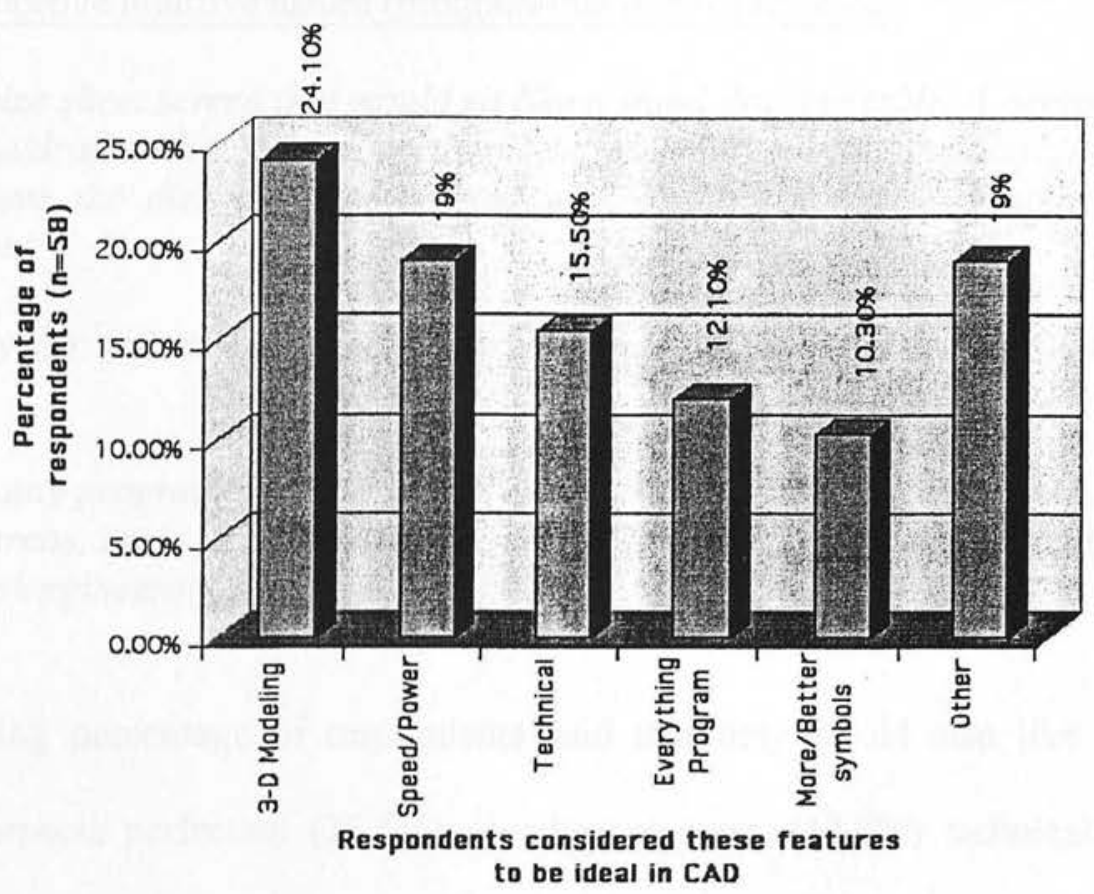

Figure 71: Respondents considered these features to be ideal in CAD.

Desire to improve 3-D modeling/walk-throughs

"3-D walkthroughs. I believe more clients will want this in the future and designer should be able to provide it as a standard service."

"Easier site modeling tools."

"Walk-throughs and landscape growth programs."

Desire to improve speed/ease of power/use

"Easier graphic presentation with less computer knowledge required."

"More (better) plant symbols, irrigation design modules, easier grading program.'

Desire to improve technical features (cut and fill capabilities/slope analysis/ estimating/lighting)

"A high level of accuracy for earthworks calculations."

"We need auto- slope analysis."

"Easy 3-D modeling for contour grading." 
Desire to improve intuitive nature (program that does everything)

“A full 'E' size sheet screen that would sit like a stand drafting table. A person would be able to draw/draft with a stylus directly on the screen like traditional design work. This would remove the disconnect associated with pushing a mouse around in a CAD environment."

"The ability for software to break the rectilinear drafting and be able 'to do curvy' designs."

"Basically, any program/software which is tailored for landscape architects, ie EASILY calculates areas, costs, etc., but also allows for easy integration and compatibility with architecture/engineering programs."

The following percentage of respondents said that they would also like to see the following aspects perfected: (36.5\%) speed/ease/power, (12.7\%) technical drawings/ calculations, (11.1\%) compatibility, (11.1\%) 3-D/modeling, $(9.5 \%)$ graphics that are less rigid/more intuitive, $(4.8 \%)$ more /better symbols, $(4.8 \%)$ precision, and $(9.5 \%)$ other $(n=63)$.

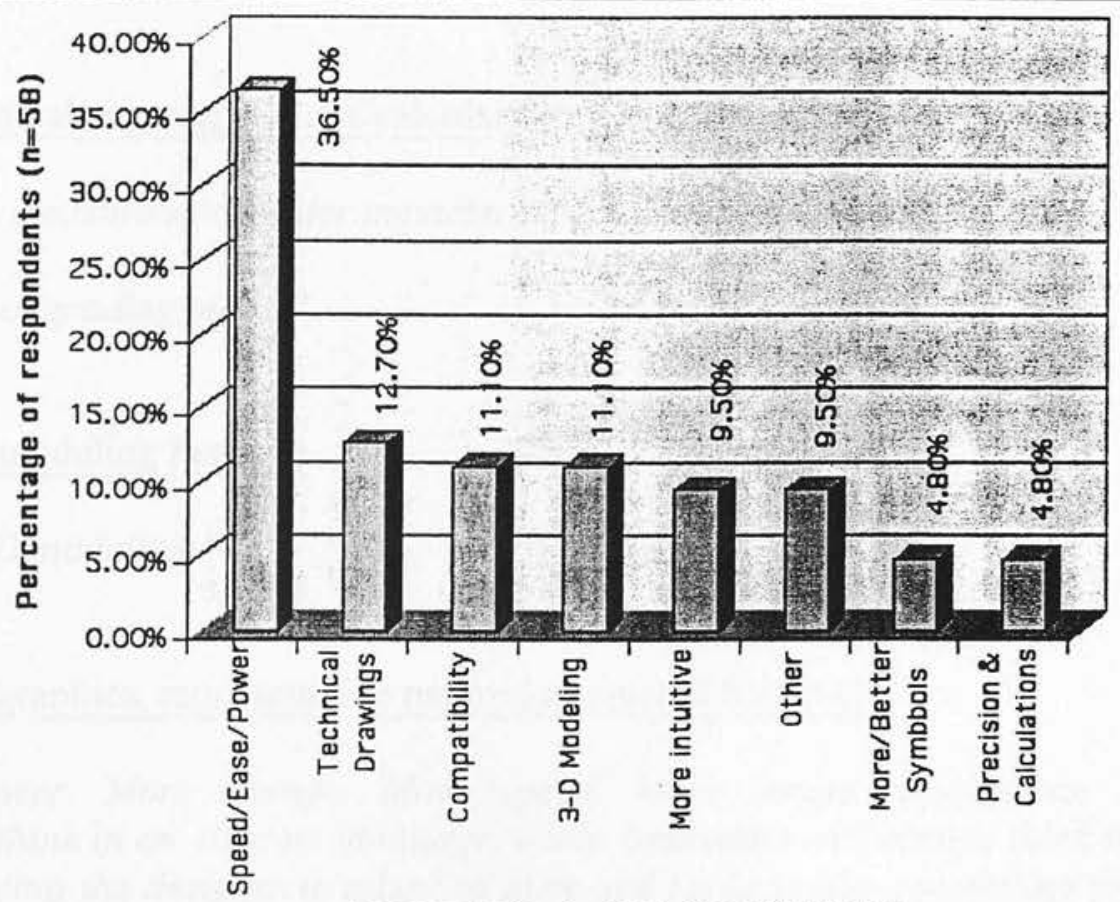

Respondents desired thesefeatures to be perfected

Figure 72: Respondents desired these features to be perfected in CAD. 
Below are selected comments made by respondents regarding aspects of computers to be improved.

\section{Speed/ease/power}

"With recently learning computers and the different software, it has been a challenge learning the different programs. Seeing more programs become user friendly and receiving more training would be of benefit."

"Faster, faster, faster-x ... still can't keep up with me."

\section{More Compatibility}

"More seamless compatibility between graphic programs, AutoCAD, and GIS programs."

"All in one software: word processing, database management, photo-renderings, desktop publishing, etc."

"Compatibility with older/newer software and hardware. Small offices have to struggle to afford to keep up-each new hardware and operating system advance has ramifications for us. Our larger consultants upgrade rapidly and necessitate us keeping pace."

More technical drawing features/calculations

"Ability to measure stormwater impacts, especially water quality."

"Drafting of grading plans."

More 3-D/modeling Features

"Better 3-D modeling."

Less rigid graphics, more intuitive nature (automated features)

"More power. More storage. More speed. More innate capabilities. Landscape architects think in an abstract language, while computers will always think in ones and zeros. Forcing the designer to adapt to ones and zeros is like committing professional suicide." 
"More intuitive data entry that would better support digital 'sketching'."

"More intuitive (or profession-specific) software."

"Self-healing, self-fixing features. I'm talking head and shoulders above the stuff on the market today."

"Using a pen on screen to draw or voice commands. Whether using keystrokes or icons, often times repetitive tasks are cumbersome (3-4 steps) to draw a line from point $A$ to point B."

"Standardization of line weight commands--plug-ins by which any drawing can be converted to standard colors/line weights."

"Input and interface. The mouse isn't natural when working on plans. Perhaps a touchsensitive combination digitizer/monitor for collaborations and teaming. (It's hard to have five people lean over a monitor)."

"Standardization of layering."

"Be able to click on a tree symbol and it goes right to that layer."

$\underline{\text { Other }}$

"The operator-I am not joking!"

In the survey's final analysis, $65.6 \%$ do not feel the totally digital office will ultimately replace the traditional office and $34.4 \%$ felt just the opposite. Example respondents' remarks include:

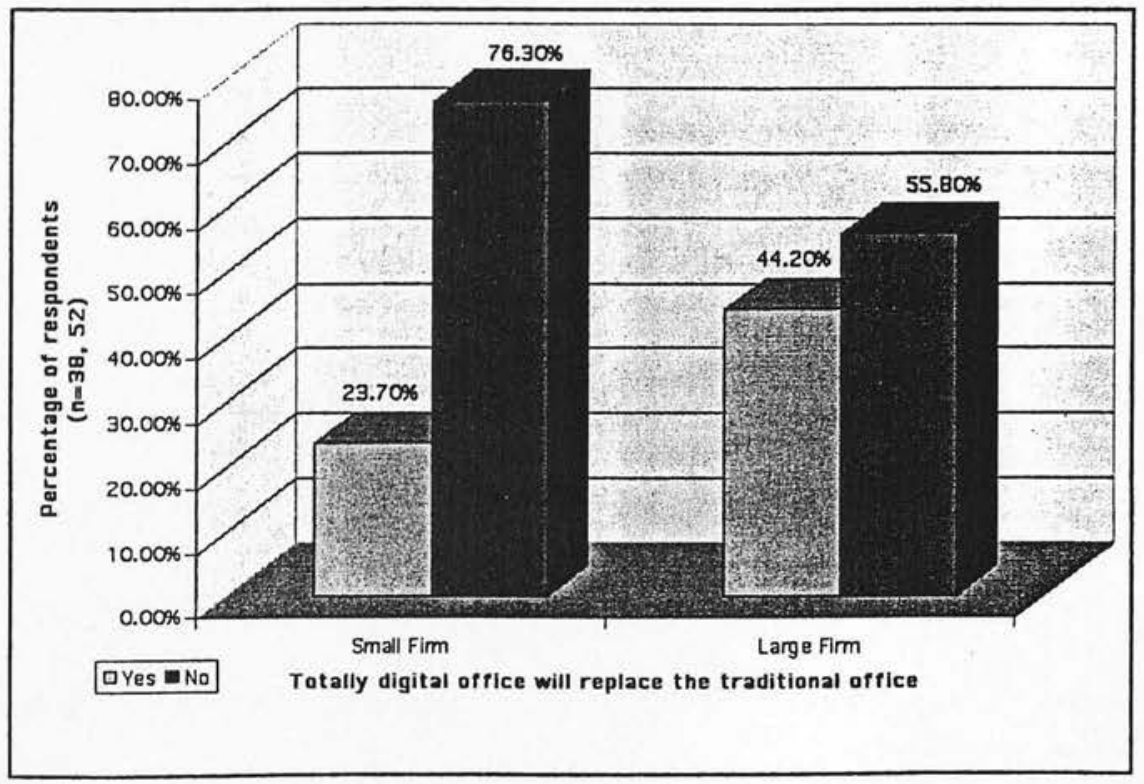

Figure 73: Totally digital office will replace the traditional office. 
"Even though we do most everything on CAD, we still design using trash paper, napkins, and models. Design is a minor part of what we do, it takes the least amount of time. Selling the design, making it buildable takes more of the time."

"For some it already has...I think ultimately, it will for all, but not as soon as some have predicted."

"In some segments of the landscape architecture industry, that could happen."

"Largely, it already has."

"We don't have drafting tables in our office."

"Computer will never completely replace the tactile feeling of paper and the ease with which one can design on paper."

"The computer isn't equipped to handle creative 'out of the box' design development and concept conveyance. It is however capable of producing drawings efficiently to communicate construction and direction of a project."

"I hope not." 
6.3 Results from supplemental interviews

\subsubsection{Results from supplemental interviews conducted about firms' Web sites}

The results of the frequency distribution for the two interview questions are as follows:

1) "Have you had any responses to your Web page?"

$$
\text { yes- }-100 \% \text { no- } 0 \%(n=12)
$$

2) "Have you received any work from your Web page

$$
\text { yes-33.3\% no- } 66.7 \%(n=12)
$$

The firms that were interviewed for this section all had a Web site. They stated that the purpose of their Web site was not for acquiring new clients, but simply to give the firm a presence on the Internet and to refer clients or prospective clients to their Web site to view examples of their work. All of them indicated they received many hits from students, salesmen, and job seekers.

The respondents indicated that they obtained work through conventional means and not through the Internet. Only a few of the firms received work from their Web site. At one such firm, Studio Green, chief designer John Merten said that $15 \%$ of the work in his firm for the year was a result of the Web site. He remarked, "The number of phone calls and e-mails from the Web site has been getting smaller in the past 6 months. I believe there are more and more firms with Web sites, so it is more difficult to be found." Another firm, Dynamic, noted they made $\$ 60,000$. in gross sales from their site after having it up for approximately 6 months. A respondent from the firm of HGR reported, "We have only gotten one job where someone looked at our Web site and called us. Tim Dixon with Hughes, Goodhue, O'Leary and Ryan stated, "We've received approximately 20 inquiries with regard to designing a residence since we went on-line 2 
years ago. This is without any advertisement of the Web site, and we don't display any residential work on the Web site.

Overall, this case study suggested the Internet had not replaced traditional ways of advertising, but was being used to help enhance the already existing advertising and marketing methods.

\subsubsection{Results from supplemental interviews conducted on the use of 3-D modeling}

The results of the frequency distribution for the 3-D modeling interview questions are as follows:

1) Does 3-D modeling play an important role in your design process and presentations?

Design- $0 \% \quad$ presentation-36\% both-64\% $\quad(n=25)$

2) Has the way you think about design been affected by 3-D modeling?

yes- $44 \% \quad$ no- $56 \% \quad(n=25)$

3) Has designing with 3-D modeling enhanced your designs?

yes-72\% no-28\% $\quad(n=25)$

4) Does the use of 3-D modeling help you to save time in the design process?

yes- $40 \% \quad$ no- $60 \% \quad(n=25)$

5) When using 3-D modeling, do you feel a sense of artistic quality is lost?

yes $-24 \% \quad$ no- $76 \% \quad(n=25)$

6) Do you feel pressured to keep up with computer technology in 3-D modeling to stay competitive?

yes-56\% no- $12 \% \quad$ committed $-32 \% \quad(n=25)$

7) Is the use of $3-D$ modeling required by clients?

yes $-52 \% \quad$ no- $-48 \% \quad(n=25)$ 
8) Has a client ever not understood what he is looking at when showing an animation or walkthrough of a design?

yes- $24 \% \quad$ no- $76 \% \quad(n=25)$

Of those answering "yes", $8 \%$ indicated that the presentation was too schematic while the remaining $16 \%$ indicated that the presentation was too technical.

9) Have you gotten a job or won over a client due to 3-D modeling and presentations?

solely on $3-\mathrm{D}-48 \% \quad$ no part-40\% combination- $12 \% \quad(\mathrm{n}=25)$

10) What programs do you use for 3-D modeling and presentations?

-AutoCAD \& 3-D Studio Viz/Max-36\%

-AutoCAD, 3-D Studio Viz \& Arch. Desktop-20\%

-AutoCAD/FormZ-24\%

-Arch. Desktop-20\% $\quad(\mathrm{n}=25)$

The professionals interviewed for this section consisted of high-end computer users. $36 \%$ of the respondents used AutoCAD and 3-D Studio Viz/Max. $64 \%$ of them responded that 3-D modeling played an important role in the design process and presentations and only $36 \%$ said it played an important role in presentation only. $56 \%$ indicated the way they think about their designs were affected by 3-D modeling. $76 \%$ felt that although computer models and presentations were different in quality compared to hand rendered presentations, the computer work can be generated with artistry by those who have computer proficiency.

$76 \%$ of those interviewed had developed 3-D models which they considered were very sophisticated, and easily understood by the client. On the contrary, $24 \%$ of the them felt that unsophisticated or low quality computer models which lacked detail or possessed 
too much detail were a problem. In spite of the problems reported, respondents indicated that $52 \%$ of the clients required the use of 3-D modeling.

While less than half $(40 \%)$ of the firms said that the use of 3-D modeling saved time, nearly all of them admitted to the overwhelming advantages of 3-D modeling to hand modeling. $48 \%$ of the respondents indicated that their firm had won over a client due to 3-D modeling presentations.

Of the firms interviewed, $72 \%$ said that $3-\mathrm{D}$ modeling for this reason enhanced their designs.

\subsection{References}

163 Nachmias, C. (2000). Social Statistics for a Diverse Society. Pine Forge Press, Thousand Oaks, CA. 


\section{CHAPTER 7 - DISCUSSION}

\subsection{Introduction}

The outcome from this research indicated that computer use had influenced office procedures and efficiency in landscape architecture practice, but not the nature of design itself. Computer use has permeated the landscape architecture practice and work in the office. It has enhanced old capabilities and replaced old methods with electronic versions. In addition, it has genuinely added new capabilities, particularly in the quality of design. These findings point to significant implications for the future.

The use of computers has unequivocally moved into different arenas since the $1980 \mathrm{~s}$ when $\mathrm{CAD}$ was used almost exclusively as a drafting tool. Landscape architects have accepted and even embraced computer technology. $99 \%$ of the survey respondents used computers to draft and enhance their design work regardless of firm size. Only one respondent, from a small firm, out of 102 respondents did not use the computer. This result shows a revealing contrast when compared to Palmer's 1993 and 1996 surveys which reported only $30 \%$ of the respondents were using computers. Of these, $57 \%$ were using CAD and $6 \%$ were using GIS (164). $90 \%$ had no experience with 3-D graphics (165). In stark contrast, Anderson's 1983 survey revealed only $10 \%$ using CAD and GIS and $67 \%$ having no computing skills (166).

\subsection{Execution of design tasks}

In this survey, most of the office design tasks were accomplished in-house with the use of computers. Some examples included Web design, and design drawings. A vast percentage $(93 \%)$ of the firms executed computer design tasks in-house and only $6.1 \%$ out-sourced it. In addition, a large number $(65.7 \%)$ of the respondents indicated that even their Web site was designed by an in-house professional. 
Originally, 3-D modeling was out-sourced to graphic artists because of the high costs of software and difficulty in learning these programs. As technology became easier to master and more readily available, firms could afford to have modeling done in-house (167).

Responses from interviews indicated that because landscape architects are designers, they were likely to do a better job on Web designs than outside professionals. In a "Special to The Times" issue, Morris Newman wrote, "If designers are disappearing from the architectural labor pool, it is no mystery where they have gone. The 'dot.coms' and entertainment companies have snatched up many new architects, at least in the greater Los Angeles area. The intense work ethic of design school makes architecture graduates a good match for demanding Internet and entertainment jobs." (Newman, 2000)(168). Andrew Cohen, managing principal of Gensler in Santa Monica said, "The profession is in a crisis because we can't find enough experienced people for the amount of work that is being generated" (Newman, 2000).

\subsection{Design Efficiency}

The benefits of CAD appeared to be recognized by survey respondents. Work was executed more efficiently and drawing quality was better (e.g. accurate, consistent, neat, etc.) and drawings were looking better (e.g. enhanced/edited drawings, realistic/3-D, etc. Most of the respondents $(70.4 \%)$ indicated that the use of computers increased efficiency in the design process. In fact, over half of the respondents $(56 \%)$ indicated it saved time during the first year and $43.8 \%$ after the first year. Most of the people who were interviewed also felt that computer use saved time. They noted various CAD features for carrying out design and drawing tasks which helped to achieve efficiency. Examples include the precision for technical drawings, layering system and symbols for 
ease of drawing and making revisions, 3-D capabilities for generating perspectives, solid modeling for 3-D visualization, and digital terrain modeling (DTMs) for formulating complex geometry. One of the interviewees, Peter Stebbing, with FWA Group, emphatically remarked, "The speed has increased to approximately five times the rate at which projects were completed compared to by hand!" (personal communication, April 7, 1999). Perhaps, this is attributed to the combination of upgrades in software that resolve frustrating glitches while improving the functions in $\mathrm{CAD}$ and landscape architects who are embracing and becoming more acclimated to the computer technology. One improvement in a CAD function can save hours or days in time. While large firms are more advanced and have used computers longer, small firms including the one-person firms are equipped with computer technology. Laura Gaynor, ASLA, principal of a sole proprietor firm of Allees, said, "I can work out of my home because of the computer technology. I have all the hardware and software necessary to conduct business from here. I send drawings out either on pdf (portable document format), compressed zip files or simply plt (plot) files to the printer and they deliver them to the client and mail copies back to me. I also have a free Internet answering service, known as Callwave to take my calls when I am out in the field" (personal communication, December 15, 2000).

Based on the time saved, many of the $(61.2 \%)$ respondents said that they took on more work and almost $40 \%$ (a significant percentage)said they spent more time doing other design tasks. If the design process, set up time, meetings, and transfer of files are all easier, maybe landscape architects can finally start taking advantage of computer use and really become more creative. However, it was difficult to determine how they actually used the extra time, since there was a very strong likelihood that the practitioners took on more work, as opposed to spending time doing other design tasks, because of the thriving economy during the late 1990s. Many of responses from 
personal interviews confirmed this was the case. Additionally, in 1999, Jan Schach, president of ASLA, reported that there was a shortage of landscape architects in the profession. Due to this situation, many landscape architects have had difficulty finding new employees and there was limited time to do other tasks.

\subsection{Efficiency in Communication}

Many of $(65.3 \%)$ the respondents always or often used e-mail or the Internet to transfer digital files and $34.7 \%$ seldom used it. $52.2 \%$ of the respondents who saved time with the use of computers had fewer meetings.

Interviews with landscape architects revealed that e-mail was an effective inter-office communication tool. Team members could send files to each other very efficiently. Blair Isreal, with Odell Associates stated, "Set up time is extremely fast with the computer and I could switch from one project to another with ease. I can also send drawings through inter-office communications with ease" (personal communication, April 6, 1999).

In addition, landscape architects that consulted with firms also used e-mail extensively. E-mail was a particularly effective tool for employees working from remote locations. Melissa Ols, a landscape architect working with the firm of Arbor Engineering said, "I had been working at Arbor for eight years. With a family, it became difficult for me to work regular hours and Arbor wanted me to stay with the firm. Now, I can work from home and use electronic communication for receiving and sending drawings." (personal communication, April 8, 1999).

Many of the survey responses also affirm the efficiency of digital communication. Respondents commented, "There is possibly fewer meetings when it comes to 
reviewing or coordinating other consultants' work. We can now do this almost instantly via e-mail when previously it took much longer to transmit information." We are also setting up project Web sites to view the status."

Although results of interviews indicated there were fewer meetings due to electronic communication, it seemed many survey respondents still felt the face to face interaction was nevertheless very important. Respondents remarked, "There are fewer meetings, but far more communiqués." "We use it mainly to schedule meetings, however face to face contact is still important."

It seemed the general consensus among the respondents was that design is an art. Regardless of whether the paperless office is a possibility in the future, it may not be realized for the landscape architecture design discipline. Design is a uniquely human process that often involves interaction between other individuals and their feedback which cannot be simulated fully through digital technology. Many of the respondents actually said that they hoped that the totally digital office was never going to take place for this reason. 


\subsection{Firm Web site}

Survey responses indicated most of the firms had a Web site, regardless of the firm size: $83 \%$ of the large firms and $52.6 \%$ of the small firms had a Web site. In addition, most of the respondents had a Web site with access privileges for clients.

Many of the respondents ( $81 \%$ from large firms and $53.8 \%$ from small firms) received inquiries from various people through their site. Most of the firms (61.1\%) did not get any work from their Web site. Neither small (76\%) firms nor large firms (53.5\%) received new work from their Web site.

In the interviews about Web sites, a majority of the respondents indicated that they received "hits" from students, salesmen, consultants, and prospective employees. Candace Hitchcock with LandDesign, Inc. stated concisely the general opinions of other respondents, "The real value of our Web site is that it gives us a strong Internet presence, allows visitors to our site the opportunity to view a sampling of our project work and the job opportunities available to the firm. I do not believe we have secured any projects because of the web site. However, I know prospective clients and job applicants have been referred to it for a comprehensive view of the company" (personal communication, April 7, 1999). Kelly Rench of The Berger Parnership, P.S. added, "We did not create the site to elicit responses or to land projects. It serves as a supplement to our marketing efforts. All our marketing material goes out with our Web address so that more of our work is available for viewing by our commercial clients requesting brochures or proposals. Additionally, it may be interesting to know that $40 \%$ of our work is residential. However, we do not have a single residential project on our site. We avoided promoting this market because we did not want every do-it-yourself browsing the web to e-mail us about when to plant their bulbs or to ask us how to kill weeds" (personal communication, April 7, 1999). 
However, a few of the firms did receive work and also sold some products from their web site. One firm, Studio Green, replied that $15 \%$ of their work for the year came from their Web site and another, Dynamic Environments, Inc. said they made $\$ 60,000$. in gross sales off their site in the last six months.

Although landscape architects have Web sites in order to exhibit a presence on the Internet today and not necessarily for obtaining new work, it may be possible for them to obtain work from their site as well as marketing certain products. It seems that landscape architecture firms may need to examine and acquire better and more effective links from various search engines. This would help those who may be searching for landscape architecture services on the World Wide Web to find them more readily and rapidly.

Perhaps, this is an area in which landscape architects should consider obtaining outside professional Web design assistance for a more effective Web site. Since some Web sites obtained work as well as sold various products, landscape architects might ask themselves how their Web site can be designed, constructed, linked, and connected to the server where the site will be hosted to elicit the most efficient and productive responses. There are so many aspects of Web design that must be considered. For example, it is a great advantage to create a site that can be viewed across platformsbetween MacIntosh and PC as well as between Web browsers-Netscape and Internet Explorer (including each of the versions). It is always a plus to have a Web site appear at the top of a list on a search engine. Some of the other important Web design considerations include, optimizing graphics for faster loading, ensuring that details such as colors are appropriately represented, adding interactive links, sound, and/or 
animation for information and interest, providing secure spaces and/or transactions with passwords. If this can be accomplished, it is likely for landscape architects to be able to successfully market their services on the Web.

\subsection{Professionals in the design office}

When survey respondents were asked, "Has the integration of computers affected the make up of your firm?" almost half $(42.6 \%)$ of the respondents indicated that there were now more junior landscape architects with CAD knowledge, $11.9 \%$ indicated there were more computer technicians, only $2.0 \%$ indicated there were fewer senior landscape architects, and $43.6 \%$ indicated there were no changes.

Many of those who were interviewed indicated that during the prosperous economic times of the late 1990s, firms hired new employees because of their large workload. Typically, in landscape architecture practice, junior staff persons are usually the first to be hired to help with the extra workload. According to survey results, most of the respondents would have hired junior landscape architects with traditional and $\mathrm{CAD}$ experience.

Among firm employees, over a third (33\%) indicated they can easily advance in their firm with their expertise and skills in $\mathrm{CAD}$ and $18.2 \%$ indicated that they would be categorized as the CAD person and must seek a position elsewhere to advance. This question "did not apply" to $48.9 \%$ of the respondents. Survey responses suggested that it was not only CAD, but "many other factors that affect advancement." Survey respondents remarked, "CAD had become one of the standard 'languages' with which we as landscape architects communicate. In our office (as with most) good communication skills are required to not only advance, but to survive. Today's 
landscape architects must be able to communicate in many different ways: CAD drawings, sketching, rendering, written, and verbal presentation." "If a person is unable to communicate in one or more of these areas, it certainly limits their ability to easily advance and take advantage of opportunities." Another respondent added, "All three are possible. Someone who excels in CAD may get held back by those who can't. However, in our office everyone uses $\mathrm{CAD}$ so it relates to the person's performance and advancement." "People who are pigeon-holed as a CAD jockey allow themselves to be!" Many similar responses indicated that experience and proficiency with CAD was an advantage as opposed to a disadvantage.

When it comes to new hires, $92.5 \%$ of the respondents said that they did not hire strictly on CAD skills. Of course, those who felt computers played a role in the design process were likely to hire new employees with computer presentation skills. Most of the respondents $(60 \%)$ ranked both computer drafting and traditional presentation skills as highly important. Computer presentation and traditional drafting skills were ranked as highly important by over one third of the respondents.

It appears that recent grads will have a difficult time finding employment without both traditional and highly technical skills. Personal interviews with almost all the firms reinforced the strong emphasis of hiring new employees with a fair amount of CAD experience and especially AutoCAD.

This has already had an affect on education and will likely continue to do so in the future. Even the Landscape Architecture Accreditation Board in the United States has strongly recommended incorporating computer technology in the curriculum. Thus, most schools have already adopted $\mathrm{CAD}$ in their curriculum. It seems that schools will 
need to continue to plan and commit to providing the support necessary (software, hardware, technical support, space, teaching faculty etc.) for developing successful pedagogical environment in design and technology. This will not only enhance the students' education, but also respond to the desires of the professionals seeking graduates with traditional and high technology skills. Moreover, these professionals will also have to invest in their employees with on-going education in order to maintain and stay abreast of the technology. In the meanwhile, many students today have the opportunity to do internships and gain high technology experience as part of the work experience.

\subsection{Office Size}

Most of the respondents $(60 \%)$ indicated that their office size stayed the same with the integration of computer use. The notion of moving towards a paperless or digital office would seem to suggest the demise of drafting tables and the proliferation of space saving hardware such as the flat monitors, resulting in smaller offices. Increased efficiency would suggest decreased number of employees. However, many of the individuals who were interviewed remarked that during the prosperous economic times, firms hired more employees and grew in size. Thus, the use of computers may or may not have had any direct impact on the size of the firm.

It seems there is a symbiotic relationship between the firm and the sophistication of their technology. Firms buy into computer technology which, in turn, allows them to bill at higher rates, allowing them to buy more sophisticated technology. Thus it is likely that as the firm grows, so does the sophistication of its technological base. The firm does not grow necessarily because of the sophisticated computer technology, but the technology grows because the firm can afford to buy it and have the know-how to 
use it. It seems if computers allow practitioners to take on more work they are definitely contributing to the size of the firm, if not in number of employees or square footage, then in dollars.

\section{8 $\quad$ CAD in the design process}

Computers appear to be used in all aspects of the landscape architecture design practice with the majority $(80.4 \%)$ of the survey respondents indicating that they played a large role in the design process. Most $(82.5 \%)$ of the small firms have used computers for 110 years and large firms have used them for $10+$ years. This finding is not surprising since computer equipment and software were cost prohibitive when they first emerged on the market in the early 1980s and large firms were the only ones likely to afford it (169).

Nevertheless, the use of CAD has apparently been dominant in the profession. Most of the survey respondents $(87.2 \%)$ revealed that clients were requiring the use of $\mathrm{CAD}$. They indicated many governmental agencies for example were requiring drawings to be completed with CAD and to be submitted in a digital format. The ability to transfer digital files between clients and consultants was noted as a necessity in practice.

Among respondents who used $\mathrm{CAD}$, AutoCAD was the leading stand-alone software as well as some Microstation users and other $\mathrm{CAD}$ programs. Almost half of the respondents indicated that the software was chosen for compatibility with that of clients/associates. Respondents also noted specific features in software to be an important consideration for choosing software. 
Although results indicated AutoCAD was the industry standard, there were other software choices used by professionals. Popular CAD options included LandCADD, 3D Studio, GIS, FormZ, and DesignCAD. Less used options include ArchiCAD, DataCAD, CAD Plus, Easysurf, Modelview, PowerCADD, and Vectorworks.

Most of respondents $(68.4 \%)$ had not switched software since computer design had been in use at their firms. During interviews, these respondents said they were satisfied with the original software and saw marked improvement with each new version. Ed Pinckney, of Edward Pinckney/Associates Ltd., said, "We use AutoCAD because it was the main software ten years ago when we were making the decision to go digital and we have stayed with it" (personal communication, April 10,1999). Almost one third (31.6\%) switched to be compatible with industry standard (e.g. from one CAD program to AutoCAD) and others added new software to obtain specific capabilities (e.g. GIS and FormZ).

Many $(63.9 \%)$ survey participants believed that 3-D capabilities was an important feature in software. Although, less than half (40\%) said they used intermediate programs (3-D and other) and walk-throughs or 3-D imaging in their presentations. Small firms used this less than large firms. When asked, "What are you creating on the computer which you feel is very innovative?" only $19.6 \%$ responded with 3-D modeling. Then, when asked, "What features would you consider to be ideal for landscape architects?" only $24.1 \%$ responded with 3-D modeling and walkthroughs.

These responses suggest that although respondents felt 3-D capabilities were important, few of them actually utilized 3-D. It may also suggest that many that were using 3-D capabilities did not feel they were producing innovative drawings. This is likely due to 
the amount of time required for creating 3-D models. Over one third $(30.7 \%)$ of the respondents indicated they had a difficult time utilizing these capabilities due to lack of know-how, time consumption and steep learning curve. In an interview with Mark Byington, Landscape Architect, he said, "I looked into getting into 3-D modeling, GIS and even virtual reality, but I don't have time or the money" (personal communication, 1999). Raymond Strychalski with Nimrod Long and Associates, remarked, "The modeling properties and rendering abilities of CAD are too time consuming to be justified. "Sometimes the use of these will convince clients that the project will work" (personal communication, 1999). This is unfortunate since it seems the ability to support design creativity may be enhanced if designs could easily be viewed and evaluated in 3-D during earlier stages of the design process. Even $60 \%$ of those interviewed who were high-end users of 3-D modeling indicated that creating 3-D models was time consuming. Perhaps improvements and changes in the software will ease the use and increase the utilization of 3-D modeling in the future.

Among responses from interviews with high-end users of 3-D modeling, a large percentage $(72 \%)$ of them found 3-D modeling to have enhanced their designs. Most of them $(64 \%)$ said that $3-\mathrm{D}$ modeling played an important role in both the design process and presentations while $36 \%$ said it played an important role for presentation only. Over half of the respondents $(56 \%)$ indicated the way they think about their designs were affected by $3-\mathrm{D}$ modeling. Also, interview responses indicated more than half $(52 \%)$ of the clients required the use of 3-D modeling.

This is an interesting finding about the influence of computers on high-end users of computers in landscape architecture practice. It seems that there must be a willingness to use computers for 3-D modeling among these high-end firms in order to meet the clients' expectations and to compete and qualify for jobs. 
Over three-quarters felt that although computer models and presentations were different in quality compared to hand rendered presentations, the computer work can be generated with artistry by those who have computer proficiency. One-quarter of those surveyed felt that unsophisticated or low quality computer models which lacked detail or possessed too much detail were a problem. A majority (three-quarters) of the respondents felt that the 3-D models which they created gave clients a much better understanding of the overall design. These models clearly depicted the project context and materials, in addition to being able to place the client in the project via walkthrough and animation.

At the same time, many professionals do not believe that computer generated 3-D models have the loose, "touchy feely" quality of a hand rendered drawing and may look finished, when it is not, thus giving the client the impression that the design is finalized and cannot be changed. In the landscape architecture discipline, many professionals are trained to see their designs and presentations as works of art and this is an important aspect of their work. Often, they believe it is the artistic quality that potentially "makes or breaks" a design for the client. Some respondents perceived that computer presentations lacked artistic quality.

Although over half of the respondents said that the use of 3-D modeling did not save time, nearly all of them admitted to the overwhelming advantages of 3-D modeling to hand modeling. For instance, advantages include the ability to make changes to the model or presentation quickly, visualizing many more variations of designs, and the capability of using the 3-D model in future marketing ventures. Just under half of the respondents indicated that their firm had won over a client due to 3-D modeling presentations. 
Does computer-modeling produce a better design than traditional techniques? Most of the people interviewed regarded this as the ability to see a representation of the aspects of a design that traditional modeling and drawing could not show. They were then able to correct the mistakes that could only have been seen once the design was built. Of the firms interviewed, most said that 3-D modeling for this reason enhanced their designs. Almost half of the respondents said that their firms have obtained jobs due to 3-D modeling in their presentations.

\subsection{Role of computers in the design process}

A significant percentage (80.4\%) of the respondents from large and small firms $(85.5 \%$ and $70.7 \%$ ) indicated that computers play a large role in the design process. Threequarters believed the computer improved their design work. $25.5 \%$ responded that the use of computers helped creativity, $45.1 \%$ indicated it did not affect their creativity, and $29.4 \%$ said it hindered their creativity (Figure 91 ). It is interesting to note that, although the survey asked several questions with regard to creativity.and although the notion of creativity is subjective and difficult to measure, the respondents did not appear to have any problems understanding the nature of the questions asked. $18.3 \%$ of the respondents believed that the use of CAD had improved their artistic quality, $41.9 \%$ thought it stayed the same, and $39.8 \%$ thought is was worse. These findings on the effect of CAD in the design process is very revealing. CAD was found to be used by both small and large firms predominantly for working drawings, final presentations, and firm qualification presentations. It was however also used in earlier stages of the design process. 


\subsubsection{Working drawings}

In the final analysis, compared to traditional drawings, a majority $(59.2 \%)$ of the respondents perceived their drawings to be better, $27.6 \%$ thought they were the same and $13.3 \%$ thought they were worse.

A majority $(89.5 \%)$ of the respondents indicated that the use of computers played a large role in working drawings: $94.2 \%$ of the responses were from large firms and $80.1 \%$ were from small firms. Working drawings are precise drawings and details used with specifications for the construction of a landscape project (170) and can effectively be produced by CAD. A high percentage $(72.4 \%)$ of respondents used CAD for working drawings because they considered computer-generated drawings to be more accurate than traditional drawings.

The availability and option of using standard details and symbols is an important aspect.

Over half $(53.9 \%)$ of the respondents selected details and symbols from existing libraries and revised them as needed, $35.1 \%$ used details and symbols from a library they created, and $8 \%$ created them as needed.

Many claimed the use of layering system and templates saved time and made it easy to amend and revise drawings. Nearly half of the respondents believed they were spending excessive time perfecting their drawing because of the ease of making changes on CAD. In an interview with Stacy Pittman with Hughes, Good, O'Leary and Ryan, Inc. she said, "...revisions are easier too. So some projects tend to get 'over-revised"' (personal communication, 1999). As many survey respondents remarked, "It allows changes to be made easier and quicker, thus more acceptable." 
The negative aspect of CAD generated working drawings is the perpetual use of the same details and ultimately the cause of lack of creativity due to the use of the same templates. For this reason, $86.2 \%$ of the respondents indicated their drawings were consistently looking the same.

Although this may seem to be a problem, it is somewhat in the nature of working drawings that these drawings are likely to appear similar each time even when they are drawn in the traditional manner. Often firms use similar details for many of their projects because these details reflect the design vocabulary of the firm. Nevertheless, perhaps, in order to generate drawings that are unique each time, it is the landscape architect working on $\mathrm{CAD}$ that should take the extra effort to be more innovative in creating new or varied details assuming the CAD expertise is there.

\subsubsection{Final presentations and firm qualification presentations}

A majority of the firms were using computers for final presentations (73.6\%): $84.9 \%$ were from large firms and $57.9 \%$ were from small firms. Most (79.6\%) of the respondents used $\mathrm{CAD}$ for firm qualification presentations. There was a strong relationship between the role of computers in the design process and its use for presentations. $63.3 \%$ of the respondents $(73.7 \%$ from small and $55.8 \%$ from large firms) were not using 3-D imaging or visualization for presentations.

Survey respondents echoed the sentiments of one respondent as he remarked, "The use of computers has created more formats of presenting information." With regard to final presentations, respondents said, "Image editing programs and visual simulations are great." Many indicated they used Powerpoint and only one respondent indicated the use of multi-media program such as Macromedia Director. This may be due to the fact that it is a very sophisticated program and is similar to the concept of "movie making." 
For example, to make a movie in Director, one must create frames, cast members (e.g. images, text, sound, video), and add customized animation for streamlining the movie (171). There is much more to Director when compared to Powerpoint. Powerpoint involves insertion of images, use of pre-programmed animation choices, and addition of text. Every "slide" and every "flying arrow" is the same. In contrast, a presentation created in Director is much more engaging because every aspect of the presentation is customized and there is no way to anticipate the next frame. However, to produce a 5minute movie in Director could take several days even for a fairly experienced multimedia user.

\subsubsection{Design development}

Over half $(52.7 \%)$ of the respondents said that CAD played a large role in design development. This is a phase that is just prior to the working drawings phase and is the preliminary plan and estimate part of a landscape architect's services and includes the preparation of detailed design sheets, specifications and cost projections (172).

Respondents indicated that compared to hand drawings, the use of computers in design development had an effect on their drawings looking better. However, respondents also indicated that the use of computers in design development had an effect on drawings consistently looking the same. This response is similar to that of working drawings, and probably for the same reasons.

Although CAD played a smaller role in design development, this is likely due to the fact that design development or "the creative layout and planning" is still in the development stages and thus, does not lend itself to complete computerization. 


\subsubsection{Schematic design}

Nearly half of the respondents $(41.8 \%)$ indicated that computers played a large role in schematic design-the first portion of a landscape architect's services which include site review, an assessment of the project requirements, programming, design and cost studies and other work necessary to the beginning of a design for a project (173).

When landscape architects were asked during interviews, "Do you use the computer for schematic design? If yes, then for what specific task and with what software?" It appeared some of the respondents used the computer for creating base information, while others used it throughout schematics and into the conceptual phase.

Warren Pruitt, ASLA of LS3P said, "We typically use AutoCAD and when required Microstation. For schematic, we set up the base information in CAD and then hand draw the design" (personal communication, 2000). Parks McLeod, ASLA of McLeod Landscape Architects said, "As a rule we use the computer to generate a base sheet and the plot it out and work off of it for a lot of the schematic design. We have found that the computer is too perfect for loose design and ideas..." (personal communication, 2000).

Susan Krowka, ASLA of Krowka and Associates said, "Actually, I tend to use the computer quite a bit for schematics. Not sure if it is actually time efficient, but I like narrowing down the actual measurements of everything early on. For example I like to insert parking rows and spots and re-arrange (rotate) or move all over 10 feet, etc. so that I can see up front what's going to work best and if my clients' parking expectations are realistic. Also, my freehand gets worse \& worse (also lettering) as I spend most of my time on the PC. (Use it or lose it!) We are currently using AutoCAD 14 w/ Softdesk" (personal communication, 2000). Barry Witherspoon, ASLA of Designworks 
said, "I use a lot of different programs, but for preliminary design I like to use an aerial photo for a background in AutoCad R14 or R 2000. Aerial photos show trees and other site conditions. I then use Spline Polylines to rough out use areas and roads. You can give widths to Polylines to represent roads. Once you convert a Polyline into a Spline it is easy to edit it by dragging around the "grips" or vertices. It really makes for nice smooth curves. I also like to use CAD to create footprints for proposed buildings and getting areas. I use templates for building types, and have plant symbols that are in color with embedded 3-D images for perspective viewing. I print a lot and draw on the prints, then input and refine. This is mostly for larger scale land planning projects. I am not a great consumer of tracing paper" (personal communication, 2000).

\subsubsection{Conceptual design}

Only $18 \%$ of the respondents indicated that CAD played a large role in conceptual design. Interestingly, respondents regarded 3-D capabilities to be an important feature regardless of whether $\mathrm{CAD}$ played a small or large role in the conceptual design. Conceptual design is the creative laying-out and planning of outdoor space for harmony, utility, and beauty (174). The area of the conceptual or forming process is the basic plan concept by which in sketch or diagram the use areas and plan forms are conceived in harmony with the natural and constructed forms, forces and features of the total project site (175). Design has an intuitive nature about it.

In personal interviews with landscape architects, many of them believed that the computer hindered creativity because of its non-intuitive nature even though there are tools available such as graphics tablets that are supposed to provide freer and intuitive drawing. For those who have used this tool, they remark that it has proved to be beneficial to some extent. However, the contact of the pressure sensitive pen still does not provide a fluid interaction when compared to pen to paper. Mark Byington, 
Landscape Architect, who was interviewed said, "I do everything by CAD except the actual design. The freedom of the pencil and paper is unlimited" (personal communication, 1999). Gary Haygood, with Perry Wood and Associates added, "There is something about the feel of the pen on paper that makes the creative juices flow more readily" (personal communication, 1999). In addition, David Tomblin, with LS3P remarked, "Computers hurt or inhibit more 'organic designs"' (personal communication, 1999). Survey respondents remarked, "CAD limits free hand design development, things tend to always be in arcs." "Must think in terms of how the design can be developed, finalized, and presented within the limitations of the technology." "People often limit their concepts to what they're able to construct in the computer." "There's more thinking about products and the process to arrive at the finished work. Each step is planned to integrate with the next step and to make the work flow as efficiently as possible." "We find we need to get off the computer at times to think more creatively. Then transfer ideas from paper to computer."

Respondents who appeared to be proponents of computer use said that the computer allows for exploration of alternatives in terms of spatial as well as technical designs with improved tools. One respondent remarked, "I can try options and make complex geometric designs more quickly. I can save old ideas for inclusion into new sites, so design is never wasted." Other respondents added, "I can explore in more detail the way the design works, or how elements can work together." "It allows us to investigate more alternatives in the same limited amount time." "The computer allows more conceptual drawings and grading plans to be tried." "The way we think about design has been impacted by the computer because we are designing more like we draw. Things such as free flowing curves are now broken down into arcs and tangents, but the computer holds us back in design because of its exactness." 
Overall, there had not been a strong impact of $\mathrm{CAD}$ on creative and artistic aspects of design and there was no statistically significant relationship found between the use of computers and impact on artistic and creative activity. 


\section{$\underline{7.10}$ References}

164 Palmer, J \& Buhman, E. (1994). “A Status Report on Computers.” Landscape Architecture, 84 (7), 54-55.

165 Palmer, J. (1998). "The 1996 Status Report on computers in Landscape Architecture." Computing 11 (1), 2-5.

166 Anderson, P. (1984). "Stats on Computer Use." Landscape Architecture, 64 (5), 101-102.

167 Ojeda, O \& Guerra, L. (1996). Hyper realistic. McGraw Hill, Inc., New York.

168 Newman, M. (2000. July, 11). “Architects Becoming a Rare Breed in Their Own Field." Special to the Times.

169 Ojeda, O \& Guerra, L. (1996). Hyper realistic. McGraw Hill, Inc., New York.

170 Morrow, B. (1988). A Dictionary of Landscape Architecture. University of New Mexico Press, NM, 373.

171 "Macromedia Technical Notes: Common Questions About Macromedia." (2000. February 23). Retrieved March 20, 2001 from the World Wide Web: http://www.macromedia.com/software/

172 Morrow, B. (1988). A Dictionary of Landscape Architecture. University of New Mexico Press, NM, 87.

173 Morrow, ibid, 297.

174 Morrow, (1988) op. cit., 87.

175 Simonds, J. (1983). Landscape Architecture. McGraw-Hill Book Company, NY, 91. 


\section{CHAPTER 8 - IMPLICATIONS}

\section{$\underline{8.1}$ Introduction}

The use of computers has had an overall positive affect on the design process. Quality of drawings was better, work was done more efficiently and new technologies enabled innovative and complex tasks to be accomplished more easily. There was, however no statistically significant relationship found between the use of computers and impact on artistic and creative activity. The predominant response was that computers were not intuitive and design is intuitive. Many cited the inflexible nature of the computer as the main drawback.

It seems high-end computer users who were interviewed have had an easier time being creative with the use of the computer. They were not battling with having to think about what to tell the computer to do. Thus, working on the computer was more natural as opposed to a conscious step-by-step instruction process.

\section{Future in Training}

Since the technology has not reached an easy or intuitive level yet, it seems landscape architects would have much to gain from appropriate training in school and then on the job. Understanding and feeling comfortable with CAD's tools and features would seem to provide an appropriate step towards designing less consciously and more intuitively. This is somewhat analogous to typing. A proficient typist can type and write in a fluid manner and typing becomes almost an unconscious task. 
Thus, the training process needs to start right at the beginning in schools. Important lessons learned from this thesis research indicate that specific factors for educators to consider include:

1. Integrating $\mathrm{CAD}$ into the curriculum.

2. Knowing when and how to teach computers.

3. Getting appropriate training for faculty to teach CAD in the studio.

4. Obtaining appropriate resources to maintain and sustain computers.

5. Communicating with administrators about long-term support of CAD in the curriculum.

Most schools offer CAD courses. Some offer it as a stand alone computer graphics course, while others integrate it with the design studio. Timothy Johnson, a professor at Penn State believes that students need to learn how to integrate the use of the computer with the studio component as opposed to a stand-alone course in order to encourage design creativity rather than utilizing $\mathrm{CAD}$ as a drafting tool. He explains, "Despite the availability of affordable hardware and software for computer graphics, most landscape architecture programs have not successfully integrated the use of computers into design and graphics studios. Most programs that do teach computer graphics use a specialized course that remains separate from graphics and design. This segmented approach to teaching computer graphics reinforces the perception of the computer as a specialized, complex, and difficult graphics tool that is only appropriate for a limited number of dedicated students. In our view, computer-aided design should not be viewed, as an environment for design or as just another drawing tool, like a pencil or pen. It is a medium that offers new opportunities for learning and creativity" (Johnson, 2001)(176).

In Penn State's landscape architecture program, students are required to complete a design project using the computer as a design medium during their junior year. The 
students are given the opportunity to explore new opportunities in design innovation rather than to have the project "fit" the computer.

Roger Trancik, a professor at Cornell University, had similar thoughts to that of Timothy Johnson. He said, "Today, one has to tackle the technology while at the same time learning all there is about urban design. It is extremely important to integrate educational content with skill development in using any software" (Trancik, 1999)(177). Trancik revitalized his urban design into a totally computerized one. In an interview Trancik said, "After 27 years of doing it by hand, I had to take the big leap and transform what we used to do manually to embrace emerging digital design technology" (1999). He claimed that in order to make it work, "Each student has to have his or her own computer, otherwise the most skilled students take over and other students don't get a chance. The group approach doesn't work in this form of teaching" (178).

As faculty members begin or continue to teach $\mathrm{CAD}$ along with studio, they will have to be committed to ongoing training in order to stay abreast of the rapid onslaught of technology. If they teach in schools with meager resources or constant budget cuts, they will have to constantly write grants to support their teaching and learning endeavors, invest in themselves to keep up with new software and upgrades, as well as convince administrators about the importance of integrating $\mathrm{CAD}$ in the curriculum. 


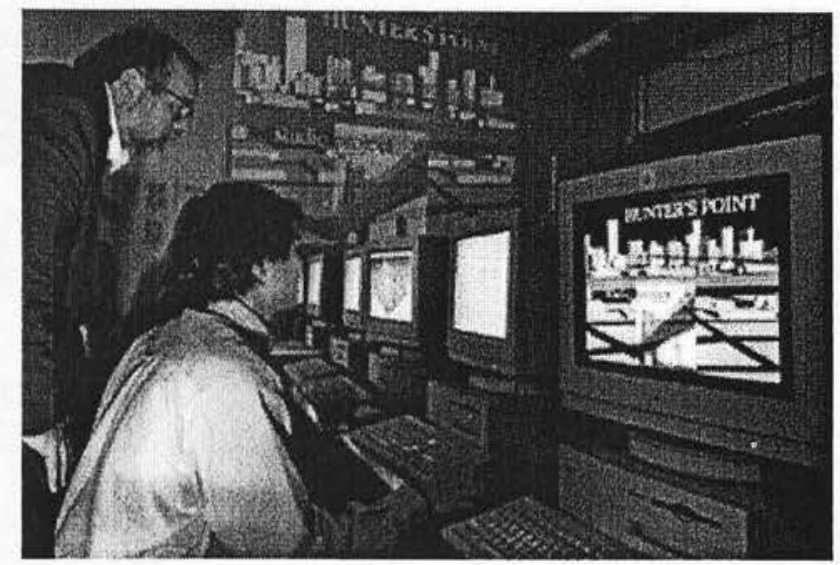

Figure 74: Roger Trancik in Martha Van Rensselaer lab, Cornell University (179).

In the professional world, continuing education has been one method of obtaining training on the job. Training is offered by software companies, product vendors, computer training companies and the ASLA. An example of continuing education offered by ASLA is one that is in partnership with The Pennsylvania State University on the 'digital office' directed by Prof. Madis Pilak of the landscape architecture department. Four courses are offered including digital multi-media; digital twodimensions, designing/drawing/drafting; three-dimensional models, and fourdimensional models (Figure 102 and 103)(180). ASLA has been providing 90-minute on-line educational sessions since 1998 (Sachet, personal communication, March 20, 2001). 


\title{
PENNSTATE World Campus

Proglam Description I Who Should Apphy I Admissions Requirements I Casts I Course Desoriptions | Course Schedule I Propram F acults: E Equipment Requirements I Tution Refund Sohedule | Language of instruotion | Certification/P artnerships | Accreditation

\section{Admissions}

\section{FACT SHEET}

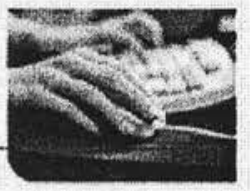

\section{Program Description}

The invention of paper oh anged the world. Today. a paper.only office is a thing of the past. That's the nature of ohange. What's cutting edge today is passe tomoutow. Le aining to maste the latest technology. While preparing for the inevitable change that is to come. is the key to success in even the most uncertain times. The Oigat Ottice ${ }^{5 m}$ Certificate program offeted through Penn State's World Campus is designed to help you make the transation from the traditional design studio.

OHfered through Penn State in oooperation with the American Society of Landscape Architects, the Digital Otfice ${ }^{\text {sm }}$ experience provides a unique combination of tradational conference material in an on-line distance education envisonment, moxed with the newest internet

technologies. Each module includes a ninety-minute video-streamed presentation by Associate Profess or Madis Pihlak, the American Society of Landscape Archilects' Conlinuing Education Chair. The presentations are coupled with hands-on projects and on-line learning resources. You can complete all four modules to earn a certiticate, or select a particular module to meet specifio professional development needs.

These short courses provide a perspective for design and planning professionak to dealwith the information technology revolution, and more specificaly, the design computing changes can improve efficiency and interaction betrueen personnel in your office. The components include information about the most appropriate sottware and hardware, as well as broader educational issues. Most importantly, the series addresses guiding principles to manage this canstantly changing options in design computing. The course broadby integrates drawing. drafting.

designing. modeling, and movie-making skilk for design professionats. Software and hardware choices are one of the key points of the class. Participants will discover and leam about some of the 140 CADD software programs.

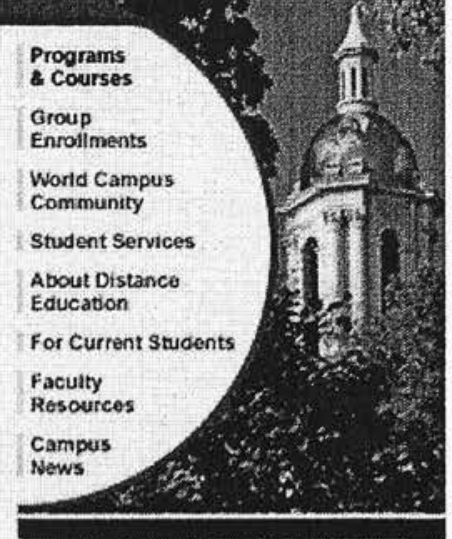

Apply How for the Certiflcate

ASLA Members Apply for Certificate

Apply Now for Individual Courses

ASLA Membars Apply for Courses

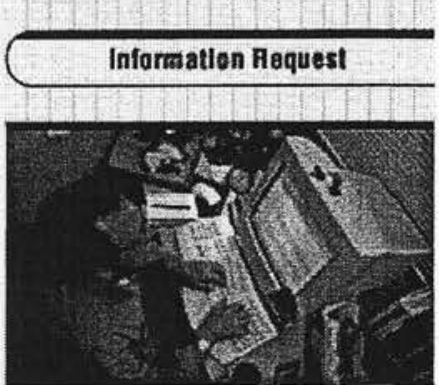

\section{Figure 75: On-line CAD course description offered by ASLA in partnership with Penn}

\author{
State University (181).
}




\section{Equipment Requirements}

\begin{tabular}{|c|c|}
\hline \multicolumn{2}{|r|}{ Digital Officest } \\
\hline Operating System & $\begin{array}{l}\text { Windows 95, } 98,2000, N T \text {, or ME } \\
\text { Macintosh System } 8.1 \text { or higher }\end{array}$ \\
\hline Processor & $300 \mathrm{MHz}$ or higher \\
\hline Memory & $\begin{array}{l}128 \mathrm{MB} \text { of RAM or higher. If you run into memory problems, } \\
\text { please feel free to e-mail the professor, Madis Pihlak at } \\
\text { madis-pilhlak@psu.edu }\end{array}$ \\
\hline Hard Drive Space & $300 \mathrm{MB}$ free disk space \\
\hline \multirow{2}{*}{ Browser } & $\begin{array}{l}\text { Netscape } 4 \text { or higher } \\
\text { Internet Explorer } 5 \text { or higher }\end{array}$ \\
\hline & $\begin{array}{l}\text { Note: Java and Javascript must be enabled } \\
\text { AOL users should upgrade to AOL } 5.0\end{array}$ \\
\hline Plug-ins & $\begin{array}{l}\text { Acrobat Feader } \\
\text { PowerPoint Viewer } \\
\text { Quicktime (optional) } \\
\text { Real Player }\end{array}$ \\
\hline Modem & $56 \mathrm{kbps}$ or ligher \\
\hline Printer & graphics-capable (inkjet or laser) printer \\
\hline CD-ROM & required \\
\hline Sound Card & required \\
\hline Monitor & $15 "$ monitor (800 x 600 resolution) \\
\hline
\end{tabular}

Figure 76: Hardware required for on-line CAD course offered by ASLA in partnership with Penn State University (182).

Until computer technology integrates more intuitive measures, training seems to be one of the methods at this time in helping to alleviate the non-intuitive aspect of computer use. Although training is available through various sources, most firms do not have a formal plan concerning training for their employees. Most firms spend money upgrading the computer rather than the employees who run them. Training is one of the 
first items to be eliminated when organizations try to cut expenses. As a result, professionals train themselves or get training from their colleagues. Ed Pinckney of Edward Pinckney/Associates, Ltd. admits, "Being committed to the computers is an expensive venture, especially where training is concerned" (personal communication, 1999). He explains that on-the-job training is expensive since he has to pay for the landscape architect's time as well as the instructor's time. Firms must recognize the value of well-educated staff and need to consider the value of investing in their employees by providing formal training (183). They will likely benefit from this as increasingly more digital tasks are carried out in-house and high-end users indicated that they are more creative with the use of computers.

\section{Future software}

Technology does not provide intuitive capabilities yet. However, if landscape architects desire to embrace the computer in the future, they need to express ideas for their needs to software design companies, even though landscape architects $(12,000)$ may have a small voice compared to architects $(70,000)$ and civil engineers $(123,000)$. AutoCAD is the industry standard for $\mathrm{CAD}$ because engineers comprise the dominant market. Of some $140 \mathrm{CAD}$ programs, (not including shareware) most of them are designed for architects and only one-third are appropriate for landscape architects. Obviously, software companies are interested in profits and thus the larger markets are the driving forces. However, landscape architects via ASLA and other professional bodies, have to take an active role to voice and satisfy their needs. Landscape architects should initiate the dialogue and maintain an ongoing communication. Positive results may materialize. For example, ESRI recently partnered with ASLA to offer GIS software at $40 \%$ discount. This may be an indication that there are possibilities for productive communication between landscape architects and software design companies. 
Survey respondents complained of problems with computer use. The top complaints cited were time consumption and high learning curve, as well as failure of equipment and poor design due to CAD limitations. In addition, survey respondents also expressed a desire for improvement of various aspects of technology including more speed; ease and power; compatibility; more/better symbols; and more/better software for precision/calculations. A quarter of the respondents felt that 3-D modeling and visualization would be ideal features for landscape architect. Some respondents even noted that they wanted "a program that does everything."

As software continues to be produced, landscape architects would likely benefit from voicing their opinions and needs. Tim Dixon, IT manager of Hughes, Good, O'Leary, and Ryan, a large Atlanta, Georgia based firm astutely stated, "I am hoping for a broader awareness from other landscape architects of the necessity of computers. This in turn will create a larger user base that will hopefully persuade software developers to develop programs suited towards landscape architecture needs" (personal communication, 1999).

Since three-quarters of the survey respondents felt pressured to keep up with computer graphics skills in order to stay competitive, it seems powerful software that is also responsive to landscape architects' needs would likely add intuitive options to the design process.

Many respondents felt that the use of computers helped to promote the profession. Large firms are more likely to feel that computers have helped to promote the 
profession than small firms. This is not surprising since they have more financial resources and generally have used computers for a longer period of time.

\section{Future of Virtual Office}

The virtual office is one in which all tasks are accomplished with the use of computers. Although, $41.8 \%$ of the survey respondents indicated that they have been involved in a 'virtual project', over three-quarters of the respondents from small firms and over half from large firms believed the total digital office was not likely going to replace the traditional office. This suggests that landscape architects were not ready yet for the virtual office. If the design process is easier and meetings can be virtual, does it seem that landscape architects can start being truly creative with computers?

Two viewpoints emerged regarding the concept of the virtual office. In several personal interviews with landscape architects, a difference of opinion was clearly detected. Greg Duckworth, of Environmental Concepts said, "The totally digital office is only a matter of time and I am gearing towards that day, but computer rendering techniques will have to come a long way before the totally digital office becomes reality" (personal communication, 1999). Art Oldham, of Oldham Planning and Design Associates, remarked, "The digital office is the environment in which landscape architects now exist. We have to keep our eyes peeled" (personal communication, 1999). He reiterates the need for firms to constantly evolve to stay ahead or even to keep up. David Perry, with Design Resource Group said, "The firm wants to continue on their current path to wherever it leads" (personal communication, 1999).

Conversely, Many respondents also felt that the intuitive process and the human and personal interaction cannot be replaced by computers. Ed Pinckney, of Edward 
Pinckney/Associates Ltd. believed, "The totally digital office will probably never come to pass because there is no substitute for the manual design process. Computers are useful when working on rectilinear designs, but become cumbersome with other shapes" (personal communication, 1999).

There has been exponential development in all areas of computers. In 1983, Anderson projected that further changes were going to be seen with software not developed yet, hardware, and affordability of computers (184). In the mid-1990s, author, Sanders predicted that we would begin to see virtual office and virtual environment in the future. His forecast for the future was to include students who would be more prepared with digital tools; the World Wide Web which would emerge as the preferred publishing medium; portable notebook computers that would supplant stationary desktops; integrated global communications that would be provided to the desktop; use of small scale catalogs from CD-ROM resources; the design of virtual environments that would emerge as a design service market (185). These forecasts have all become a reality today.

QuickTime VR and the ability of creating walk-throughs with still and video images are possible and readily accessible (186). Predictions have been made about advancements for the next $10-20+$ years. The list includes many items that seem to incorporate intuitive features.

- Virtual reality: "VR will become more real and less virtual" ("10 Technologies that Will Take Over," retrieved September 15, 2000)(187). The helmet and the gloves will be 'history' - to be replaced with holographic imagery. The game industry, for example, will be able to design games with interaction that occur with projected 3-D 
holograms which will completely engulf the field of vision, as opposed to playing the game on a monitor. In addition, "technology will eventually enable us to manipulate the brain directly so we can experience virtual sensations" ("10 Technologies that Will Take Over," retrieved September 15, 2000)(188). Thus in the VR game of the future, "you will dive into the midst of a blazing fire and actually feel the heat. But when you quit the game, you won't have a blister" ("10 Technologies that Will Take Over," retrieved September 15, 2000)(189).

- Speech recognition: voices will replace the keyboards and mice within the next decade.

- Wearable PCs: Already available wearable computers such as eyeglasses and wristwatches will be common day commodities in which one will have to put on just like shoes and coats today (190). 


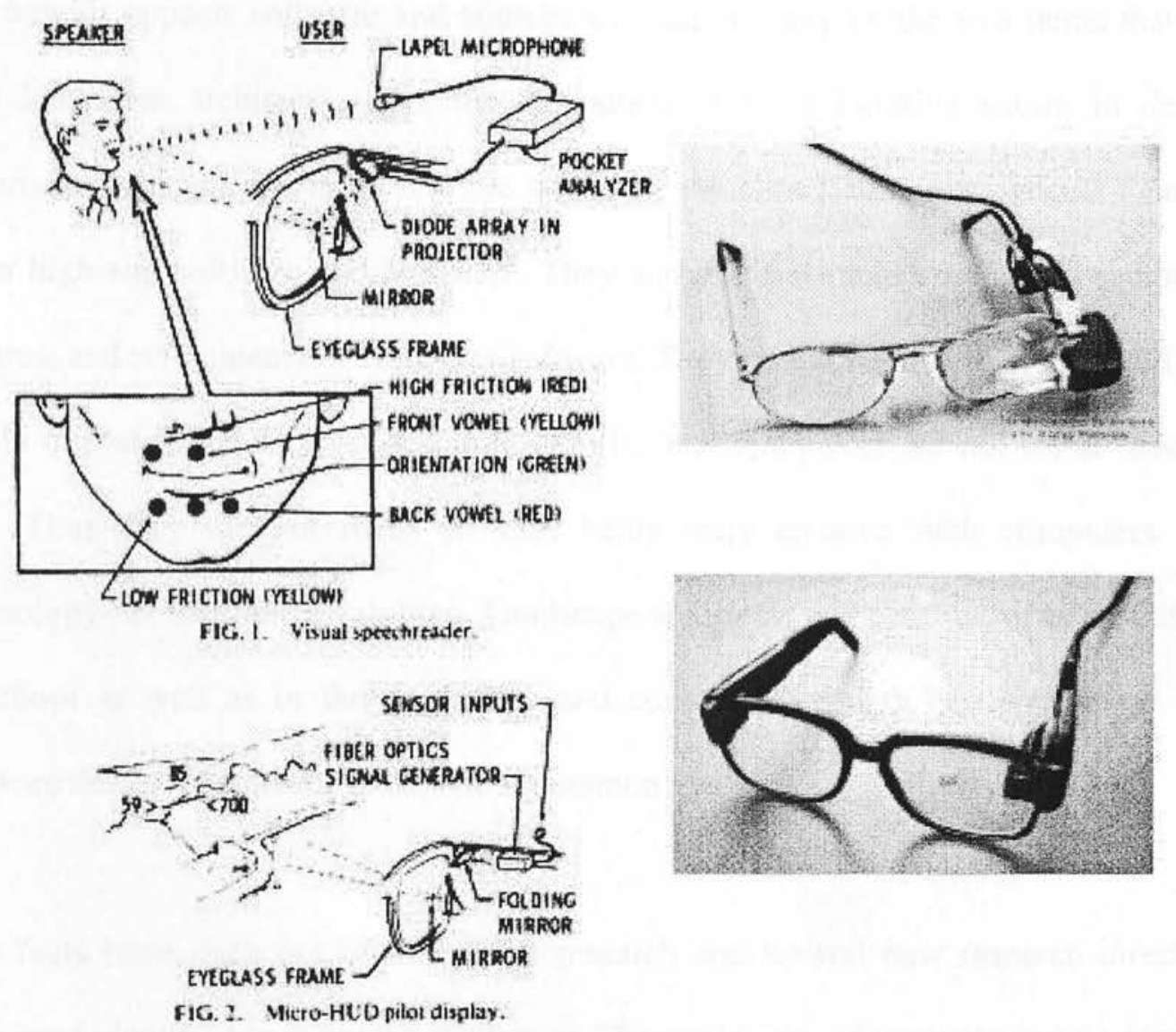

Figure 77: Left-visual speechreader. Right-wired glasses (189).

In the next 50 years, forecasters are suggesting that we will be the computers of tomorrow. "Wireless, speech recognition, wearable devices, and virtual reality-each of these technologies blurs the line between humans and computers just a little bit more... until the day comes when computers are literally inside of us" ("10 Technologies that Will Take Over," retrieved September 15, 2000)(191).

With the advancement of technology in the future, it may well be possible for a landscape architect to speak to the computer and give it instructions about how, what and when to draw and design and then step inside the virtual environment in real time animation replete with all the sensory perceptions. 
For now, it appears software and appropriate training may be the two items that will help landscape architects strive towards attaining more intuitive nature in design. Surprisingly, landscape architects are not asking for the "bells and whistles" or the super high-end software and hardware. They simply want more speed, less equipment failures, and refinements in computer software. They do not believe that there will be a totally digital office because design is intuitive and computers are not (or at least not yet). Thus they are not ready to start being truly creative with computers until technology becomes more intuitive. Landscape architects will need to focus on training in school as well as in the workplace and communicate with each other and with software design companies to meet that common goal.

New facts have risen out of this thesis research and several new research directions have been identified to follow in the future. The next series of inquiries to be addressed include:

1. Are firms willing to formally invest in their employees? If not, what are the barriers and what are their plans for the future?

2. Are schools investing effectively in their students? Are they integrating CAD into the curriculum? If so, how do they plan to sustain it for the long run?

3. Are practitioners, educators and software design companies willing to communicate with each other towards the common goal of improving software for the needs of landscape architects? If not, what are the barriers and what are the plans for the discipline in the future? 
It is through such rigorous fact finding and exploration of attitudes that researchers can provide landscape architects with new and relevant information about the profession and track and gauge the position of current and future issues facing the discipline. 


\subsection{References:}

176 Johnson, T. (2001. January 15). "Computer-based Design Studios in Landscape Architecture." Retrieved September 15, 2000 from the World Wide Web: $<$ http://cac.psu.edu/publications/web/publications/cac_guide/ets/catalog/complet ed/architecture/>

177 Trancik, R. (1999). “Cornell's Digital Outreach.” Form Z, 1998-99 Annual Report.

178 "Cornell landscape architects' rooms get technological make over to expand the range of teaching." Cornell Chronicle. (1997. March 13).

179 "Cornell landscape architects' rooms get technological make over to expand the range of teaching." ibid.

180 Digital Office Certificate. Penn State World Campus. Retrieved September 15, 2000 from the World Wide Web:

http://worldcampus.psu.edu/pub/digof/afs_prog_desc.shtml

181 Digital Office Certificate. Penn State World Campus. Retrieved September 15, 2000 from the World Wide Web:

http://worldcampus.psu.edu/pub/digof/afs_prog_desc.shtml

182 Digital Office Certificate. ibid.

183 Ojeda, O \& Guerra, L. (1996). Hyper realistic. McGraw Hill, Inc., New York.

184 Anderson, P. (1984). “ Stats on Computer Use.” Landscape Architecture, 64 (5), 101-102.

185 Ojeda, O \& Guerra, L. (1996). Hyper realistic. McGraw Hill, Inc., New York.

186 Ojeda \& Guerra. ibid.

187 "10 Technologies that Will Take Over." CNET.com. Retrieved September 15, 2000 from the World Wide Web:

http://coverage.cnet.com/Content/Reports/Features/10toWatch/ss08.html

"10 Technologies that Will Take Over." Ibid.

189 "10 Technologies that Will Take Over." CNET.com. Retrieved September 15, 2000 , op. cit.

190 "10 Technologies that Will Take Over." CNET.com. Retrieved September 15, 2000, op. cit.

191 “10 Technologies that Will Take Over." CNET.com. Retrieved September 15, 2000 , op. cit. 
APPENDIX ONE - MATERIALS USED 
Figure 50: Pilot Survey

Computers in Landscape Architecture Practice:

How has it affected you?

Results from this survey will help to assess the effect of computer technology on the design process of landscape architects. Please help with this study and complete the survey by May 1,1999 postmarked deadline. The results will be published and mailed to you.

\section{GENERAL}

1. Are you using computers in your practice? Yes No

2. How long have computers been integrated into your office?

$$
1 \text { year } \quad 2-3 \text { years } \quad 5-10 \text { years } 10+\text { years }
$$

3. How many employees are using computers?

4. How has the number of employees changed with the introduction of computers?
Increased
Decreased
Stayed the same

5. How has the number of people on a design team for a project been affected by the integration of computers?
Increased
Decreased
Stayed the same

\section{COMPUTER/USE}

6. What type of work does your firm do?

$\begin{array}{lll}\text { Residential } & \text { Industrial } & \text { Engineering } \\ \text { Commercial } & \text { Other }\end{array}$

7. How many employees work in your firm?

Landscape Architects

Engineers

Architects__ Planners ___ Other

8. What type of computer platform are you using? PC MAC

9. What is the time spent on $\mathrm{CAD}$ vs. time spent on using the other computer programs?

$25 \%$ vs $75 \% \quad 50 \%$ vs $50 \% \quad$ Other: $\%$ vs $\%$

10. What type of software are you using?

Other

Microsoft Office

Specification

Project Scheduling

Photoshop

Pagemaker 
GIS

AutoCAD

LandCAD

MiniCAD

Form Z

11. How does your firm use the computer within projects output? Please indicate $\%$ of use:

$\%$ Concept development $\%$ Presentations $\%$ Contract documentation
$\%$ Design development

$\%$ Other

12. Did you hire trained employees or train yourself?

Hired trained employee Train yourself

\section{SATISFACTION}

13. Are you and other employees satisfied with the computer programs used?

Yes

No

Explain

14. Are the principals satisfied with the computer programs used?

Yes

No

Explain

15. Are you required to use computers?

Yes No

Explain

16. Are you conveying your design ideas to your clients successfully with the use of computer drawings/presentations?

Yes

No

Explain

17. Are the others (contractors, architects, engineers, etc.) requiring computer drawings?

Yes No

Explain

\section{MAINTENANCE}

18. Is there a position in your firm dedicated to information management/technology? Yes 
19. How long did it take for computers to become cost effective?
0-1 mos.
6-12 mos.
Other
Has not yet

Explain

20. Have you in the past or currently budgeted annually for computers, such as for upgrades or new equipment?

$$
\text { Yes No }
$$

\section{SPACE}

21. How has the size of your office changed with the introduction of computers?

Increased Decreased Stayed the same

\section{EFFECTS ON DESIGN PROCESS}

22. Have you saved time from using computers? If no, skip to question 25 .

$$
\text { Yes No }
$$

23. How much faster does it take to do projects using the computer vs. by hand drawing?
$25 \%$
$50 \%$
$75 \%$
$\%$

24. How do you use the time saved from using computers? Do you spend it on:

Taking more time for design development

Taking on more projects

Completing more drawings per project

Leisure time

Other:

25. How has the computer changed the way you do work? Where do you spend time saved?

Finish one project before going on to another project

Spend more time writing memos etc.

Spend a lot of time searching on the internet

Other

Spend a lot of time learning new programs

Explain

26. Is your office locally networked?

Yes No

27. Do you have Internet access?

Yes

No

28. If you use e-mail, for what purpose do you use it? (Please rank: $5=$ most, $1=$ least)

For general correspondence

$\begin{array}{lllll}5 & 4 & 3 & 2 & 1\end{array}$

For sending and coordinating conceptual drawings

$\begin{array}{lllll}5 & 4 & 3 & 2 & 1\end{array}$

For sending and coordinating contract documentation

$\begin{array}{lllll}5 & 4 & 3 & 2 & 1\end{array}$ 
For sending presentation drawings

Other

29. What form of communication do you use? How do you communicate with clients and consultants since the integration of computers? (Please rank: $5=$ most, $1=$ least)

$\begin{array}{llllll}\text { E-mail } & 5 & 4 & 3 & 2 & 1 \\ \text { Fax } & 5 & 4 & 3 & 2 & 1 \\ \text { Phone } & 5 & 4 & 3 & 2 & 1 \\ \text { Mail } & 5 & 4 & 3 & 2 & 1 \\ \text { In-person } & 5 & 4 & 3 & 2 & 1 \\ \text { Other } & 5 & 4 & 3 & 2 & 1\end{array}$

30. How do you do your work?

By hand By hand and by computer By computer only

Explain

\section{FUTURE OUTLOOK}

31. What is your firms' ultimate goal for computers in your office? Is there a time frame for accomplishing the goal?

Explain

32. What are you hoping for in the future?

Explain

33. What did you hope to accomplish from the use of computers vs. what you actually accomplished?

Explain 
Questions are in one of the following categories:
(1): computer use
(2): design process
(3): other related effect

Type (1):

1. Are you using computers in your practice?

30. How do you do your work?
By hand
By hand and by computer
By computer only
Explain

1. Do you use computers to draft or enhance your design work?

The revised question allows for only those using CAD.

Type (1):

2. How long has computers been integrated into your office?
1 year
2-3 years
5-10 years
$10+$ years

2. How long has your office been using computers for these purposes?

1 Year 2-3 Years 5-10 years 10+ Years

Type (1):

6. What type of work does your firm do?

$\begin{array}{llll}\text { Residential Industrial Engineering } & \text { Commercial } \\ \text { Other } & \end{array}$

3. What kind of firm are you working with? small landscape architecture (1-10) medium landscape architecture (11-20) large landscape architecture ( 21 and above) other:

Type (3):

3. How many employees are using computers?

4. How has the number of people on a design team for a project been affected by the integration of computers?
Increased
Decreased
Stayed the same

7. How many employees work in your firm?

Landscape Architects Engineers

Architects Planners

Other

4. Has the integration of computers affected the make up of your firm?

There are

-more junior landscape architects with cad knowledge

-more computer technicians

-more senior landscape architects

-fewer senior landscape architects

-no changes. The office make up has stayed the same. 
Type (3):

4. How has the number of employees changed with the introduction of computers?

Increased Decreased Stayed the same

21. How has the size of your office changed with the introduction of computers? Increased Decreased Stayed the same

5. Has the integration of computers affected the physical office size?

The office is

smaller with more employees

smaller with fewer employees

larger with more employees

larger with fewer employees

Type (2):

11. How does your firm use the computer within project output? Please indicate $\%$ of use:

$\%$ Concept development

$\%$ Presentations

$\%$ Design development

$\%$ Other

6. Does the computer play a large role in your design process?

Yes No

If so, what task do you accomplish with the use the computer?

Please rank from 1-6 (6=most and 1=least).

conceptual design

design development

schematic design

working drawings

final presentations

Firm qualification presentations

Other:

\section{Type (2):}

25. How has the computer changed the way you do work? Where do you spend time saved?

Finish one project before going on to another project

Spend more time writing memos etc.

Spend a lot of time searching on the Internet

Spend a lot of time learning new programs

Other

Explain

7. Has the way you think about design been affected by the computer?

If so, explain. 
Question was not on pilot survey

Type (2):

8. Compared to traditional hand drawings, are your drawings now better worse the same

Question was not on pilot survey

Type (2):

9. Has designing on the computer helped your creativity hindered your creativity not affected your creativity

Type (2):

22. Have you saved time from using computers? If no, skip to question 22.

Yes No

23. How much faster does it take to do projects using the computer vs. by hand drawing?

$25 \%$ $50 \% \quad 75 \%$ $\%$

19. How long did it take for computers to become cost effective?
0-1 mo.
6-12 mos.
Other
Has not yet

Explain

10. Do you feel that overall you save time by using computers in your design process?

Yes No

If yes, when did you begin to see a savings in time?

first year

second year

third year

other

Type (2):

24. How do you use the time saved from using computers? Do you spend it on:

Taking more time for design development

Taking on more projects

Completing more drawings per project

Leisure time

Other:

11. What do you do with the extra time saved?

take on more work

spend time for leisure

spend more time doing other design tasks 
Question was not on pilot survey

Type (2):

12. When you design details and symbols, do you

draw them as needed

use details and symbols from a library you created

select details and symbols from existing libraries and revise them as needed

Question was not on pilot survey

Type (2):

13. Do you feel digital drawings are

More accurate than traditional drawings

Less accurate than traditional drawings

Just as accurate as traditional drawings

Question was not on pilot survey

Type (2):

14. With the ease of making changes on CAD drawings, do you find yourself spending excessive time perfecting your drawings?

Yes No

Question was not on pilot survey

Type (2):

15. When using the computer, do you feel your artistic quality is better

worse

the same

Question was not on pilot survey

Type (2):

16. With the use of computers, are your drawings for your projects consistently looking the same are very different each time

Type (3):

12. Did you hire trained employees or do you train yourself? Hired trained employee Train yourself

18. Is there a position in your firm dedicated to information management/technology? Yes No

17. When hiring a recent landscape architecture graduate do you hire strictly on CAD skills? Yes No If not, what skills are you expecting from them? Please rank from 1-5 (5=most, $\quad 1$ =least) 
Computer drafting

Computer presentation

Traditional drafting

Traditional presentation

All of the above

Question was not on pilot survey

Type (3):

18. How does your office execute computer design tasks?

Outsource it

In-house CAD specialist or operators

In-house graphic artist

Task delegated to design team within office

Question was not on pilot survey

Type (3):

19. Do you feel with expertise and skills in CAD you can easily advance in the firm

be categorized as the CAD person and must seek a position

elsewhere to in order to advance

Does not apply to you

Question was not on pilot survey

Type (3):

20. Do you feel pressured to keep up with the computer graphics skills in order to stay competitive.

Yes No

Type (3):

15. Are you required to use computers?

Yes No

Explain

17. Are the others (contractors, architects, engineers, etc.) requiring computer drawings?

Yes No

Explain

21. Is the use of $\mathrm{CAD}$ required by your clients? Yes No

If yes.

Some Most All clients

Question was not on pilot survey

Type (3):

26. Is your office locally networked?

Yes No 
27. Do you have Internet access?

Yes No

28. If you use e-mail, for what purpose do you use it? (Please rank: $5=$ most, $1=$ least)

For general correspondence

$\begin{array}{lllll}5 & 4 & 3 & 2 & 1\end{array}$

For sending and coordinating conceptual drawings

For sending and coordinating contract documentation

$\begin{array}{lllll}5 & 4 & 3 & 2 & 1\end{array}$

For sending presentation drawings

$\begin{array}{lllll}5 & 4 & 3 & 2 & 1\end{array}$

Other

29. What form of communication do you use? How do you communicate with clients

and consultants since the integration of computers? (Please rank: $5=$ most, $1=$ least)

$\begin{array}{llllll}\text { E-mail } & 5 & 4 & 3 & 2 & 1 \\ \text { Fax } & 5 & 4 & 3 & 2 & 1 \\ \text { Phone } & 5 & 4 & 3 & 2 & 1 \\ \text { Mail } & 5 & 4 & 3 & 2 & 1 \\ \text { In-person } & 5 & 4 & 3 & 2 & 1 \\ \text { Other } & 5 & 4 & 3 & 2 & 1\end{array}$

22. Do you use the Internet or email? If so, how often do you use it to send files via the Internet or email?
Always
Often
Seldom

Question was not on pilot survey

Type (3):

23. How has electronic communication affected the frequency of meetings with clients and consultants?

fewer meetings

more meetings

same number of meetings

Question was not on pilot survey

Type (3):

24. Has the communication by e-mail or Internet with your clients, engineers, architects affected the integrity of your designs?

Yes No

Question was not on pilot survey

Type (3):

25. What do you experience when exchanging files with other offices? compatibility problems

miscommunication due to lack of personal contact no problems 
Question was not on pilot survey

Type (3):

26. Do you have a Web site? Yes No

If yes,

it is created by an in-house employee

designed by outside web design professional

Question was not on pilot survey

Type (3):

27. Have you received any inquiry about your firm from your Web site?

Yes No

Question was not on pilot survey

Type (3):

28. Have you gotten any new work from the Web site?

Yes No

Question was not on pilot survey

Type (3):

29. Does your Web site have access to specific areas for your clients?

Yes

No

Question was not on pilot survey

Type (2):

30. Do you do presentations with the use of the computer?

Yes No

Question was not on pilot survey

Type (2):

31. Do you use walk-throughs or 3-D imaging for presentations?

Yes No

Question was not on pilot survey

Type (3):

32. How are projects archived at your firm?

Electronic storage media

Traditional storage methods

Question was not on pilot survey

Type (3):

33. Are you digitizing your slide library?

Yes No 


\section{Type (1):}

8. What type of computer platform are you using? PC MAC

10. What type of software are you using?

Other

Microsoft Office

Specification

Project Scheduling

Photoshop

Pagemaker

GIS

AutoCAD

LandCAD

MiniCAD

Form Z

34. What type of software do you use for design?

2-D CAD 3-D CAD Rendering Animation Imaging Graphic

Type (1):

9. What is the time spent on CAD vs. time spent on using the other computer programs?

$25 \%$ vs $75 \% \quad 50 \%$ vs $50 \% \quad$ Other: __ $\%$ vs _ $\%$

35) List the most used software in your office for drawing.

Question was not on pilot survey

Type (1):

36) What was the main reason you choose the software you are presently using?

Start-up cost

Easy learning curve

Specific features

Compatibility with client/associates

Peer suggestion

Question was not on pilot survey

Type (1):

37. Have you switched software since computer design has been in use at your firm?

Yes No

If you have switched software, what have you switched from and to what? 
Question was not on pilot survey

Type (1):

38) Are you using 3-D modeling software?

Yes No

If yes, do you find 3-D capabilities an important feature to have with your software?

Yes No

Question was not on pilot survey

Type (1):

20. Have you, in the past or currently budgeted annually for computers, such as for upgrades or new equipment?

Yes No

39. Do you annually budget for computer use?

Yes No

Question was not on pilot survey

Type (2):

40. Would you say that the computer has improved your design work? Yes No

Question was not on pilot survey

Type (1):

41. Do you think the use of computers in the landscape architecture office has helped promote the profession?

Yes No

Type (2):

13. Are you and other employees satisfied with the computer programs used? Yes No

14. Are the principals satisfied with the computer programs used? Yes No Explain

16. Are you conveying your design ideas to your clients successfully with the use of computer drawings/presentations?

Yes No

Explain

42. What are you creating on the computer which you feel is very innovative?

Question was not on pilot survey

Type (2):

43. What features would you consider would be ideal for landscape architects? 
Question was not on pilot survey

Type (2):

44. What would be one feature you would want to perfect in regard to the computer?

\section{Type (12):}

13. Are you and other employees satisfied with the computer programs used? Yes No Explain

14. Are the principals satisfied with the computer programs used?

Yes No

Explain

16. Are you conveying your design ideas to your clients successfully with the use of computer drawings/presentations?

Yes No

Explain

45. Name one instance in which the use of computers hurt instead of help.

Question was not on pilot survey

Type (3):

46. How will the results of this survey affect your firm in relation to computer use?

promote the use

inhibit the use

not affected by it

affect the firm in other ways

Question was not on pilot survey

Type (2):

47. Do you feel you can you compete today without the use of computers? Yes No

Question was not on pilot survey

Type (2):

48. Have you been involved in a "virtual" project (one done completely by computer)?

Yes No 
Type (2):

31. What is your firms ultimate goal for computers? What is the time frame for achieving this goal?

Explain

32. What are your hopes for the future?

Explain

33. Have you accomplished what you hoped for with the use of computers? Explain

49. Do you feel the totally digital office will ultimately replace the traditional

office?

Yes No

Comment:

Type (1):

50. What is your name, firm, and email/phone? 
Figure 52: Modified survey after pilot questionnaire

Thank you in advance for your assistance with this important survey!

Results from this survey will help to assess how computer technology has affected or changed the way in which landscape architects think, design, draw, organize and manage their office etc. It will help determine how computer technology has affected the professional practice of landscape architecture.

Personal interviews with over 50 landscape architects assisted in the compilation of these survey questions.

If you are interested in the results of this survey, please attach your email address below:

\section{Effect of computer technology on the design process and professional practice.}

1. Do you use computers to draft or enhance your design work?

Yes No

2. How long has your office been using computers for these purposes?

1 Year 2-3 Years 5-10 years 10+ Years

3. What kind of firm are you working with?

-small landscape architecture (1-10)

-medium landscape architecture (11-20)

-large landscape architecture ( 21 and above)

-other

4. Has the integration of computers affected the make up of your firm? There are -more junior landscape architects with $\mathrm{CAD}$ knowledge

-more computer technicians

-more senior landscape architects

-fewer senior landscape architects

-no changes. The office make up has stayed the same.

5. Has the integration of computers affected the physical office size? The office is - smaller with more employees

- smaller with fewer employees

- larger with more employees

-larger with fewer employees

-stayed the same 
6. Does the computer play a large role in your design process? Yes No If so, what task do you accomplish with the use the computer?

Please rank from 1-6 (6=most and 1=least).

-conceptual design

-schematic design

-design development

-working drawings

-final presentations

-firm qualification presentations

-other

7. Has the way you think about design been affected by the computer? If so, explain.

8. Compared to traditional hand drawings, are your drawings now

-better

-worse

-the same

9. Has designing on the computer

-helped your creativity

-hindered your creativity

-not affected your creativity

10. Do you feel that overall you save time by using computers in your design process?

Yes No

If yes, when did you begin to see a savings in time?

-first year

-second year

-third year

-other

11. What do you do with the extra time saved?

-take on more work

-spend time for leisure

-spend more time doing other design tasks

12. When you design details and symbols, do you

-draw them as needed

-use details and symbols from a library you created

-select details and symbols from existing libraries and revise them as needed

13. Do you feel digital drawings are

-more accurate than traditional drawings

-less accurate than traditional drawings

-just as accurate as traditional drawings

-other 
14. With the ease of making changes on CAD drawings, do you find yourself spending excessive time perfecting your drawings?

Yes No

15. When using the computer, do you feel your artistic quality is

-better

-worse

-the same

-other

16. With the use of computers, are your drawings for your projects

-consistently looking the same

-very different each time

-other

17. When hiring a recent landscape architecture graduate do you hire strictly on CAD skills? Yes No

If not, what skills are you expecting from them? Please rank from 1-5 (5=most, $1=$ least)

-computer drafting

-computer presentation

-traditional drafting

-traditional presentation

-all of the above

18. How does your office execute computer design tasks?

-outsource it

-in-house CAD specialist or operators

-in-house graphic artist

-task delegated to design team within office

19. Do you feel with expertise and skills in CAD you can

easily advance in the firm

-be categorized as the $\mathrm{CAD}$ person and must seek a position

-elsewhere to in order to advance

-does not apply to you

-other

20. Do you feel pressured to keep up with the computer graphics skills in order to stay competitive.

Yes No

21. Is the use of CAD required by your clients? Yes No

If yes. -some -most -all clients 


\section{Electronic Communication}

22. Do you use the Internet or email? If so, how often do you use it to send files via the Internet or email?

-always -often -seldom

23. How has electronic communication affected the frequency of meetings with clients and consultants?

-fewer meetings

-more meetings

-same number of meetings

-other

24. Has the communication by email or Internet with your clients, engineers, architects affected the integrity of your designs?

Yes No

-other

25. What do you experience when exchanging files with other offices?

-compatibility problems

-miscommunication due to lack of personal contact

-no problems

26. Do you have a Web site? Yes No

If yes,

-it is created by an in-house employee

-designed by outside web design professional

27. Have you received any inquiry about your firm from your Web site?

Yes No

28. Have you gotten any new work from the Web site?

Yes No

29. Does your Web site have access to specific areas for your clients?

Yes No

30. Do you do presentations with the use of the computer?

Yes No

31. Do you use walk-throughs or 3D imaging for presentations?

Yes No

\section{Archiving}

32. How are projects archived at your firm?

-electronic storage media

-traditional storage methods

-both:

33. Are you digitizing your slide library?

Yes No 


\section{Software}

34. What type of software do you use for design?

-2-D CAD - 3-D CAD -rendering -animation -imaging -graphic

35. List the most used software in your office for drawing.

36. What was the main reason you choose the software you are presently using? -start-up cost

-easy learning curve

-specific features

-compatibility with client/associates

-peer suggestion

37. Have you switched software since computer design has been in use at your firm?

Yes No

If yes, what have you switched from and to what?

38. Are you using 3-D modeling software? Yes No

If yes, do you find 3-D capabilities an important feature to have with your software?

Yes No

39. Do you annually budget for computer use?

Yes No

\section{Summary and Future outlook}

40. Would you say that the computer has improved your design work? Yes No

41. Do you think the use of computers in the Landscape Architecture office has helped promote the profession?

Yes No

42. What are you creating on the computer which you feel is very innovative?

43. What features would you consider would be ideal for landscape architects?

44. What would be one feature you would want to perfect in regard to the computer?

45. Name one instance in which the use of computers hurt instead of help. 
46. How will the results of this survey affect your firm in relation to computer use? -promote the use

-inhibit the use

-not affected by it

-affect the firm in other ways

-other

47. Do you feel you can compete today without the use of computers?

Yes No

48. Have you been involved in a "virtual" project (one done completely by computer)?

Yes No

49. Do you feel the totally digital office will ultimately replace the traditional office?

Yes No

Comment

50. What is your name, firm, and email/phone? 


\section{Figure 53: Design format of the questionnaire survey.}

The questionnaire survey was designed with the use of the software Macromedia Dreamweaver. It is a web authoring program, which easily allows for the integration of radio buttons, check boxes, text field, and select boxes. It was essential to provide an easy format for answering the questions. In all, there were 50 questions. The questionnaire was designed with:

- 16 radio buttons (section/question: I.1, I.2, I.14, I.20, II.6, II.7, II.8, II.9, II.10, III.2, IV.5, IV.6, V.1, V.2, V.8, and V.9)

- 2 check boxes (section/question: I.4, IV.1)

- 7 text field (section/question: I.7, IV.2, V.3, V.4, V.5, V.6, and V.11)

- 9 select boxes (section/question: I.5, I.8, I.9, I.11, I.12, I.18, II.1, II.4, and III.1)

- 3 radio buttons and select box (section/question: I.17, I.21, II.5)

- 3 radio buttons and text fields (section/question: II.3, IV.4, and V.10)

- 2 radio buttons select boxes and text fields (section/question: I.6, I.10,)

- 1 check boxes and text fields (section/question: IV.3)

- 7 select boxes and text fields (section/question: I.3, I.13, I.15, I.16, I.19, II.2, and V.7)

In order not to bias survey participants, many text field questions were incorporated. In the final analysis, these questions gave more insight on the attitudes of landscape architects that would not have been apparent otherwise. 


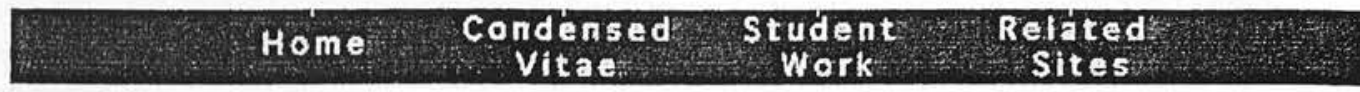

\title{
Survey Sections:
}

\author{
I. Effect of Computer Technology on the Design Process and Professional Practice \\ II. Electronic Communication \\ III. Archiving \\ IY. Softrare \\ Y. Summary and Future Oatlook
}

I.Effect of computer technology on the design process and professional practice.

1. Do you use computers to draft or enhance your design work?

$\mathrm{O}$ Yes $\mathrm{NO}$

2. How long has your office been using computers for these purposes?

$\bigcirc 1$ Year $\bigcirc 2-3$ Years $\bigcirc$ 5-10 Years $\bigcirc 10+$ Years

3. What kind of firm are you working with?

select one of the following

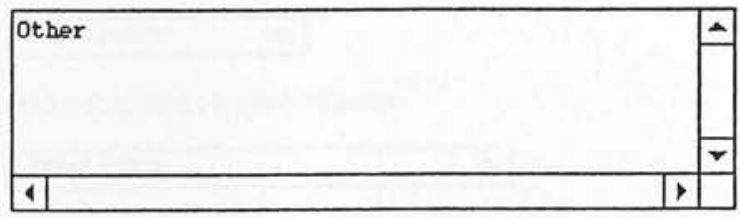

4. Has the integration of computers affected the make up of your fim? There are
More junior landscape architects with cad knowledge
More computer technicians
More senior landscape architects
Fewer senior landscape architects
No changes. The office make up has stayed the same.

5. Has the integration of computers affected the physical office size? The office is 
6. Does the computer play a large role in your design process?

$\mathrm{O}$ Yes $\mathrm{O}$ No

If so, what task do you accomplish with the use the computer? Please rank from 1-6 ( $6=$ most and $1=$ least).

$0 \quad \rightarrow$ Conceptual design

$0 \quad \Rightarrow$ Design development

0 Schematic design

$0 \quad 0$ Working drawings

$0 \leqslant$ Final presentations

$0 \triangleq$ Firm qualification presentations

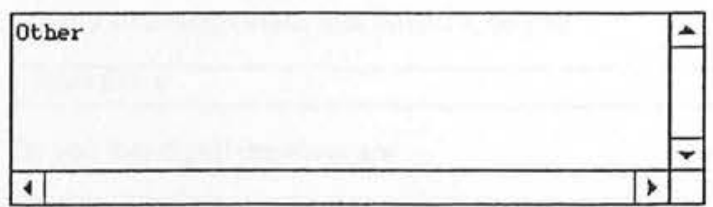

7. Has the way you think about design been affected by the computer? If so, explain.

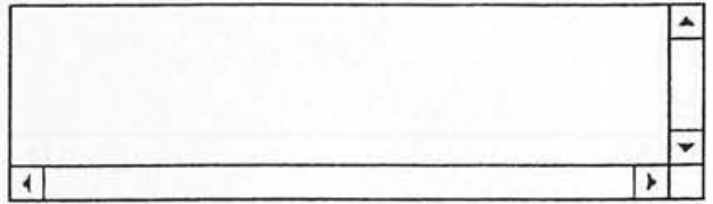

8. Compared to traditional hand drawings, are your drawings now:

Select Below

4

9. Has designing on the computer

Select Below $\leqslant$ 
10. Do you feel that oyerall you save time by using computers in your design process?

O Yes $O$ No

If yes, when did you begin to see a savings in time?

Select Below

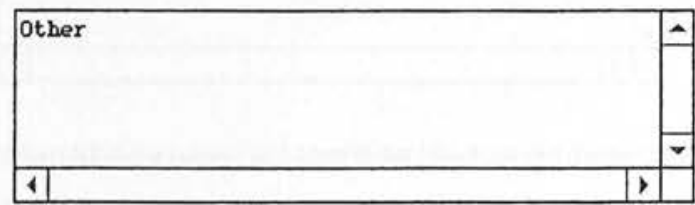

11. What do you do with the extra time sayed?

Select Below

12. When you design details and symbols, do you

Select Below

13. Do you feel digital drawings are

Select Below

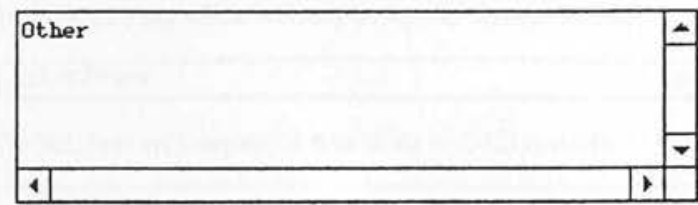

14. With the ease of making changes on CAD drawings, do you find yourself spending excessive time perfecting your drawings?

O Yes O No

15. When using the computer, do you feel your artistic quality is

Select Below

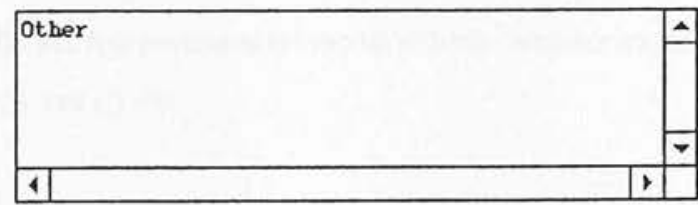


16. Whth the use of computers, are your drawings for your projects

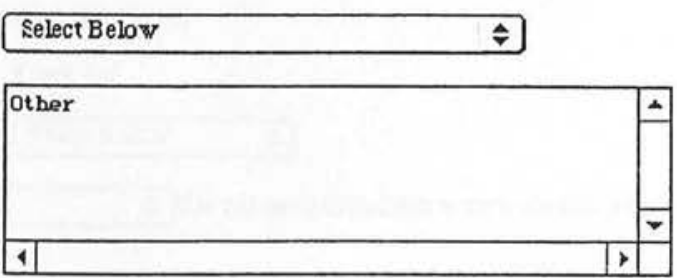

17. When hiring a recent landscape architecture graduate do you hire strictly on CAD skills?

$O$ Yes $O$ No

If not, which skills would you consider most important? Please rank from 1-5 ( $5=$ =most, $1=$ least)

$0 \quad \div$ Computer drafting

$0 \div$ Computer presentation

$0 \quad \div$ Traditional drafting

$0 \leqslant$ Traditional presentation

18. Haw does your office execule computer design tasks?

Select Below

19. Do you feel with expertise and skills in CAD you can

Select Below

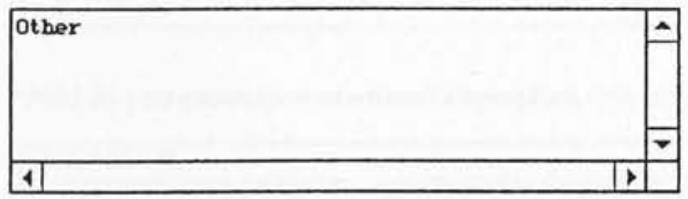

20. Do you feel pressured to keep up with the computer graphics skills in order to stay competitive.

O Yes O No 
21. Is the use of CAD required by your clients?

O Yes O No

If yes, by

Select Below

Go to - Use this navigational link to view the different parts of the survey. Otherwise simply move on to the next section.

II. Electronic Communication

1. Do you use the Internet or $\epsilon$-mail? If 30 , how often do you use it to send files yia the Internet or $\epsilon$-mail?

Select Below $\rightarrow$

2. How has electroric communication affected the frequency of meetings with clients and consultants?

Select Below

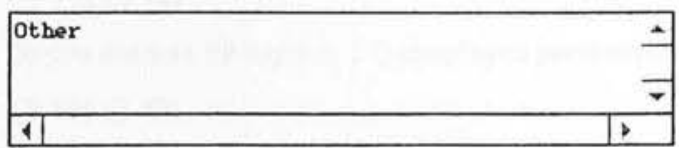

3. Has the commun cation by $€$-mail or Internet with your slients, engineers, architects affected the integrity of your designs?

Y Yes $O$ No

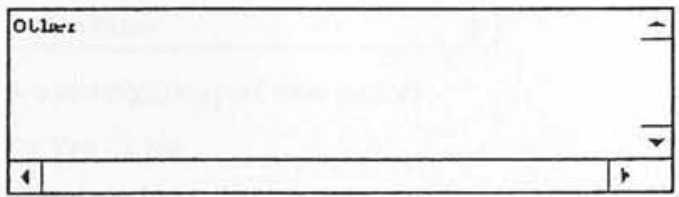

4. What do you experience when excranging files with other offices? 
5. Do you have a Web site?

$O$ Yes $O$ No

If yes,

Select Below

6. Have you received any inquiry about your firm from your Web site?

O Yes $O$ No

7. Have you received any new work from the Web site?

$\mathrm{O}$ Yes $\mathrm{O}$ No

8. Does your Web site have access to specific areas fcr your clients?

$\mathrm{O}$ Yes O No

9. Do you do presentations with the use of the computer?

O Yes O no

10. Do you use walk throughs or 3-D imaging for presentations?

$\mathrm{O}$ Yes $\mathrm{O}$ No

Go to $\quad-$ Use this navigational link to view the differert parts of the survey. Otherwise simply move on to the next section.

\section{Archiying}

1. How are projects archired at your firm?

Select Below

$\rightarrow$

2. Are you digitizing your slide library?

$\mathrm{O}$ Yes $\mathrm{O}$ No

Go to $\quad$ Use this navigational link to view the differert parts of the survey. Otherwise simply move on to the next section. 


\section{Software}

1 What type of sofware do you use for design?
2-D CAD
3-D CAD
Rendering
Animation
Imaging
Graphic

2 List the most used software in your office for drawing.

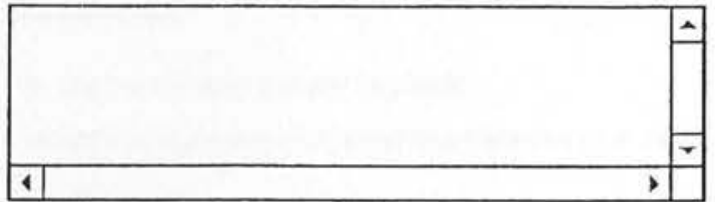

3 What was the main reason you crose the software you are presently using?

Start-up cost

Easy learning curve

Specific fea:ures

Compatibility with clientrassociates

Peer suggestion

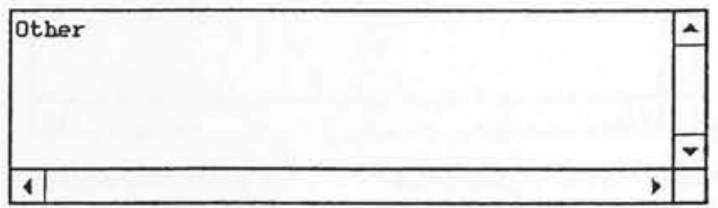

4 Haye you switched software since computer desigr has been in use at your firm?

O Tes O No

If yes, what have you switched from and to what?

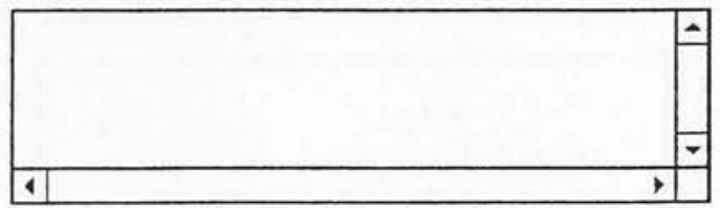


5. Are you using 3-D modeling software?

O Yes O No

If yes, do you find 3-D capabilities an important feature to have with your software?

O Yes O No

6. Do you annually budget for computer use?

O Yes O No

Go to $\quad$ Use this navigational link to view the different parts of the survey. Otherwise simply move on to the next section.

Y. Summary and Future Outlook

1. Would you say that the computer has improved your design work?

$O$ Yes $O$ No

2. Do you think the use of computers in the Landscape Architecture office has helped promote the profession? O Yes O No

3. What are you creating on the computer which you feel is very innovative?

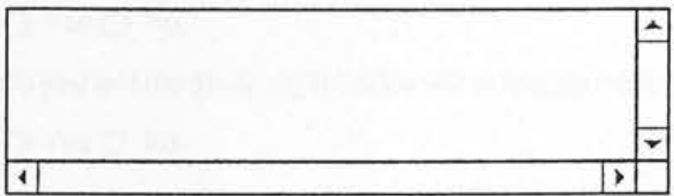

4. What features would you consider would be ideal for landscape architects?

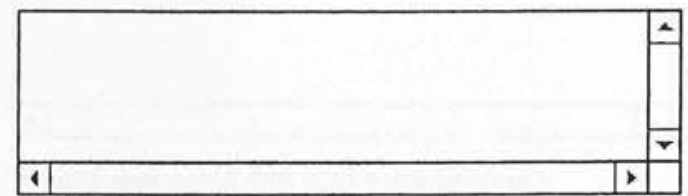

5. What would be one feature you would want to perfect in regard to the computer?

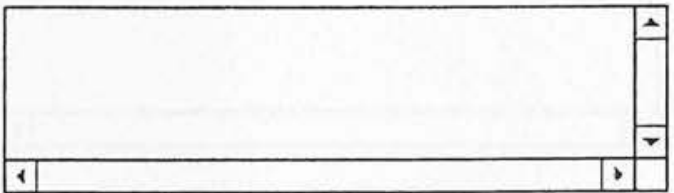


6. Name one instance $n$ which the use of computers hurt instead of help.

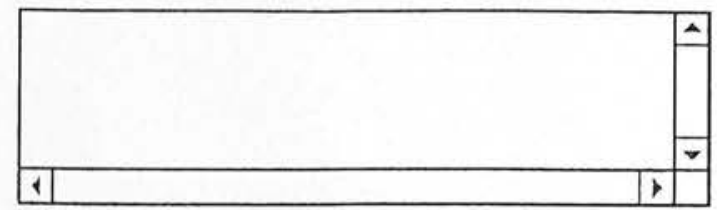

7. How will the results of this survey affect your fim in relation to computer use?

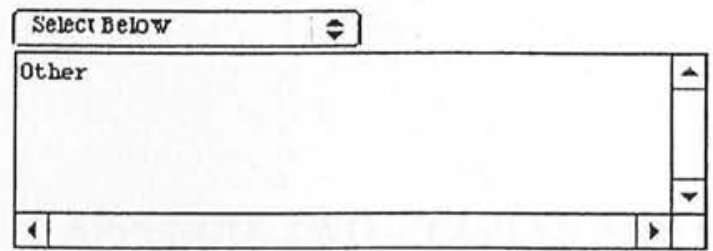

8. Do you feel you can you compete today without the use of computers?

$\mathrm{O}$ Yes $\mathrm{O}$ No

9. Have ycu been invo ved in a "virtual" project ione done completely by computer)?

$\mathrm{O}$ Yes $\mathrm{O}$ No

10. Do you feel the totally digital office will ultimalely replace the traditional office?

D Yes Do

Comment:

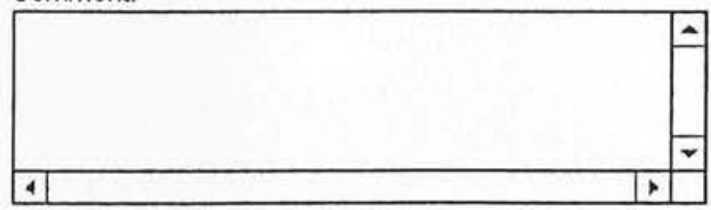

11. What is your name, firm, and e-rraillphone?

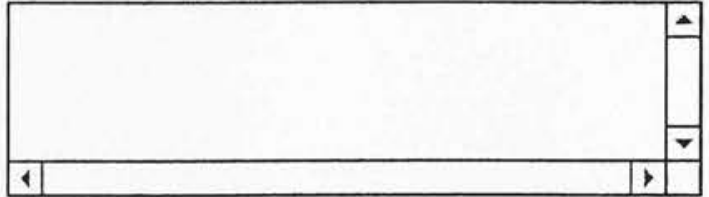

Submit survey 
APPENDIX TWO - TABLES AND ILLUSTRATIVE MATERIAL 


\section{SURVEY}

I. Effects of computer technology on the design process and professional practice

1. Do you use computers to draft or enhance your design work?

Yes $99 \% \quad$ No $\quad 1 \% \quad n=102$

2. How long has your office been using computers for these purposes?

-1 Year - $\quad 5.0 \%$

$-2-3$ Years - $13.9 \%$

$-5-10$ years - $52.5 \%$

$-10+$ Years $-28.7 \% \quad n=101$

3. What kind of firm are you working with?

-small landscape architecture (1-10) -

-medium landscape architecture (11-20) - $\quad 17.7 \%$

-large landscape architecture ( 21 and above)- $\quad 39.6 \%$

-other -

$0.0 \%$

$n=96$

4. Has the integration of computers affected the make up of your firm? There are -more junior landscape architects with CAD knowledge - $\quad 42.6 \%$

-more computer technicians - $\quad 11.9 \%$

-more senior landscape architects - $\quad 0.0 \%$

-fewer senior landscape architects - $\quad 2.0 \%$

-no changes. The office make up has stayed the same - $\quad 43.6 \% \quad n=101$

5. Has the integration of computers affected the physical office size? The office is

- smaller with more employees -

\section{$5.1 \%$}

- smaller with fewer employees -

$2.0 \%$

- larger with more employees -

- larger with fewer employees -

$6.1 \%$

- stayed the same -

$62.6 \%$

$\mathrm{n}=99$ 
6. Does the computer play a large role in your design process? Yes No

Yes $80.4 \% \quad$ No $19.6 \% \quad \mathrm{n}=102$

If yes, what task do you accomplish with the use the computer?

Please rank from 1-6 ( $1=$ low use and 6=high use).

\begin{tabular}{|l|l|r|r|r|r|r|r|r|r|}
\hline & Design process & Low & & & & & High & & \\
\hline & & $\%$ use & $\%$ & $\%$ & $\%$ & $\% \%$ use & & \\
\hline & Ranking & 1 & 2 & 3 & 4 & 5 & 6 & $\begin{array}{l}\text { missin } \\
\mathrm{g}\end{array}$ & $\mathrm{n}=$ \\
\hline 6a) & $\begin{array}{l}\text { qualification } \\
\text { presentations }\end{array}$ & 10.8 & 4.8 & 4.8 & 15.7 & 18.1 & 45.8 & 19 & 83 \\
\hline 6b) & schematic design & 11 & 23.1 & 24.2 & 12.1 & 17.6 & 12.1 & 11 & 91 \\
\hline 6c) & lonceptual design & 45.7 & 17 & 19.1 & 5.3 & 3.2 & 9.6 & 8 & 94 \\
\hline 6d) & design development & 10.8 & 15.1 & 21.5 & 18.3 & 14 & 20.4 & 9 & 93 \\
\hline 6e) & schematic design & 11 & 23.1 & 24.2 & 12.1 & 17.6 & 12.1 & 11 & 91 \\
\hline 6f) & working drawings & 2.1 & 1.1 & 7.4 & 5.3 & 11.6 & 72.6 & 7 & 95 \\
\hline 6g) & final presentations & 2.2 & 7.9 & 10.1 & 25.8 & 20.2 & 33.7 & 13 & 89 \\
\hline
\end{tabular}

7. Has the way you think about design been affected by the computer?

If so, explain

Yes $52.7 \% \quad$ No $47.3 \% \quad n=74$

List of example comments include:

-"Design becomes reality faster. Exactness of the design is enhanced. Complex physical relationships can be easily explored."

-"I can explore in more detail the way the design works or how elements can work together."

-"Yes. There is a possibility of the computer to be able to enhance the design, as well as, the design process. The computer can handle labor and time intensive tasks. This in turn, can lead to more time with the actual design.

-"Yes. We are designing more like we draw. Things such as free flowing curves are now broken down into arcs and tangents. The computer holds us back in design because of its exactness."

-"No. Design is still in the mind and hand."

-"No. The design process is still the same. The computer is a tool to accelerate the process."

-"We find we need to get off the computer at times to think more creatively." Then transfer ideas from paper to computer."

-"No. Conceptual design is still extremely cumbersome for landscape architects to do in the computer. Most of the conceptual design is till done by hand. Landscape architects feel threatened/inhibited when truing to use a computer 
for design, unless it is extremely geometric."

8. Compared to traditional hand drawings, are your drawings now

better $\quad 59.2 \%$

worse $\quad 13.3 \%$

the same $\quad 27.6 \% \quad n=102$

9. Has designing on the computer

-helped your creativity $\quad 25.5 \%$

-hindered your creativity $\quad 29.4 \%$

-not affected your creativity $45.1 \% \quad \mathrm{n}=102$

10. Do you feel that overall you save time by using computers in your design process?

$\begin{array}{llll}\text { Yes } 70.4 \% & \text { No } \quad 29.6 \% & \mathrm{n}=98\end{array}$

If yes, when did you begin to see a savings in time?

-first year $\quad 56.3 \%$

-second year $\quad 25.0 \%$

-third year $\quad 18.8 \%$

$\begin{array}{lll}\text {-other } & 0.0 \% & \mathrm{n}=64\end{array}$

11. What do you do with the extra time saved?

-take on more work $\quad 60.9 \%$

-spend time for leisure $\quad 1.4 \%$

-spend more time doing other design tasks $\quad 37.7 \% \quad n=69$

12. When you design details and symbols, do you

-draw them as needed

-use details and symbols from a library you created $35.1 \%$

-select details and symbols from existing $\quad 56.7 \%$

libraries and revise them as needed

$\mathrm{n}=97$

13. Do you feel digital drawings are

-more accurate than traditional drawings 
-less accurate than traditional drawings

14. With the ease of making changes on CAD drawings, do you find yourself spending excessive time perfecting your drawings?

$\begin{array}{llll}\text { Yes } \quad 49.5 \% \quad \text { No } & 50.5 \% & n=99\end{array}$

15. When using the computer, do you feel your artistic quality is

-better $\quad 18.3 \%$

-worse $\quad 39.8 \%$

-the same $\quad 41.9 \%$

-other $\quad 0.0 \% \quad n=93$

16. With the use of computers, are your drawings for your projects -consistently looking the same $86.2 \%$

-are very different each time $13.8 \%$

-other

$0.0 \%$ $\mathrm{n}=87$

17. When hiring a recent landscape architecture graduate do you hire strictly on
CAD skills?
Yes $\quad 7.5 \%$ No
$92.5 \%$
$\mathrm{n}=93$

If not, what skills are you expecting from them? Please rank from 1-5 (1=least and $5=$ most)

\begin{tabular}{|c|c|c|c|c|c|c|c|}
\hline & Skills & $\begin{array}{l}\text { Low } \\
\% \text { use }\end{array}$ & & $\begin{array}{r}\text { Neutr } \\
\text { al } \\
\% \text { use }\end{array}$ & & $\begin{array}{l}\text { High } \\
\% \text { use }\end{array}$ & \\
\hline & Ranking & 1 & 2 & 3 & 4 & 5 & \begin{tabular}{l|l}
$\operatorname{missing}$ & $\mathrm{n}$
\end{tabular} \\
\hline 17a) & computer drafting & 1.1 & 13.8 & 23 & 31 & 31 & $15 n=87$ \\
\hline 17b) & traditional presentation & 8.1 & 21.6 & 27.5 & 19.6 & 8.8 & \begin{tabular}{l|l}
16 & $n=86$ \\
\end{tabular} \\
\hline 17c) & traditional drafting & 8.3 & 27.4 & 26.2 & 27.4 & 10.7 & \begin{tabular}{l|l}
18 & $n=84$ \\
\end{tabular} \\
\hline $17 d)$ & computer presentation & 7 & 14 & 23.3 & 25.6 & 30.2 & \begin{tabular}{l|l}
16 & $n=86$ \\
\end{tabular} \\
\hline
\end{tabular}

18. How does your office execute computer design tasks?

$\begin{array}{ll}\text {-out-source it } & 6.1 \% \\ \text {-in-house CAD specialist or operators } & 32.7 \% \\ \text {-in-house graphic artist } & 2.0 \% \\ \text {-task delegated to design team within office } & 59.2 \%\end{array}$


19. Do you feel with expertise and skills in CAD you can

-easily advance in the firm

-be categorized as the CAD

person and must seek a position

elsewhere to in order to advance

-does not apply to you

$48.9 \%$

$\mathrm{n}=88$

20. Do you feel pressured to keep up with the computer graphics skills in order to

$\begin{array}{llll}\text { stay } & \text { competitive. Yes } 75.2 \% \quad \text { No } 24.8 \% \\ n=101 & & \end{array}$

21. Is the use of $\mathrm{CAD}$ required by your clients?

Yes $88 \% \quad$ No $12 \% \quad n=100$

21a. If yes. Some $27.7 \% \quad$ Most $53 \%$ All clients $19.3 \% \quad n=83$

II. Electronic Communication

22. Do you use the Internet or email? If so, how often do you use it to send files via the Internet or email?
Always $16.8 \%$
Often $48.5 \%$ Seldom $34.7 \%$
$\mathrm{n}=101$

23. How has electronic communication affected the frequency of meetings with clients and consultants?

-fewer meetings

$42.3 \%$

-more meetings

$2.1 \%$

-same number of meetings

$55.7 \%$

$\mathrm{n}=97$

-other

$0.0 \%$

24. Has the communication by email or Internet with your clients, engineers, architects affected the integrity of your designs?
Yes $\quad 51.5 \%$
No
$48.5 \%$
Other $0 \% \quad n=97$

25. What do you experience when exchanging files with other offices?

-compatibility problems $\quad 44 \%$

-miscommunication due $\quad 10 \%$ 
to lack of personal contact

-no problems

$46 \%$

$\mathrm{n}=100$

26. Do you have a Web site? Yes $70.8 \%$ No $29.2 \% \quad n=96$

If yes,

-it is created by an in-house employee

$65.7 \%$

-designed by outside web design professional $\quad 34.3 \%$

27. Have you received any inquiry about your firm from your Web site?

Yes $72.2 \%$

No $\quad 27.8 \% \quad \mathrm{n}=72$

28. Have you received any new work from the Web site?

Yes $38.9 \% \quad$ No $\quad 61.1 \% \quad n=72$

29. Does your Web site have access to specific areas for your clients?

Yes $65.8 \% \quad$ No $\quad 34.2 \% \quad n=73$

30. Do you do presentations with the use of the computer?

Yes $75.3 \% \quad$ No $24.7 \% \quad n=97$

31. Do you use walk-throughs or 3-D imaging for presentations?

Yes $38.5 \% \quad$ No $\quad 61.5 \% \quad n=96$

\section{Archiving}

32. How are projects archived at your firm?

-electronic storage media

$19.8 \%$

-traditional storage methods

$5.9 \%$

-both

$74.3 \% \quad n=101$

33. Are you digitizing your slide library?

Yes $\quad 43 \% \quad$ No $\quad 57 \% \quad n=100$

\section{Software}

34. What type of software do you use for design?

2-D CAD 3-D CAD Rendering Animation Imaging Graphic -Basic (2-D and others)

$46.7 \%$ 
-Intermediate (3-D and others)

-Advanced (Animation and others) $\quad 13.3 \% \quad \mathrm{n}=75$

Examples of items listed under "others" include:

-Rendering, imaging, and/or graphic for basic

$-2-D$, rendering, imaging, and/or graphic for intermediate

-2-D, 3-D, rendering, imaging, graphic, and/or animation for advanced

35. List the most used software in your office for drawing.

-AutoCAD only

$32.6 \%$

-AutoCAD and others

$55.8 \%$

-Microstation

$9.5 \%$

-Microstation and others

$2.1 \% \quad \mathrm{n}=95$

Example of items listed under "others" include: Photoshop, Corel Draw, LandCADD, Arview GIS, Freehand, 3-D Studio, Pagemaker, and Formz.

36. What was the main reason you choose the software you are presently using?

-start-up cost $3.9 \%$

-easy learning curve $2.0 \%$

-specific features $15.7 \%$

-compatibility with clients/associates $55.9 \%$

-peer suggestion $5.9 \%$

-features and compatibility $16.7 \%$

with clients/associates $\mathrm{n}=102$

37. Have you switched software since computer design has been in use at your firm? Yes $31.6 \%$ No $\quad 68.4 \%$ $\mathrm{n}=98$

If you have switched software, what have you switched from and to what? Example responses include: switched for upgrades (AutoCAD r14 to AutoCAD 2000) and/or just added new software (e.g. ArcView GIS).

38. Are you using 3-D modeling software? Yes $50.5 \%$ No $49.5 \%$ $\mathrm{n}=101$ If yes, do you find 3-D capabilities an important feature to have with your software? Yes $63.6 \% \quad$ No $36.4 \% \quad n=77$ 
39. Do you annually budget for computer use?

Yes $78 \% \quad$ No $22 \% \quad n=100$

V. Summary and Future outlook

40. Would you say that the computer has improved your design work? Yes $72.4 \% \quad$ No $27.6 \% \quad n=98$

41. Do you think the use of computers in the Landscape Architecture office has helped promote the profession?

Yes $71.6 \% \quad$ No $28.4 \% \quad \mathrm{n}=95$

42. What are you creating on the computer which you feel is very innovative?

-3-D models

$19.6 \%$

-composite images

$11.8 \%$

-proposed design $\mathrm{w} /$ existing conditions $7.8 \%$

-multi-media presentation

$5.9 \%$

-other

$54.9 \%$

$\mathrm{n}=51$

Example of items listed under "other" include:

to produce more precise drawings for working drawings, design portfolio, better quality drawing, and give drawing a different look from everyone else.

43. What features would you consider would be ideal for landscape architects?

-3-D modeling/walkthroughs

$24.1 \%$

-speed/ease of power/use

$19.0 \%$

-cut-fill capabilities/slope

$15.5 \%$

analysis/estimating/lighting

-program that does everything

$12.1 \%$

-more/better symbols

$10.3 \%$

-other

$19.0 \%$

$\mathrm{n}=58$

Example of items listed under "other" include:

compatibility with civil engineers, architects and clients, standardized layering system, and ability to use computer as a pencil is used-naturally.

44. What would be one feature you would want to perfect in regard to the computer? -speed/ease/power 
-technical drawings/calculations

$12.7 \%$

-compatibility

$11.1 \%$

-3-D/modeling

$11.1 \%$

-less rigid graphics/more intuitive

$9.5 \%$

-more/better symbols

$4.8 \%$

-precision

$4.8 \%$

-other

$9.5 \%$

$\mathrm{n}=63$

Example of items listed under "other" include:

Standardization (of line weight commands, layering, etc.), reduce number of upgrades in software, the $\mathrm{CAD}$ operator, improve the computer screen so that line weights can be seen more easily, and scaling.

45. Name one instance in which the use of computers hurt instead of help.

-time consumption/high learning curve $30.7 \%$

- equipment failure

-poor design based on computer

$12.0 \%$

drafting limitation

-mistakes due to operator error

$9.3 \%$

-software incompatibility when

$6.7 \%$

exchanging files

-drawings look finished when not

$4.0 \%$

-other

$14.7 \%$

$\mathrm{n}=75$

Example of items listed under "other" include:

can be intimidating for some, it may not be worthwhile to input a design it can be drawn faster by hand and if there is no reason to computerize it, being stuck in front of the computer for $\mathrm{x}$ number of hours, new comers to firm who have to conform to non-familiar standards, distrust of things too technical, and Internet surfing on company time.

46. How will the results of this survey affect your firm in relation to computer use?

-not affected by it

-promote the use

-inhibit the use

-affect the firm in other ways
$54.2 \%$

$22.9 \%$

$22.9 \%$

$0.0 \%$

$\mathrm{n}=83$ 
47. Do you feel you can you compete today without the use of computers?

No $86 \%$ Yes $14 \% \quad n=100$

48. Have you been involved in a "virtual" project (one done completely by computer)?

No $\quad 58.2 \% \quad$ Yes $\quad 41.8 \% \quad \mathrm{n}=98$

49. Do you feel the totally digital office will ultimately replace the traditional office?

No $65.6 \% \quad$ Yes $34.4 \% \quad n=96$

Example of list of example comments include:

-"I sure hope not."

-"Computers will never replace the tactile feeling of paper and the ease with which one can design on paper."

-"We need to remember the traditional practice in terms of executing a craft and not cranking out plans for a successful bottom line."

-"Largely it already has."

-"Those who don't will be left by the sidelines."

-"We don't have drafting tables in our office."

50. What is your name, firm, and email/phone? 
Table7: Data reduction categories for "Survey section I: effects of computer technology on the design process and professional practice" variables

New Variable percent n Old Variable
2. How long has your office been using computers for these purposes?

$\begin{array}{lcclr}-1-10 \text { Years } & 71.3 \% & (72) & -1 \text { Year } & 5 \\ & & & -2-3 \text { Years } & 14 \\ & & & -5-10 \text { years } & 53 \\ \text {-10+ Years } & 28.7 \% & (29) & -10+\text { Years } & 29 \\ \text {-Missing } & & (1) & \text {-Missing } & 1 \\ \text { Total } & & 102 & & \end{array}$

3. What kind of firm are you working with?

-Small landscape $42.7 \% \quad(41) \quad$-Small landscape architecture 41 architecture (1-10) (1-10)

-Medium (11-20)57.3\% (55) and large landscape architecture (21 and above)

-Medium landscape architecture 17

(11-20)

-Large landscape architecture $\quad 38$

(21 and above)

$\begin{array}{lcrr}\text {-Missing } & (6) & \text {-Missing } & 6 \\ \text { Total } & 102 & & 102\end{array}$


Table 7: Data reduction categories for "Survey section I: effects of computer technology on the design process and professional practice" variables

\begin{tabular}{lllll}
\hline New Variable percent & $\mathrm{n}$ & Old Variable & $\mathrm{n}$ \\
\hline
\end{tabular}

6. Rank the impact that the computer plays on each of the tasks you accomplish with the use of the computer. (1=low use and $6=$ high use).

Design Process:

6a. -Qualification $20.5 \%$

Presentations (low use)

-Qualification $\quad 79.5 \%$

Presentations (high use)

-Missing

Total

6b. -Conceptual $81.9 \%$ design (low use)

-Conceptual $\quad 18.1 \%$ design (high use)

-Missing

Total

6c. -Design $\quad 47.3 \%$ development (low use)

-Design $\quad 52.7 \%$

development (high use)

-Missing

Total

6d. -Schematic $58.2 \%$ design (low use)

-Schematic $\quad 41.8 \%$ design (high use)

-Missing

Total
Degree of role $\mathrm{n}$

(66)

-Rank 1 9

-Rank 2

-Rank 3

4

-Rank 4

-Rank 5

-Rank 6

13

-Missing

38

19

102

(77) $\quad$-Rank 1

-Rank 2

16

-Rank 3

18

-Rank 4

5

-Rank 5

3

-Rank 6

9

(8)

-Missing

8

102

102

-Rank 1

10

-Rank 2

14

-Rank 3

20

-Rank 4

17

-Rank 5

13

-Rank 6

19

(9)

102

-Missing

9

102

$(53$

)-Rank 1

10

-Rank 2

21

-Rank 3

-Rank 4

$\frac{22}{11}$

-Rank 5

16

-Rank 6

11

-Missing

11

102 
Table 7: Data reduction categories for "Survey section I: effects of computer technology on the design process and professional practice" variables

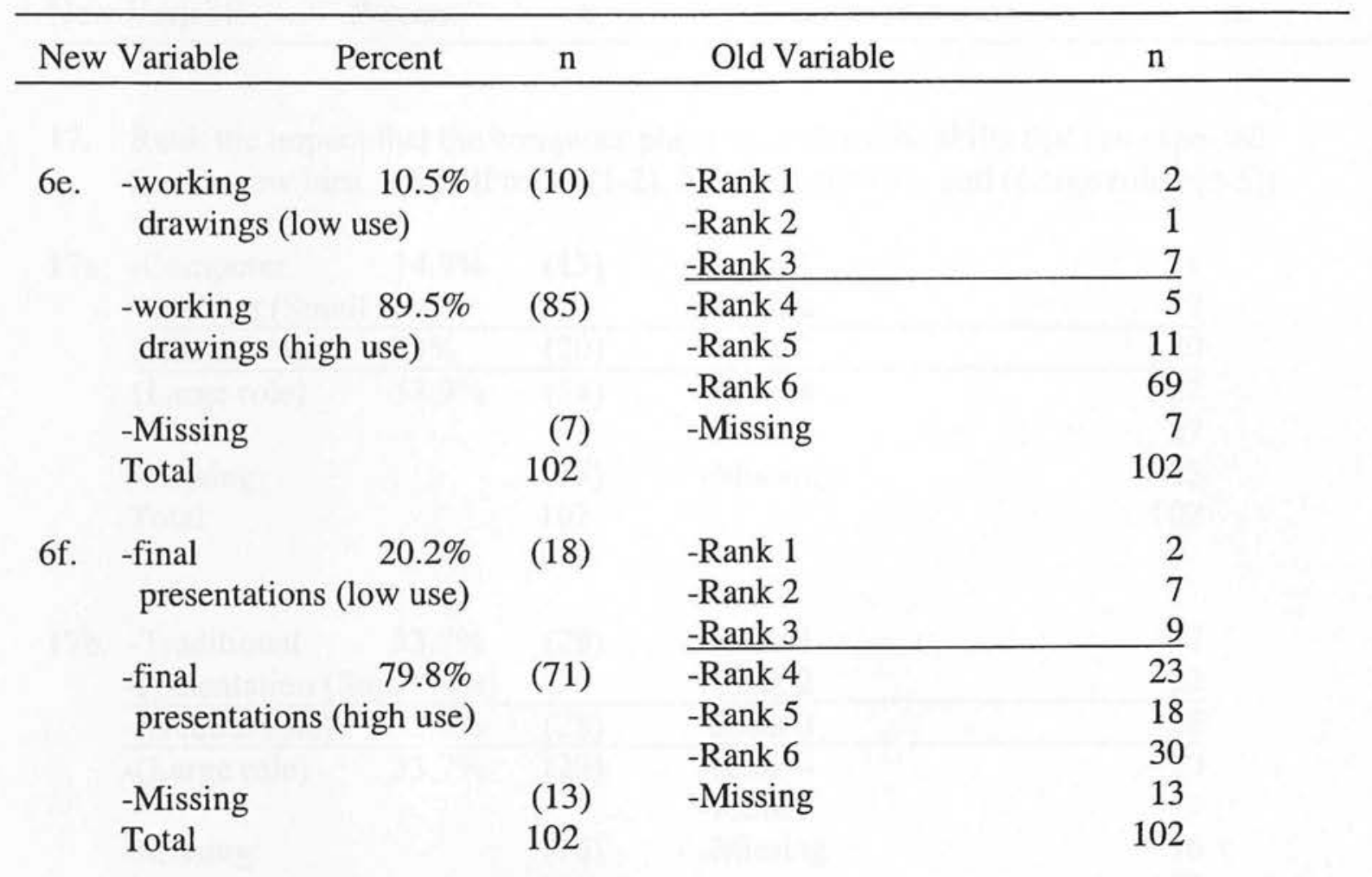

10. Do you feel that overall you save time by using computers in your design process? If yes, when did you begin to see a savings in time?

$\begin{array}{llllr}\text {-First year } & 56.3 \% & (36) & \text {-First year } & 36 \\ & & & \text {-Second year } & 16 \\ \text {-After the } & 43.8 \% & (28) & \text {-Third year } & 12 \\ \text { first year } & & & & 38 \\ \text {-Missing } & & (38) & \text {-Missing } & 102 \\ \text { Total } & & 102 & & \end{array}$

11. What do you do with the extra time saved?

$\begin{array}{lllr}\text {-Take on more work 61.2\% (41) } & \text {-Take on more work } & 41 \\ & & \text {-Spend time for leisure } & 2 \\ \text {-Spend more time 38.8\% } & (26) & \text {-Spend more time doing } & 26 \\ \text { doing other design tasks } & & \text { other design tasks } & \\ \text {-Missing } & (35) & \text {-Missing } & 33 \\ \text { Total } & 102 & & 102\end{array}$


Table 7: Data reduction categories for "Survey section I: effects of computer technology on the design process and professional practice" variables

\begin{tabular}{lllll}
\hline New Variable & Percent & $\mathrm{n}$ & Old Variable & $\mathrm{n}$ \\
\hline
\end{tabular}

17. Rank the impact that the computer plays on each of the skills that are expected from a new hire. $\quad($ Small role $=(1-2)$, Neutral role $=(3)$, and $($ Large role $=(4-5))$

\begin{tabular}{llllr} 
17a. - Computer & $14.9 \%$ & $(13)$ & -Rank 1 & 1 \\
drafting (Small role) & & -Rank 2 & 12 \\
\hline (Neutral role) & $23 \%$ & $(20)$ & -Rank 3 & 20 \\
\hline (Large role) & $52.9 \%$ & $(54)$ & -Rank 4 & 27 \\
& & & -Rank 5 & 27 \\
-Missing & & $(15)$ & -Missing & 15 \\
Total & & 102 & & 102
\end{tabular}

\begin{tabular}{|c|c|c|c|c|}
\hline$\frac{\text {-Presentation (S }}{\text {-(Neutral role) }}$ & $\frac{\text { all role) }}{32.6 \%}$ & (28) & $\begin{array}{l}\text {-Rank } 2 \\
\text {-Rank } 3\end{array}$ & $\frac{22}{28}$ \\
\hline -(Large role) & $33.7 \%$ & (29) & $\begin{array}{l}- \text {-Rank } 4 \\
\text {-Rank } 5\end{array}$ & $\begin{array}{r}20 \\
9\end{array}$ \\
\hline -Missing & & $\begin{array}{l}(16) \\
102\end{array}$ & -Missing & $\begin{array}{r}16 \\
102\end{array}$ \\
\hline
\end{tabular}

\begin{tabular}{llllr} 
17c. - & & \\
draditional & $35.7 \%$ & $(30)$ & -Rank 1 & 7 \\
\multicolumn{2}{l}{ drafting (Small role) } & & -Rank 2 & 23 \\
\hline -(Neutral role) & $26.2 \%$ & $(22)$ & -Rank 3 & 22 \\
\hline -(Large role) & $38.1 \%$ & $(32)$ & -Rank 4 & 23 \\
& & & -Rank 5 & 9 \\
-Missing & & $(18)$ & -Missing & 18 \\
Total & & 102 & & 102
\end{tabular}

\begin{tabular}{|c|c|c|c|c|}
\hline -Computer & $17.6 \%$ & (18) & -Rank 1 & $\begin{array}{r}6 \\
12\end{array}$ \\
\hline -Presentation (S & mall role) & & -Rank 2 & $\frac{12}{20}$ \\
\hline -(Neutral role) & $19.6 \%$ & (20) & -Rank 3 & 20 \\
\hline$-($ Large role) & $47.1 \%$ & (48) & $\begin{array}{l}- \text {-Rank } 4 \\
\text {-Rank } 5\end{array}$ & $\begin{array}{l}22 \\
26\end{array}$ \\
\hline -Missing & & $\begin{array}{l}(16) \\
102\end{array}$ & -Missing & $\begin{array}{r}16 \\
102\end{array}$ \\
\hline
\end{tabular}


18. How does your office execute computer design tasks?

-Out-source it -In-house

$6.1 \%$ $93.9 \%$

-Missing

Total
(6) -Outsource it -In-house CAD specialist or operators -In-house graphic artist 2 -Task delegated to design team within office

(4) -Missing 
Table 8: Data reduction categories for "Survey section IV: software" variables

$\begin{array}{lllll}\text { New Variable } & \text { Percent } n & \text { Old Variable }\end{array}$

34) What type of software do you use for design?

\begin{tabular}{|c|c|c|c|}
\hline $\begin{array}{l}\text {-Basic } \\
\text { (2-D and others) }\end{array}$ & $46.7 \%$ & (35) & $\begin{array}{l}-2-D \text { CAD } \\
-2-D \text {, graphic } \\
-2-D \text {, graphic, imaging } \\
-2-D, \text { graphic, imaging, rendering }\end{array}$ \\
\hline $\begin{array}{l}\text {-Intermediate } \\
\text { (3-D and others) }\end{array}$ & $40 \%$ & (30) & $\begin{array}{l}-3-D \text { CAD } \\
-3-D, \text { rendering } \\
\text {-3-D imaging, graphic } \\
-3-D \text {, rendering, imaging, graphic } \\
-2-D, 3-D \\
-2-D, 3-D \text {, graphic } \\
-2-D, 3-D \text {, imaging, graphic } \\
-2-D, 3-D, \text { rendering, graphic } \\
-2-D, 3-D \text {, rendering, imaging } \\
\text {-2D, 3-D, rendering, imaging, } \\
\text { graphic }\end{array}$ \\
\hline
\end{tabular}

\begin{tabular}{|c|c|c|}
\hline $\begin{array}{l}\text {-Advanced } 13.3 \% \\
\text { (Animation and others) }\end{array}$ & (10) & $\begin{array}{l}-2-\mathrm{D}, 3-\mathrm{D} \text {, rendering, animation, } \\
-3-\mathrm{D} \text {, rendering, animation, } \\
\text { imaging, graphic } \\
-3-\mathrm{D} \text {, animation, graphic } \\
\text {-All }\end{array}$ \\
\hline -Missing & (27) & -Missing \\
\hline Total & 102 & \\
\hline
\end{tabular}


$\underline{\text { Table 9: List of cross tabulations that are statistically significant }}$

$\underline{\text { Results of cross-tabulations comparing firm size and other variables that may impact }}$ $\underline{\text { computer use and design process: }}$

\section{Use of Computers:}

Small firms are likely to have used computers for 1-10 years. Large firms are likely to have used them for longer than 10 years.

\section{Table 1: Crosstab 2-Firm size by years of computer use}

\begin{tabular}{|c|c|c|}
\hline Years of computer use & $\underline{\text { Small firm }}$ & $\underline{\text { Large firm }}$ \\
\hline $1-10$ years & $82.5 \%$ & $65.5 \%$ \\
\hline $10+$ years & $17.5 \%$ & $34.5 \%$ \\
\hline Total & $100 \%$ & $100 \%$ \\
\hline $\mathrm{n}=$ & 40 & 55 \\
\hline
\end{tabular}

$\chi^{2}(\mathrm{df}=1, \mathrm{n}=95)=3.385, \mathrm{p}=.066,(\Phi)=0.427$

Small firms are more likely to have used computers for 1-10 years. There is a moderate relationship between firm size and years of computer use.

All firms budget annually for computers but, more respondents from large firms are likely to budget for computer use.

\section{Table 2: Crosstab 49-Firm size by budget annually for computer use}

Budget annually

for computer use

Yes

No

Total

$\mathrm{n}=$

$\chi^{2}(\mathrm{df}=1, \mathrm{n}=94)=3.666, \mathrm{p}=.056$,

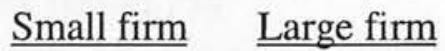

$\begin{array}{lr}66.7 \% & 83.6 \% \\ 33.3 \% & 16.4 \% \\ 100 \% & 100 \%\end{array}$

39

There is a strong relationship between the size of the firm and annually budgeting for computer use. 
They all have clients who require the use of $\mathrm{CAD}$ but respondents from large firms are more likely to use CAD because clients require their use.

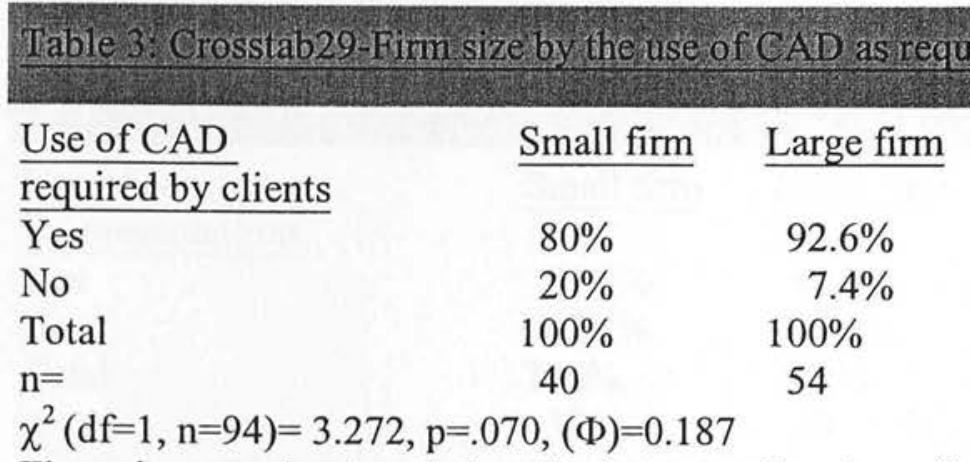

There is a moderate relationship between the size of the firm and the use of CAD required by clients.

\section{In the design process}

The use of computers plays a large role in the design process. However, large firms are more likely to have computers play a large role in the design process.

\section{Table 4: Crosstab 5-Firm size by role of computer in design process}

\begin{tabular}{|c|c|c|}
\hline$\frac{\text { Role of computer }}{\text { in design process }}$ & $\underline{\text { Small firm }}$ & $\underline{\text { Large firm }}$ \\
\hline$\overline{\text { Yes }}$ & $70.7 \%$ & $85.5 \%$ \\
\hline No & $29.3 \%$ & $14.5 \%$ \\
\hline Total & $100 \%$ & $100 \%$ \\
\hline $\mathrm{n}=$ & 41 & 55 \\
\hline
\end{tabular}

$\chi^{2}(\mathrm{df}=1, \mathrm{n}=96)=3.087, \mathrm{p}=.079,(\Phi)=0.179$

There is a weak relationship between the size of the firm and the role of computers in the design process.

The use of computers plays a large role in the working drawings. However, large firms are more likely to have computers play a large role in working drawings.

Table 5: Crosstab 9-Firm size by role of computer in working drawings

\begin{tabular}{lccc}
\cline { 1 - 1 } Role of computer & Small firm & & Large firm \\
Large role & & \\
Small role & $18.1 .1 \%$ & & $94.2 \%$ \\
Total & $100 \%$ & & $5.8 \%$ \\
$\mathrm{n}=$ & 37 & $100 \%$ \\
\cline { 2 - 3 } & & 52
\end{tabular}

$\chi^{2}(\mathrm{df}=1, \mathrm{n}=89)=3.748, \mathrm{p}=.053,(\Phi)=0.205$

There is a strong relationship between the size of the firm and the role of computers in the working drawings. 
All firms use computers for presentations. However, large firms are more likely to use computers for presentations.

Table 6: Crosstab 40-Firm size by use computer for presentations

\begin{tabular}{|c|c|c|}
\hline $\begin{array}{l}\text { Use of computers } \\
\text { for presentations }\end{array}$ & $\underline{\text { Small firm }}$ & $\underline{\text { Large firm }}$ \\
\hline$\overline{\text { Yes }}$ & $57.9 \%$ & $84.9 \%$ \\
\hline No & $42.1 \%$ & $15.1 \%$ \\
\hline Total & $100 \%$ & $100 \%$ \\
\hline $\mathrm{n}=$ & 38 & 53 \\
\hline
\end{tabular}

There is a strong relationship between the size of the firm and presentations with the use of computers.

Less than $50 \%$ of all firms are likely to use walk-throughs or 3-D imaging in their presentations, and small firms are even less likely to use this for presentations.

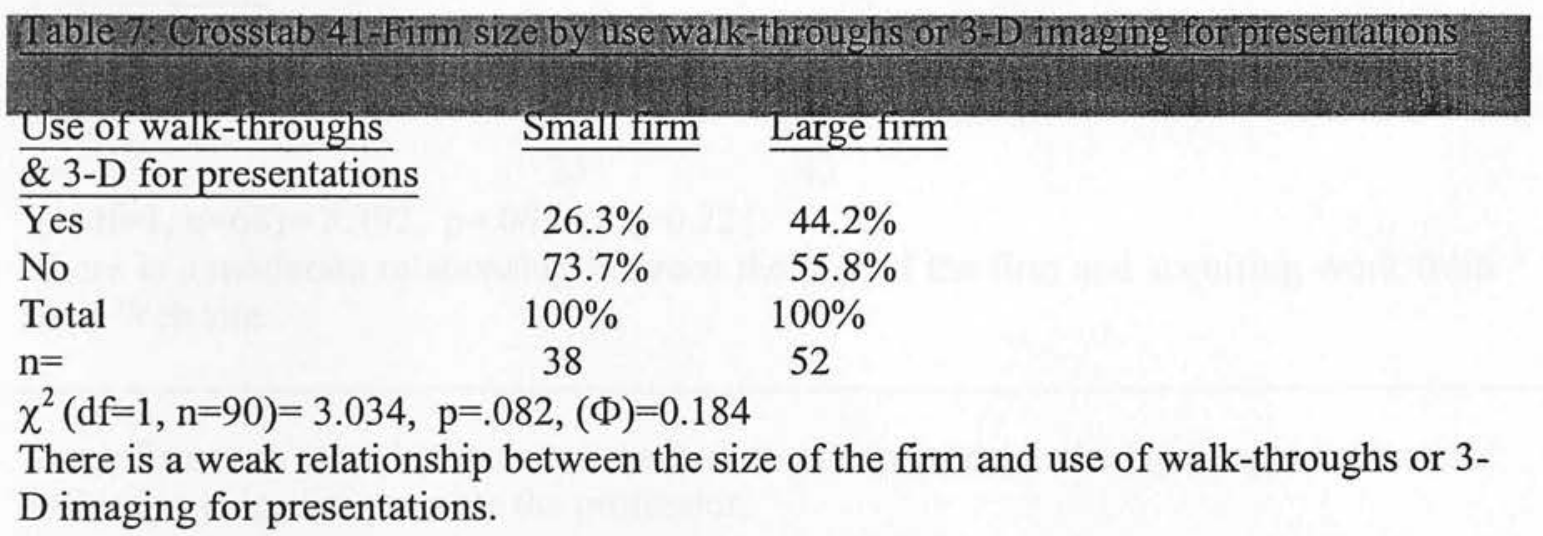

Large firms are more likely to have a Web site.

\section{Table 8: Crosstab 36-Firm size by the existence of a Web site.}

\begin{tabular}{|c|c|c|}
\hline Existence of & $\underline{\text { Small firm }}$ & $\underline{\text { Large firm }}$ \\
\hline a Web site & & \\
\hline$\overline{Y e s}$ & $52.6 \%$ & $83 \%$ \\
\hline No & $47.4 \%$ & $17 \%$ \\
\hline Total & $100 \%$ & $100 \%$ \\
\hline $\mathrm{n}=$ & 38 & 53 \\
\hline
\end{tabular}

$\chi^{2}(\mathrm{df}=1, \mathrm{n}=91)=9.794, \mathrm{p}=.002,(\Phi)=0.328$ There is a strong relationship between the size of the firm and the existence of a Web site. 


\section{Table 9. Crosstab37-Em size by inquiries to firm from Web site}

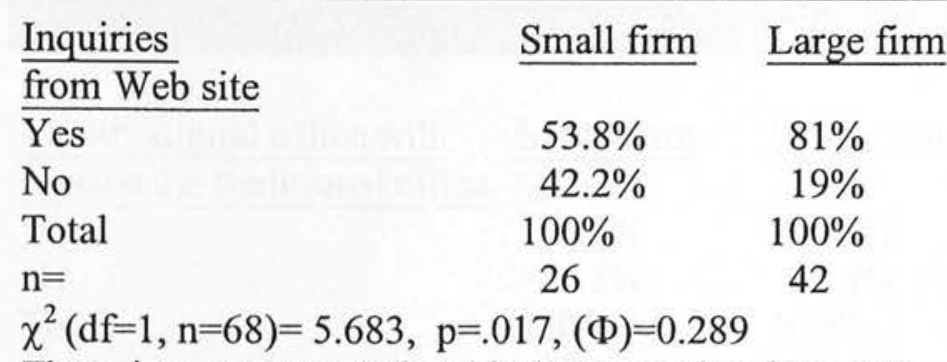

There is a strong relationship between the size of the firm and inquiries to them from their Web site.

Large firms are more likely to acquire work from their Web site.

Table 10. Crosstab 38-Firm size by acquiring work from Web site

\begin{tabular}{|c|c|c|}
\hline Acquiring work & $\underline{\text { Small firm }}$ & $\underline{\text { Large firm }}$ \\
\hline from Web site & & \\
\hline$\overline{\text { Yes }}$ & $24 \%$ & $46.5 \%$ \\
\hline No & $76 \%$ & $53.5 \%$ \\
\hline Total & $100 \%$ & $100 \%$ \\
\hline $\mathrm{n}=$ & 25 & 43 \\
\hline
\end{tabular}

There is a moderate relationship between the size of the firm and acquiring work from their Web site.

Large firms are more likely to believe the use of computers in the landscape architecture office has helped to promote the profession.

Table 11: Crosstab 51. firm size by believe the use of computers in the landscape
architecture office has helped to promote the profession

\begin{tabular}{|c|c|c|}
\hline$\frac{\text { Computers helped to }}{\text { promote profession }}$ & $\underline{\text { Small firm }}$ & $\underline{\text { Large firm }}$ \\
\hline Yes & $61.5 \%$ & $80.4 \%$ \\
\hline No & $38.5 \%$ & $19.6 \%$ \\
\hline Total & $100 \%$ & $100 \%$ \\
\hline $\mathrm{n}=$ & 39 & 51 \\
\hline
\end{tabular}

There is a strong relationship between the size of the firm and the use of computers in the landscape architecture office that helped to promote the profession. 
Small firms are less likely to believe the totally digital office will replace the traditional office.

\section{Table 12: Crosstab 61 Fim size by totally digital office will replace the traditional}

affice

\begin{tabular}{|c|c|c|}
\hline$\frac{\text { Totally digital office will }}{\text { replace the traditional office }}$ & $\underline{\text { Small firm }}$ & $\underline{\text { Large firm }}$ \\
\hline Yes & $23.7 \%$ & $44.2 \%$ \\
\hline No & $76.3 \%$ & $55.8 \%$ \\
\hline Total & $100 \%$ & $100 \%$ \\
\hline$n=$ & 38 & 52 \\
\hline
\end{tabular}

There is a strong relationship between the size of the firm and the belief that the totally digital office will replace the traditional office. 
$\underline{\text { Results of cross-tabulations comparing role of computers in the design process and }}$

other variables that may impact specific computer use and design task:

Computers play a large role in design process and are likely to be used for presentations.

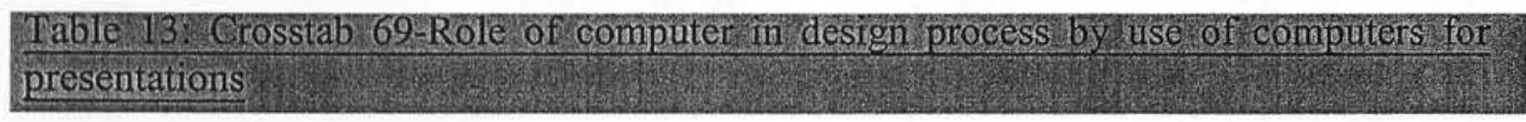

Use computers for

presentations

Yes

No

Total

$\mathrm{n}=$

$\chi^{2}(\mathrm{df}=1, \mathrm{n}=97)=15.699, \mathrm{p}=.0000,(\Phi)=0.402$

There is a strong relationship between the role computer plays in the design process and use of computers for presentations.

Regardless if computers play a small or large role in design development, the drawings seem to look the same.

Table 14: Crosstab 96-Computer plays a role in design developinent by impact on $100 \mathrm{~K}$ of drawings with use of computers

Impact on look of drawings

with use of computers

Consistently looking same

Are different every time

Total

$\mathrm{n}=$

$\chi^{2}(\mathrm{df}=1, \mathrm{n}=81)=3.023, \mathrm{p}=.082,(\Phi)=0.193$

There is a weak relationship between the role computer plays in the design development and the impact on the look of drawings with use of computers. 
Regardless of whether computers play a small or large role in design development, respondents' drawings are better than traditional drawing.

Table 15: Crosstab 118-Computer plays a role in design development by quality of your computer drawings now compared to hand drawings

\section{Quality of drawing now \\ compared to hand drawings}

better

worse

same

Total

$\mathrm{n}=$

$\chi^{2}$

$\underline{\text { Role of computers }}$

in design development

Small

$73.8 \%$

$9.5 \%$

$16.7 \%$

$100 \%$

42
Large

$51 \%$

$16.3 \%$

$32.7 \%$

$100 \%$

49

There is a weak relationship between the role of computers in design development and the quality of $\mathrm{CAD}$ drawings when compared to hand drawings.

Computers played a large role in the design process and are likely to save time.

Table 16: Crosstab 169-Role in design process by impact of use of computer on time savings

\begin{tabular}{lcc} 
Impact of computers on & \multicolumn{2}{c}{ Role of computers } \\
\cline { 2 - 3 } time savings & \multicolumn{2}{c}{ in design process } \\
Yes & $77.5 \%$ & Yes \\
No & $22.5 \%$ & $61.9 \%$ \\
Total & $100 \%$ & $100 \%$ \\
$\mathrm{n}=$ & 80 & 18 \\
$\chi^{2}(\mathrm{df}=1, \mathrm{n}=98)=10.514, \mathrm{p}=.001,=(\Phi) 0.328$ &
\end{tabular}

There is a strong relationship between role of computers in design process and impact computer use has on time savings. 
Computers play a large role in concept design and respondents are likely to consider 3D capability an important feature in software.

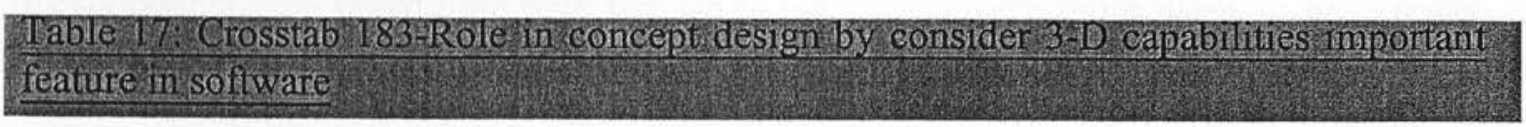

\section{3-D capabilities considered} important

Yes

No

Total

$\mathrm{n}=$

\begin{tabular}{|c|c|}
\hline \multicolumn{2}{|c|}{$\begin{array}{l}\text { Role of computers } \\
\text { in design concept }\end{array}$} \\
\hline Small & Large \\
\hline $57.6 \%$ & $92.3 \%$ \\
\hline $42.4 \%$ & $7.7 \%$ \\
\hline $00 \%$ & $100 \%$ \\
\hline
\end{tabular}

59

13

$\chi^{2}(\mathrm{df}=1, \mathrm{n}=72)=5.554, \mathrm{p}=.018,=(\Phi) 0.278$

There is a strong relationship between role of computer in concept design and respondents who consider 3-D capabilities an important feature in software.

Regardless of whether computers played a role in the design process, firms were unlikely to have been involved in a virtual project.

\begin{tabular}{|c|c|c|}
\hline \multirow[t]{2}{*}{$\frac{\text { Involved in a }}{\text { virtual project }}$} & \multicolumn{2}{|c|}{$\frac{\text { Role of computers }}{\text { in design concept }}$} \\
\hline & Yes & No \\
\hline Yes & $49.4 \%$ & $10.5 \%$ \\
\hline No & $50.6 \%$ & $89.5 \%$ \\
\hline Total & $100 \%$ & $100 \%$ \\
\hline $\mathrm{n}=$ & 79 & 19 \\
\hline \multicolumn{3}{|c|}{$\begin{array}{l}\chi^{2}(\mathrm{df}=1, \mathrm{n}=98)=9.496, \mathrm{p}=.002,=(\Phi) 0.311 \\
\text { There is a strong relationship between role of computers in design process and }\end{array}$} \\
\hline
\end{tabular}

Computers play a small role in schematic design.

\begin{tabular}{lcc}
\hline Table 19. Crosstab & 192-Role in schematic design by involved in a virtual project \\
\hline Involved in a & \multicolumn{2}{c}{ Role of computers } \\
\cline { 2 - 3 } virtual project & in schematic design \\
\cline { 2 - 3 } Yes & $36 \%$ & $55.3 \%$ \\
No & $64 \%$ & $44.7 \%$ \\
Total & $100 \%$ & $100 \%$ \\
$\mathrm{n}=$ & 50 & 38 \\
$\chi^{2}(\mathrm{df}=1, \mathrm{n}=88)=3.247, \mathrm{p}=.072,=(\Phi) 0.192$ & \\
There is a moderate relationship between the role computers play in schematic design \\
and involvement in a virtual project.
\end{tabular}


Respondents who did not save time with the use of computers in the design process were more likely to have the same number of meetings with or without computer use. Respondents who saved time with the use of computers were more likely to have fewer meetings.

Table 20: Crosstab 203-Use of computers saved time by impact of electronic communication on frequency of meetings

\begin{tabular}{lcc} 
Impact of electronic & \multicolumn{2}{c}{ Use of computers saved time } \\
\cline { 2 - 3 } communication on & in design process & \\
\cline { 2 - 3 } frequency of meetings & Yes & No \\
fewer & $52.2 \%$ & $22.2 \%$ \\
more & $0.0 \%$ & $7.4 \%$ \\
same & $47.8 \%$ & $70.4 \%$ \\
Total & $100 \%$ & $100 \%$ \\
$\mathrm{n}=$ & 67 & 27
\end{tabular}

$\chi^{2}(\mathrm{df}=2, \mathrm{n}=94)=10.751, \mathrm{p}=.005,(\gamma)=0.483$

There is a strong relationship between use of computers and time savings and the impact of electronic communication on frequency of meetings.

If computers do not play a large role in the design process, their use for walk-throughs or 3-D imaging for presentations was very unlikely.

Table 21: Crosstab 70-Role of computer in design process by use of walk-throughs or 3-D imaging for presentations

Use computers for

walk-throughs or

3-D imaging for presentations

Yes

No

Total

$\mathrm{n}=$

$\chi^{2}(\mathrm{df}=1, \mathrm{n}=96)=7.037, \mathrm{p}=.008,(\Phi)=0.271$

Role of computers

in the design process

$\begin{array}{cc}\text { Yes } & \text { No } \\ 44.9 \% & 11.1 \% \\ 55.1 \% & 88.9 \% \\ 100 \% & 100 \% \\ 78 & 18\end{array}$

There is a strong relationship between the role computer plays in the design process and the use of walk-throughs or 3-D imaging for presentations. 
Respondents who feel computers have not improved design work are not likely to have been involved in a virtual project.

Table 22: Crosstab 140-Computer improved design work by involved in virtual project

Involved in a

virtual project

$\begin{array}{lcl} & \text { Yes } & \text { No } \\ \text { Yes } & 49.3 \% & 22.2 \% \\ \text { No } & 50.7 \% & 77.8 \% \\ \text { Total } & 100 \% & 100 \% \\ \mathrm{n}= & 69 & 27 \\ \chi^{2}(\mathrm{df}=2, \mathrm{n}=96)=5.843, \mathrm{p}=.016,(\Phi)=0.247 & \end{array}$

There is a strong relationship between believing computers have improved design work and having been involved in a virtual project.

Computers play a moderate role in the design process and one likely to impact hiring new employees with moderate level of computer presentation skills.

Table 23: Crosstab 105-Computer plays a role in design process by firms hire strictly on computer presentation skills

\begin{tabular}{|c|c|c|}
\hline \multirow{2}{*}{$\begin{array}{l}\text { Firms hire strictly on } \\
\text { computer presentation skills }\end{array}$} & \multicolumn{2}{|c|}{$\underline{\text { Role of computers }}$} \\
\hline & \multicolumn{2}{|c|}{ in design process } \\
\hline & Yes & No \\
\hline low & $34.8 \%$ & $27.8 \%$ \\
\hline moderate & $27.5 \%$ & $55.6 \%$ \\
\hline high & $37.7 \%$ & $16.7 \%$ \\
\hline Total & $100 \%$ & $100 \%$ \\
\hline $\mathrm{n}=$ & 69 & 18 \\
\hline
\end{tabular}

$\chi^{2}(\mathrm{df}=2, \mathrm{n}=87)=5.464, \mathrm{p}=.065, \gamma=0.136$

There is a moderate relationship between the role computers play in the design process and hiring strictly based on computer presentation skills. 
APPENDIX THREE - BIBLIOGRAPHY \&GLOSSARY 


\section{Bibliography}

1. Alton, K. (1992). "Guidelines to Automating the Small Business." Cadence Magazine, 7 (11), 42-45.

2. Becker, C. (1988). "Systems for a Small Office." Landscape Architecture, 78 (4), 106-111

3. Bennett, P. (1998). “Learning Curve." Landscape Architecture, 88 (5), 52-57.

4. Bissell, D. (1990). "The Uneasy Marriage of CAD and Architecture." Cadence Magazine, 5 (6), 95-98.

5. Bond, E. “ 'Hoteling' Office Design Proves To Be An Efficiency Asset.” Retrieved November 10, 1999 from the World Wide Web: http://www.isdesignet.com/Magazine/Jul'95/instal_AltOffice.html

6. Button, M. (1995). "Forecasting Future Scenery." Landscape Architect, 11 (1), 24.

7. Cade, D. (1999). "Vectorworks.” Landscape Architect, 15 (12),15-16.

8. Caldwell, B. and Gambon, J. (1999, January 22). "It's More Than Just Fantasy. In Fact, Virtual Teams Are Saving Money and Boosting Productivity at America West, IBM, and Elsewhere." Retrieved April 10, 1999 from the World Wide Web: http://techweb.cmp.com/iw/563/63mtoff.html

9. Calnan, T. (1997). "Knowledge is power!" Landscape Design Extra, Section 1 (3), 3.

10. Campbell, D. "A Critique of Virtual Reality in the Architectural Design Process." Retrieved April 10, 1999 from the World Wide Web: http://www.hitl.washington.edu/projects/architecture/R94-3.html

11. Claridge, R. (1996). "AutoCAD in Architecture." Cadence Magazine, (4), 5.

12. Clay, G. and Lindhult, M. (1991). "Managing CAD." Landscape Architecture, (5), 88-92.

13. Combs, C. (1998, November 29). "Engineers Design Cyber Fashions.” February 14, 1999 from the World Wide Web:http://www.popularscience.com/news/11291998.cyberfashions.html

14. Contie, T. (1997). "Providing First-Rate User Support-A Strategic Approach for CAD Managers." Cadence Magazine, 12 (11), 47-52.

15. Crone, J. (1986). "Guide to 3-D." Landscape Architecture, (3), 100-103.

16. Danahy, M. and Robert W. (1988). "Designing with 3-D Simulations." Landscape Architecture, 78 (4), 64-7. 
17. Dawson, N. (1991). "Hand-Drawn and CAD-Drawn: Both Have Advantages For the Designer." Cadence Magazine, 6 (2), 49-51.

18. "Design and Planning Applications of Computer Technology: A National Survey." (1984). Landscape Architecture, 64 (4 ), 74-75.

19. D'Hulst, M. (2000). "Networking Solutions." Landscape Architect, 16 (4), 16 18.

20. Evans, D. (1991). "Implementing CAD From the Ground Up." Cadence Magazine, 6, (11), 43-45, 158.

21. Evans, D. (1991). "Freedom of Expresson: Autocad in Architecture." Cadence Magazine, 6 (2), 45-47.

22. Ervin, S. (1997). "Virtual Possibilities.” Landscape Architecture, 87 (6), 46-50.

23. Ervin, S. "Designing with Maps: Integrating GIS and CAD." Retrieved April 10, 1999 from the World Wide Web:

http://www.gsd.harvard.edu/ servin/giscad/giscad.html

24. Floyd, E. (1990). "CAD and Sun Network Help Cut Man-hours." Cadence Magazine, 5 (2), 40.

25. “'Fourth Wave' Consultancies? 'Virtual' Offices... OK, But Does It Work? Don't Take Our Word For It: Ask For a Second Opinion." Retrieved April 10, 1999 from the World Wide Web: http://www.lamtar.com/virtual.htm

26. Fulton, N. (1992). "Streamlining the Path From Design to Production." Cadence Magazine, 7 (4), 48-50.

27. Green, R. (1998). "Budgeting for Success.” Cadence Magazine, 13, (7), 4.

28. Green, R., McPhail, D., Ward, H., and Evans, D. (1998). “Cadence Channel: Trial Runs." Cadence Magazine, 13 (9), 10.

29. Hahn,H. (1986). “Site Design.” Landscape Architecture, 76 (4),101-104.

30. "Hey, Where is my desk?" Retrieved February 14, 1999 from the World Wide Web: http://www.cyber24.com/htm1/2_5.htm

31. Hill, J. (1999). "Erosion Control Software.” Landscape Architect, 15 (10),12-14.

32. Retrieved April 10, 1999 from the World Wide

Web:http://www.hitl.washington.edu/projects/architecture/R94-3.html

33. Retrieved April 10, 1999 from the World Wide Web:

http:www. clr. utoronto.ca/ARCHIVES/HMAI/larch/date.html

34. Hoffer, E. (1992). "Image Editing: A Primer." Landscape Architecture, 82 (5), 70-71. 
35. Hughes, J. (1991). "Designing from the Ground Up." Cadence Magazine, 6 (2), 52-57.

36. Hustead, V. (1999). “Computer Budgeting.” Landscape Architect, 15 (1), 14-16.

37. Jameson, G. (1997). "Technology: Are We Really Better Off." Landscape Architect, 13 (12), 72.

38. Johnson, P. (1991). "Bread and Bitter Autocad: Architectural Firm Uses Autocad for Speed and Accuracy." Cadence Magazine, 6 (12), 65-66.

39. Johnson, T. (1995). "Myriad Options in Multimedia." Landscape Architecture, 85 (9), 26-31.

40. Itami, R. (1988). “Cellular Worlds.” Landscape Architecture, 78 (4), 52-57.

41. Kelly, B. \& McGraw, B. "Successful Management in the Virtual Office." Retrieved April 10, 1999 from the World Wide Web: http://allison.clark.net/pub/kmcgraw/guide/telgd1.htm

42. Kesler, G. (1985). “Spreadsheets.” Landscape Architecture, 75 (4), 93-94.

43. Kramer, M. (1997, October 21). "Virtual Office: Pretty Empty.” Retrieved April 10, 1999 from the World Wide Web: PC Week, http://www.zdnet.com/zdnn/content/pcwk/1444/pcwk0026.html

44. Kulack, A. (1988). "CADD: More Than a New Way of Looking.” Landscape Architecture, 78 (1), 70.

45. Kvan, T. "Design Services in the Era of the Web." Retrieved February 12, 1999 from the World Wide Web: coxegroup.com/articles/web.htm>

46. Kvan, T. "Reflections on Computer-Mediated Architectural Design.” Retrieved February 12, 1999 from the World Wide Web: http://arch.hku.hk/people/tkvan/acm-94.html

47. Kvan, T. "Is Design Really Social?" Retrieved February 12, 1999 from the World Wide Web: http://arch.hku.hk/people/tkvan/designsocial.htm

48. Kvang, L. and Turner, R. (1989). “Autocad for Environmental Consulting CAD \& GIS.” Cadence Magazine, 4 (11), 48-52.

49. Lebus, H. (1998). "Business Management: Plan Right and Bill Quick!" Landscape Architect, 14 (9), 12.

50. Lebus, H. (1999). “3-D Modeling: Landscape Applications of EasySite." Landscape Architect, 15 (4), 14-18.

51. Lebus, H. (1998). "Irrigation Plans: Save Time with Design Software." Landscape Architect, 14 (11), 12. 
52. Lebus, H. (1998). "Specification Software: Digitized Plant Selection." Landscape Architect, 14 (8),12.

53. Lindhult, M. (1989). “Color Output.” Landscape Architecture, 79 (12), 73-75.

54. Lindhult, M. (1985). "Perspective Sketching with Computers." Landscape Architecture, 75 (4), 56-57.

55. Lindhult, M. (1990). "CAD and Video in the Small Office.” Landscape Architecture, 80 (9), 84-86.

56. Lindhult, M. (1988). "Redefining Roles in the CAD Era." Landscape Architecture, 78 (4), 128-131.

57. Mackin, K. (1995). “Throwing the Switch.” Cadence Magazine, 10 (7), 26-27, 30, 33-34, 36.

58. Maher, K. (1993). "Project Management: Increasing Productivity and Efficiency." Cadence Magazine, 8 (4), 67-70.

59. Maynard, M. (1999). "Pushing GIS Forward.” Land, 38 (9),11.

60. McAulay, I. (1997). "Moulding the Software Market." Landscape Design Extra, Section 1 (3), 3.

61. McCullough, M. (1990). "Computer Aided Conceptual Design?" Cadence Magazine, 5 (7), 31-34,123.

62. Metzger, J. (1990). "Visual Solutions Through System Integration." Landscape Architecture, vol. (4), 72-75.

63. Moore, R. (2000). "The Digital Portfolio." Landscape Architecture News Digest, 42 (2), 7.

64. Moore, S. (1997). "Sieving the New Information Overload." Landscape Design Extra, Section 3 (3), 6.

65. Mullins, R. "Virtual' offices: hot button for less space Telecommuting gets push for office cost savings." Retrieved February 12, 1999 from the World Wide Web: http://www.amcity.com/milwaukee/stories/070797/focus2.html

66. Neeley, D. (1994). “The Networked Architect." Cadence Magazine, 9 (4), 53 59.

67. Neeley, D. (1991). "Networking CAD Sites: From a Card to a Server, Networks Come in Many Configurations." Cadence Magazine, 6 (10), 85.

68. Neeley, D. (1991). "Small is Beautiful and Efficient: CAD Allows Architectural Firm to Complete On the Big Jobs." Cadence Magazine, 6 (3), 8789. 
69. Neeley, D. (1990). "Saving Time and Money Through Automation: Who Benefits?" Cadence Magazine, 5 (12), 32, 186-187.

70. Neeley, D. (1990). "Determining the Fate of CAD." Cadence Magazine, 5 (3), 95-97.

71. "Netscape and Concentric Network to Launch Netscape Virtual Office by Concentric-An Innovative Monthly Service Online for Busy Professionals, Small Businesses and Project Teams." Retrieved February 12, 1999 from the World Wide Web:

http://www-me1.netscape.com/newsref/pr/newsrelease431.html

72. Nolan, R. and Galal, H. "The Harvard Business School \&Charles Tuller BM Virtual Offices: New Arrangements for Redefining Organization Boundaries." Retrieved April 14, 1999 from the World Wide Web: http://www.hbs.harvard.edu/mis/multimedia/link/p_virtual_office.html

73. Norton, S. (1999). "ASLA-CADdetails and the Landscape Architect." Landscape Architecture News Digest, 41 (8), 8.

74. Orland, B. (1988). "Video Imaging: A Powerful Tool for Visualization and Analysis." Landscape Architecture, 78 (4), 78-88.

75. Orland, B. (1986). "Image Advantage." Landscape Architecture, 76 (1), 58-63.

76. Palmer, J. (1994). "The Use of Computers and Simulation Technology by Landscape Architects on National Forests." (Report distributed to all US Forest Service landscape architects on the service-wide Data General system), 16.

77. Pihlak, M. and Mcintosh, J. (1990). "High Resolution." Landscape Architecture, 80 (7), $70-71$.

78. Rapoport, E. (1990. November). "Community CAD." Cadence Magazine.

79. Risley, M. "The Virtual Office Warrior." Retrieved February 11, 1999 from the World Wide Web:

http://www.ccnmag.com/livingdigital/nov1997/soho/soho.htm

80. Sharp, C. (1996). "Architectural CAD Productivity.” Cadence Magazine, 11 (10), 46-49.

81. Sharp, C. (1995). “Windows CAD Programs for Under $\$ 500 . "$ Cadence Magazine, 10 (4), 72-82.

82. Scheu, D. (1998). "LandTech Puts Spotlight on Education." Land, 40 (8), 14.

83. Schieman, S. (1988). "New Applications for Videodiscs." Landscape Architecture, 78 (4), 58-63.

84. Sipes, J., Hendrix, W., and Ostergaard, R. (1992). "Computer Animation in Landscape Design." Landscape Architecture, 82 (8), 68-71. 
85. Sipes, J. (1999). “Digital Drafting.” Landscape Architecture, 89 (4), 38-42.

86. Sipes, J. (2000). "Digital Video Made Simple.” Landscape Architecture, 90 (6), 36-40.

87. Sipes, J. and Dylan, P. (1995). "Excitement for Computer Images." Landscape Architecture, 85 (3), 25-27.

88. "Quality In, Quality Out.” Landscape Architecture, 86 (3), $42-49$.

89. Sipes, J. (1998). "Shaping the Digital Terrain.” Landscape Architecture, 88 (12), 30-35.

90. Sipes, J. (2000). "Video on the Web." Landscape Architecture, 90 (11), 36-41.

91. "Source: 301 Great Ideas for Using Technology Topic: cost control." Retrieved April 14, 1999 from the World Wide Web:

http://www.inc.com/301/ideas/3158.html

92. “The Digital Experiment.” Land, 42 (5), 10.

93. “The Virtual Office." Landscape Architecture, vol. (May), 52-56.

94. "The Virtual Office - Is It For You?" (1996, March). Retrieved April 10, 1999 from the World Wide Web:

http://www.dgl.com/tbm/tbm9603.html

95. "The Virtual Office Lessons and Challenges." Retrieved April 14, 1999 from the World Wide Web:

http://www.hbs.edu/mis/reengineer/projects/team8/1lessons.htm

96. Thompson, W (1996) Reconsidering The Cutting Edge, Landscape Architecture, (January) pp36-49

97. Trask, M. and Stephan, G. (1995). “The Upgrade Game.” Cadence Magazine, $10(2), 37-42$.

98. “Using Technology to Break Through the Glass Ceiling." (1997, May 15).

Retrieved April 10, 1999 from the World Wide Web:

http://www.webcom.com/rtyee/minority.html

99. Vandergriff, E. "CAD, Internet and the Engineer." Consulting Specifying Engineer, 24 (1) pp40-42

100. "Vers Une Architecture Virtuelle... as seen in Crit 34." (1996, March 10).

Retrieved April 10, 1999 from the World Wide Web:

http://www.hitl.washington.edu/people/dace/portfoli/crit34.html

101. "Vers Une Architecture Virtuelle...to be seen in Crit 35." (1996, March 10).

Retrieved April 10, 1999 from the World Wide Web:

http://www.hitl.washington.edu/people/dace/portfoli/crit35.html 
102. "Vers Une Architecture Virtuelle...to be seen in Crit 36" (1996, March 10). Retrieved April 10, 1999 from the World Wide Web: http://www.hitl.washington.edu/people/dace/portfoli/crit36.html

103. "Virtual Business - What Will It Mean For Me?" (1995, June). Retrieved April 11, 1999 from the World Wide Web: http://dgl.com/tbm/tbm9506.html

104. "Virtual Corporations, Human Issues \& Information Technology: What do virtual companies do about trust? Are managers worried about supervising employees, and if so, how do they go about 'monitoring' off-site workers?" Retrieved April 11, 1999 from the World Wide Web: http://www.brint.com/interview/astdint.htm

105. "Virtual Office: Profile." Retrieved April 11, 1999 from the World Wide Web: http://www.hort.purdue.edu/hort/landarch/virtoff/profile.htm>

106. Walsch, G. (1997). "Autodesk's R14 in the Real World." Cadence Magazine, $12(6), 30-40$.

107. Walsh, G. and Roopinder, T. (1997). "Autodesk's in the Real World and AutoCAD Users.” Cadence Magazine, 12 (6), 7.

108. "Walter Jacobi and Sons, Inc. Modernizes Family Craft." Retrieved February 14, 1999 from the World Wide Web:

http://www.autodesk.com/solution/customer/jacobwww.htm

109. Watson, D. (1997). "Digital Cinderella." Landscape Design Extra, Section 3 (3), 4.

110. "Wearing Your Computer." (1998, January). Retrieved February 14, 1999 from the World Wide Web: Scientific American, http://www.sciam.com/1998/0198issue/0198cyber.html

111. Weingberg, S. (1998). "Electronic Brochures: Add Versatility to Your Marketing.”Landscape Architect, 14 (10), 12.

112. Weingberg, S. (1999). "LandCADD and Recreation Design: A Perfect Match." Landscape Architect, 15 (3), 14-16.

113. Weingberg, S. (1999). "Paper Space: A New Dimension." Landscape Architect, $15(2), 12-14$.

114. Weingberg, S. (1998). "Pro Landscape: A Good Way to Communicate." Landscape Architect, 14 (12), 12.

115. Welsh, B. (1999). “ASLA's Electronic Capitol.” Landscape Architecture News Digest, 41 (3), 11.

116. Welsh, B. (2000). "The Electronic Community." Landscape Architecture News Digest, 42 (2), 3. 
117. Welsh, B. (1999). "Computer-Aided Design: Equipment Training and Standards."Land, 41 (2), 6.

118. Williams, A. (1997). "A chance to Do CAD Management Right." Magazine, 12 (11), 112.

119. Wodtke, M. (1988). "Integrating Applications in Higher Education." Landscape Architecture, 78 (4), 90.

120. Wohlers, T. (1990). "Is Drafting A Dying Dinosaur?: Automation Mandates Evolution." Cadence Magazine, 5 (9), 75-77.

121. Wohlers, T. (1990). "Report Confirms Autocad Dominance." $\underline{\text { Cadence }}$ Magazine, 5 (6), 29-32.

122. Wolf, K. (1992). "Digital Sketching." Landscape Architecture, 82 (5), 75-77.

123. Wright, V. (1990). "What's in Store for Autocad?: Predictions for Release 10." Cadence Magazine, 5 (3), 99-102.

124. Yee, R. "Virtual Corporation: The Wave of NOW!" (1997, June 23). Retrieved February 12, 1999 from the World Wide Web:

http://www.webcom.com/rtyee/The_Wave_of_Now.html

125. Youngs, D. (1995). “CAD.” (6 Jan 1995). Retrieved April 10, 1999 from the World Wide Web:

http://www.clr.toronto.edu/ARCHIVES/HMAIL/larch194/0328.html

126. Yudkowsky, C. "Cybersense Virtual offices Create Benefits, Pose Problems." Retrieved February 14, 1999 from the World Wide Web: http://search.amcity.com/tampabay/stories/082597/smallb3.html

127. Yudkowsky, C. "Cyber Sense Various Technologies Will Aid Home-Office Workers."

Retrieved February 12, 1999 from the World Wide Web: http://www.amcity.com/louisville/stories/101397/smallb6.html

128. Yudkowsky, C. "High tech changes workplace." Retrieved February 16, 1999 from the World Wide Web:

http://www.amcity.com/consultants/columns/cyber67.html

129. Zampi, G. and Morgan, C. (1995). Virtual Architecture. B.T. Batsford Ltd., London

130. Zellner, P. (1999). Hybrid Space, Rizzoli, New York 


\section{Glossary}

$\underline{\mathbf{A}}$

Animation-a movie or pictures consisting of a series of drawn, painted, or modeled scenes (192).

AutoCAD-AutoCAD® software is a customizable 2-D and 3-D design and drafting environment and toolset. Architects, engineers, drafters, and design-related professionals use it to create, view, manage, plot and output, share, and reuse accurate, information-rich drawings (193).

\section{$\underline{B}$}

Bitmap-computer image represented as bits: a representation of a graphic image in computer memory consisting of rows and columns of dots, each corresponding to a pixel. For monochrome images one bit is sufficient to represent each dot, while colors and shades of gray require more than one bit of data for each dot (194).

$\underline{\mathrm{C}}$

CAD-computer-aided design (195). Architecture or mechanical-engineering drawing and documentation using computer systems and techniques to track and control the flow of information, (materials, structures and systems) in the course of designing and producing a building (196).

CAD/CAM-computer-aided design and manufacturing (197). Technique using computer systems to track and control the flow of information, materials, energy and labor throughout the factory manufacturing process, completely or in part (198).

CDR-(Compact Disk Recordable). A compact disk that can be used to record something but cannot be erased. (199).

CD-ROM-(Full form compact disk read-only memory). Compact disk with fixed content: a compact disk containing a large amount of data, including text and images, that can be viewed using a computer but cannot be altered or erased (200).

CPU-(Central Processing Unit). Main part of computer: the part of a computer that performs operations and executes software commands (201).

Computer-any machine that takes input, applies rules to process the input and outputs the results. Typical analog computers may use a mechanical system of cams, gears and levers to produce output in the form of a mechanism's position or a system of variable electrical circuits to produce outputs as a trace on an oscilloscope. A slide rule is a simple analog computer. At the most fundamental level, all digital computers use discrete electrical signals (bits) as input and output and Boolean algebra to process the input. A calculator is a simple digital computer (202).

$\underline{\mathbf{D}}$

Digital-representing data as numbers: processing, operating on, storing, transmitting, representing, or displaying data in the form of numerical digits, as in a digital computer (203). 
Digital computer-processing data in binary form: a computer that stores and performs a series of mathematical and logical operations on data expressed as discrete signals interpreted as numbers, usually in the form of binary notation (204).

Digital imaging-the recording, storage and manipulation of images in computer systems in the form of electronically encoded picture elements (205).

Digitizer-a computer input device that allows an image, graph or other data to be converted into digital form for use on a computer.

Dot matrix printer-A printer that uses a grid of dots to display or print letters, numbers, and other symbols (206). Creates characters by striking pins against an ink ribbon. Each pin makes a dot, and combinations of dots form characters and illustrations (207).

Download-to copy data (usually an entire file) from a main source to a peripheral device. The term is often used to describe the process of copying a file from an online service or bulletin board service (BBS) to one's own computer. Downloading can also refer to copying a file from a network file server to a computer on the network. In addition, the term is used to describe the process of loading a font into a laser printer. The font is first copied from a disk to the printer's local memory. A font that has been downloaded like this is called a soft font to distinguish it from the hard fonts that are permanently in the printer's memory. The opposite of download is upload, which means to copy a file from your own computer to another computer. (208).

DVD-ROM-a high-capacity digital video disk on which data can be stored but cannot be altered. Full form digital versatile disc read only memory (209).

DXF-(data exchange file)-a two-dimensional graphics file format supported by virtually all $\mathrm{PC}$-based $\mathrm{CAD}$ products. It was created by AutoDesk for the AutoCAD system (210).

$\underline{\mathbf{E}}$

Extranet-an extension of the intranet of a company or organization. An extranet gives authorized outsiders, for example, customers, suppliers, or business partners, controlled access to parts of the intranet (211).

$\underline{\mathbf{F}}$

Flatbed scanner-a type of optical scanner that consists of a flat surface on which you lay documents to be scanned. Flatbed scanners are particularly effective for bound documents (212).

Floppy disk-a small flexible magnetically coated disk, on which data can be stored or retrieved by a computer, or the disk and the rigid protective plastic case in which it is contained (213).

FTP-(file transfer protocol).

$\underline{\mathbf{G}}$

GUI-(Graphical User Interface). GUI in computer science, a display format that enables the user to choose commands, start programs, and see lists of files and other options by pointing to pictorial representations (icons) and lists of menu items on the 
screen (see User Interface). Choices can generally be activated either with the keyboard or with a mouse. GUIs were inspired from the pioneering research of computer scientists at the Xerox Corporation's Palo Alto Research Center in the 1970s. Modern GUIs are used on the Macintosh operating system, Microsoft Windows, and the OS/2 Presentation Manager (214).

GIS-a computerized information system for storing, manipulating and analyzing spatially indexed information (215).

$\underline{\mathrm{H}}$ Hardware-the equipment and devices that make up a computer system as opposed to the programs that are used on it (216).

Hard disk drive (HD)-a rigid disk inside a computer that is magnetized to hold a large quantity of computer data and programs (217).

I

Image processing-various techniques of manipulating images in a computer environment, whether by program or y adjusting individual pixels or areas of the image (218).

Interactive multi-media-communication of a person with software and hardware using a wide variety of media such as film, video, and music as well as text and numbers (219).

Internet-a network that links computer networks all over the world by satellite and telephone, connecting users with service networks such as e-mail and the World Wide Web (220).

Internet Service Provider-a business that provides access to the Internet, usually for a monthly fee. Some large providers offer users a wide range of news, information, and entertainment services (221).

Intranet-a network of computers, especially one using World Wide Web conventions, that can be accessed only by an authorized set of users, for example, those within a single company (222).

Ink jet printer-Unlike daisy wheel and dot matrix printers, which rely on physical contact with the an inked ribbon and paper, ink jet printers simply spray ink in a series of dots to form characters. While early ink jets were prone to clogging, they were capable of delivering good print speeds and relatively high-quality text and graphics. Today's best ink jet printers have eliminated most of the clogging problems, rival laser printers for text quality, and can also produce color images with near-photographic quality--all for even less money than a low-end laser printer (223).

Inkjet plotter-an inkjet computer output device that draws graphs and other pictorial images on paper, sometimes using attached pens. Large plotters are used in computeraided design applications to produce more rapidly the engineering drawings and architectural plans once prepared by skilled drafts people (224). Sprays ink at a sheet of paper. Ink-jet printers produce high-quality text and graphics (225). 
Iomega-Makes personal data storage solutions that include Zip, Jaz, Clik! and now the ZipCD (226).

$\underline{\mathbf{J}}$

JPEG-a very popular digital camera file format that uses lossy compression to reduce file sizes. Developed by the Joint Photographic Experts Group (227).

\section{$\underline{\mathbf{K}}$}

$\underline{\mathbf{L}}$

Laptop-a small portable personal computer, especially a battery operated one, usually consisting of a hinged outer case that opens to reveal a screen set in the upper part and a compact keyboard set in the lower part (228).

Laser printer-a computer printer that uses a focused laser beam to place an image on a photosensitive drum, which uses an electrostatic charge to transfer the image to paper (229). Uses the same technology as copy machines. Laser printers produce very high quality text and graphics (230).

LCD-Abbreviation of liquid crystal display, a type of display used in digital watches and many portable computers. LCD displays utilize two sheets of polarizing material with a liquid crystal solution between them. An electric current passed through the liquid causes the crystals to align so that light cannot pass through them. Each crystal, therefore, is like a shutter, either allowing light to pass through or blocking the light.

Monochrome LCD images usually appear as blue or dark gray images on top of a grayish-white background. Color LCD displays use two basic techniques for producing color: Passive matrix is the less expensive of the two technologies. The other technology, called thin film transistor (TFT) or active-matrix, produces color images that are as sharp as traditional CRT displays, but the technology is expensive. Recent passive-matrix displays using new CSTN and DSTN technologies produce sharp colors rivaling active-matrix displays.

Most LCD screens used in notebook computers are backlit to make them easier to read (231).

Local area network-a network of personal computers and peripheral devices linked by cable and able to share resources (232).

$\underline{\mathrm{M}}$

Macintosh-personal computer, developed by Apple Computer, Inc., that pioneered the use of a graphical interface. The Macintosh is a major family of computers (233).

Macromedia Director-Macromedia Director 8 Shockwave Studio is thesolution for developing magnetic Internet destinations and powerful powerful multimedia.

Directorcombines graphics, sound, animation, text, and video to create streaming, multiuser, interactive Web content that is easy to deploy for CD-ROM, DVD-ROM, and the Web (234).

Mainframe-a fast powerful computer with a large storage capacity that has a number of terminals for individual users connected to it (235). 
MHz-Abbreviation for megahertz. One $\mathrm{MHz}$ represents one million cycles persecond. The speed of microprocessors, called the clock speed, is measured in megahertz. For example, a microprocessor that runs at $200 \mathrm{MHz}$ executes 200 million cycles per second. Each computer instruction requires a fixed number of cycles, so the clock speed determines how many instructions per second the microprocessor can execute. To a large degree, this controls how powerful the microprocessor is. Another chief factor in determining a microprocessor's power is its data width (that is, how many bits it can manipulate at one time). In addition to microprocessors, the speeds of buses and interfaces are also measured in $\mathrm{MHz}$ (236).

Minicomputer-a computer of a size, speed, and capacity intermediate between a standard personal computer and a mainframe (237.

Microcomputer-a small computer in which the central processing unit is a single silicon chip (238).

Microstation-MicroStation/J is the new edition of MicroStation. It inherits all functionality of MicroStation SE, but is based on the new JMDL kernel, which includes Sun's Java Virtual Machine. MicroStation/J includes the Parasolid solid modeling kernel. Purchasers of new licenses of MicroStation/J are entitled to an additional license for one of the engineering configurations for building engineering, geoengineering, or manufacturing and mechanical engineering. MicroStation $/ \mathrm{J}$ is also a new architecture for Bentley's MicroStation product line. The first edition of MicroStation/J will use the Bentley DGN file format for data storage. In subsequent releases, Bentley will introduce the concept of component modeling for creating fully associative engineering models that encapsulate real-world behavior, not just a geometric representation (239).

Modeling-generally, the process of representing a real-world object or phenomenon as a set of mathematical equations. More specifically, the term is often used to describe the process of representing 3-dimensional objects in a computer. All 3-D applications, including CAD/CAM and animation software, perform modeling (240).

Modem-an electronic device that connects computers via a telephone line, allowing the exchange of information. It consists of a modulator to convert computer information into a telephone signal and a demodulator to convert it back again (241).

$\underline{\mathbf{P}}$

Parallel port-a port on the computer that is faster than a serial port but slower than SCSI, USB, or IEEE 1394 ports. Often used by printers and flash card readers (242).

Pentium microprocessor-a 32-bit microprocessor introduced by Intel in 1993. It contains 3.3 million transistors, nearly triple the number contained in its predecessor, the 80486 chip. Though still in production, the Pentium processor has been superseded by the Pentium Pro and Pentium II microprocessors. Since 1993, Intel has developed the Pentium III and more recently the Pentium 4 microprocessors (243).

Pict file format-A file format developed by Apple Computer in 1984. PICT files are encoded in QuickDraw commands and can hold both object-oriented images and bit- 
mapped images. It is supported by all graphics programs that run on Macintosh computers. The original PICT format supported 8 colors. Modern versions of PICT, including PICT2, support 32-bit color (more than 16 million colors) (244).

PDF-(portable document format).

Pixelization-an effect seen when you enlarge a digital image too much and the pixels become obvious (245).

Pixels-the small picture elements that make up a digital photograph (246).

Plot-to produce an image by drawing lines. You can program a computer to plot images on a display screen or on paper (247).

Plotter-a device that draws pictures on paper based on commands from a computer. Plotters differ from printers in that they draw lines using a pen. As a result, they can produce continuous lines, whereas printers can only simulate lines by printing a closely spaced series of dots. Multicolor plotters use different-colored pens to draw different colors. In general, plotters are considerably more expensive than printers. They are used in engineering applications where precision is mandatory (248).

Port-an electrical connection on the computer into which a cable can be plugged so the computer can communicate with another device such as a printer or modem (249).

\section{PLT-(plot files).}

PC - a computer with its own operating system and wide selection of software intended to be used by one person (250).

PC card-a card, in the case of cameras usually a storage device, that plugs into a slot in a notebook or hand-held computer. Originally called PCMCIA cards (251).

PC processor-the central processing unit that performs the basic operations in a microcomputer. It consists of an integrated circuit contained on a single chip (252).

Pict file format-a file format developed by Apple Computer in 1984. PICT files are encoded in QuickDraw commands and can hold both object-oriented images and bitmapped images. It is supported by all graphics programs that run on Macintosh computers. The original PICT format supported 8 colors. Modern versions of PICT, including PICT2, support 32-bit color (more than 16 million colors)(253).

\section{Q}

QuickTime VR-an enhanced version of the QuickTime standard developed by Apple for displaying multimedia content (animation, audio, and video) on computers. This enhanced version adds the ability to display and rotate objects in three dimensions. A QuickTime VR plug-in is available for most Web browsers. You prepare visual material for QuickTime VR from computer-generated 3D artwork or from a series of photographs. To use photographs, an object must be photographed from various angles. The QuickTime viewer is able to stitch the photos together in a realistic way as you move about outside an object or inside a space (254). 
Raster graphics-computer display that employ pixels, which store component data for a given image (255).

Resolution-an indication of the sharpness of images on a printout or the display screen. It is based on the number and density of the pixels used. The more pixels used in an image, the more detail can be seen and the higher the image's resolution (256).

\section{$\underline{\mathbf{S}}$}

SCSI port-a port that's faster than the serial and parallel ports but slower and harder to configure than the newer USB port. Also know as the Small Computer System Interface (257).

Serial port-very slow port on the computer used mainly by modems. Many digital cameras come equipped with cable to download images through this port but it's slow! Both parallel and USB ports are faster connections (258).

Softwarer-computer programs and applications, such as word processing or database packages, that can be run on a particular computer system (259).

Simulation-the process of imitating a real phenomenon with a set of mathematical formulas. Advanced computer programs can simulate weather conditions, chemical reactions, atomic reactions, even biological processes. In theory, any phenomena that can be reduced to mathematical data and equations can be simulated on a computer. In practice, however, simulation is extremely difficult because most natural phenomena are subject to an almost infinite number of influences. One of the tricks to developing useful simulations, therefore, is to determine which are the most important factors. In addition to imitating processes to see how they behave under different conditions, simulations are also used to test new theories. After creating a theory of causal relationships, the theorist can codify the relationships in the form of a computer program. If the program then behaves in the same way as the real process, there is a good chance that the proposed relationships are correct (260).

Scanner-a device used to convert an image into digital form for storage, retrieval, and transmission (261).

Spline-with its control points and tangential handles in three-dimensional modeling software, the spline originates directly from naval hitecture, where a curve was created by a wooden spine bent by the positioning of several weights at the "control points." The line is not separated from the point, but every vertex is the basis of a vector. If one changes the position or direction of the vector, the others also change, in accordance with their mutual dependency. In this case the line becomes an action, and not the trace of an action (262).

$\underline{T}$

Thermal printer-an inexpensive printer that works by pushing heated pins against heat-sensitive paper. Thermal printers are widely used in calculators and fax machines (263).

TIFF-Acronym for tagged image file format, one of the most widely supported file formats for storing bit-mapped images on personal computers (both PCs and Macintosh 
computers). Other popular formats are BMP and PCX. TIFF graphics can be any resolution, and they can be black and white, gray-scaled, or color. Files in TIFF format often end with a tif extension (264).

2-D drafting-drafting or drawing a form with only two dimensions, length and width.

3-D-three dimensional. Possessing or appearing to possess the dimensions of height, width, and depth (265).

Triangulated Irregular Networks (TINs)-a surface representation derived from irregularly spaced points and breakline features. Each sample point has an $\mathrm{x}, \mathrm{y}$ coordinate and a $\mathrm{z}$ value or surface value (266).

$\underline{\mathbf{U}}$ URL-(Uniform Resource Locator). The address of a Web site (267).

USB-(Universal Serial Bus). It's the Plug and Play peripheral connection. Over 450 leading manufacturers of PCs, peripherals, and software have joined forces to create a new way to connect PCs to a fast-growing list of new peripherals. USB is more than a "one-plug fits all" Plug and Play peripheral connection. It lets you use your PC and peripherals in some very interesting new ways. Why USB is a "must-have" feature USB is the solution for any PC user who has ever dreamed about an instant, no-hassle way to connect a new digital joystick, a scanner, a set of digital speakers, a digital camera or a PC telephone to their computer. Adding an old-fashioned peripheral device can be a scary proposition, requiring a ton of computer savvy and a certain amount of luck! First you had to figure out which port to use from a bewildering array of possibilities. Then in most cases, you had to pry open your PC to install an add-in card and set DIP switches. Then there were those touchy IRQ settings to configure, not to mention other alphabet soup. It was enough to deter most users from even thinking about adding a new peripheral (268).

Upload-sending a file from your computer to another device.

USB port-a high-speed port that lets you daisy-chain devices (connect one device to another)(269).

V

Vector graphics-computer graphics employing series of lines as the display elements, storing a list of the coordinates for the starting and ending points of each line. In contrast to bitmap graphics, vector-based images are not resolution-dependent (270).

Video camera-a camera that records onto videotape (271).

Virtual reality-a technique by which a computer simulates a three-dimensional physical environment using visual and auditory stimuli with and within which people can interact to affect what happens in the simulation (272).

VRML-a computer-graphics programming language used to create images of threedimensional scenes. Abbreviation of Virtual Reality Modeling Language (273). 


\section{$\underline{\mathbf{W}}$}

World Wide Web-(WWW) the very large set of linked documents and other files located on computers connected through the Internet and used to access, manipulate, and download data and programs (274).

$\underline{\mathbf{X}}$

$\underline{\mathbf{Y}}$

$\underline{\mathbf{Z}}$

Zip drive-a high-capacity floppy disk drive developed by Iomega Corporation. Zip disks are slightly larger than conventional floppy disks, and about twice as thick. They can hold 100 or $250 \mathrm{MB}$ of data. Because they're relatively inexpensive and durable, they have become a popular media for backing up hard disks and for transporting large files (275). 
192 Encarta® World English Dictionary [North American Edition] @ \& \& (P) 2001 Microsoft Corporation. Retrieved March 20, 2001 from World Wide Web.

193 Autodesk AutoCAD Product Center@. Retrieved March 20, 2001 from World Wide Web:

http://www3.autodesk.com/adsk/index/0,,297419-123112,00.html

194 Encarta® World English Dictionary [North American Edition] @ \& (P) 2001 Microsoft Corporation. Retrieved March 20, 2001 from World Wide Web: http://dictionary.msn.com/find/entry.asp?search=bitmap

195 Encarta® World English Dictionary [North American Edition] @ \& (P) 2001 Microsoft Corporation. Retrieved March 20, 2001 from World Wide Web.

196 Zellner, P. (1999). Hybrid Space: New Forms in Digital Architecture. Thames \& Hudson, Lt., London, 90-91.

197 Encarta® World English Dictionary [North American Edition] @ \& (P) 2001 Microsoft Corporation. Retrieved March 20, 2001 from World Wide Web.

198 Zellner, P. (1999). Hybrid Space: New Forms in Digital Architecture. Thames \& Hudson, Lt., London, 90-91.

199 Encarta ${ }^{\circledR}$ World English Dictionary [North American Edition] @ \& \& (P) 2001 Microsoft Corporation. Retrieved March 20, 2001 from World Wide Web.

200 Encarta ${ }^{\circledR}$ World English Dictionary [North American Edition] @ \& (P), ibid.

201 Encarta ${ }^{\circledR}$ World English Dictionary, 2001, op. cit.

202 Zellner, P. (1999). Hybrid Space: New Forms in Digital Architecture. Thames \& Hudson, Lt., London, 90-91.

203 Encarta® World English Dictionary, 2001, op. cit.

204 Encarta® World English Dictionary, 2001, op. cit.

205 Zellner, P. (1999). Hybrid Space: New Forms in Digital Architecture. Thames \& Hudson, Lt., London, 90-91.

206 Encarta ${ }^{\circledR}$ World English Dictionary, 2001, op. cit.

207 Webopedia. Retrieved March 21, 2001 from World Wide Web: http://webopedia.internet.com

208 Webopedia. Retrieved March 20, 2001 from World Wide Web: http://www.webopedia.com 
209 Encarta ${ }^{\circledR}$ World English Dictionary, 2001, op. cit.

210 Webopedia. Retrieved March 21, 2001 from World Wide Web: http://webopedia.internet.com

211 Encarta ${ }^{\circledR}$ World English Dictionary, 2001, op. cit.

212 Webopedia. Retrieved March 21, 2001 from World Wide Web: http://www.webopedia.com

213 Encarta® World English Dictionary, 2001, op. cit.

214 Encarta ${ }^{\circledR}$ World English Dictionary, 2001, op. cit.

215 Geographic Information Systems@ 2001 About.com 3/21/01 http://gis.about.com/science/gis/library/glossary/bldeftin.htm

216 Encarta® World English Dictionary, 2001, op. cit.

217 Encarta® World English Dictionary, 2001, op. cit.

218 Zellner, P. (1999). Hybrid Space: New Forms in Digital Architecture. Thames \& Hudson, Lt., London, 90-91.

219 Encarta ${ }^{\circledR}$ World English Dictionary, 2001, op. cit.

220 Encarta ${ }^{\circledR}$ World English Dictionary, 2001, op. cit.

221 Encarta ${ }^{\circledR}$ World English Dictionary, 2001, op. cit.

222 Encarta® World English Dictionary, 2001, op. cit.

223 CNET Glossary. Retrieved March 20, 2001 from World Wide Web: http://www.cnet.com/Resources/Info/Glossary/Terms/inkjetprinter.html

224 Encarta® World English Dictionary, 2001, op. cit.

225 Webopedia. Retrieved March 21, 2001 from World Wide Web: http://www.webopedia.com

226 Retrieved March 21, 2001 from World Wide Web: http://www.iomega.com/

227 Retrieved March 22, 2001 from World Wide Web: http://www/shortcourses.com/choosing/glossary/19.htm

228 Encarta ${ }^{\circledR}$ World English Dictionary, 2001, op. cit.

229 Encarta® World English Dictionary, 2001, op. cit.

230 Webopedia. Retrieved March 21, 2001 from World Wide Web: http://www.webopedia.com 
231 Retrieved May 30, 2001 from World Wide Web: http://webopedia.internet.com/TERM/L/LCD.html

232 Encarta® World English Dictionary, 2001, op. cit.

233 Encarta® World English Dictionary, 2001, op. cit.

234 Macromedia Technical Notes: common questions about Macromedia, February 23, 2000, <http://www.macromedia.com/software/

235 Encarta® World English Dictionary, 2001, op. cit.

236 Retrieved May 30, 2001 from World Wide Web: http://webopedia.internet.com/TERM/M/MHz.html

237 Encarta® World English Dictionary, 2001, op. cit.

238 Encarta® World English Dictionary, 2001, op. cit.

239 Retrieved March 21, 2001 from World Wide Web: http://www.bentley.com/products/mstation/j/qanda.htm\#whatisj

240 Retrieved March 21, 2001 from World Wide Web: http://www.webopedia.com

241 Encarta ${ }^{\circledR}$ World English Dictionary, 2001, op. cit.

242 http://www.shortcourses.com/choosing/glossary/19.htm

243 Retrieved March 21, 2001 from World Wide Web: http://www.webopedia.com

244 Retrieved March 21, 2001 from World Wide Web: http://www.webopedia.com

245 Retrieved March 21, 2001 from World Wide Web: http://www.shortcourses.com/choosing/glossary/19.htm

246 Retrieved March 21, 2001 from World Wide Web: http://www.shortcourses.com/choosing/glossary/19.htm

247 Retrieved March 21, 2001 from World Wide Web: http://www.webopedia.com

248 Retrieved March 21, 2001 from World Wide Web: http://www.webopedia.com

249 Retrieved March 21, 2001 from World Wide Web: http://www.shortcourses.com/choosing/glossary/19.htm

250 Encarta ${ }^{\circledR}$ World English Dictionary, 2001, op. cit.

251 Retrieved March 21, 2001 from World Wide Web: http://www.shortcourses.com/choosing/glossary/19.htm 
252 Encarta® World English Dictionary, 2001, op. cit.

253 Retrieved March 21, 2001 from World Wide Web: http://www.webopedia.com

254 Retrieved March 21, 2001 from World Wide Web: http://www.webopedia.com

255 Zellner, P. (1999). Hybrid Space: New Forms in Digital Architecture. Thames \& Hudson, Lt., London, 90-91.

256 Retrieved March 21, 2001 from World Wide Web: http://www.shortcourses.com/choosing/glossary/19.htm

257 Retrieved March 21, 2001 from World Wide Web: http://www.shortcourses.com/choosing/glossary/19.htm

258 Retrieved March 21, 2001 from World Wide Web: http://www.shortcourses.com/choosing/glossary/19.htm

259 Encarta® World English Dictionary, 2001, op. cit.

260 Retrieved March 21, 2001 from World Wide Web: http://www.webopedia.com

261 Encarta® World English Dictionary, 2001, op. cit.

262 Zellner, P. (1999). Hybrid Space: New Forms in Digital Architecture. Thames \& Hudson, Lt., London, 90-91.

263 Retrieved March 21, 2001 from World Wide Web: http://www.webopedia.com

264 Retrieved March 21, 2001 from World Wide Web: http://www.webopedia.com

265 Encarta® World English Dictionary, 2001, op. cit.

266 Geographic Information Systems@ 2001 About.com 3/21/01 http://gis.about.com/science/gis/library/glossary/bldeftin.htm

267 Retrieved March 21, 2001 from World Wide Web: http://www.shortcourses.com/choosing/glossary/19.htm

268 Retrieved March 21, 2001 from World Wide Web: http://www.usb.org/overview.html

269 Retrieved March 21, 2001 from World Wide Web: http://www.shortcourses.com/choosing/glossary/19.htm

270 Zellner, P. (1999). Hybrid Space: New Forms in Digital Architecture. 'Thames \& Hudson, Lt., London, 90-91. 
271 Encarta ${ }^{\circledR}$ World English Dictionary, 2001, op. cit.

272 Encarta® World English Dictionary, 2001, op. cit.

273 Encarta ${ }^{\circledR}$ World English Dictionary, 2001, op. cit.

274 Encarta ${ }^{\circledR}$ World English Dictionary, 2001, op. cit.

275 Retrieved March 21, 2001 from World Wide Web: http://www.webopedia.com 